NISTIR 6969

\title{
Selected Laboratory and Measurement Practices and Procedures to Support Basic Mass Calibrations (2019 Ed)
}

Georgia L. Harris 
NISTIR 6969

\section{Selected Laboratory and Measurement Practices and Procedures to Support Basic Mass Calibrations (2019 Ed)}

Georgia L. Harris NIST Office of Weights and Measures

This publication is available free of charge from:

https://doi.org/10.6028/NIST.IR.6969-2019

May 2019

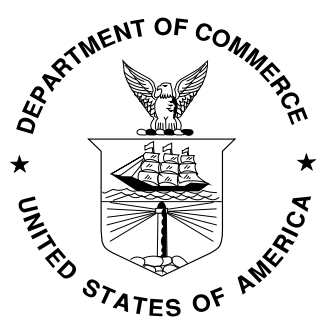

U.S. Department of Commerce Wilbur L. Ross, Jr., Secretary 
Certain commercial entities, equipment, or materials may be identified in this document in order to describe an experimental procedure or concept adequately. Such identification is not intended to imply recommendation or endorsement by the National Institute of Standards and Technology, nor is it intended to imply that the entities, materials, or equipment are necessarily the best available for the purpose.

National Institute of Standards and Technology Interagency or Internal Report 6969

Natl. Inst. Stand. Technol. Interag. Intern. Rep. 6969, 237 pages (May 2019)

This publication is available free of charge from: https://doi.org/10.6028/NIST.IR.6969-2019 


\section{Foreword}

This NIST IR of Selected Publications was first compiled in 2003 and intended as an interim update for Good Laboratory Practices, Good Measurement Practices, Standard Operating Procedures, Statistical Techniques, and Reference Tables for procedures used in mass calibrations. This publication was used as a reference document to support the CD-ROM Mass Metrology Course (NIST Special Publication 1001 and 1001S in Spanish) prepared by the NIST Office of Weights and Measures. This publication has since been updated in 2012, 2014, interim procedural updates in 2015, 2016, 2018, and now again in 2019 (See Table 1).

Many of these procedures are updates to procedures that were originally published in NBS Handbook 145, Handbook for the Quality Assurance of Metrological Measurements, in 1986, by Henry V. Oppermann and John K. Taylor. The 2003 updates incorporated many of the requirements noted for procedures in ISO Guide 25, ANSI/NCSL Z 540-1-1994, and ISO/IEC 17025 laboratory quality systems. The major changes incorporated 1) uncertainty analyses that comply with current international methods and 2) measurement assurance techniques using check standards. No substantive changes were made to core measurement processes or equations, with the exception of SOP 2, Standard Operating Procedure for Applying Air Buoyancy Corrections. Procedures were updated in 2003 in conjunction with Jose A. Torres-Ferrer.

The CIPM 1981/91 equation for calculating air density was added to SOP 2 in 2003 and updated in 2012 based on the 2007 CIPM equation.

The following Practices and Procedures were new in the 2012 publication:

Good Measurement Practices for:

- Assignment and Adjustment of Calibration Intervals for Laboratory Standards (11)

- Standard Operating Procedure Selection (12)

- Ensuring Traceability (13)

- Selection and Use of Sensitivity Weights in Weighing Procedures (14) - converted to SOP 34 in the 2014 version of the publication.

Standard Operating Procedures were included in 2012 for:

- Assignment of Uncertainty (29)

- Process Measurement Assurance Program (30)

- Standard Operating Procedure for the Calibration of Weight Carts (33)

The essential portions of SOP 29, Standard Operating Procedure for Assignment of Uncertainty were first published in 1994 for the NCSL Conference and Symposium and to assist State weights and measures laboratories comply with the ISO Guide to the Expression of Uncertainty in Measurements (1993).

Key updates in 2012 were made to address updated definitions of metrological traceability. Key updates in 2014 have been to clarify procedures after national review by users as well as to add example uncertainty budget tables in each SOP.

The 2019 version of this publication has been updated to include modifications to comply with the 2017 edition of ISO/IEC 17025 and to clarify observed gaps in laboratory applications. A summary of updates since the 2014 edition are included in Table 1. Additional accessibility requirements were 
addressed in the 2019 edition, including adding equation numbers and alternate text for all equations, tables and figures.

Table 1. Updates of procedures since 2014 edition.

\begin{tabular}{|c|c|c|}
\hline Procedure & $\begin{array}{c}\text { Title } \\
\end{array}$ & 2015 to 2019 Changes \\
\hline GLP 1 & $\begin{array}{l}\text { Quality Assurance of the } \\
\text { Measurement Process }\end{array}$ & $\begin{array}{l}2017 \\
\text { - Major re-write of GLP } 1 \text { to incorporate additional measurement } \\
\text { assurance concepts, references, and components from to the } \\
\text { ISO/IEC } 17025 \text { standard. } \\
2018 \\
\text { • No additional changes. } \\
\text { 2019 } \\
\text { - No additional changes. }\end{array}$ \\
\hline GLP 4 & $\begin{array}{l}\text { Periodic Recalibration of State } \\
\text { Standards }\end{array}$ & $\begin{array}{l}2018 \\
\text { - Clarified calibration interval requirements for State weights and } \\
\text { measures laboratories; state laws primarily state that labs will } \\
\text { maintain calibration as prescribed by NIST, so this GLP was made } \\
\text { more prescriptive based on gaps observed in laboratories during } \\
\text { an inventory assessment of standards in } 2017 \text {. } \\
2019 \\
\text { - Additional clarifications and up-front reference to GMP } 11 \text { and } \\
13 \text {. }\end{array}$ \\
\hline GLP 9 & $\begin{array}{l}\text { Rounding Expanded } \\
\text { Uncertainties and Calibration } \\
\text { Values }\end{array}$ & $\begin{array}{l}2016 \\
\text { - Added two additional options for rounding practices to include } \\
\text { use of Excel and rounding up. The current even/odd rounding } \\
\text { remains Option A. There are no changes to identifying significant } \\
\text { digits. (This GLP was modified so that laboratories who have } \\
\text { written deviations in conflict with the original GLP will have an } \\
\text { official NIST document that does not require supplemental } \\
\text { documentation for how the laboratory will round measurement } \\
\text { results. Laboratories using the previously documented methods in } \\
\text { GLP } 9 \text { do not need to make changes in their methods.) } \\
2018 \\
\text { • No additional changes. } \\
2019 \\
\text { - No additional changes. }\end{array}$ \\
\hline GLP 11 & Painting Weights & $\begin{array}{l}2018 \\
\text { No significant changes. } \\
2019 \\
\text { • Removed “tolerance test” language and clarified “as found” and } \\
\text { "as left” based on training feedback. Added safety clause. }\end{array}$ \\
\hline GMP 1 & $\begin{array}{l}\text { Reading Turning Points on An } \\
\text { Equal Arm Balance }\end{array}$ & $\begin{array}{l}2018 \\
\text { No significant changes. Very few laboratories using equal arm } \\
\text { balances, this procedure may be archived on the next revision. } \\
2019 \\
\text { - } \quad \text { No additional changes. }\end{array}$ \\
\hline GMP 10 & $\begin{array}{l}\text { Understanding Factors } \\
\text { Affecting Weighing Operations }\end{array}$ & $\begin{array}{l}2018 \\
\text { - Added language to address automated systems per laboratory } \\
\text { request. } \\
2019 \\
\text { - Clarified explanations that have been addressed in training but are } \\
\text { often not found in other documents. }\end{array}$ \\
\hline
\end{tabular}




\begin{tabular}{|c|c|c|}
\hline Procedure & $\begin{array}{c}\text { Title } \\
\end{array}$ & 2015 to 2019 Changes \\
\hline GMP 11 & $\begin{array}{l}\text { Assignment and Adjustment of } \\
\text { Calibration Intervals for } \\
\text { Laboratory Standards }\end{array}$ & $\begin{array}{l}\text { - } 2016 \text { Modified the baseline recalibration interval for liquid in glass } \\
\text { thermometers in Table 9, due to a complaint and additional } \\
\text { reference materials that were provided. The } 10 \text { year calibration } \\
\text { interval that was modified during review of the } 2013 \text { version was } \\
\text { not appropriate for liquid in glass thermometers. } \\
\text { - } \quad \text { Added } 100 \text { g starting restraints and check standards to Table } 2 \text { for } \\
\text { maintaining suitable intervals for mass calibrations for } \\
\text { laboratories working at the Echelon I levels of calibration to } \\
\text { ensure consistency with what is presented in training materials } \\
\text { and discussed in NISTIR 5672. } \\
\text { - Minor editorial changes. } \\
\text { 2018 } \\
\text { - Added table for Mass Echelon III calibration intervals } \\
\text { - Clarified calibration intervals should not exceed } 10 \text { years for } \\
\text { anything without substantial evidence of data and analysis } \\
\text { Clarified balance service interval requirement based on ISO/IEC } \\
\text { 17025 for equipment maintenance since many laboratories have } \\
\text { misinterpreted guidance for "no calibration required" (service is } \\
\text { still required). } \\
\text { 2019 } \\
\text { - Added language related to risk from ISO/IEC } 17025 \text { and clarified } \\
\text { language regarding “calibration programs" as discussed in training } \\
\text { seminars as related to ISO/IEC 17025. No baseline calibration } \\
\text { intervals were modified. }\end{array}$ \\
\hline GMP 12 & $\begin{array}{l}\text { Standard Operating Procedure } \\
\text { Selection }\end{array}$ & $\begin{array}{l}2018 \\
\text { - Added reference document for length that was published in } 2014 . \\
\text { - } \quad \text { Removed dates from reference documents. } \\
\text { - Added a section of publication titles that are used to determining } \\
\text { appropriate procedures. } \\
\text { - } 2019 \\
\text { Removed language related to "test" in favor of “calibration". } \\
\text { Updated Small Volume Prover to Compact Displacement Prover } \\
\text { to be consistent with American Petroleum Institute (API) } \\
\text { publications. Updated reference dates on documentary standards. }\end{array}$ \\
\hline GMP 13 & Ensuring Traceability & $\begin{array}{l}\text { - } 2018 \\
\text { - Updated language to clarify options for referencing other } \\
\text { documents within the laboratory and for combining tracking } \\
\text { information for standards with the requirements from GMP } 11 \\
\text { within the laboratory to improve efficiency in managing and } \\
\text { maintaining up to date calibration status. } \\
\text { 2019 } \\
\text { - Limited editorial clarifications and language related to a } \\
\text { calibration program. }\end{array}$ \\
\hline SOP 1 & $\begin{array}{l}\text { Preparation of Calibration } \\
\text { Certificates }\end{array}$ & $\begin{array}{l}2018 \\
\text { - Updated entire SOP based on changes to ISO/IEC 17025:2017, } \\
\text { Section 7.8. } \\
2019 \\
\text { - Conformity Assessment criteria added to checklists and to } \\
\text { example certificate (was already in the text of procedure). }\end{array}$ \\
\hline SOP 2 & $\begin{array}{l}\text { Applying Air Buoyancy } \\
\text { Corrections }\end{array}$ & $\begin{array}{l}\text { - Added equations for effective density that were in SOP } 28 \text { so that } \\
\text { they are more readily available and noted that some standards, }\end{array}$ \\
\hline
\end{tabular}




\begin{tabular}{|c|c|c|}
\hline Procedure & Title & 2015 to 2019 Changes \\
\hline & & $\begin{array}{l}\text { check standards, or tare weights when used in summation will } \\
\text { need to use the effective density of the summation. Equations } \\
\text { were only in NISTIR } 5672 \text { prior to the } 2016 \text { changes. } \\
2018 \\
\text { - Fixed a variable in the equations for air density (was noted as rho } \\
\text { in the equation instead of p as listed in the variable table). } \\
\text { Validated against the CIPM equation and Metrologia reference } \\
\text { paper. } \\
2019 \\
\text { - Explanations for subscripts in equation for effective density added } \\
\text { based on inquiries. }\end{array}$ \\
\hline SOP 4 & $\begin{array}{l}\text { Weighing by Double } \\
\text { Substitution Using a Single Pan } \\
\text { Mechanical Balance, a Full } \\
\text { Electronic Balance, or a } \\
\text { Balance with Digital } \\
\text { Indications and Built in } \\
\text { Weights }\end{array}$ & $\begin{array}{l}\text { - } 2015 \\
\text { - } \quad \text { Added 2.5.2.6. to repeat the measurement process with a check } \\
\text { standard. } \\
\text { - } \quad \text { Equations 3.1.1. and 3.1.2., 3.2.2.1., 3.2.2.2. were all updated to } \\
\text { start calculations with the check standards and then substitute } S_{c} \\
\text { with } X \text { in all equations. Equations 3.2.2.1., 3.2.2.2. previously had } \\
\text { a mix of } S_{c} \text { and } X \text { subscripts as well. } \\
\text { - } \quad 3.2 .5 \text { numbering was empty/off. Renumbered subsequent sections. } \\
2018 \\
\text { - } \quad \text { Added equation for conducting t-test in section on Measurement } \\
\text { Assurance based on questions raised regarding SOP } 5 \text { from } \\
\text { NISTIR 5672. } \\
\text { - Added specific reporting requirements for Section 6: conventional } \\
\text { mass and calculated uncertainties. } \\
\text { 2019 } \\
\text { - Explanations for converting expanded uncertainty to combined } \\
\text { uncertainty if coverage factor not provided. } \\
\text { Clarified criteria and improved consistency with other mass SOPs } \\
\text { for situation when standard deviation is less than one balance } \\
\text { division. Clarified related section in uncertainty budget table. } \\
\text { Moved conformity assessment from uncertainty section to } \\
\text { reporting section. }\end{array}$ \\
\hline SOP 7 & $\begin{array}{l}\text { Weighing by Single } \\
\text { Substitution Using a Single Pan } \\
\text { Mechanical Balance, a Full } \\
\text { Electronic Balance, or a } \\
\text { Balance with Digital } \\
\text { Indications and Built in } \\
\text { Weights }\end{array}$ & $\begin{array}{l}2018 \\
\text { - Added specific reporting requirements for Section 6: conventional } \\
\text { mass and calculated uncertainties. } \\
\text { - Added equation for conducting t-test in section on Measurement } \\
\text { Assurance based on questions raised regarding SOP } 5 \text { from } \\
\text { NISTIR 5672. } \\
2019 \\
\text { - Explanations for converting expanded uncertainty to combined } \\
\text { uncertainty if coverage factor not provided. } \\
\text { Clarified criteria and improved consistency with other mass SOPs } \\
\text { for situation when standard deviation is less than one balance } \\
\text { division. Clarified related section in uncertainty budget table. } \\
\text { Moved conformity assessment from uncertainty section to } \\
\text { reporting section. }\end{array}$ \\
\hline SOP 8 & $\begin{array}{l}\text { Medium Accuracy Calibration } \\
\text { of Mass Standards by Modified } \\
\text { Substitution }\end{array}$ & $\begin{array}{l}2015 \\
\text { - Section 1.2.5.1, Updated Table } 2 \text { Inside Limits as signs were } \\
\text { reversed: } \\
\text { - Inside upper or lower limits }>18^{\circ} \mathrm{C} \text { and }<27^{\circ} \mathrm{C} \\
2018\end{array}$ \\
\hline
\end{tabular}




\begin{tabular}{|c|c|c|}
\hline Procedure & Title & 2015 to 2019 Changes \\
\hline & & 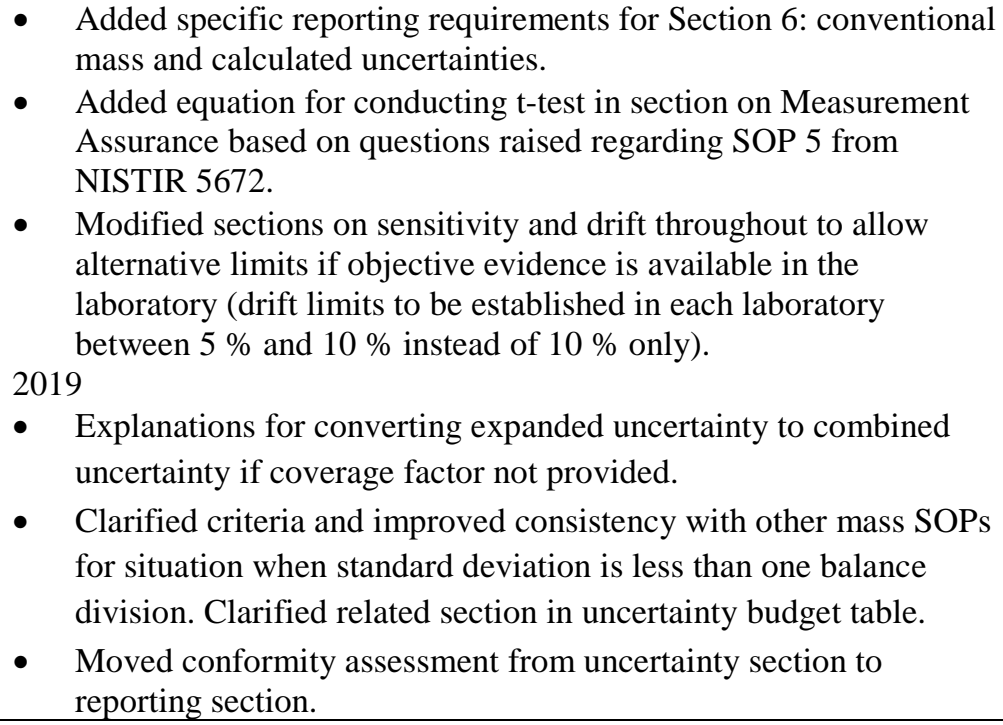 \\
\hline SOP 9 & $\begin{array}{l}\text { Control Charts for Calibration } \\
\text { of Mass Standards }\end{array}$ & $\begin{array}{l}2018 \\
\text { - Reorganized and retitled sections to address revised teaching } \\
\text { approach to a DMAIC model (Define, Measure, Analyze, } \\
\text { Improve, and Control). } \\
\text { - Added the equations for Normalized Error and uncertainty for a } \\
\text { mean value of check standards to assess the mean value versus a } \\
\text { calibrated reference value to this SOP instead of the measurement } \\
\text { SOPs (where only one data point might be compared to a } \\
\text { reference value). } \\
2019 \\
\text { - Clarified and edited language based on evaluation of laboratory } \\
\text { implementation of measurement assurance concepts during } 2018 \\
\text { State laboratory annual reviews. }\end{array}$ \\
\hline SOP 29 & Assignment of Uncertainty & $\begin{array}{l}2018 \\
\text { - Updated language regarding inclusion of bias as optional and } \\
\text { clarified language regarding application of bias as an uncorrected } \\
\text { systematic component in calculations. } \\
2019 \\
\text { - Improved reference to the GUM in Appendix A and addressed } \\
\text { effective degrees of freedom throughout the text. }\end{array}$ \\
\hline SOP 30 & $\begin{array}{l}\text { Process Measurement } \\
\text { Assurance Program }\end{array}$ & $\begin{array}{l}2018 \\
\text { - Reorganized and retitled sections to address revised teaching } \\
\text { approach to a DMAIC model (Define, Measure, Analyze, } \\
\text { Improve, and Control). } \\
2019 \\
\text { - No additional changes. }\end{array}$ \\
\hline SOP 33 & Calibration of Weight Carts & $\begin{array}{l}2016 \\
\text { - Added that the mean value of replicate measurements is to be } \\
\text { reported and that adjustments must be taken into consideration } \\
\text { when determining the mean value to report. } \\
\text { - Minor editorial changes. } \\
2018 \\
\text { - Added specific reporting requirements for Section 6: conventional } \\
\text { mass and calculated uncertainties. } \\
2019\end{array}$ \\
\hline
\end{tabular}




\begin{tabular}{|c|c|c|}
\hline Procedure & Title & 2015 to 2019 Changes \\
\hline & & $\begin{array}{l}\text { - Updated tolerances per the draft of Handbook 105-8 (2019 } \\
\text { edition) } \\
\text { - Added conformity assessment language to certificate example and } \\
\text { instructions. }\end{array}$ \\
\hline SOP 34 & $\begin{array}{l}\text { Selection and Use of } \\
\text { Sensitivity Weights and Tare } \\
\text { Weights in Weighing } \\
\text { Procedures (formerly GMP 14) }\end{array}$ & $\begin{array}{l}2016 \\
\text { - Updated Tables } 1 \text { and } 2 \text { to clarify the intent based on conflicts that } \\
\text { resulted when the } 2012 \text { version was updated in } 2013 \text {. } \\
2018 \\
\text { - No additional changes. } \\
2019 \\
\text { - No additional changes. }\end{array}$ \\
\hline Section 8 & $\begin{array}{l}\text { Statistical Techniques (Updated } \\
\text { Section } 8 \text { of NBS Handbook } \\
145,1986 \text { ) }\end{array}$ & $\begin{array}{l}2018 \\
\text { Added section to address pooling degrees of freedom for standard } \\
\text { deviations from multiple sets of replicate runs for uncertainty } \\
\text { calculations } \\
2019 \\
\text { - No additional changes. }\end{array}$ \\
\hline Section 9 & $\begin{array}{l}\text { Reference Tables (Updated } \\
\text { Section } 9 \text { of NBS Handbook } \\
\text { 145, 1986) }\end{array}$ & $\begin{array}{l}2018 \\
\text { - Table } 9.10 \text { - Added CCE for Seraphin provers; removed linear } \\
\text { coefficient of expansion for provers as not applicable } \\
\text { - Table } 9.12 \text { - Added F-table for use with Mass calibrations at } 95 \% \\
\text { - Table } 9.13 \text { - Added F-max table for use with multiple } \\
\text { comparisons of standard deviations } \\
\text { 2019 } \\
\text { - Subscripts on degrees of freedom numerators fixed on one table. }\end{array}$ \\
\hline
\end{tabular}




\section{Table of Contents}

Foreword $\quad$ i

Good Laboratory Practices

1 Quality Assurance of the Measurement Process $\quad$ GLP 1-1

4 Periodic Recalibration of State Standards

GLP 4-1

$9 \quad$ Rounding Expanded Uncertainties and Calibration Values

GLP 9-1

11 Painting Weights

GLP 11-1

Good Measurement Practices

1 Reading Turning Points on An Equal Arm Balance GMP 1-1

10 Understanding Factors Affecting Weighing Operations GMP 10-1

11 Assignment and Adjustment of Calibration Intervals for Laboratory GMP 11-1

Standards

12 Standard Operating Procedure Selection

GMP 12-1

13 Ensuring Traceability

GMP 13-1

\section{Standard Operating Procedures}

$1 \quad$ Preparation of Calibration Certificates

SOP $1-1$

2 Applying Air Buoyancy Corrections

SOP 2-1

$4 \quad$ Weighing by Double Substitution Using a Single Pan Mechanical

SOP 4-1

Balance, a Full Electronic Balance, or a Balance with Digital Indications and Built in Weights

$7 \quad$ Weighing by Single Substitution Using a Single Pan Mechanical

SOP 7-1

Balance, a Full Electronic Balance, or a Balance with Digital Indications and Built in Weights

8 Medium Accuracy Calibration of Mass Standards by Modified

SOP 8-1

Substitution

9 Control Charts for Calibration of Mass Standards

SOP 9-1

29 Assignment of Uncertainty

SOP 29-1

Process Measurement Assurance Program

SOP 30-1

Calibration of Weight Carts

SOP 33-1

34 Selection and Use of Sensitivity Weights and Tare Weights in

SOP 34-1

Weighing Procedures (formerly GMP 14)

\section{Reference Materials}

Section 8 Statistical Techniques (Updated Section 8 of NBS Handbook 145, 8-1 1986)

Section 9 Reference Tables (Updated Section 9 of NBS Handbook 145, 1986) 
This page is intentionally blank. 
Good Laboratory Practices 
This page is intentionally blank. 


\section{GLP 1}

\section{Good Laboratory Practice \\ for the \\ Quality Assurance of Laboratory Measurement Results ${ }^{1}$}

Quality assurance of laboratory measurement results (measurement assurance) means understanding, modeling, measuring, and managing a measurement assurance system appropriate to the laboratory's scope of activities. Having such a system in place will allow the laboratory to know, within the limits of a measurement process, that measurement results are valid with respect to stated traceability, accuracy, and precision. A well-designed measurement assurance system provides confidence and credibility in the quality of the laboratory's measurement results by ensuring that the measurement results are metrologically traceable to appropriate reference standards and measurement units, with suitably valid uncertainties.

Quality assurance (QA) and quality control (QC) methods should consider both internal and external data for evaluating the ongoing stability and control of the measurement results and processes. At its core, the concept of measurement assurance is one of risk identification and mitigation. It provides methods for monitoring the standards and as well as the measurement process, and varying combinations of each depending on the priorities of the methods chosen.

Software quality assurance is a key function of ensuring the quality of laboratory measurement results but is outside the scope of this procedure.

\section{Internally Obtained Measurement Assurance Data}

The validity of calibrations needs to be monitored with quality control procedures. Statistical techniques are used to record, analyze, and monitor charted measurement results to permit the ongoing assurance of valid and stable measurement results, integration of intermediate checks, and/or the detection of trends. The metrologists and laboratory management should also plan and review the results from quality assurance monitoring as methods are integrated into calibration procedures and during periodic management reviews and internal assessments (internal audits).

Steps taken to ensure the quality of the measurement process may include, but are not limited to:

a. Regular use of reference materials or quality control;

b. Regular use of alternative instrumentation that has been calibrated to provide traceable results;

c. Functional checks of measuring and testing equipment;

d. Use of check or working standards with control charts, where applicable;

e. Periodic intermediate checks on measuring equipment;

f. Replicate tests or calibrations using the same or different methods, with the use of standard deviation charts or range charts where applicable;

g. Retesting or recalibration of retained items (e.g., customer items that are not immediately returned);

h. Correlation of results for different characteristics of an item;

i. Review of reported data by competent laboratory personnel;

\footnotetext{
${ }^{1}$ See also Section 7.7 of ISO/IEC 17025:2017 General Requirements for the Competence of Testing and Calibration Laboratories.
} 
j. Intralaboratory comparisons; and

k. Blind tests.

Each measurement parameter in the laboratory's scope of activities must be reviewed and analyzed to determine the validity of the measurement process.

The standards and the measurement process for each parameter must be in a state of statistical control. Statistical control means that the variability of the measurement process is known, stable and observed values are adequately close to reference values, within the chosen statistical limits. When a process is in statistical control and the reference values are within suitable limits, we can assume that the reported measurement uncertainties are valid.

Minimizing risks of measurement errors includes all the following laboratory functions:

a. Training staff and evaluating effectiveness and proficiency;

b. Monitoring the laboratory environment to minimize potential errors or excess variation;

c. Maintaining suitable equipment (including installation, monitoring, approvals, and integrated software);

d. Selecting and calibrating standards;

e. Ensuring suitable suppliers for materials and calibrations;

f. Selecting and validating procedures with evaluation of accuracy/bias and precision;

g. Ensuring proper care and handling of laboratory standards, equipment, and items submitted for calibration;

h. Accurately and effectively calculating, evaluating, and reporting measurement uncertainty;

i. Participating in inter- and intra-laboratory comparisons;

j. Creating and reviewing calibration certificates to ensure accuracy of measurement results and the effective communication of results; and

k. Controlling data - information management (including software and information technology controls).

While other quality assurance methods could meet these objectives, the control programs developed for measurement assurance greatly increase the comprehensiveness of the program.

2 Externally Obtained Data Used for Measurement Assurance

Data from measurement results obtained external to the laboratory need to be considered when evaluating the quality control and measurement assurance. Such steps that may be taken include:

a. Evaluation of the calibration history of reference standards, working standards, and check standards;

b. Evaluation of before/after calibrations within a laboratory to compare and evaluate results obtained from an external calibration provider;

c. Review of historical calibration data for items calibrated having demonstrated stability;

d. Comparison of all calibration results and calibration history on control charts for working standards and check standards with results from external calibration sources;

e. Participation in proficiency testing using the same procedures and handling methods used for routine laboratory calibrations; 
f. Use of externally obtained data from calibrations, proficiency tests, and interlaboratory comparisons in the assessment of errors and bias in measurement results; and

g. Participation in interlaboratory comparisons other than proficiency testing (e.g., for method validation or as a training activity).

Data from all the measurement assurance activities should be analyzed and monitored to both control and improve the laboratory's activities, if applicable. When the results of the data analyses from monitoring activities are found to be outside pre-defined criteria, appropriate actions shall be taken to prevent incorrect results from being reported to the customer.

The strength of the measurement assurance approach lies in its applicability to a wide variety of measurements with sufficient flexibility to permit each measurement control program to be tailored to the needs of a given measurement area. The sophistication of the control program depends on the criticality of the measurement.

\section{Integration of Data from Multiple Sources}

Measurement results collected over several years may be statistically evaluated with current results being compared to results from previous years. Any observed problems or changes in the measurement results are investigated and, as appropriate, corrective action taken. Ongoing monitoring establishes a continuous and comprehensive internal laboratory measurement assurance program.

Data from internal measurement assurance programs should be compared to the results of calibration history assessments, interlaboratory comparisons or proficiency tests, and other external sources of data.

Data and analysis from the integrated assessment of measurement assurance data provides assurance of measurement quality, provides input to and validation of measurement uncertainties, supports selection and adjustment of calibration intervals for standards and laboratory instruments, and provides a graphical and statistical basis for evaluating and making decisions regarding the quality of measurement results.

\section{$4 \quad$ NIST Office of Weights and Measures Resources}

The National Institute of Standards and Technology (NIST) provides technical guidance and support to laboratories to develop suitable measurement control programs that provide a systems approach to measurement assurance as a part of published resources and training seminars. Objectives to evaluate the entire measurement process, as a system or as a production process, will consider all the following:
a. Personnel;
b. Facility/accommodations;
c. Procedures and method validation;
d. Equipment; and
e. Standards.

One quality tool that is often used to present the concept of monitoring the entire measurement process is a Cause and Effect Diagram where the branches represent the components on this list, 
examples of measurement assurance methods, and the output represents the results of a measurement process.

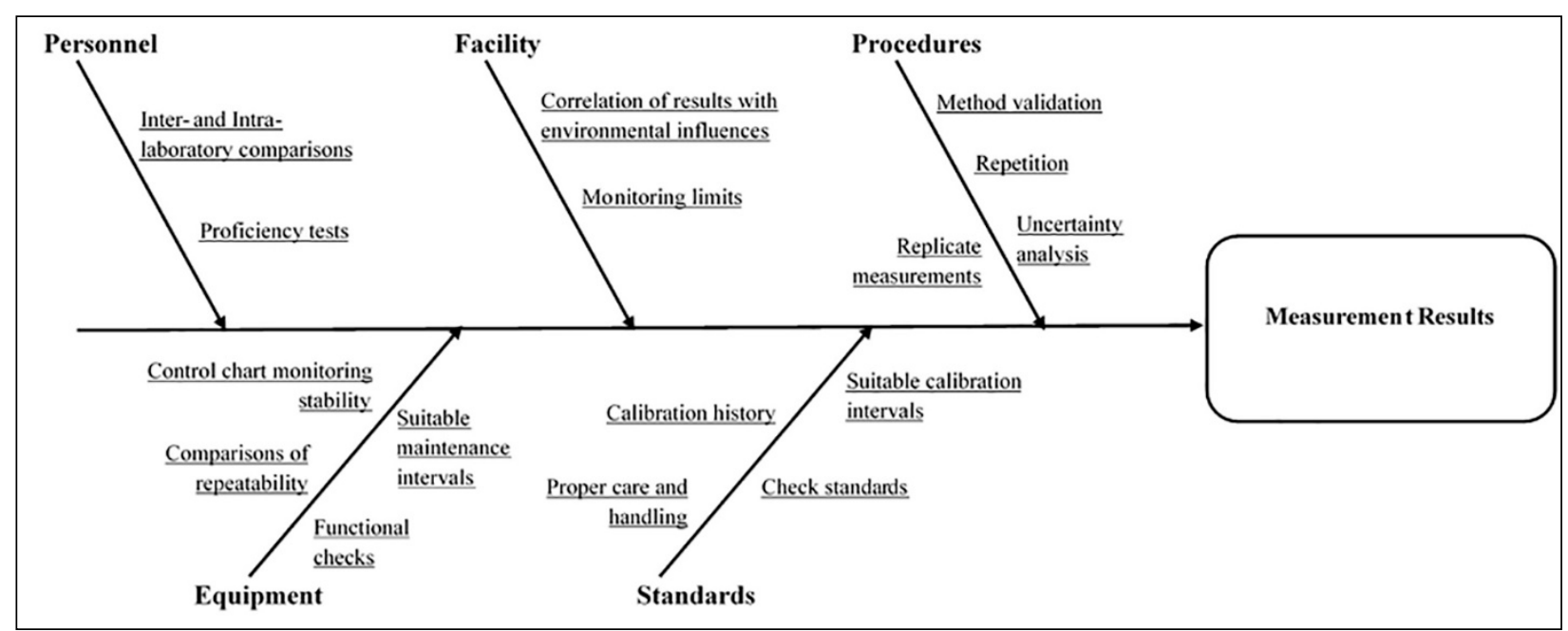

Figure 1. Cause and effect diagram with measurement assurance perspective.

Please see examples of related measurement assurance resources in Table 1. 
Table 1. Examples of Measurement Assurance Procedures and Tools Available from the NIST and the NIST Office of Weights and Measures

\begin{tabular}{|c|c|c|}
\hline $\begin{array}{c}\text { Title } \\
\end{array}$ & $\begin{array}{l}\text { Description } \\
\end{array}$ & $\begin{array}{c}\text { Type of Assessments } \\
\end{array}$ \\
\hline $\begin{array}{l}\text { NISTIR 6969, SOP 9, } \\
\text { Control Charts for } \\
\text { Calibration of Mass } \\
\text { Standards. (Includes } \\
\text { spreadsheet job aid.) }\end{array}$ & $\begin{array}{l}\text { This procedure describes procedures } \\
\text { for the development of control charts } \\
\text { and their use for demonstrating } \\
\text { attainment of statistical control of a } \\
\text { mass calibration process. The } \\
\text { procedure may be applied to other } \\
\text { calibration processes as well. }\end{array}$ & $\begin{array}{l}\text { Procedure for: } \\
\text { - } \quad \text { recommended check standards } \\
\text { - } \text { for mass calibrations; } \\
\text { establishing control charts and } \\
\text { control chart limits; } \\
\text { - monitoring and evaluating } \\
\text { control chart data; } \\
\text { - } \text { monitoring reference values; } \\
\text { - } \quad \text { transferring measurement } \\
\text { - } \quad \text { statistics for uncertainties; and } \\
\text { checklist for evaluation of } \\
\text { control chart design. }\end{array}$ \\
\hline $\begin{array}{l}\text { NISTIR 7383, SOP 17, } \\
\text { Control Charts of } \\
\text { Laboratory Owned Check } \\
\text { Standards. (Includes } \\
\text { spreadsheet job aids.) }\end{array}$ & $\begin{array}{l}\text { This procedure may be used to } \\
\text { develop and maintain control charts } \\
\text { to monitor the statistical } \\
\text { control of laboratory check standards } \\
\text { when replicate measurements are } \\
\text { made as a part of the standard } \\
\text { operating procedure. This procedure } \\
\text { may be used for volume, length, } \\
\text { time, or other calibrations when } \\
\text { replicate measurements are made. }\end{array}$ & $\begin{array}{l}\text { Procedure for: } \\
\text { - } \quad \text { establishing control charts and } \\
\text { control chart limits; } \\
\text { - monitoring and interpretation } \\
\text { of control chart data; and } \\
\text { - demonstrating example } x \text {-bar } \\
\text { and } s \text { (standard deviation) } \\
\text { charts and a data form for } \\
\text { replicate data. }\end{array}$ \\
\hline $\begin{array}{l}\text { NISTIR 7383, SOP 20, } \\
\text { Standard Deviation and } \\
\text { Range Charts. (Includes } \\
\text { spreadsheet job aids.) }\end{array}$ & $\begin{array}{l}\text { This procedure describes a process to } \\
\text { be followed to monitor the statistical } \\
\text { control of a measurement process } \\
\text { using standard deviation charts or } \\
\text { range charts for any calibration } \\
\text { method where replicate } \\
\text { measurements are performed and } \\
\text { where it is not practical or feasible to } \\
\text { maintain laboratory check standards. } \\
\text { Standard deviation charts are } \\
\text { preferred to the use of range charts } \\
\text { for monitoring and evaluation } \\
\text { process standard deviations when } \\
\text { replicate measurements are made. }\end{array}$ & $\begin{array}{l}\text { Procedure for: } \\
\text { - } \quad \text { calculating initial statistics; } \\
\text { - creating appropriate charts and } \\
\text { limits; } \\
\text { - using and interpreting standard } \\
\text { deviation charts for monitoring } \\
\text { measurement processes; and } \\
\text { - demonstrating example data } \\
\text { form for replicate evaluation of } \\
\text { measurement results. }\end{array}$ \\
\hline
\end{tabular}




\begin{tabular}{|c|c|c|}
\hline $\begin{array}{c}\text { Title } \\
\end{array}$ & Description & Type of Assessments \\
\hline $\begin{array}{l}\text { NISTIR 6969, SOP 30, } \\
\text { Process Measurement } \\
\text { Assurance Program. }\end{array}$ & $\begin{array}{l}\text { The Process Measurement Assurance } \\
\text { Program (PMAP) is used for the } \\
\text { control and surveillance of } \\
\text { measurement performance using } \\
\text { check standards in measurement and } \\
\text { calibration procedures. Incorporation } \\
\text { of these measurement control steps } \\
\text { ensures the validity of the } \\
\text { measurement process and the } \\
\text { standards used. The variables used in } \\
\text { calculation and assignment of } \\
\text { uncertainty can be } \\
\text { determined and controlled using this } \\
\text { procedure. }\end{array}$ & $\begin{array}{l}\text { Procedure for: } \\
\text { - } \quad \text { modeling the measurement } \\
\text { process; } \\
\text { - } \quad \text { selecting and calibrating } \\
\text { - } \quad \text { estable check standards, } \\
\text { - } \quad \text { creating and preparing charts; } \\
\text { - } \quad \text { establishing statistical and } \\
\text { - } \quad \text { evaluating process uncertainty } \\
\text { - } \quad \text { memponents; } \\
\text { - } \quad \text { managing check standards; } \\
\text { - measurement process; } \\
\text { - } \quad \text { onging statistical tools for } \\
\text { - instructions on actions. }\end{array}$ \\
\hline $\begin{array}{l}\text { All measurement SOPs for } \\
\text { mass, volume, and length. }\end{array}$ & $\begin{array}{l}\text { Calibration procedures published in } \\
\text { NISTIR } 6969^{2} \text {, } \\
\text { NISTIR } 5672^{3} \text {, } \\
\text { NISTIR } 7383^{4} \text {, } \\
\text { And NISTIR } 8028^{5} \text {. }\end{array}$ & $\begin{array}{l}\text { All Standard Operating Procedures } \\
\text { (SOP) incorporate a section on } \\
\text { measurement assurance methods } \\
\text { specific to that calibration } \\
\text { procedure. }\end{array}$ \\
\hline $\begin{array}{l}\text { Measurement Assurance } \\
\text { System Evaluation Form. }\end{array}$ & $\begin{array}{l}\text { Used for laboratory recognition } \\
\text { and/or accreditation to evaluate } \\
\text { measurement assurance programs. } \\
\text { Should be integrated as a part of the } \\
\text { laboratory Quality Management } \\
\text { System. }\end{array}$ & $\begin{array}{l}\text { Provides an outline for systematic } \\
\text { evaluation of a laboratory } \\
\text { measurement parameter, including } \\
\text { a series of questions to document a } \\
\text { periodic assessment. Posted with } \\
\text { SOP } 30 \text {. }\end{array}$ \\
\hline PT Follow-Up Form. & $\begin{array}{l}\text { Originally developed as a form } \\
\text { associated with NISTIR 7214. Used } \\
\text { for annual assessment of laboratory } \\
\text { PT results. Should be integrated as a } \\
\text { part of the laboratory Quality } \\
\text { Management System. }\end{array}$ & $\begin{array}{l}\text { Provides a framework for a } \\
\text { systematic review of proficiency } \\
\text { testing results. Posted on OWM } \\
\text { Proficiency Testing website. }\end{array}$ \\
\hline $\begin{array}{l}\text { PT Reporting 4-year } \\
\text { Analysis Form. }\end{array}$ & $\begin{array}{l}\text { Used for laboratory recognition } \\
\text { and/or accreditation assessments and } \\
\text { tracking. Should be integrated as a } \\
\text { part of the laboratory Quality } \\
\text { Management System. }\end{array}$ & $\begin{array}{l}\text { Form for tracking laboratory } \\
\text { results on a rolling 4-year basis } \\
\text { with plans for the coming year. } \\
\text { Includes space for tracking } \\
\text { corrective actions, preventive } \\
\text { actions, and improvement actions. }\end{array}$ \\
\hline
\end{tabular}

\footnotetext{
${ }^{2}$ NISTIR 6969, Selected Laboratory and Measurement Practices, and Procedures to Support Basic Mass Calibrations, Georgia L. Harris.

${ }^{3}$ NISTIR 5672, Advanced Mass Calibrations and Measurements Assurance Program for the State Calibration

Laboratories, Kenneth L. Fraley, Georgia L. Harris.

${ }^{4}$ NISTIR 7383, Selected Procedures for Volumetric Calibrations, Georgia L. Harris.

${ }^{5}$ NISTIR 8028, Selected Laboratory and Measurement Practices and Procedures for Length Calibrations, Jose A.

Torres, Georgia L. Harris.
} 


\begin{tabular}{|c|c|c|}
\hline Title & Description & Type of Assessments \\
\hline $\begin{array}{l}\text { Method Validation } \\
\text { Administrative Procedure } \\
\text { (Sample). Posted with } \\
\text { OWM State Laboratory } \\
\text { Resources. }\end{array}$ & $\begin{array}{l}\text { This sample metrology laboratory } \\
\text { policy and procedure is used for } \\
\text { developing and validating test or } \\
\text { calibration methods when no } \\
\text { international or national procedures } \\
\text { are available, when deviating from } \\
\text { standardized methods, or when no } \\
\text { standard procedures are available. } \\
\text { Should be integrated as a part of the } \\
\text { laboratory Quality Management } \\
\text { System. }\end{array}$ & $\begin{array}{l}\text { Outlines responsibility and } \\
\text { authority for method validations } \\
\text { and approvals; includes: } \\
\text { - } \quad \text { procedures for method } \\
\text { validation; } \\
\text { - types of assessments that } \\
\text { should be utilized to assure the } \\
\text { quality of measurement results; } \\
\text { and } \\
\text { - } \quad \text { a sample evaluation form that } \\
\text { can be used to document the } \\
\text { assessment of new/laboratory } \\
\text { procedures; } \\
\text { - use of replicate tests or } \\
\text { calibrations using the same or } \\
\text { different methods; } \\
\text { - use and evaluation of check } \\
\text { standards; and } \\
\text { use of interlaboratory } \\
\text { comparisons. }\end{array}$ \\
\hline $\begin{array}{l}\text { NIST IR } 6969^{6} \text {, Section 8, } \\
\text { Statistical Techniques. } \\
\text { Associated with Section 9, } \\
\text { Reference Tables. }\end{array}$ & $\begin{array}{l}\text { Includes statistics that are used in } \\
\text { metrology to summarize } \\
\text { experimental data, to provide the } \\
\text { basis for assessing its quality, and to } \\
\text { provide a basis for making } \\
\text { probabilistic decisions in its use. }\end{array}$ & $\begin{array}{l}\text { Includes: } \\
\text { - } \quad \text { calculation of standard } \\
\text { deviations; } \\
\text { - } \quad \text { pooling standard deviations, } \\
\text { - } \quad \text { estimates of standard deviation } \\
\text { from range data; } \\
\text { - } \quad \text { estimates of within and } \\
\text { between standard deviation; } \\
\text { - } \quad \text { determining confidence and } \\
\text { - } \quad \text { statistical tolerance intervals; } \\
\text { using F-test, t-test, and Welch } \\
\quad \text { Satterthwaite equation for } \\
\text { estimating effective degrees of } \\
\text { freedom; and } \\
\text { - using random numbers. }\end{array}$ \\
\hline
\end{tabular}

${ }^{6}$ NISTIR 6969, Selected Laboratory and Measurement Practices, and Procedures to Support Basic Mass Calibrations, Georgia L. Harris. Section 8 was originally part of NIST Handbook 145, Handbook for the Quality Assurance of Metrological Measurements, John K. Taylor and Henry V. Oppermann, 1986, which is out of print. 


\begin{tabular}{|c|c|c|}
\hline Title & Description & Type of Assessments \\
\hline $\begin{array}{l}\text { NIST/SEMATECH e- } \\
\text { Handbook of Statistical } \\
\text { Methods }^{7}\end{array}$ & $\begin{array}{l}\text { Web-based reference that helps } \\
\text { scientists and engineers incorporate } \\
\text { statistical methods into their work as } \\
\text { efficiently as possible. Serves as a } \\
\text { reference on experimental design } \\
\text { and appropriate data analyses when a } \\
\text { statistician is not available to help. } \\
\text { Serves as a useful educational tool to } \\
\text { help users of statistical methods and } \\
\text { consumers of statistical information } \\
\text { better understand statistical } \\
\text { procedures and their underlying } \\
\text { assumptions, and more clearly } \\
\text { interpret scientific and engineering } \\
\text { results stated in statistical terms. }\end{array}$ & $\begin{array}{l}\text { Includes } 8 \text { Chapters: } \\
\text { 1. Exploratory Data Analysis. } \\
\text { 2. Measurement Process } \\
\text { Characterization. } \\
\text { 3. Production Process } \\
\text { Characterization. } \\
\text { 4. Process Modeling. } \\
\text { 5. Process Improvement. } \\
\text { 6. Process or Product Monitoring } \\
\text { and Control. } \\
\text { 7. Product and Process } \\
\text { 8. Comparisons. } \\
\text { 8ssessing Product Reliability. }\end{array}$ \\
\hline
\end{tabular}

${ }_{7}^{7}$ NIST/SEMATECH e-Handbook of Statistical Methods, http://www.itl.nist.gov/div898/handbook/, January 19,
2019. 


\section{GLP 4}

\section{Good Laboratory Practice \\ for \\ Periodic Recalibration of State Standards}

$1 \quad$ Purpose

Many States have provisions in their weights and measures laws that require the periodic submission of their State standards to NIST for calibration. Those provisions are based on an early version of the Model Law (1911), which was considered appropriate for the circumstances that prevailed prior to the establishment of the new State Standards Program by NIST. Periodic calibration is necessary on a defined regular, periodic basis, and when measurement control results from internal control charts or external interlaboratory comparisons indicate questionable data. Good Measurement Practices 11 and 13 provide guidance regarding appropriate calibration intervals and documentation of metrological traceability.

Standards of mass, volume, and length, fabricated from modern materials, kept in the controlled environment of a State metrology laboratory under the custody of trained metrologists, are generally stable and not subject to excessive change. The cooperative NIST-State audit programs often identify changes in ample time for corrective action in the unlikely event that such a change should occur. These same programs provide the necessary evidence of the ability to provide metrological traceability of measurement results at a level of confidence sufficient for the need.

The process of packing, shipping, and unpacking exposes the standards to unnecessary hazards that could result in damage, compromising their integrity. The return and recalibration could take several months, causing an unavailability of State services that would be disruptive to the performance of the mission of the State laboratories.

To develop a policy for the guidance of and implementation by all 50 States regarding this subject, the following actions are recommended:

2.1 States should recognize the fact that periodic return of their State standards to NIST (or another suitable and accredited calibration laboratory) for re-calibration is essential to comply with State laws regarding metrological traceability and with ISO/IEC 17025, GMP 11, and when: 1) data regarding traceability is unavailable; 2) charted measurement results indicate that the standards are out of control; 3) measurement results on interlaboratory comparisons or performance tests are suspect; or 4) NIST advises the State of the need.

2.2 GMP 11 and GMP 13 provide the basis for documenting metrological traceability and provide baseline calibration intervals. These publications are templates that must be modified to specific measurement parameters and applications in each laboratory. Documented calibration intervals may state that calibrations are 
obtained whenever evidence from outside evaluations, proficiency tests, and/or internal controls indicate that significant changes may have taken place, or when measurement results are suspect, but shall not exceed a specified number of years (with the number specified) and may not exceed limits defined in GMP 11 and 13 without significant statistical and technical analysis by the laboratory and by the NIST Office of Weights and Measures. Statements such as "calibration as needed" are unacceptable for both laboratory measurement equipment and measurement standards.

2.3 References to the periodic re-calibration of State standards in the law such as,

"He (the director) shall maintain the State standards in good order and shall submit them, at least once in ten years, to the National Institute of Standards and Technology for calibration,"

should be followed, if present, and may be amended to reflect a more frequent interval, plus calibration based on identified needs. Alternatively, the wording of Sections 3 and 12 of the present Uniform Law from NIST Handbook $130^{1}$ may be substituted:

"SECTION 3. PHYSICAL STANDARDS. -- Weights and measures that are traceable to the U.S. prototype standards supplied by the Federal Government, or approved as being satisfactory by NIST, shall be the state reference and working standards of weights and measures, and shall be maintained in such calibration as prescribed by the NIST as demonstrated through laboratory accreditation or recognition. All field standards may be prescribed by the Director and shall be verified upon their initial receipt, and as often thereafter as deemed necessary by the Director."

"SECTION 12. POWERS AND DUTIES OF THE DIRECTOR. -- The director shall:

12 (a) maintain traceability of the state standards as demonstrated through laboratory accreditation or recognition."

The approach described above is recommended by NIST because many States that participate in the Office of Weights and Measures Laboratory Metrology Program have the capability of evaluating their own State standards, with adequate statistically valid data, and with the necessary documentation referencing metrological traceability to the International System of Units (SI) (or "national standards", when required by State laws). The Laboratory Metrology Program provides interaction between the State standards laboratories and NIST, ensuring satisfactory laboratory conditions suitable for reference standards and/or working standards in addition to the proper use of NIST procedures in standards calibration. Thus, each State program is evaluated and, if found in compliance, is Recognized to perform the measurements listed on the Certificate of

\footnotetext{
${ }^{1}$ NIST Handbook 130, Uniform Laws and Regulations in the Areas of Legal Metrology and Engine Fuel Quality (Latest Edition). This text was originally published in the 2005 version of Handbook 130 and has not been updated as of the publication of this Good Laboratory Practice.
} 
Metrological Traceability according to the requirements in ISO/IEC 17025 as referenced in NIST Handbook 143, Program Handbook (latest edition). 
This page is intentionally blank. 


\section{GLP 9}

\section{Good Laboratory Practice \\ for \\ Rounding Expanded Uncertainties and Calibration Values}

A calibration is not complete until the expanded uncertainty associated with the calibration is determined and reported. Each Standard Operating Procedure (SOP) includes information regarding the calculation of uncertainties. The expanded uncertainty is generally reported with approximately a $95 \%$ confidence interval (95.45\%). The confidence interval is determined by multiplying a coverage factor (often 2 , but based on the degrees of freedom or effective degrees of freedom) times the combined uncertainty, $\mathrm{u}_{\mathrm{c}}$; the combined uncertainty is usually the root sum square of properly combined Type A and Type B evaluated components according to the calibration procedure and rounded according to this GLP, ISO/IEC Guide to the Expression of Uncertainty in Measurement (GUM, 2008), Section 7, and ISO 80000-1:2009, Quantities and units, Part 1. Three Options for rounding presented in this GLP that are all commonly used by calibration and testing laboratories. The laboratory should document which method(s) will be used.

Note: do not round intermediate calculations; rounding intermediate values can cause rounding errors in the final results and should only take place after the final expanded uncertainty has been determined.

1 Rounding Steps. The steps for reporting corrections and uncertainties are as follows:

1.1 Identify the first two significant digits in the expanded uncertainty. Moving from left to right, the first non-zero number is considered the first significant digit. Zeros, which follow a decimal point, when there are only zeros ahead of the decimal point, are not considered significant figures.

1.2 Round the expanded uncertainty following Option A, B, or C.

1.3 Round the reported measurement result, correction, or error to the same number of decimal places as the least significant digit of the uncertainty with both value and uncertainty being in the same units. Both the measurement result and uncertainty will be rounded to the same level of significance.

$2 \quad$ Rounding Methods

2.1 Option A. Even/Odd Method ${ }^{1}$.

2.1.1 Use the following rules to round measurement data using the even/odd rounding rules, consistent with the level of significance:

\footnotetext{
${ }^{1}$ This is the historical method used in this GLP. Where statistics matter, and where numbers that end with the 5 are common, this method is preferred, because it avoids asymmetry due to rounding up. Normally there are 5 situations when you round up (0.5 to 0.9 ) but only 4 to round down (0.1 to 0.4 ). By using the even/odd method you introduce more balance in the final results that may avoid bias in mean values over the long term.
} 
2.1.2 When the digit next beyond the one to be retained is less than five, keep the retained figure unchanged. For example: 2.541 becomes 2.5 to two significant figures.

2.1.3 When the digit next beyond the one to be retained is greater than five, increase the retained figure by one. For example: 2.453 becomes 2.5 to two significant figures.

2.1.4 When the digit next beyond the one to be retained is exactly five, and the retained digit is even, leave it unchanged; conversely if the digit is odd, increase the retained figure by one (even/odd rounding). Thus, 3.450 becomes 3.4 but 3.550 becomes 3.6 to two significant figures.

2.1.5 When two or more figures are to the right of the last figure to be retained, consider them as a group in rounding decisions. Thus, in 2.4(501), the group (501) is greater than 5 while for 2.5(499), (499) is less than 5.

2.2 Option B. Standard Spreadsheet Rounding.

Use standard rounding practices that are used in spreadsheet software such as Microsoft Excel and by following the steps for rounding shown above. (This will generally round up. Do not use truncations.)

2.3 Option C. Round Uncertainties Up.

Round uncertainties up to the next larger value when there are any digits beyond the second significant digit. This conservative approach may be used for reporting uncertainties, for evaluating compliance of the uncertainties against maximum permissible errors (mpe), tolerances, or risk assessments (including guard banding) and may also be used when reporting values on an accreditation Scope. Follow the steps for rounding shown above.

$3 \quad$ Examples of Rounding

Several examples to illustrate the proper method of reporting corrections and uncertainties follow. The number of significant digits will be identical for these examples for all three options.

\subsection{Example 1}

Suppose the correction for a weight is computed to be $1.3578 \mathrm{mg}$ and the uncertainty is $0.5775 \mathrm{mg}$. First, round the uncertainty to two significant figures, that is, $0.58 \mathrm{mg}$. Then state the correction as $1.36 \mathrm{mg}$. Notice that the uncertainty and the correction express the same number of decimal places. Report the correction as $1.36 \mathrm{mg} \pm 0.58 \mathrm{mg}$. This result will be identical for Options A, B, and C. 


\subsection{Example 2}

The volume of a given flask is computed to be $2000.714431 \mathrm{~mL}$ and the uncertainty is $0.084024 \mathrm{~mL}$. First, round the uncertainty to two significant figures, that is, $0.084 \mathrm{~mL}$. (Do not count the first zero after the decimal point.) Round the calculated volume to the same number of decimal places as the uncertainty statement, that is, $2000.714 \mathrm{~mL}$. Report the volume as $2000.714 \mathrm{~mL} \pm 0.084 \mathrm{~mL}$. Options A and B follow this example. Option $\mathrm{C}$ will round the uncertainty to $0.085 \mathrm{~mL}$ since it rounds up for evaluation. The result for Option C will be $2000.714 \mathrm{~mL} \pm 0.085 \mathrm{~mL}$.

\subsection{Example 3}

The correction for a weight is computed to be $4.3415 \mathrm{mg}$ and the uncertainty is $2.0478 \mathrm{mg}$. First, round the uncertainty to two significant figures, that is, $2.0 \mathrm{mg}$. (Notice that two significant figures are shown. The zero is a significant figure since it follows a non-zero number.) Then, round the correction to the same number of decimal places as the uncertainty statement, that is, $4.3 \mathrm{mg}$. Report the correction as $4.3 \mathrm{mg} \pm 2.0 \mathrm{mg}$ for Options $\mathrm{A}$ and $\mathrm{B}$. Option $\mathrm{C}$ will be $4.3 \mathrm{mg} \pm 2.1 \mathrm{mg}$ since any value after the 0 in 2.0 will cause it to be rounded up to 2.1.

\subsection{Example 4}

The correction for a weight is computed to be $285.41 \mathrm{mg}$ and the uncertainty is $102.98 \mathrm{mg}$. Because this uncertainty is a large number, we first convert both values to the next larger commonly reported unit (i.e., $0.28541 \mathrm{~g}$ and $0.10298 \mathrm{~g}$ respectively). First, round the uncertainty to $0.10 \mathrm{~g}$. (The first nonzero digit (1) is the first significant figure and the remaining digits are rounded to the nearest number following the first nonzero digit.) Then, round the correction to the point where the rounding occurred in the uncertainty statement. Round the correction to $0.29 \mathrm{~g}$. Report the correction as $0.29 \mathrm{~g} \pm 0.10 \mathrm{~g}$ (290 $\mathrm{mg} \pm 100 \mathrm{mg}$ ) for Options A and B. Option C will be reported as $0.29 \mathrm{~g} \pm 0.11 \mathrm{~g}$ (290 $\mathrm{mg} \pm 110 \mathrm{mg})$.

\subsection{Example 5}

The correction for a weight is computed to be $285.41 \mathrm{mg}$ and the uncertainty is $33.4875 \mathrm{mg}$. First, round the uncertainty to two significant figures, that is $33 \mathrm{mg}$. Then, round the correction to the same number of decimal places as the uncertainty statement, that is, $285 \mathrm{mg}$. Report the correction as $285 \mathrm{mg} \pm 33 \mathrm{mg}$ for Options A and B. Report the correction as $285 \mathrm{mg} \pm 34 \mathrm{mg}$ for Option C.

\subsection{Example 6}

The length of a calibrated interval is computed to be $9.9994558 \mathrm{ft}$ and the uncertainty is 0.0035617 in. First, make sure both values are reported in the same unit (i.e., convert the uncertainty to ft, $0.000296808 \mathrm{ft}$.) Then, round the value to two significant figures, that is, $0.00030 \mathrm{ft}$. Then, round the length of the interval to the same number of decimal places as the uncertainty value, that is, $9.99946 \mathrm{ft}$. Report the length of the interval as $9.99946 \mathrm{ft} \pm 0.00030 \mathrm{ft}$. This result will be identical for Options A, B, and C. 
Rather than stating the uncertainty value with each correction, it is also proper to place the correction values in a column headed by the words "Correction" or "Error," etc., and place the uncertainties (without plus-minus signs, \pm ) in a column headed "Expanded Uncertainty". 


\section{GLP 11}

\section{Good Laboratory Practice \\ for \\ Painting Cast Iron Weights}

Large cast iron or steel weights should be painted both for their protection and to preserve their mass integrity. Unprotected weights are subject to corrosion. Furthermore, when corrosion is present, the extent and any changes resulting from it may be difficult to estimate.

Thin even coats of aluminum paint are recommended for this purpose. Spray applications are best if large weights or many small weights are to be painted. In preparation for painting, a weight should be cleaned, and loose scale should be removed using a wire brush (DO NOT remove old paint and corrosion by means of sand blasting or pressure washing. Severe damage may result.). The painting should be done before the weights are calibrated, unless arrangements are made to obtain "as found" values. If "as found" values are desired, two calibrations may be required (one before painting as the "as found" values and one after painting and after any adjustments as the "as left" values).

Painting should be done in an area reserved for this purpose, or at least in a place which is removed from laboratory measurement operations. Painting operations must follow applicable safety standards with appropriate Safety Data Sheets available and using appropriate Personal Protective Equipment (PPE). The weights should be protected from dust or dirt contamination while the coating is drying. 
This page is intentionally blank. 
Good Measurement Practices 
This page is intentionally blank. 


\section{GMP 1}

\section{Good Measurement Practice \\ for \\ Reading Turning Points on an Equal-Arm Balance}

The damping of the beam oscillations of an equal-arm balance is generally very slow. Consequently, it is practical to read the turning points (the highest and lowest value of the beam oscillation) on the graduated scale and use the sum of the turning points as the observation value rather than wait for the beam to come to rest. This GMP requires that the graduated scale be numbered such that adding weights to the left arm increases the readings.

Suppose the graduated scale has 20 graduations that are numbered from 0 to 20 . The loads on the balance arms should be adjusted so that the sum of the turning points is approximately twice the midscale reading. In this example, the sum of the turning points should be within one division of twenty. Turning points should be estimated to at least 0.1 division in this example, which is typical of the Russell balance. This means that the final rest point is approximately 10, the midscale reading. Motion to the beam may be induced or dampened so that the turning points can be read easily. Care should be taken so that the beam does not hit limiting stops during its normal oscillation while turning points are being read. The amount of the beam oscillation is not critical although a span of from three to ten divisions is adequate.

Once motion has been induced for the beam oscillation, wait for at least one complete oscillation cycle for the beam motion to stabilize. After this time, the turning points can be read. The readings may begin with either the high or low turning point. The turning points for at least two consecutive oscillation cycles should be recorded. The turning points should reveal a consistent pattern of slow damping; that is, the turning points should gradually converge to the eventual rest point. For example, if the last high turning point was greater than the previous high turning point (if the readings normally drop on successive readings), this would indicate that something has interfered with beam oscillation, hence the last reading was not valid with respect to the previous readings. Under these circumstances, turning points should continue to be read until a consistent damping pattern has been obtained. In some cases, the balance oscillation will dampen so slowly that the same readings may be obtained for several oscillations before a decrease is observed. These readings are valid and may be used to compute the sum of the turning points.

When at least four satisfactory turning points have been obtained (two high and two low turning points), all but the last three readings should be discarded. This will leave two high and one low turning point or vice versa. The two readings for the high or low turning points should be averaged and added to the single turning point to obtain the sum of the turning points. The sum should be carried out to two decimal places if the second decimal place digit is nonzero. As an example, the following readings were obtained: $15.5,4.3,15.4,4.4$. The sum of the turning points is computed as shown in Eqn. 1:

$$
\left(\frac{4.3+4.4}{2}\right)+15.4=19.75
$$


This technique of reading turning points has been successfully used to obtain readings on a digital loadcell system where the overall hoisting system is not sufficiently rigid to allow stable unchanging indications when under load. If there is a slowly oscillating digital variation, where the readings seemingly wander back and forth around a central value on a period of at least 5 seconds, it may be appropriate to read a series of maximum and minimum values and calculate the central value using the turning point method. Turning points have been used with loadcell systems to calibrate weight carts and large weights suspended from an overhead hoisting system where there was a slow indication oscillation caused by flexing of the overall supporting structure. 


\section{GMP 10}

\section{Good Measurement Practice \\ for \\ Understanding Factors Affecting Weighing Operations}

Good laboratory techniques and practices, as well as good standards and balances, are required to obtain good mass measurements. Errors can arise from a variety of sources, such as balance drift, air currents, lack of thermal equilibrium, magnetic or electrostatic fields, and manipulative skills while using the balance. The magnitude and significance of these errors depends upon the laboratory environment, the balance, and the accuracy required for the measurement. Different methods of weighing are used to eliminate or reduce the effects of sources of error. Sources of error and ways to eliminate the errors are discussed with the weighing procedures. The accuracy required for a measurement and the criticality of the measurement often influence the choice of the weighing method used in the measurement. Regardless of the procedure used, several practices should be followed to promote good measurements.

\section{$1 \quad$ Environment and Preparation}

First, the balance should be installed in a laboratory having good temperature and humidity control. The requirements for temperature stability increase as more precision is needed in the measurement. For high precision measurement, the temperature should not vary by more than $\pm 1{ }^{\circ} \mathrm{C}$ in a $24 \mathrm{~h}$ period throughout the year and should vary by less than $0.5^{\circ} \mathrm{C}$ during any one measurement series (typically less than $1 \mathrm{~h}$ ). Automated systems will require tighter limits to environmental variations, possibly over a longer period. General laboratory measurements can probably withstand temperature variations of $\pm 2{ }^{\circ} \mathrm{C}$ per day. Varying temperatures result in balance drift and in unequal temperatures for the air, balance, and objects to be weighed. The relative humidity should be maintained between $40 \%$ and $60 \%$ which is the recommended limits provided by most balance manufacturers and by OIML $\mathrm{R} 111$. If the relative humidity falls significantly below $40 \%$, electrostatic discharge may be generated both in and near the balance. This can result in erratic readings and make precision weighing impossible. If precision mass standards are cleaned, they should stabilize in the laboratory environment for at least seven to ten days.

Thermal and environmental equilibrium are critical for mass calibrations. Therefore, each mass SOP provides instruction that the environment must be stable and the weights set in or near the balance for 24 hours prior to a calibration. The test objects, balances, reference standards, and air should all be in thermal equilibrium. When possible, the objects to be weighed and the reference standards should be placed either in the balance chamber or adjacent to the balance, so all can come to the same thermal equilibrium. If there is a lack of thermal equilibrium, convection currents will be generated when an object is on the balance pan and an erroneous reading may result. These types of errors are likely to go unnoticed when check standards are handled the same way, so care must be taken to reduce the likelihood of their occurrence. Tests have shown that these types of errors depend upon the temperature differences among the objects and the balance, and on the geometry of the objects being weighed. On 20 g standards of greatly differing geometry, studies have shown that errors as large as $0.2 \mathrm{mg}$ can occur for a $4{ }^{\circ} \mathrm{C}$ temperature difference among the standards and the balance. Errors as large as $3 \mathrm{mg}$ have also been observed at $1 \mathrm{~kg}$ loads when 
standards were stored in a cabinet and unknown test items near the balance where a temperature gradient of $2{ }^{\circ} \mathrm{C}$ was present (when the expanded uncertainty was less than $0.1 \mathrm{mg}$ ). When weights are delivered to the laboratory, care must be taken to ensure adequate environmental equilibration, especially when outside conditions deviate from those in the laboratory by more than $10^{\circ} \mathrm{C}$. The presence of frost, ice, or condensation on the weights is a common occurrence and may not be readily visible.

The balance must be installed in an area free from air currents. Air flow should be less than $2 \mathrm{~m} / \mathrm{s}$ in mass calibration areas. Balances should be installed away from heating/cooling vents. It is not adequate to merely close vents when weighing because disrupting the temperature control system may result in temperature changes near the balances that exceed limits specified in the procedures and/or documentary standards.

\section{Handling Weights}

The masses of standard weights or objects weighed can be affected significantly by the way they are handled. Human contact can leave grease or oily films that affect the mass at the time of measurement and can even cause permanent damage due to corrosion.

Small weights should never be touched by hand, but handled using forceps, clean gloves, or swatches of cloth. In the latter case, the cloth must be lint free. Instructions for cleaning weights and for removing adhering foreign material are described in GMP 5.

Large weights of lower tolerance classes (NIST Class F) may be handled by bare hands. Large weights are a source of special problems. Fork lifts, portable cranes, hoists, or even overhead cranes may have to be used to move the weights within the laboratory and on or off the balances. Laboratory personnel must become expert in using such equipment, as necessary, to avoid damage to the laboratory facilities, to the balances used, and even to the weights themselves. Special hoist/crane hydraulics or multi-speed systems are available to gently set large weights in place on large comparators to avoid damage. The problem of temperature equilibrium for large weights is qualitatively the same as for small weights and needs consideration on an individual basis.

Large weights must be clean at the time of use, but cleaning may be a problem. Minimally, they should be inspected to ensure that foreign material is not present. Cleaning is addressed further in GMP 5.

Cleanliness of weight handling materials is just as critical as their use. Forceps, gloves, and other lifting materials are prone to contamination and must be regularly cleaned. Care must be taken when using gloves to ensure that heat and moisture are not transferred to the weights, that other laboratory materials (balances, pens, computers) are not handled that will cause contamination, and that gloves are not used simply to keep hands clean!

\section{$3 \quad$ Balance and Weighing Operations}

Analytical balances are high precision instruments and should be operated carefully. Excessive shock can damage a balance. Avoid shock loading the balance. Gently place all weights in the center of the weighing pan/platform. The dials on mechanical balances should be turned slowly and gently. Careful balance operation will improve the repeatability of measurements. 
Mechanical analytical balances are provided with partial and full release positions. The partial release position is used when determining if an unknown load will provide an on-scale reading. The balance beam has limited movement in this position. The partial release position provides some protection to the balance when the dialed-in weights are not close to the actual mass placed on the pan. It is good practice to arrest the pan each time a dial is being changed to protect the balance from shock loading. It is acceptable to change the dial representing the smallest built-in weights when in the partial release position because the small weight changes should not result in shock loading of the balance.

When releasing the pan to either the full or partial release position, the action should be done slowly and carefully. The objective is to minimize disturbances to the balance as much as possible.

Similarly, all loads should be placed on the balance pan carefully and centered on the pan.

When a mechanical balance is released, the beam goes through a series of oscillations. The frequency of these oscillations diminishes as time passes until they are almost imperceptible to the naked eye. At this point, optimal stabilization is achieved. This stabilization of the balance typically lasts for a very short period, after which the balance reading will usually drift. A similar situation occurs when a mass is placed on the pan of an electronic balance. Therefore, readings should be taken at the precise moment of achieving balance stability. This interval between the releasing of a pan on a mechanical balance, or the placing of a mass on an electronic balance, and the reading of the observation, varies from balance to balance. Stabilization time differs for all balances, even among those of the same type and model. Knowledge of the operating characteristics of each instrument is critical to correctly establish this time interval. Although manufacturers will usually state this value, it is necessary for the metrologist to verify its reliability. Many electronic balances have a stability signal incorporated into the design, but stability also must be verified. All measurements in a calibration should be performed at the same time interval, and within the shortest time possible.

All balances should be exercised before taking readings. A load equal to the load to be measured should be placed on the balance, a reading taken, and the pan arrested, if appropriate, or the weight removed from electronic balances. This operation should be repeated several times before readings are taken for measurement purposes. Once the balance has been "warmed-up", better repeatability will be achieved. Balances can be very accurate even when used without being exercised first, but improved results can be obtained by going through a "warm-up" procedure. If the larger variation present in initial weighings on a balance that has not been exercised is not significant to the measurement, the warm-up procedure may be minimized. The warm-up description provided here is not related to ensuring an instrument is plugged in and turned on, although following manufacturers recommendations regarding electronic warm-up periods are also important.

To determine the repeatability of measurements when a balance has not been exercised versus its performance after being exercised, and to determine how much warm-up time or exercising is required, begin measurements using the process that will be used starting with the unexercised balance and record the readings. Repeat a series of measurements until you have obtained several measurements after the balance has been exercised. This process can be repeated over several days using the same objects and the results compared. The readings obtained when using an unexercised balance are likely to show a slightly larger variation than those obtained after the balance has been 
exercised. Balance drift is likely to be larger initially and then reach a steady state when the balance has been exercised.

\section{Comparison (Substitution) Weighing - Mechanical Balance}

For mass calibrations, the unknown object must be compared to, or substituted with, a mass standard with known calibration values. Comparison weighing (also called substitution weighing) eliminates the errors of the built-in weights, reduces disturbances during the measurement because dial settings are not changed during the measurement, and can minimize the effects of drift by selecting the appropriate weighing design and appropriate sensitivity weight(s). Comparing the unknown, $X$, to a standard, $S$, eliminates the built-in weights (and associated calibrations) from the measurement: thus, the built-in weights act only as counterweights; they do not affect the difference measured between $X$ and $S$. Consequently, the dial settings must not be changed during a comparison measurement; otherwise the built-in weights would be part of the measurement.

When comparison measurements are made on a single pan mechanical balance, all readings are taken from the optical scale. The unknown and the standard must have nearly the same mass so that the difference between them can be measured on the optical scale. If the masses of the unknown and the standard are significantly different, small mass standards are used as tare weights with either the unknown or the reference standard or both to obtain an observed mass difference that is significantly less than one-fourth the range of the optical scale.

As part of a comparison measurement, the mass value of a scale division is determined by performing a sensitivity determination. The small mass standard used as part of the weighing design to calibrate the optical scale is called the sensitivity weight and should have a mass between $1 / 5$ and $1 / 2$ the range of the optical scale, inclusive. Additionally, the mass of the sensitivity weight should have a mass that is at least twice the observed mass difference between the standard and the unknown. Since the maximum size of the sensitivity is limited to one-half the range of the optical scale, it may be necessary to carry tare weights with the standard and the unknown to ensure that the observed difference between them is less than one-half the mass of the sensitivity weight. The value of the sensitivity weight should include the correction plus its nominal value. For high precision calibrations, the inclusion of the air buoyancy correction for the sensitivity weight is critical and the sensitivity weight usually needs to be four times the difference between the standard and unknown (with any associated tare weights). See SOP 34 for detailed guidance on the selection of sensitivity weights.

The first readings for the standard and the unknown in a comparison on a single pan balance should fall in the first quarter of the optical scale, but well ahead of zero, so the balance drift will not result in negative values for any readings. Although negative numbers may be used in calculations, they are avoided to simplify calculations and reduce calculation errors. Because the sensitivity weight may have a mass as large as one-half the range of the optical scale and the measured difference between the standard and the unknown may be as large as one-fourth the range of the optical scale, it is necessary to obtain the first two readings in the first quarter of the optical scale so all readings will remain on-scale for the measurement. In this way it is not necessary to change the dial settings to measure the difference between the standard and the unknown. 
Measurements made on a full electronic balance are simplified because there are no built-in weights to consider. Although many electronic balances are equipped with a built-in calibration weight, the internal weights are not involved in the comparison (substitution) weighing.

The principles for comparison weighing on a full electronic balance are the same as when using a single pan mechanical balance. The balance indications are used to measure the mass difference between the standard and the unknown, and a sensitivity weight is used to establish the mass value for a digital division on the balance. Since there are no built-in weights in the full electronic balance, the entire range of the digital indications can be considered for "optical scale" of the balance.

For comparison weighing the standard and the unknown should be equally nominal or "nearly the same mass." Since a full electronic balance has a much larger range for indicating mass values, the masses do not have to be as close together as when a mechanical balance is being used. When using an electronic balance, the difference in mass between the standard and unknown should be less than $0.05 \%$ of the balance capacity. Tare weights that are known standards should be used if the masses are not sufficiently close together. The sensitivity weight used to determine the mass per digital division should have a mass that is at least 10 to 20 times the mass difference between the standard and the unknown but not exceeding $1 \%$ of the balance capacity. For high precision weighing, air buoyancy corrections must be made for all objects used in the intercomparison. See SOP 34 for detailed guidance on the selection of sensitivity weights.

Care must be taken when weighing magnets or objects having electrostatic charges. A magnetic field will likely affect results of a mass measurement. A magnet is attracted to ferromagnetic materials in the balance and balance chamber. The magnetic field may also affect the magnetic field generated in an electronic balance that utilizes the principle of magnetic force restoration as its method of measurement.

Weights made of ferromagnetic material can become magnetized during manufacture or during use if they are placed in a strong magnetic field. Magnetized weights can result in measurement errors that may go undetected. If a measurement problem is suspected, the weights should be checked for magnetism and may have to be rejected if excessively magnetized.

If magnets or magnetized material must be weighed, the material should be placed in a magnetically shielded container to prevent the magnetic field from generating measurement errors. If balance design and conditions permit, an alternative is to position the magnetized material a relatively large distance from the balance pan using a non-ferromagnetic object on the pan to serve as a platform for the magnetic. Since the strength of the magnetic field drops off at a rate of the cube of the distance from the magnetic, it may be possible to effectively isolate the magnet from other ferromagnetic material in the balance.

Electrostatic fields can also cause errors in measurements. If there is a static charge in a mechanical balance, the balance may give erratic readings and lack repeatability. If the object being weighed has a significant electrostatic charge, it may result in measurement errors and may leave a static 
charge on the balance. Electrostatic charges are of concern when plastic containers are placed on the balance.

Care should be taken to remove electrostatic charges from objects being weighed by grounding the objects, if necessary, before placing them on the balance. To prevent the build-up of static electricity in a balance, the relative humidity in the laboratory should be maintained between $40 \%$ and $60 \%$ which are also the general manufacturer's specified limits for precision balance operations. The water vapor in the air will serve to drain off electrostatic charges from the balance.

Balances utilizing the magnetic force restoration principle for weighing should be checked to verify that the magnetic field generated by the magnetic cell in the balance does not exist around the balance pan. If the shielding of the magnetic cell is inadequate, measurement errors may occur when weighing ferromagnetic objects or when the balance is placed on a surface comprised of ferromagnetic material. 


\section{GMP 11}

\section{Good Measurement Practice for}

\section{Assignment and Adjustment of Calibration Intervals for Laboratory Standards}

Introduction

\section{$1.1 \quad$ Purpose}

Measurement processes are dynamic systems and often deteriorate with time or use. The design of a calibration program is incomplete without some established means of determining how often to calibrate instruments and standards. A calibration performed only once establishes a one-time reference of uncertainty. Periodic recalibration detects uncertainty growth, serves to reset values while keeping a bound on the limits of errors and minimizes the risk of producing poor measurement results. A properly selected interval assures that an item will be recalibrated at the proper time. Proper calibration intervals allow specified confidence intervals to be selected and they support evidence of metrological traceability. The following practice establishes calibration intervals for standards and instrumentation used in measurement processes.

Note: This Good Measurement Practice provides a baseline for documenting calibration intervals. This GMP is a template that must be modified beyond Section 4.1 to match the scope ${ }^{1}$ and specific measurement parameters and applications in each laboratory. Legal requirements for calibration intervals may be used to supplement this procedure but are generally established as a maximum limit assuming no evidence of problematic data.

For legal metrology (weights and measures) laboratories, no calibration interval may exceed 10 years without exceptional analysis of laboratory measurement assurance data. Associated analyses may include a detailed technical and statistical assessment of historical calibration data, control charts, check standards, internal verification assessments, demonstration of ongoing stability through multiple proficiency tests, and/or other analyses to unquestionably demonstrate adequate stability of the standards for the prescribed interval. Extended calibration intervals in legal metrology laboratories recognized by the NIST Office of Weights and Measures, must approved by NIST OWM. (See also GLP 4).

\footnotetext{
${ }^{1}$ The laboratory scope is also called calibration and measurement capability (CMC). The CMC includes 1) measurement parameters, 2) range of nominal values, 3) associated expanded uncertainties, and 4) documented and validated calibration methods.
} 


\subsection{Prerequisites}

1.2.1 Calibration history and valid calibration certificates, with suitable calibration providers and sufficiently small uncertainties, for all laboratory standards.

1.2.2 Up-to-date measurement assurance and uncertainty data, with adequate degrees of freedom, for all measurement processes in the laboratory that match the laboratory Scope.

1.2.3 Expected tolerance limits where applicable.

\subsection{Safety}

\subsubsection{No outstanding safety concerns}

$2 \quad$ Methodology

\subsection{Summary}

Recommended calibration intervals are based on various examples of metrological traceability as described in GMP 13, Good Measurement Practice for Ensuring Metrological Traceability. As data is collected and evaluated, the laboratory technical manager may adjust the calibration intervals to ensure that measurement results are not invalidated by the intervals selected according to this procedure.

\subsection{Apparatus}

None.

\subsection{Procedure}

\subsubsection{Identification of Parameters}

The laboratory must identify all measurement parameters associated with the Scope of calibrations (and tests) that will be performed in the laboratory. All standards used in a calibration process must be assessed to determine their level of significance and to minimize the risk of producing erroneous results on calibration certificates.

2.3.2 Standards are identified as being critical parameters or secondary parameters.

\subsubsection{Critical Parameters}

Components that contribute more than $25 \%$ of a measurement's uncertainty are identified as critical parameters with a higher risk for impacting the measurement results. To ensure an accurate 
evaluation of performance, calibration intervals are determined to meet a $99 \%$ reliability target.

\subsubsection{Secondary Parameters}

Components that contribute less than $25 \%$ but more than $1 \%$ of a measurement's uncertainty are identified as secondary parameters. Secondary parameters are assigned calibration intervals designed to meet a $95 \%$ reliability target.

\subsubsection{Assignment of Initial Intervals}

Assignment of initial intervals is based on examples and recommendations given in this GMP as maximum limits. Otherwise, an initial interval is equivalent to the amount of time that passes before a metrologist makes the first observation of a result lying outside the warning limits of a control chart when the investigation yields no apparent correctable cause or when results from proficiency tests fail the normalized error assessment (or when the observed bias exceeds the laboratory uncertainty), or the maximum authorized through law or technical review.

\subsubsection{Initial Intervals - Additional Standards}

A calibration program and periodic calibration interval must be documented for all standards used in the laboratory to comply with the definition and interpretation of metrological traceability. Statements such as "as needed" are not acceptable alone without additional qualifications. A statement such as "calibrations are conducted on an annual basis and may be extended based on demonstrated control through technical and statistical analysis of historical calibration data, control charts, surveillance testing, and multiple interlaboratory comparisons, but will not exceed five years" would be acceptable.

\subsubsection{Absence of Control Charts or Measurement Assurance Data}

If no initial measurement assurance data is available, the laboratory's Technical Manager should assign initial intervals based on guidance and limits provided in this GMP. Intervals may be adjusted based on adequate data and criteria in Section 2.4 and NIST recommendations. Lacking adequate data for setting and adjusting calibration intervals is a risk that must be addressed by the laboratory.

\subsubsection{Tracking and Scheduling}

The laboratory must have a program of documenting and monitoring calibration status and scheduling calibrations on the defined intervals. Examples include software systems that flag past-due standards prior to use, scheduling on a calendaring system, or periodic reviews to monitor the 
calibration status prior to regular management reviews so that adequate resources are available to obtain calibrations in a timely manner and to prevent the use of standards after their calibration due date(s).

\subsection{Adjustment of Intervals}

2.4.1 Intervals may be adjusted when determined to be necessary by the laboratory's Technical Manager based on adequate data, valid technical and statistical analysis, and documentation of the assessment. Subsequent intervals may be adjusted based on documented analysis of adequate measurement assurance data, demonstrated control through surveillance assessments, and ongoing stability as demonstrated through multiple interlaboratory comparisons or proficiency tests.

2.4.2 Calibration intervals may be lengthened or shortened by performing a technical and statistical analysis, taking the following factors into consideration as appropriate, and fully documenting the data and assessment:

- calibration history;

- measurement assurance data;

- interlaboratory comparisons;

- data for the population of similar standards, equipment or technologies;

- $\quad$ NIST recommendations;

- $\quad$ statistical analysis methods; and

- manufacturer's recommendations.

2.4.3 Inadequate reasons for adjusting intervals might include failure to have an adequate system for tracking due dates, lack of funding for suitable calibrations, loss of competent staff, or other related operational risks. Extending calibration intervals must be based on valid, technically supported, and documented assessments to ensure that metrological traceability is supported for all measurement results provided by the laboratory.

Assignment of Uncertainty

The uncertainty associated with the establishment of calibration intervals is not included as a part of the uncertainties associated with the respective measurement SOPs. See SOP 29 for calculating uncertainties for standards and measuring instruments. 
4 Calibration Intervals for the Laboratory Scope

4.1 As this document is a template, the laboratory may eliminate all examples in this section and reference another laboratory document that combines metrological traceability information and calibrations in one file if it completely states calibration intervals. It is NOT recommended to include calibration intervals in the laboratory Quality Manual to ensure that updates are regularly implemented when calibrations are performed without excessive document approval requirements. The tables of calibration intervals noted in this GMP may be combined with the tables of reference, working, and check standard tables from the worksheets and hierarchies of GMP 13 to minimize the need for multiple tracking methods in the laboratory.

4.2 In the following sections, where Lab or Accredited Lab is noted, the measurement capability must be noted on the Scope of the laboratory performing the measurements and suitable supplier evaluations must be in place. For each level of calibration, a higher-level calibration is required for check standards.

\subsection{Examples for Mass}

\subsubsection{Mass Critical Parameters}

\subsubsection{Balance and Measurement Process Performance}

It is important to keep measuring equipment clean and in good working condition. If problems with the equipment are observed, the device should be evaluated and may require maintenance or repair before being put back into service. Regular service, maintenance, and calibration schedules may prevent equipment problems from occurring. When problems are observed, immediate service is required prior to use.

Balance performance in weighing processes following SOP 5 and SOP 28 (e.g., Echelon I) is evaluated in each measurement series. An F-test ratio evaluates the observed standard deviation of the process against the accepted standard deviation of the process. However, while balance calibration might be considered part of a mass calibration procedure, maintaining equipment in good operating condition that minimizes contamination and prevents deterioration is a requirement for all laboratory balances and comparators as a part of accreditation and recognition. The laboratory may have additional procedures to ensure suitable maintenance of balances that ensures proper functioning and prevents contamination and deterioration. 
All other weighing processes have incorporated measurement control procedures and control charts that must be evaluated for balance performance characteristics as data is collected.

Table 1. Recommended intervals for balances used for mass (and gravimetric volume) calibrations.

\begin{tabular}{|l|c|c||}
\hline \multicolumn{1}{|c||}{ Equipment } & $\begin{array}{c}\text { Initial Service and Calibration } \\
\text { Interval (months) }\end{array}$ & Source \\
\hline $\begin{array}{l}\text { Balances and Mass } \\
\text { Comparators }\end{array}$ & 12 & Approved Provider \\
\hline
\end{tabular}

\subsubsection{Mass Standards}

Each weighing series in Echelon I also incorporates a check standard with a value that is evaluated using a t-test. The observed value is compared to the accepted reference value to determine if there might be problems. Even with the extreme care in storage and handling required for mass standards at this level, mass standards are dynamic with use. Wear, contamination and other factors can cause drift from accepted values. Thus, the following intervals have been set:

Table 2. Recommended calibration intervals for mass standards where Echelon I or II are in place and standards are used at Echelon I or II.

\begin{tabular}{|c|c|c|}
\hline Standards & Initial Interval (months) & Source \\
\hline $\mathrm{R} 1 . \mathrm{kg}$ and $\mathrm{R} 1 . \mathrm{kg}$ & 48 & NIST \\
\hline $\mathrm{S}_{\mathrm{c}} 1 . \mathrm{kg}$ and $\mathrm{S}_{\mathrm{c}} 1 . \mathrm{kg}$ & (alternating 2 years) 48 & NIST \\
\hline R 100. g and R 100. g & 48 & NIST \\
\hline$S_{c} 100 . g$ and $S_{c} 100 . g$ & (alternating 2 years) 48 & NIST or Accredited Lab \\
\hline R $30 \mathrm{~kg}$ to R $2 \mathrm{~kg}$ & 12 & $\begin{array}{l}\text { Lab (Echelon I) or Accredited Lab } \\
\text { (Echelon II) }\end{array}$ \\
\hline R 500 g to R1 mg & 12 & $\begin{array}{l}\text { Lab (Echelon I) or Accredited Lab } \\
\text { (Echelon II) }\end{array}$ \\
\hline $\mathrm{S}_{\mathrm{c}} 500 \mathrm{~g}$ to $\mathrm{S}_{\mathrm{c}} 1 \mathrm{mg}$ & 12 & Accredited Lab \\
\hline W $25 \mathrm{~kg}$ to W $1 \mathrm{mg}$ & 12 & Lab \\
\hline $\mathrm{R} 500 \mathrm{lb}$ to $1 \mu \mathrm{lb}$ & 12 & Lab \\
\hline $\mathrm{W} 5000 \mathrm{lb}$ to $1 \mu \mathrm{lb}$ & 12 & Lab \\
\hline $\begin{array}{l}\text { Sensitivity weights and tare } \\
\text { weights used as standards }\end{array}$ & 12 & Lab \\
\hline \multicolumn{3}{|c|}{$\mathrm{R}=$ Reference; $\mathrm{S}_{\mathrm{c}}=$ check/control; $\mathrm{W}=$ working standards } \\
\hline
\end{tabular}


Table 3. Recommended calibration intervals for mass standards for Echelon III calibrations.

\begin{tabular}{||l|c|c||}
\hline \multicolumn{1}{|c|}{ Standards } & Initial Interval (months) & Source \\
\hline \hline W 25 kg to W 1 mg* & 24 & Accredited Lab \\
\hline $\mathrm{S}_{\mathrm{c}} 25 \mathrm{~kg}$ to $\mathrm{S}_{\mathrm{c}} 1 \mathrm{mg}^{*}$ & 24 & Accredited Lab \\
\hline R $500 \mathrm{lb}$ & 120 & Accredited Lab \\
\hline W $5000 \mathrm{lb}$ to $500 \mathrm{lb}$ & 24 & Lab or Accredited Lab \\
\hline $\begin{array}{l}\text { Sensitivity weights and tare } \\
\text { weights used as standards }\end{array}$ & 12 & \multicolumn{2}{|c||}{$\mathrm{R}=$ Reference; $\mathrm{S}_{\mathrm{c}}=$ check/control; W = working standards } \\
\hline \multicolumn{2}{|c||}{} \\
\hline $\begin{array}{l}\text { Note: where Echelon II is not also in place, reference standards and/or working standards may all need } \\
\text { to be calibrated by a suitable calibration provider. *When cast iron working and check standards are } \\
\text { used, the initial calibration interval is recommended to be 6 months until adequate measurement } \\
\text { assurance data is collected showing artifact stability prior to extending the interval. }\end{array}$ \\
\hline
\end{tabular}

\subsubsection{Mass Secondary Parameters}

Availability of multiple units for environmental equipment enable the laboratory to conduct internal comparisons immediately after a calibration or between calibration cycles and generate internal calibration reports to enable extension of calibration intervals if adequate stability is demonstrated. See procedure for adjusting calibration intervals. The following table contains initial calibration intervals.

Table 4. Recommended calibration intervals for environmental standards used in calibrations.

\begin{tabular}{||l|c|c||}
\hline \multicolumn{1}{|c|}{ Standards } & Initial Interval (months) & Source \\
\hline \hline Barometer & 12 & Accredited Lab \\
\hline Hygrometer & 24 & Accredited Lab \\
\hline Thermometer (digital) & 12 & Accredited Lab \\
\hline $\begin{array}{l}\text { Data Loggers (when used for } \\
\text { calibrations) }\end{array}$ & 12 & Accredited Lab \\
\hline
\end{tabular}

4.4 Examples for Length

\subsubsection{Length Critical Parameters}

\subsubsection{Length Standards}

Length standards are dynamic with use. Wear, contamination and other factors can cause drift from accepted values. The following intervals have been set due to these factors: 
Table 5. Recommended calibration intervals for length standards.

\begin{tabular}{|l|c|c||}
\hline \multicolumn{1}{|c|}{ Standards } & Initial Interval (months) & Source \\
\hline \hline $100 \mathrm{ft}$ Tape \#1 & 60 & NIST \\
\hline $100 \mathrm{ft}$ Tape \#2 & 60 & NIST \\
\hline $25 \mathrm{ft}$ or 7 m Tape & 60 & NIST \\
\hline 18 in Steel Rule & 120 & NIST \\
\hline Length Bench & 24 (if used or moved) & Lab \\
\hline
\end{tabular}

\subsubsection{Length Secondary Parameters}

Table 6. Recommended calibration intervals for length secondary parameters used in calibrations.

\begin{tabular}{|c|c|c|}
\hline Standards & Initial Interval (months) & Source \\
\hline \hline Thermometer (digital) & 12 & Accredited Lab \\
\hline
\end{tabular}

4.5 Examples for Volume

\subsubsection{Volume Critical Parameters}

\subsubsection{Volume Standards}

Volume standards are dynamic with use. Wear, contamination and other factors can cause drift from accepted values. Seals and valves must regularly be assessed for leaks and stability. Initial calibration intervals are as follows:

Table 7. Recommended calibration intervals for volume standards.

\begin{tabular}{||l|c|c|}
\hline \multicolumn{1}{|c|}{ Standards } & Initial Interval (months) & Source \\
\hline \hline R 100 gal standard & 60 & NIST, Lab, or Accredited \\
R 25 gal standard * & 60 & Lab or Accredited Lab \\
\hline R 5 gal standard * & 24 & Lab or Accredited Lab \\
\hline $\begin{array}{l}\text { Glassware- Laboratory standard } \\
\text { Autopipettes* 5 L to 100 mL }\end{array}$ & 120 & Lab or Accredited Lab \\
\hline
\end{tabular}

*Gravimetric calibration for volumes 5 gallon or smaller, and all "slicker plate” standards. Laboratory must be qualified for performing gravimetric calibrations. Volume transfer is acceptable above 5 gallons.

*May be a "slicker plate” type. None are hand-held, “dump” style, test measures.

This GMP does not cover calibration intervals for pipettes used in analytical laboratories. 
4.5.2 Volume Secondary Parameters

Table 8. Recommended calibration intervals for volume secondary parameters (gravimetric) used in calibrations.

\begin{tabular}{||l|c|c||}
\hline \multicolumn{1}{|c|}{ Standards } & Initial Interval (months) & Source \\
\hline \hline Barometer & 12 & Accredited Lab \\
\hline Hygrometer & 24 & Accredited Lab \\
\hline Thermometer (digital) & 12 & Accredited Lab \\
\hline
\end{tabular}

Table 9. Recommended intervals for volume secondary parameters (transfer) used in calibrations.

\begin{tabular}{||c|c|c||}
\hline \multicolumn{1}{|c|}{ Standards } & Initial Cal Interval (months) & Source \\
\hline \hline Thermometer (digital) & 12 & Accredited Lab \\
\hline
\end{tabular}

4.6 Example for Thermometry

4.6.1 Thermometry Critical Parameters

4.6.1.1 Temperature Standards

Temperature standards are dynamic with use. Shock, contamination and other factors can cause drift from accepted values. Recalibration intervals are as follows:

Table 10. Recommended intervals for temperature standards.

\begin{tabular}{||l|c|c||}
\hline \multicolumn{1}{|c|}{ Standards } & Initial Cal Interval (months) & Source \\
\hline \hline 25.5 ohm SPRT & 36 & NIST \\
\hline 100 ohm PRT's & 12 & Accredited Lab \\
\hline Standard Thermistor & 12 & Accredited Lab \\
\hline Check Standards & 12 & Accredited Lab \\
\hline Liquid-in-glass standards* & $6 *$ & Accredited Lab \\
\hline $\begin{array}{l}\text { *Annual inspection must also ensure that there is no damage or separation in the liquid column. See } \\
\text { NIST SP-1088 (2009) }\end{array}$ for additional maintenance plan requirements. New thermometers should be \\
checked at least once a month at the ice point for a minimum of the first six months of use.
\end{tabular}

Where internal intrinsic or reference standards are available, and the laboratory has the demonstrated competency, the following may be used to set or adjust calibration intervals: triple point cells, melting point cells, and ice baths (using documented and validated procedures).

${ }^{2}$ NIST SP 1088, Maintenance and Validation of Liquid-in-Glass Thermometers, Christina D. Cross, Dean C. Ripple, W. W. Miller, Gregory F. Strouse, January 01, 2009, http://www.nist.gov/manuscript-publication-

search.cfm?pub_id=900914. 
This page is intentionally blank. 


\section{GMP 12 \\ Good Measurement Practice \\ for \\ Standard Operating Procedure Selection}

Good laboratory practices, use of proper standards and equipment, and selection of standard operating procedures are essential for providing calibration results with accurate and traceable values with appropriate and suitable uncertainties. The following matrix recommends SOPs based on the parameter, type of calibration items, and level of uncertainty needed.

Table 1. Procedure Selection Table.

\begin{tabular}{|c|c|c|}
\hline $\begin{array}{l}\text { Parameter or } \\
\text { Documentary } \\
\text { Standard }^{1}\end{array}$ & Calibration Item & Recommended SOP \\
\hline \multicolumn{3}{|c|}{ Mass (NISTIR 6969 and NISTIR 5672) } \\
\hline & Railroad test cars & $\begin{array}{l}\text { SOP 27, Railroad Test Cars using a Master Track } \\
\text { Scale }\end{array}$ \\
\hline HB 105-8 & Weight carts & $\begin{array}{l}\text { SOP 33, Calibration of Weight Carts (References } \\
\text { SOP } 4 \text { and SOP 7) }\end{array}$ \\
\hline $\begin{array}{l}\text { HB 105-1, Class F } \\
\text { ASTM, OIML }\end{array}$ & $\begin{array}{l}\text { Class } \mathrm{F} \\
\text { Class } 5,6,7 \\
\text { Class } \mathrm{M}_{1}, \mathrm{M}_{2}, \mathrm{M}_{3} \\
\text { e.g., } 10 \mathrm{~kg} \text { to } \\
250 \mathrm{~kg}(\geq 500 \mathrm{lb}) \text { cast iron } \\
1 \mathrm{mg} \text { to } 5 \mathrm{~kg} \\
(1 \mu \mathrm{lb} \text { to } 10 \mathrm{lb}) \text { stainless } \\
\text { steel }\end{array}$ & $\begin{array}{l}\text { SOP 8, Modified Substitution - may be used if } \\
\text { expanded uncertainty is less than } 1 / 3 \text { of the } \\
\text { tolerance } \\
\text { SOP } 7 \text {, Single Substitution - to be used, as a } \\
\text { minimum, if conditions given for SOP } 8 \text { cannot be } \\
\text { met } \\
\text { NOTE: Balances and standards must be selected } \\
\text { properly for these conditions to be met. }\end{array}$ \\
\hline ASTM, OIML & $\begin{array}{l}\text { Class } 3,4(\mathrm{P}) \\
\text { Class } \mathrm{F}_{1}, \mathrm{~F}_{2} \\
\text { e.g., } 1 \mathrm{~kg} \text { kit, } 100 \mathrm{~g} \text { kit }\end{array}$ & $\begin{array}{l}\text { SOP 7, Single Substitution - may be used if } \\
\text { expanded uncertainty is less than } 1 / 3 \text { of the } \\
\text { tolerance. If uncertainty is greater than } 1 / 3 \text { of the } \\
\text { tolerance, then use SOP } 4 \text {. } \\
\text { SOP } 4 \text {, Double Substitution - to be used for } \\
\text { buoyancy corrections and if expanded uncertainty } \\
\text { is less than } 1 / 3 \text { of the tolerance } \\
\text { NOTE: Balances and standards must be selected } \\
\text { properly for these conditions to be met. }\end{array}$ \\
\hline ASTM, OIML & $\begin{array}{l}\text { Class } 1,2(\mathrm{~S}, \mathrm{~S}-1) \\
\text { Class } \mathrm{E}_{2} \\
\text { When used for balance } \\
\text { calibration }\end{array}$ & $\begin{array}{l}\text { SOP 5, 3-1 Weighing Design (preferred) } \\
\text { SOP 4, Double Substitution - to be used for } \\
\text { buoyancy corrections and if expanded uncertainty } \\
\text { is less than } 1 / 3 \text { of the tolerance }\end{array}$ \\
\hline ASTM, OIML & $\begin{array}{l}\text { Class } 000,00,0,1(\mathrm{~S}) \\
\text { Class }_{1} \\
\text { When used as laboratory } \\
\text { standards }\end{array}$ & $\begin{array}{l}\text { Weighing Designs per NIST Technical Note (TN) } \\
\text { 952, TN 844, NISTIR 5672, SOP 28, with } \\
\text { appropriate check standards; } \\
\text { SOP 5, 3-1 Weighing Design (optional) }\end{array}$ \\
\hline
\end{tabular}

${ }^{1}$ See Table 2 for complete Titles for the Documentary Standard references used in Table 1. 


\begin{tabular}{|c|c|c|}
\hline \multicolumn{3}{|c|}{ "Volume (NISTIR 7383) } \\
\hline HB 105-2 & Glass flasks & $\begin{array}{l}\text { SOP 14, Gravimetric Calibration of Volumetric } \\
\text { Standards Using an Electronic Balance } \\
\text { SOP 16, Calibration of Measuring Flasks } \\
\text { Volume Transfer Method (acceptable) }\end{array}$ \\
\hline HB 105-3 & $\begin{array}{l}20 \text { L test measures } \\
\text { ( } 5 \text { gal or } 10 \text { gal) }\end{array}$ & $\begin{array}{l}\text { Preferred: SOP 19, Calibration of Graduated } \\
\text { Neck-Type Metal Provers (Volume Transfer } \\
\text { Method) is preferred. When temperature } \\
\text { instability is observed during the calibration } \\
\text { process, SOP } 19 \text { must be used. } \\
\text { SOP 31, Scale Plate Calibration for Volumetric } \\
\text { Field Standards } \\
\text { SOP 18, Calibration of Graduated Neck-Type } \\
\text { Metal Volumetric Field Standards Using a } \\
\text { Slicker-Plate Type Standard, may be used if } \\
\text { temperature stability and limits are acceptable } \\
\text { (single delivery from slicker plate type standard; } \\
\text { for glass standards use SOP } 19 .\end{array}$ \\
\hline HB 105-3 & $\begin{array}{l}\text { Large graduated neck type } \\
\text { provers - used for meter } \\
\text { verification }\end{array}$ & $\begin{array}{l}\text { SOP 19, Calibration of Graduated Neck-Type } \\
\text { Metal Provers (Volume Transfer Method) } \\
\text { SOP 31, Scale Plate Calibration for Volumetric } \\
\text { Field Standards }\end{array}$ \\
\hline HB 105-4 & LPG provers & $\begin{array}{l}\text { SOP 21, Calibration of LPG Provers } \\
\text { SOP 31, Scale Plate Calibration for Volumetric } \\
\text { Field Standards }\end{array}$ \\
\hline \multirow[t]{4}{*}{ HB 105-7 } & $\begin{array}{l}\text { Compact Displacement } \\
\text { Prover (Small Volume } \\
\text { Provers) }\end{array}$ & $\begin{array}{l}\text { SOP 26, Gravimetric Calibration of Dynamic } \\
\text { Volumetric Systems used as Standards }\end{array}$ \\
\hline & $\begin{array}{l}\text { Laboratory standards } \\
\text { Glassware: burets, } \\
\text { pipettes, flasks }\end{array}$ & $\begin{array}{l}\text { SOP 14, Gravimetric Calibration of Volumetric } \\
\text { Standards Using an Electronic Balance }\end{array}$ \\
\hline & $\begin{array}{l}\text { Laboratory standards } \\
\text { Laboratory slicker plate } \\
\text { standards }\end{array}$ & $\begin{array}{l}\text { SOP 14, Gravimetric Calibration of Volumetric } \\
\text { Standards Using an Electronic Balance }\end{array}$ \\
\hline & Micropipettes & $\begin{array}{l}\text { SOP 14, Gravimetric Calibration of Volumetric } \\
\text { Standards Using an Electronic Balance }\end{array}$ \\
\hline HB 105-3 & $\begin{array}{l}\text { Large graduated neck type } \\
\text { provers - used as } \\
\text { laboratory standards }\end{array}$ & $\begin{array}{l}\text { SOP 19, Calibration of Graduated Neck-Type } \\
\text { Metal Provers (Volume Transfer Method) OR } \\
\text { SOP 14, Gravimetric Calibration of Volumetric } \\
\text { Standards Using an Electronic Balance } \\
\text { SOP 31, Scale Plate Calibration for Volumetric } \\
\text { Field Standards }\end{array}$ \\
\hline
\end{tabular}




\begin{tabular}{|c|c|c|}
\hline \multicolumn{3}{|c|}{ Length (NISTIR 8028) } \\
\hline & Tapes & $\begin{array}{l}\text { SOP 11, Bench Method (lower uncertainties) OR } \\
\text { SOP 12, Tape to Tape }\end{array}$ \\
\hline & Rigid Rules & SOP 10, Rigid Rule \\
\hline & Pi Tapes & SOP 23, Pi Tape Calibration \\
\hline \multicolumn{3}{|c|}{ Liquid-in-Glass Thermometers } \\
\hline HB 105-6 & $\begin{array}{l}\text { Field standards for } \\
\text { weights and measures }\end{array}$ & SOP 25 (unpublished) \\
\hline \multicolumn{3}{|c|}{ Timing Devices } \\
\hline HB 105-5 & $\begin{array}{l}\text { Field standards for } \\
\text { weights and measures }\end{array}$ & SOP 24 (unpublished) \\
\hline \multicolumn{3}{|c|}{ Traffic Speed Gun Tuning Forks } \\
\hline & $\begin{array}{l}\text { For enforcement official } \\
\text { use }\end{array}$ & SOP 22 (unpublished) \\
\hline \multicolumn{3}{|c|}{ Measurement Assurance } \\
\hline $\begin{array}{l}\text { All Process } \\
\text { Measurement Assurance }\end{array}$ & SOP 30 & Use of process measurement assurance programs \\
\hline Mass & SOP 5, 28 & $\begin{array}{l}\text { Use of check standards in procedure } \\
\text { TN 952, TN 844, NISTIR } 5672\end{array}$ \\
\hline Mass & SOP 4, 6, 7, 8 & SOP 9 \\
\hline Length & SOP 10, 11, 12, 23 & $\begin{array}{l}\text { Redundancy built into procedures with replicate } \\
\text { measurements }\end{array}$ \\
\hline Volume & $\begin{array}{l}\text { SOP } 13,14,15,16,18 \\
19,21,26\end{array}$ & $\begin{array}{l}\text { SOP 17, laboratory check standards OR } \\
\text { SOP 20, standard deviation charts and range } \\
\text { charts }\end{array}$ \\
\hline Temperature & SOP 25 & $\begin{array}{l}\text { Use of check standards in procedure (SOP 30, } \\
\text { SOP 17) }\end{array}$ \\
\hline \multicolumn{3}{|c|}{ Uncertainty } \\
\hline All parameters & All SOPs & $\begin{array}{l}\text { SOP 29, Calculation of Uncertainty } \\
\text { Note: Each SOP for calibration procedures } \\
\text { includes a detailed uncertainty budget table } \\
\text { template identifying common components to be } \\
\text { included. }\end{array}$ \\
\hline
\end{tabular}


Table 2. Documentary Standard References.

\begin{tabular}{|c|c|c|}
\hline $\begin{array}{l}\text { Documentary } \\
\text { Standard Number }\end{array}$ & Title & $\begin{array}{l}\text { Latest Revision } \\
\text { Date }\end{array}$ \\
\hline $105-1$ & $\begin{array}{l}\text { Specifications and Tolerances for Field Standard Weights } \\
\text { (NIST Class F) }\end{array}$ & 2019 \\
\hline $105-2$ & $\begin{array}{l}\text { Specifications and Tolerances for Field Standard Measuring } \\
\text { Flasks }\end{array}$ & 1996 \\
\hline $105-3$ & $\begin{array}{l}\text { Specifications and Tolerances for Graduated Neck Type } \\
\text { Volumetric Field Standards }\end{array}$ & 2010 \\
\hline $105-4$ & $\begin{array}{l}\text { Specifications and Tolerances for Liquefied Petroleum Gas and } \\
\text { Anhydrous Ammonia Liquid Volumetric Provers }\end{array}$ & 2016 \\
\hline $105-5$ & Specifications and Tolerances for Field Standard Stopwatches & 1997 \\
\hline $105-6$ & Specifications and Tolerances for Thermometers & 1997 \\
\hline $105-7$ & $\begin{array}{l}\text { Specifications and Tolerances for Dynamic Small Volume } \\
\text { Provers }\end{array}$ & 1997 \\
\hline $105-8$ & Specifications and Tolerances for Field Standard Weight Carts & 2019 \\
\hline ASTM E617 & $\begin{array}{l}\text { Standard Specification for Laboratory Weights and Precision } \\
\text { Mass Standards }\end{array}$ & 2018 \\
\hline OIML R111 & $\begin{array}{l}\text { Weights of classes } E_{1}, E_{2}, F_{1}, F_{2}, M_{1}, M_{1-2}, M_{2}, M_{2-3} \text { and } M_{3} \\
\text { Part 1: Metrological and technical requirements }\end{array}$ & 2004 \\
\hline
\end{tabular}




\section{GMP 13 \\ Good Measurement Practice \\ for \\ Ensuring Metrological Traceability ${ }^{1}$}

1 Introduction

$1.1 \quad$ Purpose

The purpose of this Good Measurement Practice is to enable compliance with essential elements of Metrological Traceability. Traceability ensures that the measurements are accurate representations of the specific quantity subject to measurement, within the uncertainty of the measurement.

To ensure metrological traceability, suitably calibrated standards that are appropriately maintained and cared for, proper standard operating procedures, continuous measurement control, surveillance, and suitable documentation must all be present.

Test numbers issued by NIST should not be used nor required as proof of the adequacy or traceability of a test or measurement. Having a NIST number does not provide evidence that the measurement value provided by another organization has the property of metrological traceability.

GMP 13 provides the basis for documenting metrological traceability. This GMP is a template that must be modified beyond Section 4 to match the laboratory scope, specific measurement parameters, and uncertainties in each laboratory.

1.2 Metrological Traceability is defined ${ }^{2}$ as the "property of a measurement result whereby the result can be related to a reference through a documented unbroken chain of calibrations, each contributing to the measurement uncertainty."

NOTE 1: For this definition, a 'reference' can be a definition of a measurement unit through its practical realization, or a measurement procedure including the measurement unit for a non-ordinal quantity, or a measurement standard.

NOTE 2: Metrological traceability requires an established calibration hierarchy.

NOTE 3: Specification of the reference must include the time at which this reference was used in establishing the calibration hierarchy, along with any other relevant metrological information about the reference, such as when the first calibration in the calibration hierarchy was performed.

\footnotetext{
${ }^{1}$ See also the International Laboratory Accreditation Cooperation (ILAC) Policy ILAC P10:01/2013, ILAC Policy on the Traceability of Measurement Results. Available http://ilac.org/publications-and-resources/ilacdocuments/procedural-series/ (August 2014).

${ }^{2}$ These definitions are provided in the "International vocabulary of metrology — Basic and General Concepts and Associated Terms (VIM)” JCGM 100:2008 (2012).
} 
NOTE 4: For measurements with more than one input quantity in the measurement model, each of the input quantity values should itself be metrologically traceable and the calibration hierarchy involved may form a branched structure or a network. The effort involved in establishing metrological traceability for each input quantity value should be commensurate with its relative contribution to the measurement result.

NOTE 5: Metrological traceability of a measurement result does not ensure that the measurement uncertainty is adequate for a given purpose or that there is an absence of mistakes.

NOTE 6: A comparison between two measurement standards may be viewed as a calibration if the comparison is used to check and, if necessary, correct the quantity value and measurement uncertainty attributed to one of the measurement standards.

NOTE 7: The ILAC considers the elements for confirming metrological traceability to be an unbroken metrological traceability chain to an international measurement standard or a national measurement standard, a documented measurement uncertainty, a documented measurement procedure, accredited technical competence, metrological traceability to the SI, and calibration intervals (see ILAC P-10:2002).

NOTE 8: The abbreviated term "traceability" is sometimes used to mean 'metrological traceability' as well as other concepts, such as 'sample traceability' or 'document traceability' or 'instrument traceability' or 'material traceability', where the history ("trace") of an item is meant. Therefore, the full term of "metrological traceability" is preferred if there is any risk of confusion.

1.3 A Metrological Traceability Chain is defined as "traceability chain sequence of measurement standards and calibrations that is used to relate a measurement result to a reference".

NOTE 1: A metrological traceability chain is defined through a calibration hierarchy.

NOTE 2: A metrological traceability chain is used to establish metrological traceability of a measurement result.

NOTE 3: A comparison between two measurement standards may be viewed as a calibration if the comparison is used to check and, if necessary, correct the quantity value and measurement unit.

1.4 Metrological Traceability to a Measurement Unit is defined as: metrological traceability to a unit metrological traceability where the reference is the definition of a measurement unit through its practical realization

NOTE: The expression "traceability to the SI" means 'metrological traceability to a measurement unit of the International System of Units'. 


\section{$1.5 \quad$ Prerequisites}

Metrological traceability can be characterized by the following seven essential elements:

\subsubsection{Realization of SI units.}

The measurand(s) must be defined. The primary national, international or intrinsic standards must be primary standards for the realization of the International System of Units (SI) (See GMP 13 and example standard hierarchies referencing the International System of Units (SI); See also NIST Special Publication 330, The International System of Units and NIST Special Publication 811, Guide for the Use of the International System of Units (SI));

\subsubsection{Unbroken chain of comparisons.}

A documented system of comparisons with each step having the essential elements of metrological traceability going back to a standard acceptable to the parties, usually a national or international standard (See GMP 13 and example standard hierarchies referencing the International System of Units (SI);

\subsubsection{Documented calibration program.}

Calibrations of standards (and equipment where appropriate) must be repeated at established (may be defined through measurement assurance) and appropriate intervals to preserve metrological traceability of the standard over time and use (see GLP 4, GMP 11);

\subsubsection{Documented measurement uncertainty.}

The measurement uncertainty for each step in the traceability chain must be calculated according to defined methods and must be stated so that an overall uncertainty for the whole chain may be calculated (see SOP 29; See each calibration SOP published by the Office of Weights and Measures, which include detailed uncertainty budget tables);

\subsubsection{Documented measurement procedure.}

Each step in the chain must be performed according to documented and validated procedures (see GMP 12) and the measurement results with expanded uncertainties must be documented (i.e., in a calibration certificate, see SOP 1);

\subsubsection{Accredited technical competence.}

The laboratories or bodies performing one or more steps in the chain must supply evidence of technical competence (e.g., by maintaining appropriate 
training records, participating in interlaboratory comparisons, and by demonstrating that they are accredited by a recognized accreditation body; See GLP 1); and

\subsubsection{Measurement assurance.}

A proper measurement assurance program must be established to ensure the validity of the measurement process and the accuracy of standard used at the time of the measurement (see SOPs 9, 17, 20, 30, and GLP 1).

1.6 Responsibility

\subsubsection{Provider.}

Providing support for the claim of traceability of the result of a measurement or value of a standard is the responsibility of the calibration provider. Calibration certificates must contain a statement regarding metrological traceability. See Appendices C and D for a form that may be used to assess evidence supporting metrological traceability.

\subsubsection{User.}

Assessing the validity of a claim of traceability is the responsibility of the user of that result or value. Verifying claims of traceability often includes obtaining a calibration directly from a national metrology institute or another laboratory that has achieved recognition or accreditation through a recognized accrediting body. See Appendix E for a form that may be used to assess calibration certificates and standards for weights and measures applications.

1.6.3 Use of, or reference to, official test numbers of a national metrology institute.

Having an authentic test number does not provide assurance or evidence that the measurement value provided by another organization is traceable. Not only must there be an unbroken chain of comparisons, but each measurement must be accompanied by a statement of uncertainty associated with the value. Test report numbers should not be used nor required as proof of the adequacy or traceability of a test or measurement. National and international documentary standards for test and measurement quality requirements, such as ISO 10012, ISO/IEC 17025 and the ISO 9000 series, provide guidance for assessing metrological traceability and do not require the use or reporting of specific test numbers to establish metrological traceability.

\subsection{Safety}

No outstanding safety concerns. 


\subsection{Summary}

Traceability must be maintained through comparison to appropriate standards with suitable procedures and measurement uncertainties. Procedures are outlined in SOPs and GMPs. Examples of possible hierarchies of the standards leading to the metrological traceability of a calibration are provided in this document in Appendix A.

\subsection{Procedure}

\subsubsection{Create Traceability Hierarchy Charts/Diagrams for the Laboratory.}

The charts in Appendix A provide examples of possible traceability hierarchies for mass, length, volume, and temperature measurement disciplines. Each laboratory must define their exact traceability hierarchy in their quality management system (controlled laboratory documents) and have evidence of all essential elements of traceability confirmed to perform associated calibrations.

A worksheet is included as Appendix B to help in the definition and outline of the calibration system. The worksheet may be used as a template, integrated with requirements for establishing calibration intervals from GMP 11, identify suitable calibration sources in the calibration program in a single controlled reference as part of the laboratory calibration program.

2.2.2 Periodically Assess Traceability Hierarchies and the Laboratory Calibration Program.

Example tools for assessing the laboratory's objective evidence of metrological traceability are provided in Appendices C and D. Calibration laboratories need to have a calibration program that includes schedules for calibrations and regular reviews of documented evidence of metrological traceability. Regular assessments can provide ongoing confidence and assurance of metrological traceability.

Appendix C - Traceability Evaluation Form - for assessing laboratory evidence of traceability;

Appendix D - Sample Technical Audit for Traceability Evidence - tool for selecting calibration certificates and assessing the evidence in the laboratory as part of a technical audit; and

Appendix E - Evaluating Supplier Calibration Certificates for Metrological Traceability for Weights and Measures Applications - tool to assess traceability for weights and measures applications as needed. 
3 Calculations

There are no calculations in this GMP.

4 Assignment of Uncertainty

The uncertainty associated with reported calibration values is included within the uncertainty analysis for each SOP and in SOP 29, Calculating and Reporting Uncertainties. 
Appendix A - Examples

\section{Mass - Example A}

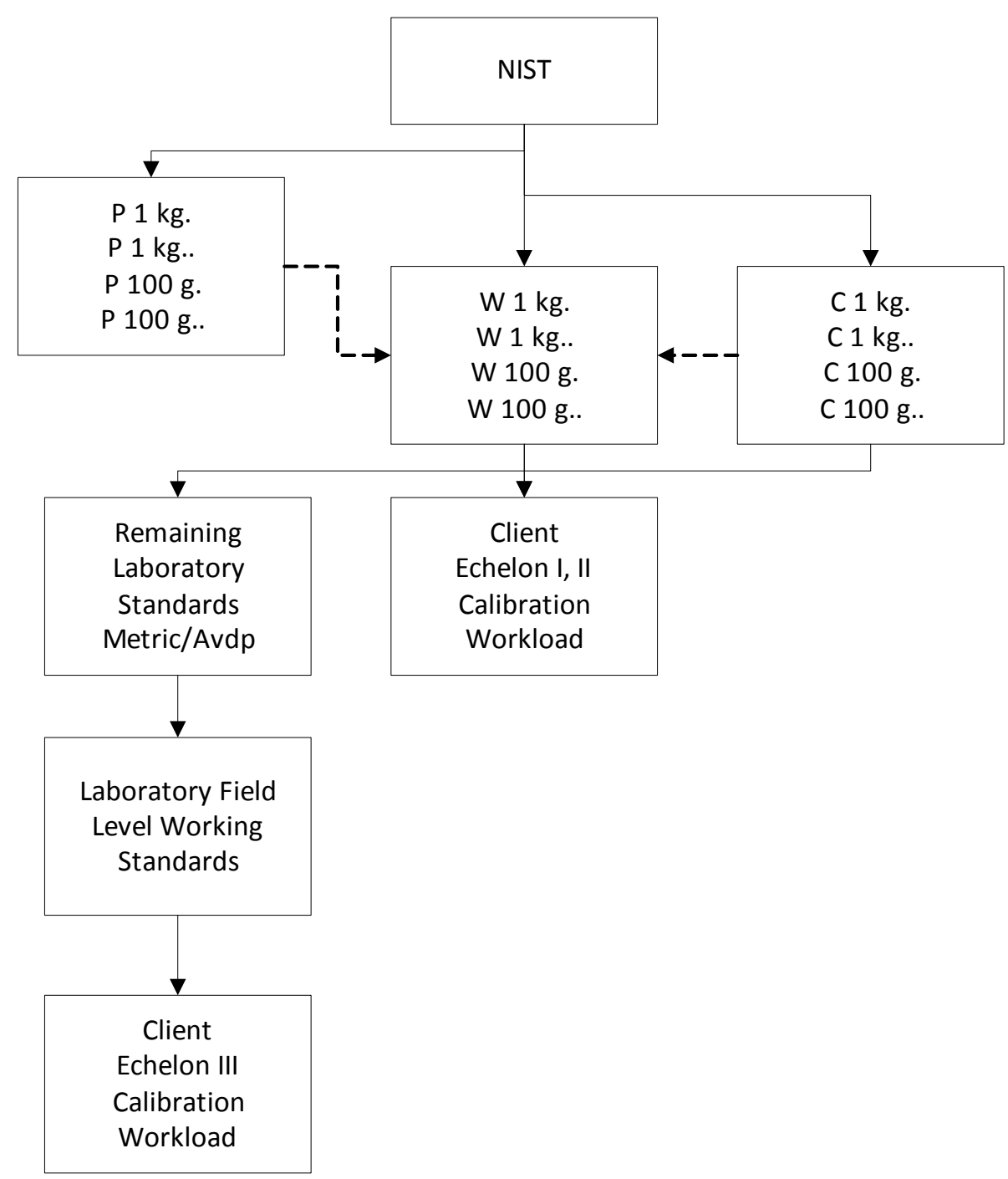

Figure 1. Mass Example A (Echelon I). 


\section{Mass - Example B}

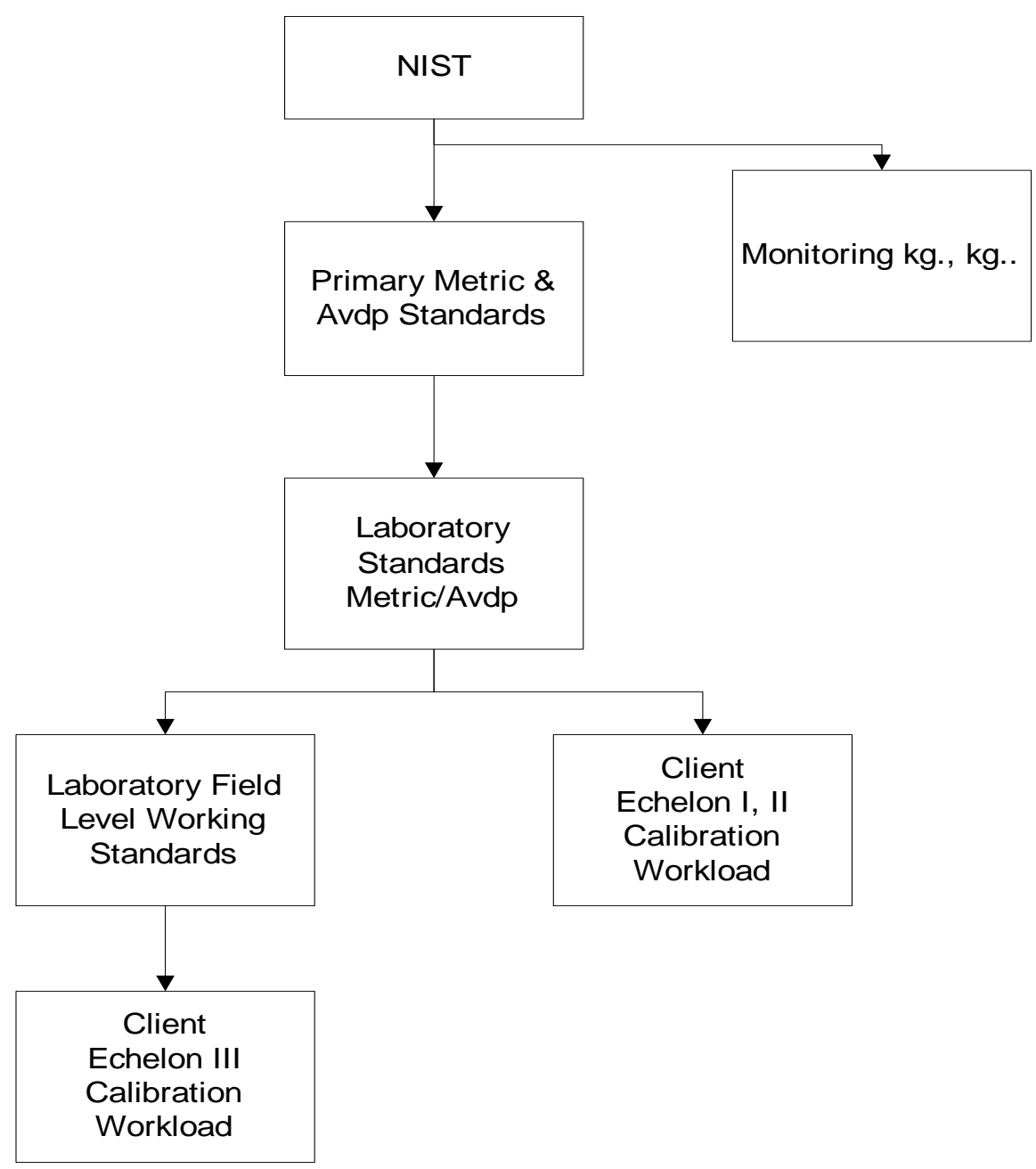

Figure 2. Mass Example B (Echelon II). 


\section{Mass - Example C}

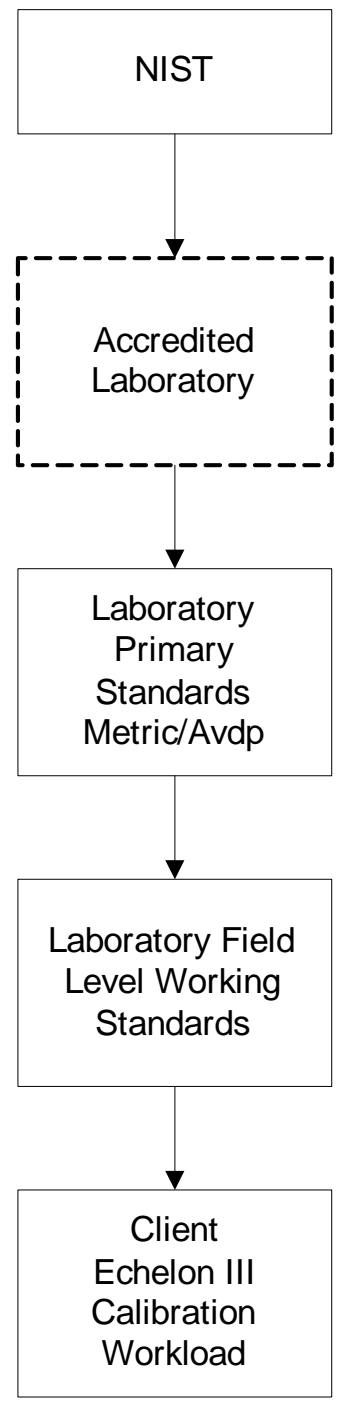

Figure 3. Mass Example C (Echelon III). 
Volume - Example A

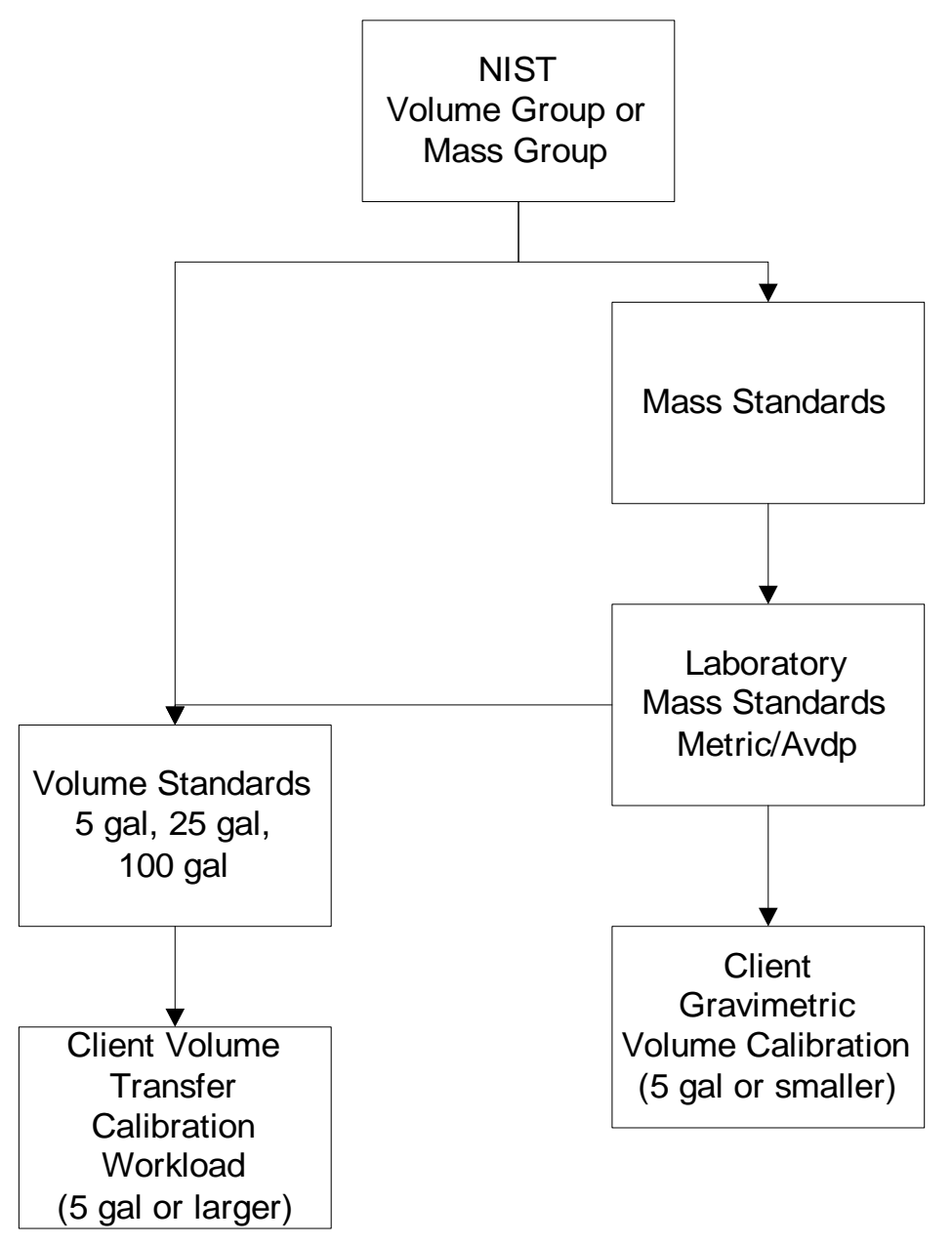




\section{Volume - Example B}

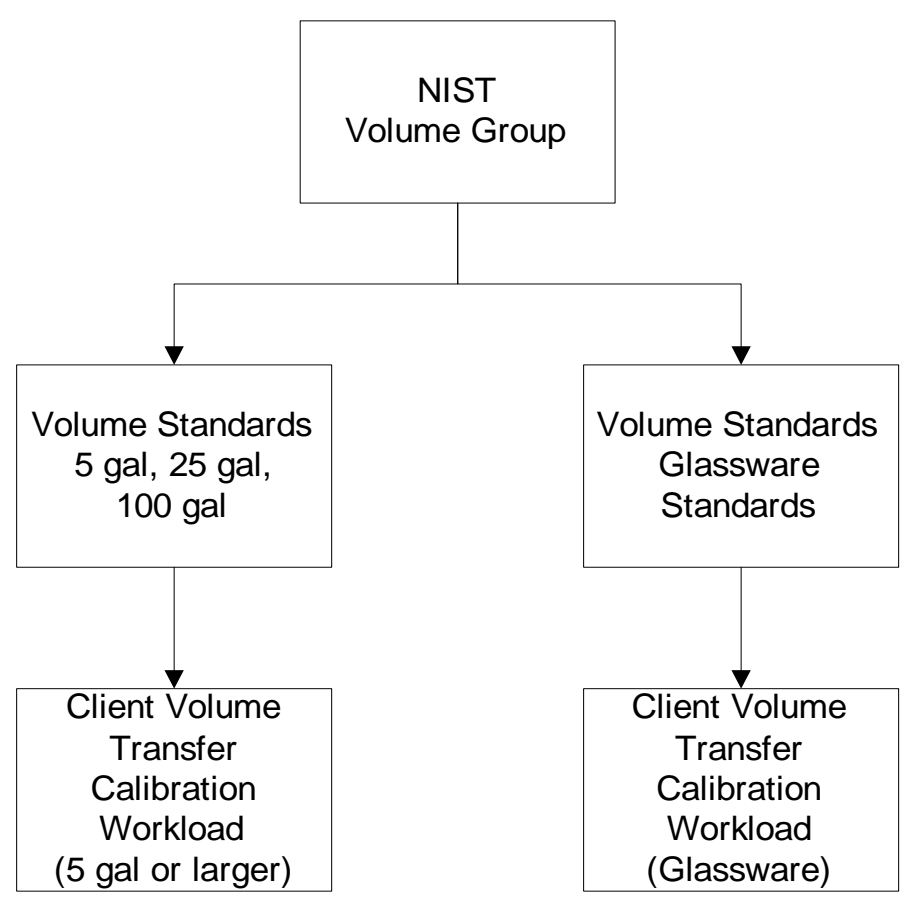




\section{Length Example}

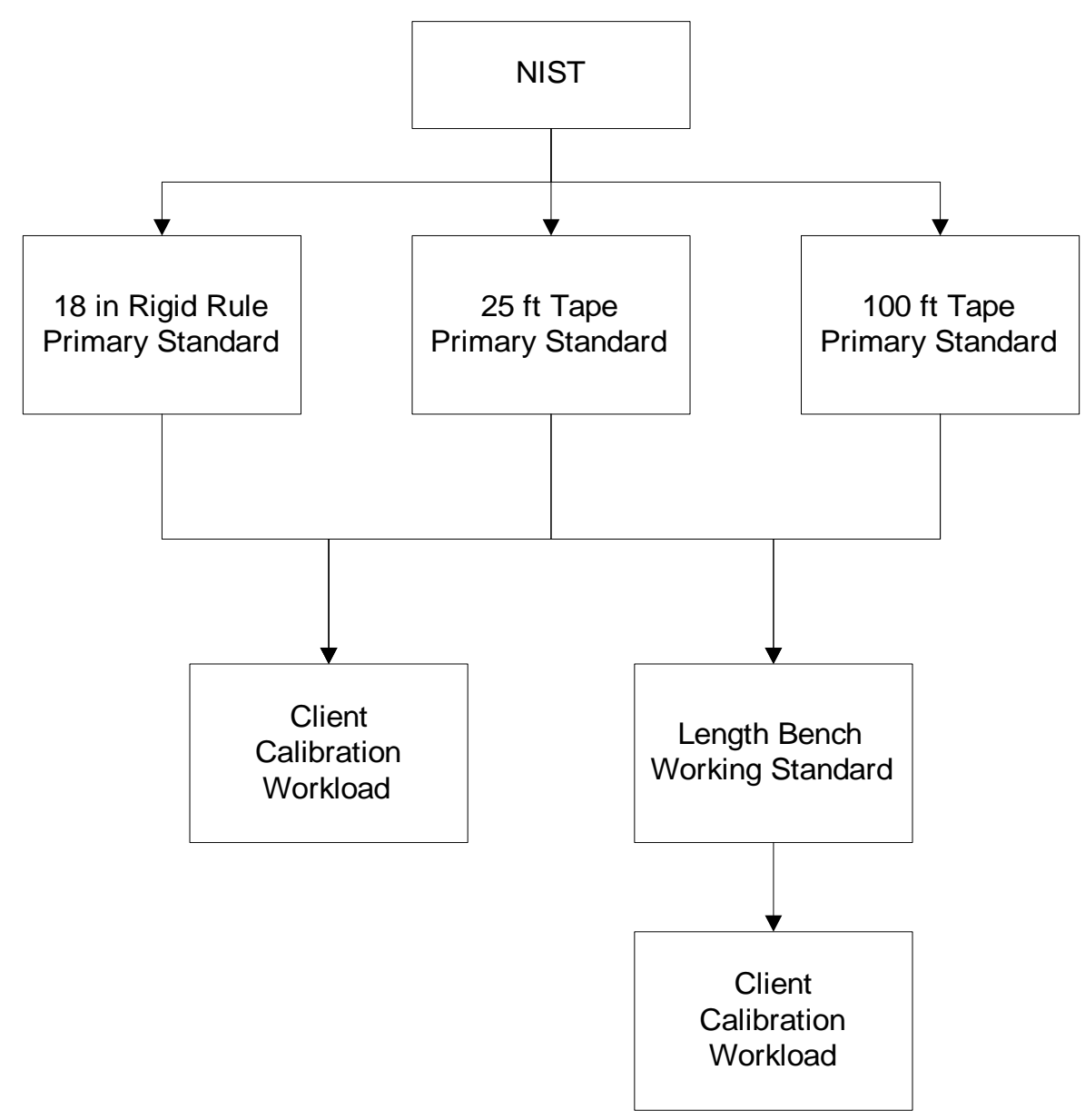




\section{Temperature Example}

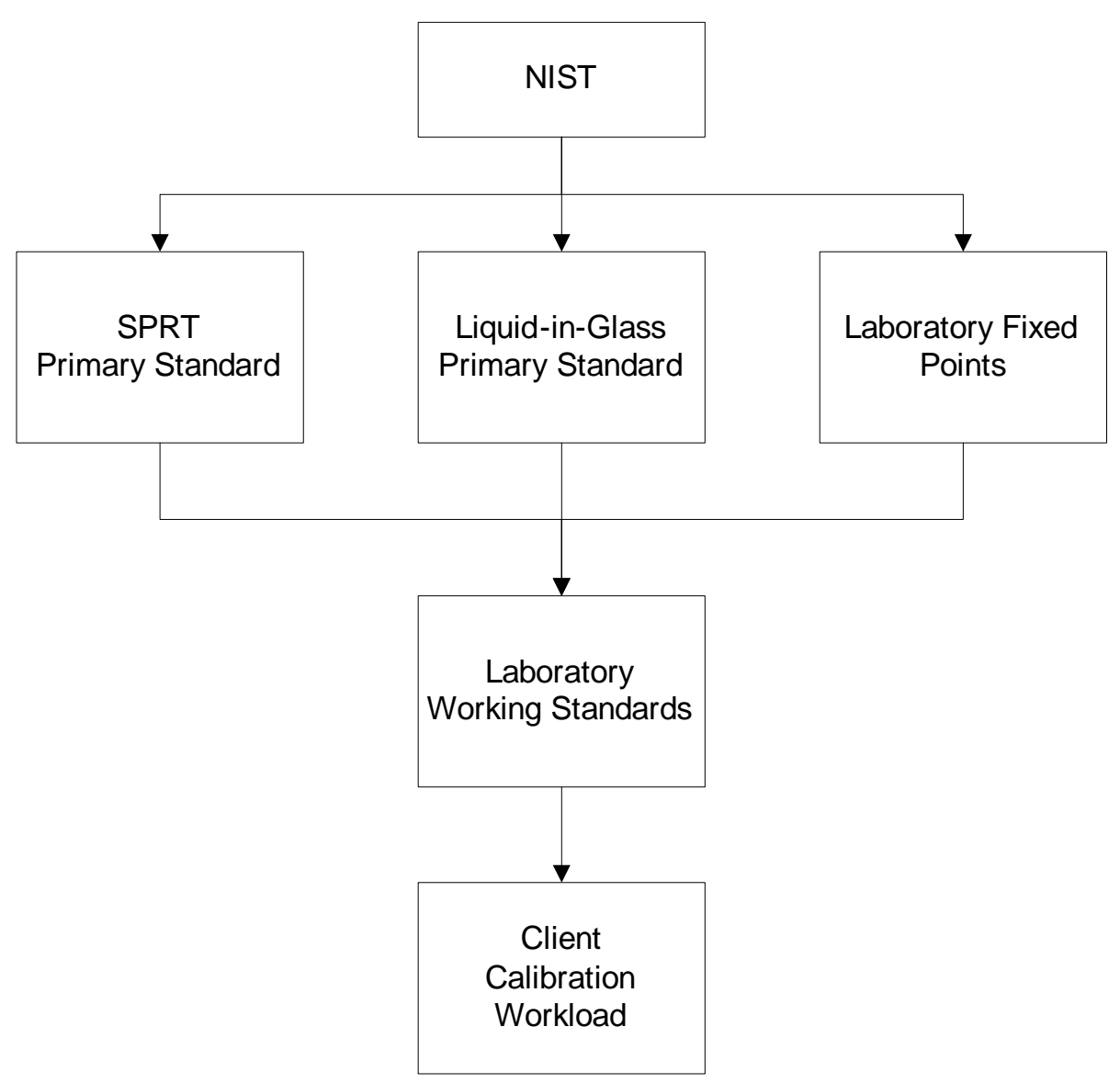

Figure 7. Temperature Example. 


\section{Appendix B - Traceability worksheet}

Parameter: Mass, Volume, Length, Temperature, Other

\begin{tabular}{|c|c|c|c|c|c|c|}
\hline \multirow{2}{*}{$\mathrm{R}$} & \multirow[b]{2}{*}{ Range } & \multirow[t]{2}{*}{$\mathrm{SI}\left(\mathrm{g}, \mathrm{L}, \mathrm{m},{ }^{\circ} \mathrm{C}\right)$} & \multirow[t]{2}{*}{ Cal. date } & \multirow[t]{2}{*}{ Source } & \multirow[t]{2}{*}{ Interval } & \multirow[t]{2}{*}{ Due Date } \\
\hline & & & & & & \\
\hline & & & & & & \\
\hline & & & & & & \\
\hline & & & & & & \\
\hline & & & & & & \\
\hline & & Customary $\left(\mathrm{lb}\right.$, gal, $\left.\mathrm{ft},{ }^{\circ} \mathrm{F}\right)$ & & & & \\
\hline & Range & & & & & \\
\hline & & & & & & \\
\hline & & & & & & \\
\hline & & & & & & \\
\hline & & & & & & \\
\hline \multirow{2}{*}{$\mathrm{W}$} & & $\mathrm{SI}\left(\mathrm{g}, \mathrm{L}, \mathrm{m},{ }^{\circ} \mathrm{C}\right)$ & Cal. date & Source & Interval & Due Date \\
\hline & Range & & & & & \\
\hline & & & & & & \\
\hline & & & & & & \\
\hline & & & & & & \\
\hline & & & & & & \\
\hline & & Customary (lb, gal, ft, $\left.{ }^{\circ} \mathrm{F}\right)$ & & & & \\
\hline & Range & & & & & \\
\hline & & & & & & \\
\hline & & & & & & \\
\hline & & & & & & \\
\hline & & & & & & \\
\hline \multirow{2}{*}{$\mathrm{S}_{\mathrm{c}}$} & & SI (g, L, m, $\left.{ }^{\circ} \mathrm{C}\right)$ & Cal. date & Source & Interval & Due Date \\
\hline & Range & & & & & \\
\hline & & & & & & \\
\hline & & & & & & \\
\hline & & & & & & \\
\hline & & & & & & \\
\hline & & Customary (lb, gal, ft, $\left.{ }^{\circ} \mathrm{F}\right)$ & & & & \\
\hline & Range & & & & & \\
\hline & & & & & & \\
\hline & & & & & & \\
\hline & & & & & & \\
\hline & & & & & & \\
\hline & & dards $\cdot \mathrm{W}=$ Working Standa & $\mathrm{S}_{\mathrm{c}}=$ Check & ards. & & \\
\hline
\end{tabular}




\section{Appendix C: Traceability Evaluation Form}

Assess whether all of the essential elements of traceability are available for the entire Scope by completing the table below. Specific Analysis: Include specific comments on what was observed and what evidence is available.

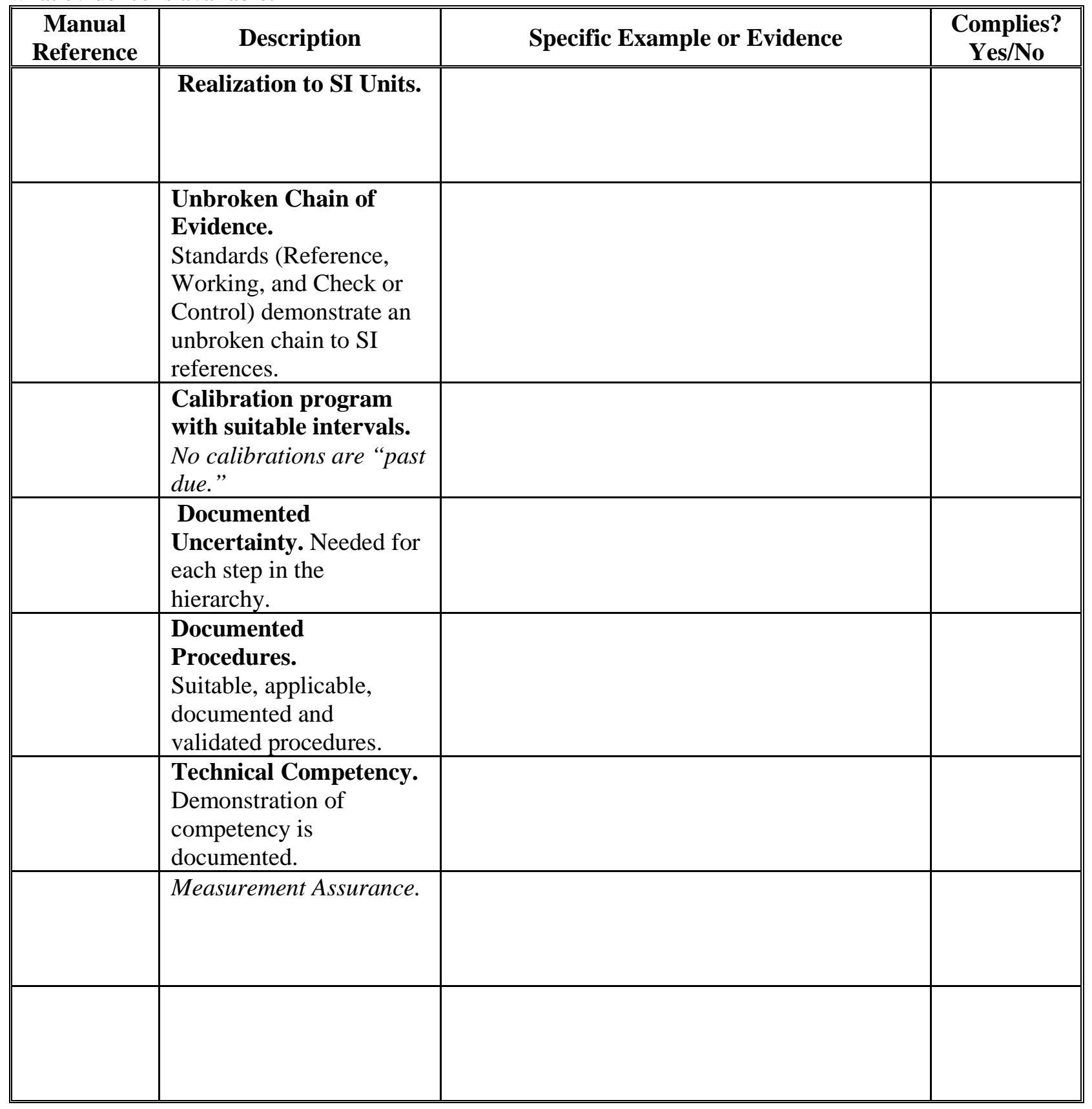




\section{Appendix D: Sample Technical Audit for Traceability Evidence}

Select 3 calibration certificates for the past year, and identify the following specific information to support traceability for each calibration. On each chart, next to each block for your primary and working standards, please list evidence that is available in your laboratory:

\begin{tabular}{|c|c|}
\hline Item Evaluated & Evidence \\
\hline $\begin{array}{l}\text { Calibration selected (Measurement } \\
\text { Type, Lab Test Number) }\end{array}$ & \\
\hline Test Number(s) for all standards used & \\
\hline Calibration Date(s) for the standards & \\
\hline $\begin{array}{l}\text { Calibration providers have been } \\
\text { evaluated and monitored and are } \\
\text { accredited }\end{array}$ & \\
\hline $\begin{array}{l}\text { Calibration program and intervals are } \\
\text { stated and up to date }\end{array}$ & \\
\hline $\begin{array}{l}\text { Uncertainty analysis components } \\
\text { included(s) }\end{array}$ & \\
\hline $\begin{array}{l}\text { Uncertainty file name where data is } \\
\text { stored }\end{array}$ & \\
\hline Documented SOP used & \\
\hline Evidence of competency & \\
\hline Measurement assurance type & \\
\hline $\begin{array}{l}\text { Measurement Assurance file name } \\
\text { where data is stored }\end{array}$ & \\
\hline $\begin{array}{l}\text { Certificates contain a Traceability } \\
\text { Statement }\end{array}$ & \\
\hline
\end{tabular}

You should be able to identify any gaps and corrective action needed in your laboratory in the area of traceability, uncertainty analysis, and measurement assurance. Note actions on laboratory action forms. 


\section{Appendix E: Evaluating Supplier Calibration Certificates for Metrological Traceability for Weights and Measures Applications}

\begin{tabular}{|c|c|c|}
\hline Step & Notes & $\begin{array}{c}\text { Accept } \\
\text { (Yes/No) }\end{array}$ \\
\hline Legal & $\begin{array}{l}\text { Does your law allow acceptance of reports for the applicable use } \\
\text { (laboratory standards, field standards, service company standards)? } \\
\text { Does your law specify traceability to NIST? To the SI? } \\
\text { Is there a required calibration interval? }\end{array}$ & \\
\hline Specifications & $\begin{array}{l}\text { Does your law require assessment against published specifications } \\
\text { like the NIST Handbook 105-series documentary standards? IF } \\
\text { SO, have the customer standards been evaluated for compliance to } \\
\text { specifications (are the standards suitable for use?) Note: This is } \\
\text { NOT common for non-governmental laboratories, even when } \\
\text { accredited, and cannot be done if there are no applicable } \\
\text { specifications. Accreditation has nothing to do with evaluating } \\
\text { compliance to specifications. }\end{array}$ & \\
\hline $\begin{array}{l}\text { Documented } \\
\text { Calibration } \\
\text { Certificate }\end{array}$ & $\begin{array}{l}\text { Is there a valid calibration certificate for all of the standards? Does } \\
\text { it (do they) comply with laboratory requirements? (Checklist } \\
\text { available.) } \\
\text { Specifically, traceability components: reference to SI and standards } \\
\text { used, traceability statement, uncertainty statement, measurement } \\
\text { results, measurement uncertainty, and reference to documented } \\
\text { procedures. }\end{array}$ & \\
\hline $\begin{array}{l}\text { Is the report from a } \\
\text { National Metrology } \\
\text { Laboratory (NMI) } \\
\text { like NIST? }\end{array}$ & $\begin{array}{l}\text { Does your law permit you to accept a calibration certificate for a } \\
\text { standard that was tested by Measurement Canada that is traceable } \\
\text { to NRC for example? } \\
\text { Has that NMI signed the CIPM MRA and is this range, scope, } \\
\text { uncertainty of measurements published in the Appendix C listing } \\
\text { maintained by BIPM? (List available.) }\end{array}$ & \\
\hline $\begin{array}{l}\text { Is the report from a } \\
\text { NIST OWM } \\
\text { Recognized } \\
\text { laboratory? }\end{array}$ & $\begin{array}{l}\text { OWM is NOT a recognized Accreditation Body and has not signed } \\
\text { the ILAC MRA. } \\
\text { Is the measurement parameter on the laboratory Scope? } \\
\text { Is the reported uncertainty acceptable for your needs? } \\
\text { (Posted on the NIST website, includes those Accredited by } \\
\text { NVLAP.) }\end{array}$ & \\
\hline $\begin{array}{l}\text { Is the report from } \\
\text { an Accredited } \\
\text { laboratory? }\end{array}$ & $\begin{array}{l}\text { Is the Accreditation Body a signatory of the ILAC MRA? } \\
\text { (List available.) } \\
\text { Is the measurement parameter on their Scope now? } \\
\text { Is the currently reported uncertainty small enough to meet } \\
\text { requirements for the laboratory or for Fundamental Considerations } \\
\text { (less than } 1 / 3 \text { the applicable tolerance)?? (Directories available } \\
\text { with Accreditation Bodies.) }\end{array}$ & \\
\hline
\end{tabular}


This page is intentionally blank. 


\section{Standard Operating Procedures}


This page is intentionally blank. 


\section{SOP 1}

\section{Recommended Standard Operating Procedure \\ for}

Calibration Certificate Preparation

1 Introduction

1.1 Calibration certificates are the visible outputs of the calibration laboratory that must be prepared with utmost care to ensure that they accurately convey all information pertaining to a calibration so that data may be used with maximum benefit by all concerned. Carefully prepared calibration certificates must contain or refer to all information necessary to justify the measurement results and must be thoroughly reviewed and authorized prior to release.

1.2 A detailed reporting of results is preferred and often required by customers in accredited and recognized laboratory systems, which includes a complete narrative describing and documenting the calibration, including those for special calibrations or tests. According to the ISO/IEC $17025^{1}$ standard, calibration results may be reported in a simplified way when agreed to by the customer. For weights and measures (legal metrology applications) reporting of elements of metrological traceability for reference to the International System of Units (SI), measurement results, and uncertainty results continue to be required with few exceptions2. All information not provided to the customer must be maintained by the laboratory and readily available.

1.3 The laboratory is responsible for all information provided within the calibration certificate, except for information that was provided by the customer. When information is provided by the customer, it shall be clearly identified. The calibration certificate will include a disclaimer notifying users that information supplied by the customer can affect the validity of results. When sampling is provided by the customer (e.g., the method sampling stage), the calibration certificate shall state that the results apply to the sample as received from the customer.

2 Content of calibration certificates.

Regardless of the final form, the calibration certificate must contain the basic information described in this procedure (see also Section 7.8 of ISO/IEC 17025 and the attached template Calibration Certificate Review Checklist, Appendix B).

Each calibration certificate, supplied in hard copy or electronic format, shall contain the following information to minimize the possibility of misunderstanding or misuse:

\footnotetext{
${ }^{1}$ ISO/IEC 17025:2017, General Requirements for the Competence of Testing and Calibration Laboratories.

2 See GMP 13, Ensuring Traceability, ISO/IEC 17025, Annex A, and International Laboratory Accreditation

Cooperation (ILAC) and accreditation body policies.
} 
2.1 Title (e.g., "Calibration Certificate”).

2.2 Name and address of the laboratory where the calibration is performed (e.g., permanent facility), including any alternative location where a calibration is performed (e.g., temporary, mobile, or alternative facility).

2.3 Unique identification that all calibration certificate components are recognized, and an identification on each page to ensure that the page is recognized as part of the complete document, and a clear identification of the end of the certificate. A unique calibration number and page $\mathrm{X}$ of $\mathrm{Y}$ formatting are frequently used to uniquely identify the components of a calibration certificate.

2.4 Customer name and contact information.

2.5 Method used -Cite the Standard Operating Procedure (SOP), including the full title or description and the version date. In the absence of a nationally or internationally published SOP, a brief but informative description of the methodology shall be included. When a customer approves of an addition, deviation, or exclusion from the published method, these departures shall also be included

2.6 Unambiguous identification and description of the calibration artifact, and when necessary, the condition of the item. Serial numbers are assigned to items by the customer, laboratory, or manufacturer to facilitate the internal control of the item during the calibration process and subsequent use by the customer. Unique identification is verified when an item is submitted to the laboratory for calibration.

2.7 Date(s) of:

- Calibration item receipt;

- Sampling, where critical to the validity and application of the results;

- Calibration or laboratory activity performance; and

- Certificate issuance.

2.8 Cite the sampling plan and methods used. Uniquely identify the items sampled. Include the:

- The date and location of sampling;

- Environmental conditions during sampling that affect the interpretation of results; and

- Information related to the measurement uncertainty, where relevant.

2.9 Calibration results and corresponding units of measurement are clearly organized in a tabular or other convenient format. When a calibration item has been repaired or adjusted, the calibration results before and after repair or adjustment shall be reported. The measurement units reported are typically related to the nominal value 
of the calibration item. Measurement units may be selected to reflect an industry practice or a customer request.

2.10 A statement of the measurement uncertainty, and corresponding measurement unit, coverage factor, and estimated confidence interval shall accompany the measurement result. The measurement uncertainty is reported in the same measurement units as the measurement result (e.g., multiple or submultiple). Special care shall be used when the coverage factor is not consistent for all calibrated items. The results table should be formatted to clearly identify individual coverage factors when variations exist (e.g., an additional column containing the corresponding coverage factors). When appropriate, significant uncertainty components and the rationale for their inclusion are included. Note: the use of standard industry practices or reporting units based on customer requests is permitted.

2.11 Environmental or other conditions under which the calibrations were made that influence the measurement results.

2.12 Clearly identify the person(s) performing the calibration and authorizing calibration certificate by stating their corresponding name, title, and signature. Each authorized signatory accepts responsibility for the technical accuracy and validity of the reported results.

2.13 A statement to the effect that the results relate only to the items calibrated or sampled.

2.14 A statement identifying how the measurements are metrologically traceable (e.g., the laboratory establishes metrological traceability to the International System of Units (SI) and is recognized by NIST OWM). The inclusion of supplemental supporting information may be requested by the customer.

2.15 When statement of compliance or non-compliance with requirements and/or specifications (e.g., a conformity assessment), where relevant. Compliance refers to an assessment of all criteria of a referenced documentary standard and not a limited assessment of a portion or specific clauses (e.g., compliance to all specifications versus only the tolerance specification). When a statement of conformity is made, the laboratory must clearly identify to which results the statement of conformity applies (e.g., all results or a specific portion of the results), which specifications, standards or parts thereof are met or not met, and the decision rule applied (unless the decision rule is inherent in the specification or documentary standard). When a statement of conformity to a specification or documentary standard is made, the laboratory shall document the decision rule applied, take into account the level of risk associated with the decision rule employed (such as false accept, false reject, and statistical assumptions), and apply the decision rule. Where decision rules regarding uncertainties and tolerances are not part of the documentary standard, decision rules will be agreed to by the customer and reported on the calibration certificate. 
2.16 Opinions and interpretations, where appropriate and needed, shall be based on the measurement results, clearly stated, and identified as such. Only technically competent laboratory personnel are permitted to express opinions and interpretations (e.g., an authorized signatory). When opinions and interpretations are directly communicated and discussed with the customer, a record of the conversation shall be documented and retained.

2.17 Results from external providers shall be clearly identified.

2.18 Additional information which may be required by specifications, specific methods, customers, or groups of customers.

2.19 To ensure parts of the calibration certificate results are not taken out of context, a statement specifying that the calibration certificate shall not be reproduced except in full, without written approval of the laboratory may be included.

2.20 A calibration certificate or calibration label shall not include any recommended calibration interval, except when required for legal applications or where requested and agreed to by the customer.

3 Review and Issue to Customer.

3.1 A thorough technical and quality review of each calibration certificate should be conducted according to laboratory Quality Management System before issuance to prevent errors, recall, and certificate amendment.

3.2 Review measurement units and symbols according to the current edition of NIST Special Publication (SP 811), The NIST Guide for the Use of the International System of Units (https://www.nist.gov/physical-measurement-laboratory/specialpublication-811).

3.3 The template Calibration Certificate Review Checklist may be used by the laboratory to aid in multiple evaluation functions (Appendix B).

3.3.1 Review each calibration certificates before issue to the customer to ensure it meets the requirements of this procedure.

3.3.2 Review external calibration certificates during the supplier evaluation process.

3.3.3 Review issued and/or template calibration certificates during a technical or quality audit.

4 Calibration Certificate Amendment.

4.1 When a calibration certificate issued to a customer must be changed, amended, or re-issued, the changed information shall be clearly identified. The reason for the change shall be included in the report, when appropriate. 
4.2 Amendments made after issue to the customer shall be made only in the form of a further document or data transfer, which includes the statement "Amendment to Calibration Certificate” or an equivalent form of wording.

4.3 When it is necessary to issue a completely new calibration certificate, it shall be uniquely identified and contain a reference to the original calibration certificate that it replaces.

4.4 Amended calibration certificates shall meet all the requirements of this procedure.

$5 \quad$ Records

5.1 The laboratory shall file, organize, and retain all calibration certificates in a systematic manner for ease of retrieval.

5.2 Retain legible copies of all issued and amended calibration certificates according to the laboratory Quality Management System. 
Calibration No.: TI-01-056

Page 1 of 2

\title{
Appendix A - Example Certificate
}

\author{
COMPLIANT CALIBRATION LABORATORY \\ 123 Some Ave. \\ City, State Mail code \\ XYZ Accreditation Body: 1234567890
}

\section{CALIBRATION CERTIFICATE}

FOR

$1 \mathrm{~kg}$ to $10 \mathrm{mg}$ kit

(Twenty-one weights)

Manufacturer: DENTROM LAKE

SUBMITTED BY:

YOUR CUSTOMER, INC.

Serial No.: 27269

Customer's Address

City, State Zip code

Phone/Email

\begin{tabular}{|c|c|c|c|c|}
\hline $\begin{array}{l}\text { Nominal } \\
\text { (g) }\end{array}$ & $\begin{array}{c}\text { Conventional Mass } \\
\text { (g) }\end{array}$ & $\begin{array}{c}\text { Conventional Mass }{ }^{3} \\
\text { Correction } \\
\text { (mg) }\end{array}$ & $\begin{array}{c}\text { Expanded } \\
\text { Uncertainty } \\
\text { (mg) }\end{array}$ & $\begin{array}{l}\text { ASTM Class } 4 \\
\text { Tolerances } \\
\text { (mg) }\end{array}$ \\
\hline 1000 & 1000.00082 & 0.82 & 0.92 & 20 \\
\hline 500 & 500.00071 & 0.71 & 0.53 & 10 \\
\hline 300 & 299.99987 & -0.13 & 0.27 & 6.0 \\
\hline 200 & 200.00067 & 0.67 & 0.18 & 4.0 \\
\hline 100 & 100.000411 & 0.411 & 0.091 & 2.0 \\
\hline 50 & 50.000318 & 0.318 & 0.051 & 1.2 \\
\hline 30 & 30.000117 & 0.117 & 0.028 & 0.90 \\
\hline 20 & 19.999987 & -0.013 & 0.023 & 0.70 \\
\hline 10 & 10.000011 & 0.011 & 0.018 & 0.50 \\
\hline 5 & 5.000022 & 0.022 & 0.015 & 0.36 \\
\hline 3 & 3.000112 & 0.112 & 0.013 & 0.30 \\
\hline 2 & 1.999965 & -0.035 & 0.012 & 0.26 \\
\hline 1 & 1.000117 & 0.117 & 0.010 & 0.20 \\
\hline 0.500 & 0.5000132 & 0.0132 & 0.0051 & 0.16 \\
\hline 0.300 & 0.3000223 & 0.0223 & 0.0048 & 0.14 \\
\hline 0.200 & 0.2000017 & 0.0017 & 0.0043 & 0.12 \\
\hline 0.100 & 0.1000013 & 0.0013 & 0.0042 & 0.10 \\
\hline 0.050 & 0.0500018 & 0.0018 & 0.0040 & 0.085 \\
\hline 0.030 & 0.0300011 & 0.0011 & 0.0037 & 0.075 \\
\hline 0.020 & 0.0200009 & 0.0009 & 0.0033 & 0.070 \\
\hline 0.010 & 0.0099997 & -0.0003 & 0.0031 & 0.060 \\
\hline
\end{tabular}

The data in the above table applies only to those items specifically listed on this calibration certificate.

\section{Uncertainty Statement:}

The combined standard uncertainty includes the standard uncertainty reported for the standard, the standard uncertainty for the measurement process, the standard uncertainty for any uncorrected errors associated with buoyancy corrections, and a component of uncertainty to account for any observed deviations from NIST values that are less than surveillance limits. The combined standard uncertainty is multiplied by a coverage factor $(k)$ of 2 to provide an expanded uncertainty, which defines a level of confidence of approximately 95 percent $(95.45 \%)$. The expanded uncertainty presented in this report is consistent with the ISO/IEC

\footnotetext{
${ }^{3}$ Conventional Mass: The conventional value of the result of weighing a body in air is equal to the mass of a standard, at reference density 8.0 $\mathrm{g} / \mathrm{cm}^{3}$, at a reference temperature $20^{\circ} \mathrm{C}$, which balances this body at this reference temperature in normal air density $0.0012 \mathrm{~g} / \mathrm{cm}^{3}$. See OIML D28 (2004), "Conventional value of the result of weighing in air."
} 
Guide to the Expression of Uncertainty in Measurement (2008). The expanded uncertainty is not to be confused with a tolerance limit for the user during application.

Traceability Statement:

The Standards of the Compliant Calibration Laboratory are traceable to the International System of Units (SI) through the National Institute of Standards and Technology, and are part of a comprehensive measurement assurance program for ensuring continued accuracy and measurement traceability within the level of uncertainty reported by this laboratory. The unique laboratory calibration number identified above shall be used in referencing metrological traceability for artifacts identified only in this certificate.

\section{Conformity Assessment:}

The weights submitted for this calibration were marked as ASTM Class 4. ASTM E617 (2018), Standard Specification for Laboratory Weights and Precision Mass Standards, was used to evaluate these weights. Weights fully comply with all requirements (both specifications and tolerances) of this documentary standard. Stated expanded uncertainties are less than onethird of the specified tolerances (maximum permissible errors, m.p.e.) and the mass value plus or minus the expanded uncertainty is within the stated tolerances.

\section{Supplemental Information:}

Description of Artifacts Submitted for Calibration:

Twenty one weights from $1 \mathrm{~kg}$ to $10 \mathrm{mg}$, marked ASTM E617 Class 4 . Weights from $1 \mathrm{~kg}$ to $1 \mathrm{~g}$ : two-piece weights, with assumed density of $8.0 \mathrm{~g} / \mathrm{cm}^{3}$. Weights from $500 \mathrm{mg}$ to $50 \mathrm{mg}$ : sheet weights, with assumed density of $16.6 \mathrm{~g} / \mathrm{cm}^{3}$. Weights from $30 \mathrm{mg}$ to $10 \mathrm{mg}$ : sheet weights, with assumed density of $2.7 \mathrm{~g} / \mathrm{cm}^{3}$.

\section{Conditions of Artifacts Submitted for Calibration:}

Artifacts showed evidence of improper handling. Fingerprints and dents were visible on the surface of the weights.

\section{Treatment of Artifacts Prior to Calibration:}

Artifacts were cleaned with cheesecloth and ethyl alcohol. Thermal equilibrium time/conditions: seven days next to balances in mass laboratory.

\section{Procedure Used:}

Double Substitution (NISTIR 6969, SOP 4, 2019)

\section{Environmental Conditions at Time of Calibration:}

Temperature: $20.1{ }^{\circ} \mathrm{C}$ to $20.2^{\circ} \mathrm{C} \quad$ Barometric Pressure: $752.7 \mathrm{mmHg} \quad$ Relative Humidity: $43.35 \%$ to $43.40 \%$

Date Artifacts Received: January 5, 2019

Date Certificate Issued: January 13, 2019

Date of Calibration: January 12, 2019

Due Date (Requested by Customer): January 15, 2019

\section{Josh Balani II}

\section{Calibration Performed by: Josh Balani II, Metrologist}

This document does not represent or imply endorsement by the Accreditation Body of Compliant Calibration Laboratory or any agency of a state and/or national government. This document may not be reproduced, except in full, without the written permission of the Compliant Calibration Laboratory. 


\title{
Appendix B - Calibration Certificate Review Checklist
}

\author{
ISO/IEC 17025:2017, Section 7.8 - Reporting of Results
}

This evaluation form may be used as an assessment tool for calibration certificates. Its use needs to include objective evidence of the assessment (e.g., a marked-up certificate).

\section{Criteria Guide}

7.8.1.2

Reported accurately, clearly, unambiguously and objectively; in accordance with method instructions; include all info requested by customer, necessary for interpretation of the results, \& required by the method

Calibration Certificate Core Requirements (Include at least the following information, unless valid reasons for not)

7.8.2.1 a)

7.8.2.1 b, c) Title

7.8.2.1 d) Laboratory name \& address and location where tests/calibrations performed Unique identification making all the portions of the certificate uniquely identifiable. Clearly indicate document end (a way to recognize a complete report). For Example: page number and total number of pages (X of $\mathrm{Y}$ )

7.8.2.1 e) Customer name and contact information

7.8.2.1 f, n)

7.8.2.1 g) Identify method used; additions, deviations, exclusions from the method

7.8.2.1 h-j) Description and unambiguous identification of the item(s) calibrated and when necessary condition

7.8.2.1 k) Dates: receipt, sampling if applicable, date(s) of performance of lab activity, certificate issue

$7.8 .211)$ Reference to sampling plan and procedures used where relevant to validity or application of results

7.8.2.1 l) Statement to the effect that the results relate only to the calibrated items

7.8.2.1 m) Note: Recommend statement shall not be reproduced except in full, without written lab approval

7.8.2.1 o) Calibration results with appropriate units of measurement, where appropriate

Calibration Certificates (In addition to 7.8.2.1)

7.8.4.1 a) $\quad$ Uncertainty of the measurement result in the same unit as that of the measured item, or unit relative

to item

7.8.4.1 b) Calibration conditions (e.g., environmental) that influence the measurement results

\begin{tabular}{l|l} 
7.8.4.1 c) Statement on how the measurements are metrologically traceable \\
\hline
\end{tabular}

\begin{tabular}{l|l} 
7.8.4.1 d) & Before and after measurement results when adjustment or repair is made
\end{tabular}

7.8.4.1 e), $\quad$ If compliance statement is made: Identify to which results they apply, clauses met/not met, and

7.8.6

7.8.4.3 account for the decision rule (e.g., uncertainty)

\begin{tabular}{l|l} 
7.8.4.3 & regulations) \\
\hline
\end{tabular}

Conformity Assessment (7.8.6)

\begin{tabular}{|l|l} 
7.8.6 & Decision rule documented in procedure or by customer; statement identifies which results are
\end{tabular} applicable and which portions of the documentary standard were or were not assessed

Sampling (7.8.5) Specific requirements noted in 7.8.3.2, 7.8.4.2

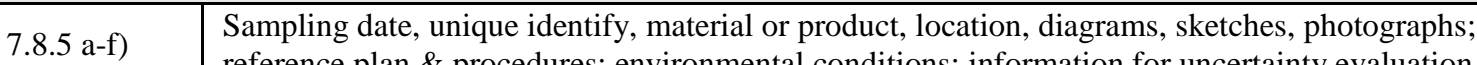
7.8.5 a-f) $\quad$ reference plan \& procedures; environmental conditions; information for uncertainty evaluation

\section{Opinions and Interpretations}

7.8.4.1. f)

7.8.7

Document basis of opinions and interpretations when included with reference to basis, performed by authorized personnel only; clearly identify

\section{Amendments}

\begin{tabular}{|l|l} 
7.8.8 & $\begin{array}{l}\text { Amendments after issue made as further document/data transfer with statement, meet all } \\
\text { requirements. New certificate is uniquely identified, and reference to the original that it replaces }\end{array}$ \\
\hline
\end{tabular} 


\section{Appendix C - Calibration Certificate Review Checklist}

\section{ISO/IEC 17025:2017, Section 7.8 - Reporting of Results}

This evaluation form may be used as an assessment tool for evaluating multiple calibration certificates; for example, during an internal audit or during review of proficiency testing certificates. Its use needs to include objective evidence of the assessment (marked-up certificates).

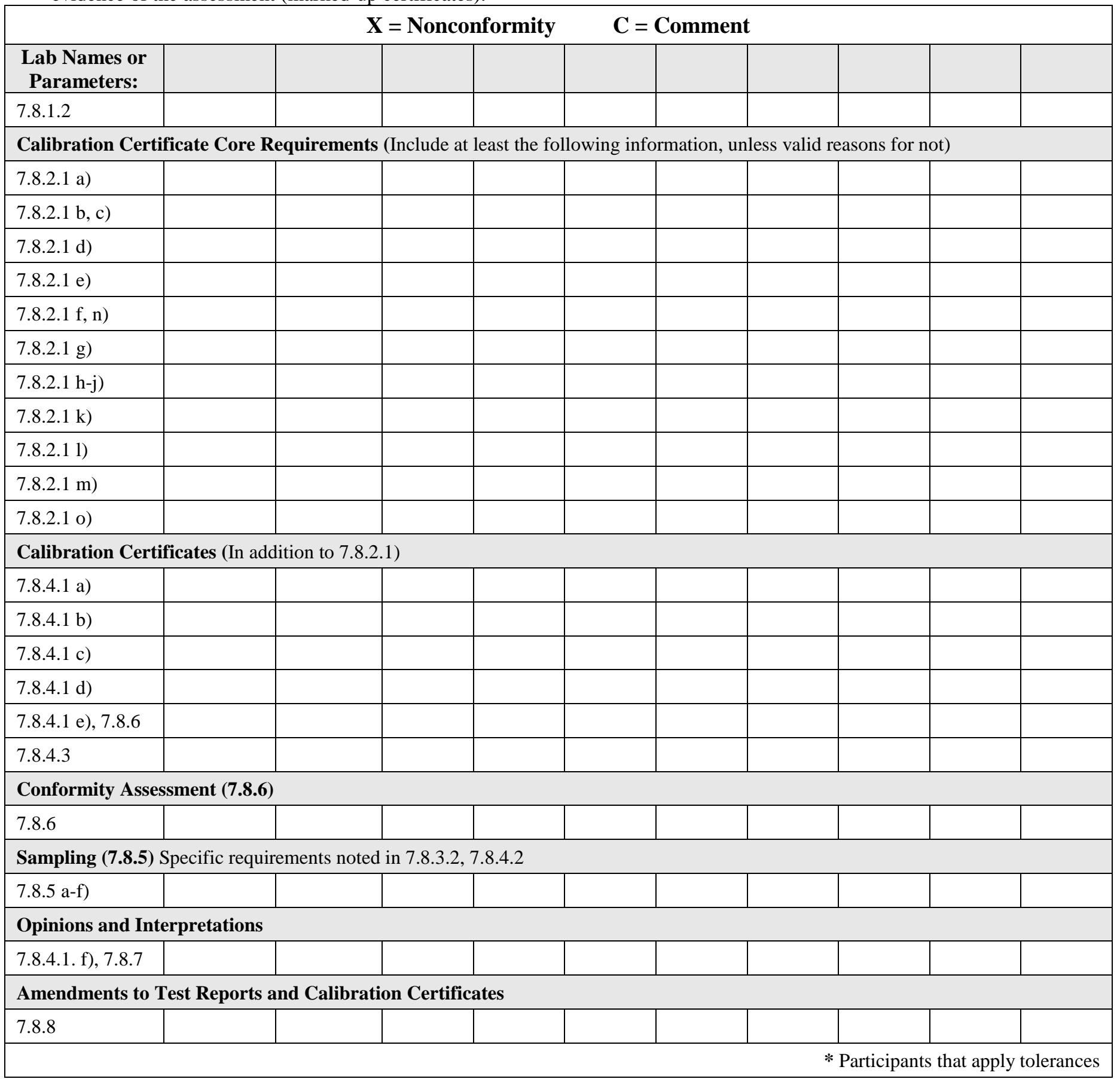


This page is intentionally blank. 


\section{SOP 2}

\section{Recommended Standard Operating Procedure \\ for}

Applying Air Buoyancy Corrections

1 Introduction

\section{$1.1 \quad$ Purpose}

If uncorrected, the effect of air buoyancy on the objects being compared is frequently the largest source of error in mass measurement. This SOP provides the equations to be used to correct for the buoyant effect of air. The significance of the air buoyancy correction depends upon the accuracy required for the measurement, the magnitude of the air buoyancy correction relative to other sources of error in the overall measurement process, and the precision of the mass measurement. An air buoyancy correction should be made in all high accuracy mass determinations. The gravimetric volume procedure uses a high accuracy mass determination with the corresponding buoyancy corrections. The Appendix to this SOP provides a brief theoretical discussion of this subject.

\subsection{Prerequisites}

1.3 Verify that (true) mass values or corrections are available for the standards used in the measurement process and that they have demonstrated metrological traceability to the international system of units (SI), which may be to the SI through a National Metrology Institute such as NIST.

1.4 Verify that the thermometer, barometer, and hygrometer used have been calibrated, and that they have demonstrated metrological traceability to the international system of units (SI), which may be to the SI through a National Metrology Institute such as NIST, and are in good operating condition as verified by periodic tests or cross-checks with other standards.

2 Methodology

\section{$2.1 \quad$ Scope, Precision, Accuracy}

This procedure is applicable to all weighings using a comparison of mass standards. The precision will depend upon the accuracy of the thermometer, barometer, and hygrometer used to determine the air density. When the calculations for the air density and air buoyancy corrections are made, a sufficient number of decimal places must be carried so the error due to the rounding of numbers is negligible relative to the error in the measurement process. Typically, carrying six to eight decimal places is sufficient, but depends upon the precision of the measurement. 


\subsection{Apparatus/Equipment Required ${ }^{1}$}

2.2.1 Calibrated barometer with sufficiently small resolution, stability, and uncertainty (e.g., accurate to $\pm 66.5 \mathrm{~Pa}(0.5 \mathrm{mmHg})$ ) to determine barometric pressure.

2.2.2 Calibrated thermometer with sufficiently small resolution, stability, and uncertainty (e.g., accurate to $\pm 0.10^{\circ} \mathrm{C}$ ) to determine air temperature.

2.2.3 Calibrated hygrometer with sufficiently small resolution, stability, and uncertainty (e.g., accurate to \pm 10 percent) to determine relative humidity.

\subsection{Estimating the Magnitude of the Air Buoyancy Correction}

2.3.1 Estimate the magnitude of the air buoyancy correct, $M A B C$, using the following formula:

$$
\text { MABC }=\left(\rho_{a}-\rho_{n}\right)\left(V_{x}-V_{s}\right)
$$

2.3.2 The equation may also be represented as follows:

$$
M A B C=m_{o}\left(\rho_{a}-\rho_{n}\right)\left(\frac{1}{\rho_{x}}-\frac{1}{\rho_{s}}\right)
$$

Table 1. Variables for MABC equation.

\begin{tabular}{||c|l||}
\hline Variable & \multicolumn{1}{|c|}{ Description of Variable } \\
\hline \hline$\rho_{a}$ & air density at the time of the measurement in $\mathrm{g} / \mathrm{cm}^{3}$ \\
\hline$\rho_{n}$ & density of "normal" air; i.e., $0.0012 \mathrm{~g} / \mathrm{cm}^{3}$ \\
\hline$m_{o}$ & nominal mass (in grams) \\
\hline$V_{x}$ & volume of the unknown weight, $X$ in $\mathrm{cm}^{3}$ \\
\hline$V_{s}$ & volume of the reference standard, $S$ in cm \\
\hline$\rho_{S}$ & $\begin{array}{l}\text { density of reference standard, } S \text { in } \mathrm{g} / \mathrm{cm}^{3} ; \\
\text { effective density is used for summations (see 4.6, Eqn. 8) }\end{array}$ \\
\hline$\rho_{x}$ & $\begin{array}{l}\text { density of unknown weight, } X \text { in } \mathrm{g} / \mathrm{cm}^{3} ; \\
\text { effective density is used for summations (see 4.6, Eqn. 8) }\end{array}$ \\
\hline
\end{tabular}

The relative magnitude of the correction can be compared to the expanded measurement uncertainty to determine the importance of the air buoyancy correction for a measurement. In some mass calibration procedures, when the calculated value is sufficiently small compared to applicable tolerances, the value may be treated as an uncorrected systematic error and incorporated into the uncertainty calculations.

\footnotetext{
${ }^{1}$ The barometer, thermometer, and hygrometer are used to determine the air density at the time of the measurement. The air density is used to make an air buoyancy correction. The accuracies specified are recommended for high precision calibration. Less accurate equipment can be used with only a small degradation in the overall accuracy of the measurement.
} 
3.1 Record the temperature, pressure, and relative humidity at the start and at the end of the measurement process as near the location of the measurement as necessary and practical. If these parameters change significantly during the measurement process, it may be necessary to wait for more stable operating conditions or to use average values to compute the air density. Use of the average environmental values may influence the uncertainty of the measurement result and must be evaluated for significance.

3.2 Determine the air density using the equation given in Section 8 of the Appendix to this SOP.

$4 \quad$ Calculations

4.1 Calculate the mass, $M_{x}$, of the unknown weight, $X$, using the following equation, where $d$ represents the "difference" obtained with buoyancy corrections applied to the sensitivity weight.

$$
M_{x}=\frac{M_{\mathrm{s}}\left(1-\frac{\rho_{a}}{\rho_{\mathrm{s}}}\right)+d}{\left(1-\frac{\rho_{a}}{\rho_{x}}\right)}
$$

4.2 If tare weights were carried with $X$ and/or $S$, use the following equation:

$$
M_{x}=\frac{M_{\mathrm{s}}\left(1-\frac{\rho_{a}}{\rho_{s}}\right)+d+M_{t_{s}}\left(1-\frac{\rho_{a}}{\rho_{t_{s}}}\right)-M_{t_{x}}\left(1-\frac{\rho_{a}}{\rho_{t_{x}}}\right)}{\left(1-\frac{\rho_{a}}{\rho_{x}}\right)}
$$


Table 2. Variables not previously defined.

\begin{tabular}{|c|l||}
\hline \hline \multicolumn{1}{|c||}{ Variable } & \multicolumn{1}{c||}{ Description of Variable } \\
\hline \hline$M_{s}$ & $\begin{array}{l}\text { measured difference between } \mathrm{X} \text { and the reference standard, S, using one of the } \\
\text { weighing designs given in other SOPs }\end{array}$ \\
\hline$M_{t_{s}}$ & {$[$ true] mass of the reference standard or summations } \\
\hline$M_{t_{x}}$ & [true] mass of the tare weight(s) carried with S \\
\hline$\rho_{s}$ & [true] mass of the tare weight(s) carried with X \\
\hline$\rho_{x}$ & density or effective density of the reference standard(s), S \\
\hline$\rho_{t_{s}}$ & density or effective density of the tare weight(s) carried with S \\
\hline$\rho_{t_{x}}$ & density or effective density of the tare weight(s) carried with X \\
\hline
\end{tabular}

4.3 If reporting the conventional mass ${ }^{2}, C M_{x}$, compute it using the following.

$$
C M_{x}=\frac{M_{x}\left(1-\frac{0.0012}{\rho_{x}}\right)}{\left(1-\frac{0.0012}{8.0}\right)}
$$

Eqn. (5)

4.4 If reporting the apparent mass, $A M_{x}$, versus brass, which is not common, compute it using the following.

$$
A M_{x \text { v brass }}=\frac{M_{x}\left(1-\frac{0.0012}{\rho_{x}}\right)}{\left(1-\frac{0.0012}{8.3909}\right)}
$$

4.5 The conventional and apparent mass values are related by the following:

$$
C M_{x}=\frac{A M_{x \text { vs brass }}\left(1-\frac{0.0012}{8.3909}\right)}{\left(1-\frac{0.0012}{8.0}\right)}
$$

${ }^{2}$ Conventional Mass: "The conventional value of the result of weighing a body in air is equal to the mass of a standard, of conventionally chosen density, at a conventionally chosen temperature, which balances this body at this reference temperature in air of conventionally chosen density.” The conventions are: reference density $8.0 \mathrm{~g} / \mathrm{cm}^{3}$; reference temperature $20^{\circ} \mathrm{C}$; normal air density $0.0012 \mathrm{~g} / \mathrm{cm}^{3}$. Conventional mass was formerly called "Apparent Mass versus $8.0 \mathrm{~g} / \mathrm{cm}^{3 ”}$ in the United States and is not recommended. See OIML D28 (2004). 
4.6 Effective density values must be calculated and used for summations of mass standards. The subscripts 5, 3, and 2 refer to the individual nominal masses that comprise the summation. This approach may also be needed with a 5, 2, 2, 1 combination. E.g., a summation of $1 \mathrm{~kg}$, might be $500 \mathrm{~g}, 300 \mathrm{~g}$, and $200 \mathrm{~g}$ (or 500 g, 200 g, 200g, and 100 g). A summation for $100 \mathrm{~g}$ would be $50 \mathrm{~g}, 30 \mathrm{~g}$, and $20 \mathrm{~g}$ (or the equivalent of a 5221 series). A metric calibration of a $4 \mathrm{oz}$ weight would need to add up to $113.389 \mathrm{~g}$ (probably $100 \mathrm{~g}, 10 \mathrm{~g}, 3 \mathrm{~g}, 300 \mathrm{mg}, 100 \mathrm{mg}$ ) and then must also address unequal nominal values as shown in the equations in SOP 4, 5, and 7 as applicable.:

$$
\text { Effective Density }=\frac{M_{5}+M_{3}+M_{2}}{\left(\frac{M_{5}}{\rho_{5}}\right)+\left(\frac{M_{3}}{\rho_{3}}\right)+\left(\frac{M_{2}}{\rho_{2}}\right)}
$$

5 Assignment of Uncertainty

The uncertainty in determining the air buoyancy correction is usually negligible relative to the precision of the measurement process itself. Consequently, the uncertainty for the measurement is based upon the uncertainty for the measurement process used and the uncertainty associated with the environmental measurement standards. The uncertainty in the CIPM $^{3} 2007$ air density equation is $0.0000264 \mathrm{mg} / \mathrm{cm}^{3}$ (or $0.0022 \%$ of normal air density.) See each SOP for uncertainties associated with buoyancy corrections.

Table 3. Tolerances for measurements related to air density estimation.

\begin{tabular}{||c|c|c|c||}
\hline \hline & \multicolumn{3}{|c||}{ Uncertainty of air density values in \% of air density } \\
\hline Variable & $\begin{array}{c}\mathbf{\pm 0 . 1} \text { \% of air } \\
\text { density }\end{array}$ & $\pm \mathbf{1 . 0} \%$ of air density & $\begin{array}{c}\text { Recommended } \\
\text { (Section } \mathbf{2 . 2})\end{array}$ \\
\hline Air pressure $(\mathrm{Pa})$ & \pm 101 & \pm 1010 & \pm 66.5 \\
\hline Air pressure $(\mathrm{mmHg})$ & \pm 0.76 & \pm 7.6 & \pm 0.5 \\
\hline Air temperature $\left({ }^{\circ} \mathrm{C}\right)$ & \pm 0.29 & \pm 2.9 & \pm 0.1 \\
\hline Relative Humidity $(\%)$ & \pm 11.3 & $\ldots \ldots \ldots$. & \pm 10 \\
\hline
\end{tabular}

${ }^{3}$ CIPM References: A Picard, R.S. Davis, M. Gläser, K. Fujii, Metrologia 45:149-155 (2008). 


\section{Appendix A}

\section{Based on "The Basic Theory of Air Buoyancy Corrections" by Richard S. Davis ${ }^{4}$}

1 Introduction

In performing measurements of mass, the balance or scale used acts as a force transducer. The force produced by an object to be weighed in air has two components: one proportional to the mass of the object, and the other proportional to its volume. The latter component, or buoyant force, may under some circumstances be large enough to require correction. The following shows under what circumstances buoyancy corrections are required as well as how they are made.

The method for applying buoyancy corrections presented below applies to mass measurements made in air. The density of air is computed from auxiliary measurements of temperature, pressure and relative humidity after which the buoyancy corrections are calculated directly from the Principle of Archimedes. The following weighing situations are considered.

\subsection{Two-Pan Balance}

\subsection{Single-Pan Balance}

\subsubsection{With Built-In Weights}

\subsubsection{With Electronic Control}

\section{Summary of Method}

In general, buoyancy corrections are applied to mass measurements by calculating the difference in volume between the unknown weight and the standard, multiplying this volume difference by the density of air at the balance or scale, and adding the product to the mass of the standard. The density of air is computed from an equation of state using measured values for the temperature, pressure and relative humidity of the air.

$4 \quad$ Significance and Use

Buoyancy corrections generally must be applied when determining the mass of an unknown object to high accuracy. The corrections may become important even at modest accuracies if the unknown object whose mass is to be determined has a density that differs widely from that of the standards (weighing of water, for example). Many mass standards are calibrated in terms of a so-called "apparent mass" [conventional mass] scale (See

\footnotetext{
${ }^{4}$ Richard S. Davis, formerly of the National Institute of Standards and Technology, Mass Group, International Bureau of Weights and Measures (BIPM), retired.
} 
Chapter 7.3, Handbook $145^{1}$ ). Use of this scale does not indiscriminately eliminate the need for buoyancy corrections as is sometimes assumed.

$5 \quad$ Terminology

\subsection{Weighing by Substitution}

Substitution weighing is the procedure by which one determines the assembly of standard weights that will produce nearly the same reading on a one-pan balance as does the unknown object. The balance thus serves as a comparator. A two-pan balance may be used in this mode if one of the pans contains a counterpoise and the standards and unknown are substituted on the second pan. (See SOP No. 3.)

\subsection{Mass}

The term "mass" is always used in the strict Newtonian sense as a property intrinsic to matter. Mass is the proportionality constant between a force on a material object and its resulting acceleration. This property is sometimes referred to as "true mass", "vacuum mass", or "mass in vacuum" to distinguish it from conventional [apparent] mass.

\subsection{Conventional [Apparent] Mass}

The mass of material of a specified density that would exactly balance the unknown object if the weighing were carried out at a temperature of $20^{\circ} \mathrm{C}$ in air of density $0.0012 \mathrm{~g} / \mathrm{cm}^{3}$. The mass, $M_{N}$, of an object, $N$, is related to its apparent mass $M_{N, A}$ by the equation:

$$
M_{N, A}=\frac{M_{N}\left(1-\frac{0.0012}{\rho_{N}}\right)}{\left(1-\frac{0.0012}{\rho_{B}}\right)}
$$

Table 4. Variables for conventional (apparent) mass equation.

\begin{tabular}{|c|l||}
\hline \hline Variable & \multicolumn{1}{|c|}{ Description } \\
\hline \hline$\rho_{N}$ & density of the object $N$ at $20^{\circ} \mathrm{C}$ in $\mathrm{g} / \mathrm{cm}^{3}$ \\
\hline$\rho_{B}$ & $\begin{array}{l}\text { density of the conventional (apparent) mass scale at } 20^{\circ} \mathrm{C} \\
\text { in } \mathrm{g} / \mathrm{cm}^{3}\end{array}$ \\
\hline
\end{tabular}

In the past, there were two apparent mass scales in wide use. The older is based on $\rho_{B}=8.4000 \mathrm{~g} / \mathrm{cm}^{3}$ at $0{ }^{\circ} \mathrm{C}$ with a coefficient of volumetric expansion of $0.000054 /{ }^{\circ} \mathrm{C}$ and the more recent (Conventional Mass) specifies $\rho_{B}=8.0000 \mathrm{~g} / \mathrm{cm}^{3}$ at $20^{\circ} \mathrm{C}$. The quantity $M_{N, A}$ is a function of the particular conventional or apparent mass scale, which has been used in its calculation. OIML D28 only recognizes Conventional Mass. 


\subsection{Sensitivity}

The response of a balance under load to an additional small weight:

$$
\text { sensitivity }=\frac{M_{s w}-\rho_{a} V_{s w}}{\Delta R}=\frac{M_{s w}\left(1-\frac{\rho_{a}}{\rho_{s w}}\right)}{\Delta R}
$$

Table 5. Variables for sensitivity equation.

\begin{tabular}{||c|l||}
\hline \hline Variable & \multicolumn{1}{|c|}{ Description } \\
\hline \hline sensitivity & balance sensitivity (mass per division) \\
\hline$M_{s w}$ & mass of the small, additional weight \\
\hline$\rho_{a}$ & density of the air \\
\hline$\rho_{s w}$ & density of the small, additional weight \\
\hline$V_{s w}$ & volume of the small, additional weight \\
\hline$\Delta R$ & $\begin{array}{l}\text { change in balance reading due to the addition of the small weight, balance } \\
\text { deflection }\end{array}$ \\
\hline
\end{tabular}

$6 \quad$ Apparatus

In order to ascertain the density of air at the balance, the following measuring instruments are necessary: thermometer, barometer, and hygrometer. Ideally, these instruments should be placed in or next to the balance case (as near the measurement location as is practical). It may only be practical for the thermometer or temperature sensor to actually be placed inside the balance chamber.

$7 \quad$ Procedure

Weigh the unknown object as directed by the balance manufacturer or in accordance with accepted procedure. Record the temperature, pressure and relative humidity of the air in the balance at the time of weighing (generally immediately before and immediately after weighings). Do not correct the barometric pressure to sea level.

8 Calculations

8.1 Air density, Option A (Option B is preferred)

The density of air, in $\mathrm{g} / \mathrm{cm}^{3}$, can be approximated for lesser accuracy from the following formula: ${ }^{5}$

$$
\rho_{a}=\left\{\frac{0.46460\left[P-\left(0.0037960 U e_{s}\right)\right]}{(273.15+t)}\right\} \times 10^{-3}
$$

\footnotetext{
${ }^{5}$ Jones, F.E., "The Air Density Equation and the Transfer of the Mass Unit," Journal of Research, National Institute of Standards and Technology, Vol. 83, 1978, p. 419.
} 
Table 6. Variables for air density equation.

\begin{tabular}{||c|l||}
\hline \hline Variable & \multicolumn{1}{c||}{ Description } \\
\hline \hline$\rho_{a}$ & density of air, $\mathrm{g} / \mathrm{cm}^{3}$ \\
\hline$P$ & barometric pressure, $\mathrm{mmHg}$ \\
\hline$U$ & \% relative humidity, entered as a whole number \\
\hline$t$ & temperature, ${ }^{\circ} \mathrm{C}$ \\
\hline$e_{s}$ & $1.3146 \times 10^{9} \times \mathrm{e}^{[-5315.56 /(\mathrm{t}+273.15)]}$ \\
\hline
\end{tabular}

Note: $\mathrm{e}_{\mathrm{s}}$ can be written as follows in a spreadsheet and in some calculators:

\subsection{E9*@EXP(-5315.56/(t+273.15))}

Small errors (of order $0.01 \%$ ) in this equation occur for locations well above sea level or under conditions in which the concentration of carbon dioxide differs greatly from the global average. See the references for a more general formulation of the equation.

\subsection{Air density, Option B - Preferred}

The density of air should be calculated with the following formulae. ${ }^{6}$

$$
\begin{gathered}
\rho_{a}=\frac{p M_{a}}{Z R T}\left(1-x_{v}\left(1-\frac{M_{v}}{M_{a}}\right)\right) \\
x_{v}=(h / 100) f \frac{p_{s v}}{p} \\
Z=1-\frac{p}{T}\left[a_{0}+a_{1} t+a_{2} t^{2}+\left(b_{0}+b_{1} t\right) x_{v}+\left(c_{0}+c_{1} t\right) x_{v}{ }^{2}\right]+\frac{p^{2}}{T^{2}}\left(d+e x_{v}{ }^{2}\right)
\end{gathered}
$$

${ }^{6}$ CIPM References: Giacomo, P. Metrologia 18: 33-40 (1982), Davis, R.S., Metrologia 29: 67-70 (1992), A Picard, R.S. Davis, M. Gläser, K. Fujii, Metrologia 45:149-155 (2008). 
Table 7. Variables for CIPM air density equation.

\begin{tabular}{|c|l|}
\hline Variable & \multicolumn{1}{c|}{ Description } \\
\hline$M_{a}$ & molar mass of the air within laboratory $28.96546 \times 10^{-3} \mathrm{~kg} / \mathrm{mol}$ \\
\hline$M_{v}$ & $18.01528(17) \times 10^{-3} \mathrm{~kg} / \mathrm{mol}$ \\
\hline$p$ & ambient barometric pressure in Pascal \\
\hline$T$ & ambient temperature in Kelvin \\
\hline$R$ & universal gas constant: 8.314 472(15) $\mathrm{J} \mathrm{mol}^{-1} \mathrm{~K}^{-1}$ \\
\hline$h$ & relative humidity in \% \\
\hline$f$ & $1.00062+\left(3.14 \times 10^{-8}\right) \mathrm{p}+\left(5.6 \times 10^{-7}\right) t^{2}$ \\
\hline$t$ & ambient temperature in degrees Celsius \\
\hline$p_{s v}$ & 1 Pascal x exp $\left(\mathrm{AT}^{2}+\mathrm{BT}+\mathrm{C}+\mathrm{D} / \mathrm{T}\right)$ \\
\hline$A$ & $1.2378847 \times 10^{-5} \mathrm{~K}^{-2}$ \\
\hline$B$ & $-1.9121316 \times 10^{-2} \mathrm{~K}^{-1}$ \\
\hline$C$ & 33.93711047 \\
\hline$D$ & $-6.3431645 \times 10^{3} \mathrm{~K}$ \\
\hline$a_{0}$ & $1.58123 \times 10^{-6} \mathrm{~K} \mathrm{~Pa}^{-1}$ \\
\hline$a_{1}$ & $-2.9331 \times 10^{-8} \mathrm{~Pa}^{-1}$ \\
\hline$a_{2}$ & $1.1043 \times 10^{-10} \mathrm{~K}^{-1} \mathrm{~Pa}^{-1}$ \\
\hline$b_{0}$ & $5.707 \times 10^{-6} \mathrm{~K} \mathrm{~Pa}^{-1}$ \\
\hline$b_{1}$ & $-2.051 \times 10^{-8} \mathrm{~Pa}^{-1}$ \\
\hline$c_{0}$ & $1.9898 \times 10^{-4} \mathrm{~K} \mathrm{~Pa}^{-1}$ \\
\hline$c_{1}$ & $-2.376 \times 10^{-6} \mathrm{~Pa}^{-1}$ \\
\hline$d$ & $1.83 \times 10^{-11} \mathrm{~K}^{2} \mathrm{~Pa}^{-2}$ \\
\hline$e$ & $-0.765 \times 10^{-8} \mathrm{~K}^{2} \mathrm{~Pa}^{-2}$ \\
\hline & \\
\hline
\end{tabular}

Calculate the average density of air at the balance during the weighing. Then determine the mass of the unknown, $M_{x}$, as follows:

8.3 If a two-pan balance is used, use one of the following equations:

$$
\begin{aligned}
& M_{x}=M_{s}+\rho_{a}\left(V_{x}-V_{s}\right)+\text { sensitivity } \Delta M_{o p t} \\
& M_{x}=\frac{M_{s}\left(1-\frac{\rho_{a}}{\rho_{s}}\right)+\text { sensitivity } \Delta M_{o p t}}{\left(1-\frac{\rho_{a}}{\rho_{x}}\right)} \\
& M_{x}=\frac{M_{s}-\rho_{a} V_{s}+\text { sensitivity } \Delta M_{o p t}}{\left(1-\frac{\rho_{a}}{\rho_{x}}\right)}
\end{aligned}
$$


Table 8. Variables not previously defined.

\begin{tabular}{||c|l||}
\hline \hline Variable & \multicolumn{1}{|c||}{ Description } \\
\hline \hline$M_{X}$ & mass of the unknown object \\
\hline$M_{S}$ & mass of the standard weights \\
\hline$\rho_{S}$ & density of the standard weights, $\frac{M_{S}}{V_{S}}$ \\
\hline$\Delta M_{\text {opt }}$ & off-balance indication read on the optical scale \\
\hline$V_{x}$ & volume of the unknown object \\
\hline$V_{s}$ & volume of the standard weights \\
\hline$\rho_{x}$ & density of the unknown object, $\frac{M_{X}}{V_{X}}$ \\
\hline
\end{tabular}

Volumes and densities are, in general, a function of temperature. The thermal coefficients of volumetric expansion of the unknown object and the standard may be significant in very accurate work. ${ }^{7}$ The coefficient of volumetric expansion is usually estimated as three times the linear coefficient of expansion of the weight material.

The error in $M_{x}$ incurred by ignoring the buoyancy correction is $\rho_{a}\left(V_{x}-V_{s}\right)$. To estimate quickly whether such an error is of consequence in a particular measurement, (assume $\rho_{a}=1.2 \times 10^{-3} \mathrm{~g} / \mathrm{cm}^{3}$ ).

If the mass and volumes of the standards have been adjusted to a conventional mass scale, then:

$$
M_{x} \approx \frac{C M_{s}\left(1-\frac{\rho_{a}}{\rho_{B}}\right)+\text { sensitivity } \Delta M_{o p t}}{\left(1-\frac{\rho_{a}}{\rho_{x}}\right)}
$$

Table A-6. Variables not previously defined.

\begin{tabular}{||c|l||}
\hline \hline Variable & \multicolumn{1}{c||}{ Description } \\
\hline \hline$C M_{s}$ & conventional mass of the standard \\
\hline \multicolumn{2}{|c||}{ The symbol $\approx$ signifies an approximation } \\
\hline
\end{tabular}

\footnotetext{
${ }^{7}$ In general, $\mathrm{V}_{\mathrm{t}}=\mathrm{V}_{20}\left[1+\beta\left(\mathrm{t}-20^{\circ} \mathrm{C}\right)\right]$ where $\mathrm{t}$ is the temperature of the weight, $\mathrm{V}_{20}$ is the volume at $20{ }^{\circ} \mathrm{C}$, and $ß$ is the cubical coefficient of expansion.
} 
8.4 If a single-pan balance with built-in weights is used, it is probable that the built-in weights have been adjusted on an apparent mass or conventional mass scale ${ }^{8}$. Determine which apparent mass scale has been used and calculate the mass of the unknown from the equation

$$
M_{\chi} \approx \frac{M_{D}\left(1-\frac{\rho_{a}}{\rho_{B}}\right)+\text { sensitivity } M_{o p t}}{\left(1-\frac{\rho_{a}}{\rho_{x}}\right)}
$$

Table 9. Variables not previously defined.

\begin{tabular}{|c|l||}
\hline \hline Variable & \multicolumn{1}{c|}{ Description } \\
\hline \hline$M_{D}$ & mass indicated by dial or digital readings \\
\hline$M_{\text {opt }}$ & mass indicated on the optical scale when present \\
\hline
\end{tabular}

If the balance has been used only as a comparator, that is, to compare the mass of the unknown object with that of some external standard, then:

$$
M_{x}=M_{s}+\rho_{a}\left(V_{x}-V_{s}\right)+\text { sensitivity } \Delta M^{\prime}{ }_{\text {opt }}
$$

Table 10. Variable not previously defined.

\begin{tabular}{|c|l||}
\hline \hline Variable & \multicolumn{1}{c|}{ Description } \\
\hline \hline$\Delta M^{\prime}{ }^{\prime}{ }^{\prime} t$ & $\begin{array}{l}\text { difference in optical scale reading between observations of the standard } \\
\text { and the unknown }\end{array}$ \\
\hline
\end{tabular}

For some balances, operation requires that the user restore the balance to null by means of a manually controlled dial. The portion of the mass reading controlled by this dial should be treated, for purposes of buoyancy corrections, as an optical scale.

8.5 If a single-pan balance with full-range electronic control is used, the following should be noted. As part of its calibration, the electronic gain has been adjusted by means of a weight of known mass. For example, if the range of electronic control is $100 \mathrm{~g}$, the electronics have been adjusted so that a $100 \mathrm{~g}$ standard weight produces an indication of precisely $100 \mathrm{~g}$. This procedure effectively builds an apparent mass calibration into the balance. The reference density of the apparent mass scale is the density of the standard mass used for the calibration and the reference air density is the air density at the time of calibration.

\footnotetext{
${ }^{8}$ Schoonover, R. M. and Jones, F. E., "Air Buoyancy in High-Accuracy Weighing on Analytical Balances," Anal.

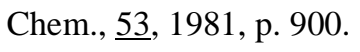


8.5.1 The mass of an unknown object weighed on the balance is then

$$
M_{x}=\frac{M_{R}\left(1-\frac{\rho_{a}}{\rho_{c}}\right)}{\left(1-\frac{\rho_{a}}{\rho_{x}}\right)}
$$

Table 11. Variables not previously defined.

\begin{tabular}{||c|l||}
\hline \hline Variable & \multicolumn{1}{|c||}{ Description } \\
\hline \hline$M_{R}$ & readout displayed on the balance \\
\hline$\rho_{a}$ & density of air at the time of balance calibration \\
\hline$\rho_{c}$ & $\begin{array}{l}\text { density of the standard used to calibrate the balance (or } \rho_{\mathrm{B}} \text { if the apparent } \\
\text { [conventional] mass of the standard was used instead of the true mass }\end{array}$ \\
\hline
\end{tabular}

If the balance includes both an electronic control system and built-in weights, the buoyancy considerations for the built-in weights are as described in section 8.2 and the considerations for the electronically determined mass are those given directly above.

8.6 Top-loading balances may be considered a form of single-pan balance and the appropriate procedure for buoyancy correction followed.

\section{$9 \quad$ Precision}

The contribution of the random error of the evaluation of air density to the precision of mass measurement may be estimated as follows:

For mechanical balances, or electronic balances used in weighing by substitution, the contribution is:

$$
\delta \rho_{a}\left(V_{x}-V_{s}\right)
$$

Table 12. Variables for above equation.

\begin{tabular}{|c|l||}
\hline \hline Variable & \multicolumn{1}{|c|}{ Description } \\
\hline \hline$\delta \rho_{a}$ & random error of evaluation of $\rho_{a}$ \\
\hline$V_{s}$ & volume of standards, if weighing by substitution \\
& $V_{s}=M_{D} / D_{B}$, if using the built-in weights on a single pan balance. \\
\hline$V_{x}$ & volume of object weighed \\
\hline
\end{tabular}

The quantity, $\delta \rho_{a}$ will have contributions from the measurements of temperature, pressure and relative humidity which are required for the calculation of $\rho_{a}$. Eqn. (11) may be used to estimate the effects of imprecision in measurements of $P, t$, and $U$. It is unrealistic to expect $\delta \rho_{a} / \rho_{a}$ ever to be less than $0.05 \%$ even using the best techniques available. 
Inattention to problems of buoyancy most often results in systematic errors. For a substitution weighing, for example, the buoyancy correction is of the order of $\rho_{a}\left(V_{x}-V_{s}\right)$. While this quantity may be significant to a measurement, day-to-day variation in $\rho_{a}$ (usually no more than $3 \%$ ) may not be noticeable and hence need not be measured. For the most accurate work, not only must $\rho_{a}$ be accurately determined, but the volumes of the unknown and standard may have to be measured to better than $0.05 \%$ which is the minimum systematic uncertainty attainable in the calculation of $\rho_{a}$.

If the standards have been calibrated in terms of conventional mass, complete neglect of buoyancy corrections will produce an error in the measured result $M_{x}$ of order:

$$
C M_{s}\left[\left(1.2 \times 10^{-3}-\rho_{a}\right)\left(\frac{1}{\rho_{s}}-\frac{1}{\rho_{B}}\right)+\left(\frac{\rho_{B}-\rho_{x}}{\rho_{B}}\right)\left(\frac{\rho_{a}}{\rho_{x}}\right)\right]
$$

This error is often unacceptably large.

Use of Eqn. (18), on the other hand, introduces only an error of approximately

$$
C M_{s}\left(1.2 \times 10^{-3}-\rho_{a}\right)\left(\frac{1}{\rho_{s}}-\frac{1}{\rho_{B}}\right)
$$

It is a requirement for manufacture that the actual density of standard weights be near enough to the assumed density of the apparent mass scale to which they are adjusted that the magnitude of (8) will always be small under normal conditions in laboratories near sea level.

The fact that there are two apparent mass scales widely used - one based on density $8.0 \mathrm{~g} / \mathrm{cm}^{3}$ and an older one based on $8.4 \mathrm{~g} / \mathrm{cm}^{3}$ - means that some caution is required on the part of the user. Conventional mass is generally preferred and reported for all calibrations where mass standards will be used to calibrate weighing instruments. For the most accurate work, the apparent mass scale should be abandoned in favor of substitution weighing with standards of known mass, density, and volume.

The user must decide the accuracy required of the particular mass measurement and choose a buoyancy correction technique commensurate with that accuracy.

The same considerations, which apply to the accuracy of buoyancy corrections in weighing by substitution, are easily extended to the other types of weighing indicated above.

There are many factors, which affect the accuracy of a mass measurement. The above has dealt only with those arising from problems of buoyancy. 


\section{Appendix B \\ Examples}

\section{Example 1:}

The weight set of Table B-1 is used with an equal-arm balance to find the mass of a piece of single-crystal silicon. The following weights were used to balance the silicon: $10 \mathrm{~g}, 3 \mathrm{~g}$. The balance pointer showed the silicon side to be light by 3.5 divisions. The $10 \mathrm{mg}$ weight of Table 1 was used to find the sensitivity of the balance. When the weight was added, the pointer moved 10.3 divisions. At the time of the weighing, the following measurements were taken:

$P=748.1 \mathrm{mmHg}$

$t=22.3^{\circ} \mathrm{C}$

$U=37 \%$ relative humidity

What is the mass of the silicon?

Answer:

Using the equation for $e_{s}$ found in Table 6, or Table B-2, calculate

$e_{s}=1.3146 \times 10^{9} \times e^{\left(\frac{-5315.56}{(22.3+273.15)}\right)}=20.194 \mathrm{mmHg}$

Then, using Eqn. (11), calculate the air density, $\left(\rho_{a}\right)$

$\rho_{a}=\left\{\frac{0.46460[748.1-(0.0037960)(37)(20.2)]}{(273.15+22.3)}\right\} 10^{-3}$

$\rho_{a}=1.17194 \times 10^{-3} \mathrm{~g} / \mathrm{cm}^{3}$

The density of silicon at $20{ }^{\circ} \mathrm{C}$ is $2.3291 \mathrm{~g} / \mathrm{cm}^{3}$ and its coefficient of linear expansion is $0.0000026 /{ }^{\circ} \mathrm{C}$.

Making use of Eqns. (10) and (17) and Table B-1:

$M_{s}=10.000130+3.000046=13.000176 \mathrm{~g}$

$V_{s}=(1.26744+0.38023)=1.64767 \mathrm{~cm}^{3}$

Calculate the balance sensitivity in g/division:

Sensitivity $=\frac{0.01000277 \mathrm{~g}-\left(0.00370 \mathrm{~cm}^{3}\right)\left(1.17194 \times 10^{-3} \mathrm{~g} / \mathrm{cm}^{3}\right)}{10.3 \text { divisions }} \mathrm{g} /$ division 
$=\frac{(0.0099984 \mathrm{~g})}{10.3 \text { divisions }}=0.00097072 \mathrm{~g} /$ division $=0.970724 \times 10^{-3} \mathrm{~g} /$ division

$M_{x}=\frac{\left[13.000176 \mathrm{~g}-\left(1.64767 \mathrm{~cm}^{3}\right)\left(1.17194 \times 10^{-3} \mathrm{~g} / \mathrm{cm}^{3}\right)\right]+\left[\left(0.970724 \times 10^{-3} \mathrm{~g} / \text { division }\right)(-3.5 \text { divisions })\right]}{\left(1-\frac{1.17194 \times 10^{-3} \mathrm{~g} / \mathrm{cm}^{3}}{2.3291 \mathrm{~g} / \mathrm{cm}^{3}}\right)}$

$M_{x}=13.001389 \mathrm{~g}$

Note that for this example the thermal expansion is insignificant.

\section{Example 2:}

Let us again consider the weighing performed in Example 1. This time, all we know about our weight set is that it has been adjusted to the 8.4 apparent mass scale at the best available commercial tolerance.

Using Eqn. (4),

$$
M_{x}=\left\{\frac{\left[13.00 \mathrm{~g}\left(1-\frac{1.17194 \times 10^{-3} \mathrm{~g} / \mathrm{cm}^{3}}{8.3909 \mathrm{~g} / \mathrm{cm}^{3}}\right)\right]+\left[0.010 \mathrm{~g}\left(1-\frac{1.17194 \times 10^{-3} \mathrm{~g} / \mathrm{cm}^{3}}{8.3909 \mathrm{~g} / \mathrm{cm}^{3}}\right)\right]\left(\frac{-3.5 \text { divisions }}{10.3 \text { divisions }}\right)}{\left(1-\frac{1.17194 \times 10^{-3} \mathrm{~g} / \mathrm{cm}^{3}}{2.3291 \mathrm{~g} / \mathrm{cm}^{3}}\right)}\right\}
$$

$M_{X}=13.001329 \mathrm{~g}$

For routine weighing, it is sometimes satisfactory to assume that the temperature is $20^{\circ} \mathrm{C}$ and the density of air is $1.2 \times 10^{-3} \mathrm{~g} / \mathrm{cm}^{3}$. Had this been done, the computed value for the silicon would be

$$
M_{x}=\left\{\frac{\left[13.00 \mathrm{~g}\left(1-\frac{1.2 \times 10^{-3} \mathrm{~g} / \mathrm{cm}^{3}}{8.3909 \mathrm{~g} / \mathrm{cm}^{3}}\right)\right]+\left[0.010 \mathrm{~g}\left(1-\frac{1.2 \times 10^{-3} \mathrm{~g} / \mathrm{cm}^{3}}{8.3909 \mathrm{~g} / \mathrm{cm}^{3}}\right)\right]\left(\frac{-3.5 \text { divisions }}{10.3 \text { divisions }}\right)}{\left(1-\frac{1.2 \times 10^{-3} \mathrm{~g} / \mathrm{cm}^{3}}{2.3291 \mathrm{~g} / \mathrm{cm}^{3}}\right)}\right\}
$$

$M_{X}=13.001442 \mathrm{~g}$

which is within $55 \mu \mathrm{g}$ of the answer found in Example 1. 


\section{Example 3:}

Another piece of silicon is measured on a single-pan microbalance. The balance weights were adjusted by the manufacturer to the conventional mass scale. The sensitivity of the balance has been determined to be exactly 1.000. This particular laboratory is well above sea level. At the time of the weighing, the following measurements were recorded:

$\mathrm{P}=612.3 \mathrm{mmHg}$

$\mathrm{t}=23.4^{\circ} \mathrm{C}$

$\mathrm{U}=23 \%$ relative humidity

The balance reading was $15.00 \mathrm{~g}$ on the built-in weights and $0.000358 \mathrm{~g}$ on the optical screen. What is the mass of the silicon?

Answer:

First, calculate $e_{s}$ and $\rho_{a}$ :

$e_{s}=21.627 \mathrm{mmHg}$

$\rho_{a}=0.95632 \times 10-3 \mathrm{~g} / \mathrm{cm}^{3}$

Then, use Eqn. (3):

$$
M_{x}=\frac{(15.00 \mathrm{~g}+0.000358 \mathrm{~g})\left(1-\frac{0.95632 \times 10^{-3} \mathrm{~g} / \mathrm{cm}^{3}}{8.0 \mathrm{~g} / \mathrm{cm}^{3}}\right)}{\left(1-\frac{0.95632 \times 10^{-3} \mathrm{~g} / \mathrm{cm}^{3}}{2.3291 \mathrm{~g} / \mathrm{cm}^{3}}\right)}
$$

$M_{X}=15.004726 \mathrm{~g}$

\section{Example 4:}

The built-in weights in Example 3 are actually stainless steel of density $7.78 \mathrm{~g} / \mathrm{cm}^{3}$ at $20{ }^{\circ} \mathrm{C}$. What is the approximate error caused by using the apparent mass scale?

\section{Answer:}

Using Eqn. (2), the error is approximately:

$15 \mathrm{~g}\left(0.95632 \times 10^{-3} \mathrm{~g} / \mathrm{cm}^{3}-1.2 \times 10^{-3} \mathrm{~g} / \mathrm{cm}^{3}\right)\left(\frac{1}{7.78 \mathrm{~g} / \mathrm{cm}^{3}}-\frac{1}{8.0 \mathrm{~g} / \mathrm{cm}^{3}}\right)=-12.92 \mu \mathrm{g}$

This discrepancy, though larger than the precision of the best analytical balances, is actually well within the tolerance of ASTM Class 1 weights. 
Table B-1. Example of calibration certificate data.

\begin{tabular}{|c|c|c|c|}
\hline $\begin{array}{c}\text { Mass } \\
\text { (g) }\end{array}$ & $\begin{array}{c}\text { Uncertainty } \\
\text { (g) }\end{array}$ & $\begin{array}{c}\text { Vol at } 20^{\circ} \mathrm{C} \\
\left(\mathrm{cm}^{3}\right)\end{array}$ & $\begin{array}{c}\text { Cubical } \\
\text { Coefficient of } \\
\text { Expansion }\left({ }^{\circ} \mathrm{C}\right)\end{array}$ \\
\hline 100.000941 & 0.000025 & 12.67439 & 0.000045 \\
\hline 50.000463 & 0.000016 & 6.33719 & 0.000045 \\
\hline 30.000293 & 0.000014 & 3.80232 & 0.000045 \\
\hline 20.000158 & 0.000011 & 2.53487 & 0.000045 \\
\hline 10.000130 & 0.000013 & 1.26744 & 0.000045 \\
\hline 5.000042 & 0.0000069 & 0.63372 & 0.000045 \\
\hline 3.000046 & 0.0000046 & 0.38023 & 0.000045 \\
\hline 2.0000063 & 0.0000033 & 0.25349 & 0.000045 \\
\hline 1.0000144 & 0.0000030 & 0.12674 & 0.000045 \\
\hline 0.4999538 & 0.0000016 & 0.03012 & 0.000020 \\
\hline 0.2999614 & 0.0000012 & 0.01807 & 0.000020 \\
\hline 0.19994984 & 0.00000087 & 0.01205 & 0.000020 \\
\hline 0.09996378 & 0.00000091 & 0.00602 & 0.000020 \\
\hline 0.04998659 & 0.00000072 & 0.00301 & 0.000020 \\
\hline 0.02999100 & 0.00000077 & 0.00181 & 0.000020 \\
\hline 0.02000570 & 0.00000066 & 0.00741 & 0.000069 \\
\hline 0.01000277 & 0.00000086 & 0.00370 & 0.000069 \\
\hline 0.00499706 & 0.00000070 & 0.00185 & 0.000069 \\
\hline 0.00300299 & 0.00000076 & 0.00111 & 0.000069 \\
\hline 0.00200197 & 0.00000066 & 0.00074 & 0.000069 \\
\hline 0.00100083 & 0.00000086 & 0.00037 & 0.000069 \\
\hline
\end{tabular}


Table B-2. $e_{s}$ approximation in terms of temperature.

\begin{tabular}{|c|c|}
\hline Temperature $\left({ }^{\circ} \mathrm{C}\right)$ & $e_{s}(\mathrm{mmHg})$ \\
\hline 18 & 15.48 \\
\hline 18.5 & 15.97 \\
\hline 19 & 16.48 \\
\hline 19.5 & 17 \\
\hline 20 & 17.54 \\
\hline 20.5 & 18.09 \\
\hline 21 & 18.65 \\
\hline 21.5 & 19.23 \\
\hline 22 & 19.83 \\
\hline 22.5 & 20.44 \\
\hline 23 & 21.07 \\
\hline 23.5 & 21.72 \\
\hline 24 & 22.38 \\
\hline 24.5 & 23.07 \\
\hline 25 & 23.77 \\
\hline 25.5 & 24.49 \\
\hline 26 & 25.23 \\
\hline 26.5 & 25.99 \\
\hline 27 & 26.77 \\
\hline 27.5 & 27.57 \\
\hline 28 & 28.39 \\
\hline 28.5 & 29.23 \\
\hline 29 & 30.09 \\
\hline 29.5 & 30.98 \\
\hline
\end{tabular}

${ }^{1}$ Handbook 145 is out of print. The archival version of Section 7 is available as a scanned PDF file on the NIST website. 
This page is intentionally blank. 


\section{SOP 4}

\section{Recommended Standard Operating Procedure \\ for Weighing by Double Substitution}

1 Introduction

\section{$1.1 \quad$ Purpose}

The double substitution procedure is one in which a standard and an unknown weight of equal nominal value are compared twice to determine the average difference between the two weights. Errors in any built-in weights or in the weighing instrument indications are minimized by using the weighing instrument as a comparator and by calibrating the weighing instrument indications over the range of use for the measurement with a sensitivity weight that has a known mass. Accordingly, the procedure is especially useful for calibrations of weights in OIML ${ }^{1}$ Classes $F_{1}$ to $M_{3}$, ASTM ${ }^{2}$ Classes 2 through 7, and forms the basis for advanced weighing designs used in SOP 5 and SOP 28 (See NISTIR 5672). The procedure incorporates two methods of measurement assurance: one is a mathematical check that evaluates the within-process repeatability and the other involves using a check standard to monitor the reference value(s) of the standard. This procedure may be used for any nominal values provided adequate standards and equipment are available. Detailed measurement ranges, standards, equipment, and uncertainties for this SOP are generally compiled in a separate document in the laboratory.

1.2 Prerequisites

1.2.1 Valid calibration certificates with appropriate values and uncertainties must be available for all of the standards used in the calibration. All standards must have demonstrated metrological traceability to the international system of units (SI), which may be to the SI through a National Metrology Institute such as NIST.

1.2.2 Standards must be evaluated to ensure that standard uncertainties for the intended level of calibration are sufficiently small. Reference standards should only be used to calibrate the next lower level of working standards in the laboratory and should not be used to routinely calibrate customer standards.

1.2.3 The weighing instrument must be in good operating condition with sufficiently small process standard deviation as verified by a valid control chart. When a new weighing instrument is put into service, preliminary

\footnotetext{
${ }^{1}$ OIML is the International Organization for Legal Metrology. Weight classes are published in OIML R 111, which is freely available at http://www.oiml.org.

${ }^{2}$ ASTM International (formerly the American Society for Testing and Materials) publishes the E617 standard for mass specifications and tolerances.
} 
experiments must be conducted to ascertain initial performance quality and adequacy.

1.2.4 The operator must be trained and experienced in precision weighing techniques with specific training in SOP 2, SOP 4, SOP 29, GMP 4, and GMP 10.

1.2.5 Laboratory facilities must comply with the following minimum conditions to meet the expected uncertainty possible with this procedure and to comply with the balance manufacturer's operating conditions specified for the balance. Equilibration of balances and weights requires environmental stability of the laboratory within the stated limits for a minimum of 24 hours before a calibration.

Table 1. Environmental conditions.

\begin{tabular}{||c|c|c||}
\hline \hline Echelon & Temperature Requirements During a Calibration & $\begin{array}{c}\text { Relative Humidity } \\
\text { (\%) }\end{array}$ \\
\hline \hline II & $\begin{array}{r}\text { Lower and upper limits: } 18^{\circ} \mathrm{C} \text { to } 23^{\circ} \mathrm{C} \\
\text { Maximum changes: } \pm 2^{\circ} \mathrm{C} / 12 \mathrm{~h} \text { and } \pm 1.5^{\circ} \mathrm{C} / \mathrm{h}\end{array}$ & 40 to $60 \pm 10 / 4 \mathrm{~h}$ \\
\hline III & $\begin{array}{r}\text { Lower and upper limits: } 18^{\circ} \mathrm{C} \text { to } 27^{\circ} \mathrm{C} \\
\text { Maximum changes: } \pm 5^{\circ} \mathrm{C} / 12 \mathrm{~h} \text { and } \pm 3^{\circ} \mathrm{C} / \mathrm{h}\end{array}$ & 40 to $60 \pm 20 / 4 \mathrm{~h}$ \\
\hline
\end{tabular}

Standards and test artifacts must be allowed to reach equilibration in or near the balance before commencing measurements. It is essential for the difference in temperature between the weights and the air inside the mass comparator to be as small as possible. Keeping the reference weight and the test weight inside, or next to, the mass comparator before and during the calibration can reduce this temperature difference.

$2 \quad$ Methodology

2.1 Scope, Precision, Accuracy

This method is applicable for all types of weighing instruments. The achievable precision and expanded uncertainty depend on the resolution, sensitivity, linearity, and other operating characteristics of the weighing instrument and the care exercised to make the required weighings. The accuracy achievable with this procedure depends on the accuracy of the calibration of the working standards and the accuracy obtained in the measurement process.

\subsection{Summary}

The weighing instrument is adjusted if necessary, to obtain measurement indications for all weighings that are within the range of the optical scale or digital

\footnotetext{
${ }^{3}$ Echelon II corresponds to weights of Classes OIML $F_{1}$ and $F_{2}$, ASTM Classes 2, 3 and 4. Echelon III corresponds to weights of Classes OIML $\mathrm{M}_{1}, \mathrm{M}_{2}$, and $\mathrm{M}_{3}$, ASTM Classes 5, 6 and 7. This procedure does not provide adequate redundancy for OIML Classes $\mathrm{E}_{1}$ or $\mathrm{E}_{2}$, ASTM Classes 000, 00, 0, or 1 and SOP 5 or SOP 28 should be used.
} 
indications without changing built-in weights, if present (this includes changing dials or the weighing platform masses). The standard and the test weight are each weighed twice. A small, calibrated weight, called a sensitivity weight, is added to the standard and unknown test weight in the latter two weighings to provide a determination of the sensitivity of the balance under the load conditions at the time of the intercomparison. All weighings are made at regularly spaced time intervals to minimize effects due to drift in the measurement process.

The double substitution procedure is the same for all weighing instruments, but the adjustment of the weighing instrument to prepare for the intercomparison and the selection of the sensitivity weight differs slightly depending upon the type of instrument used. When steps specific to a particular instrument are required, they are given in subsections of the procedure identified by a, b, and c along with the type of instrument.

\subsection{Apparatus/Equipment Required}

2.3.1 Precision analytical balance or mass comparator with sufficient capacity and resolution for the calibrations planned.

2.3.2 Calibrated working standards, of nominally equal mass to the unknown mass standards being calibrated. Calibrated tare weights are used as needed to ensure that the standard(s) and test artifacts are of equal nominal mass (See SOP 34 for suitable limits).

2.3.3 Calibrated sensitivity weights and tare weights selected to comply with the guidelines in SOP 34.

2.3.4 Uncalibrated weights to be used to adjust the balance to the desired reading range if needed.

2.3.5 Forceps to handle the weights, or gloves to be worn if the weights are moved by hand. Forceps and gloves must be selected to avoid damage or contamination of mass standards.

2.3.6 Stop watch or other timing device to observe the time of each measurement (calibration not required; this is used to ensure consistent timing of the measurement). If an electronic weighing instrument is used that has a means for indicating a stable reading, the operator may continue to time readings to ensure consistent timing that can minimize errors due to linear drift. 
2.3.7 Calibrated barometer with sufficiently small resolution, stability, and uncertainty (See SOP 2, e.g., accurate to $\pm 66.5 \mathrm{~Pa}(0.5 \mathrm{mmHg})$ ) to determine barometric pressure. ${ }^{4}$

2.3.8 Calibrated thermometer with sufficiently small resolution, stability, and uncertainty (see SOP 2, e.g., accurate to $\pm 0.10{ }^{\circ} \mathrm{C}$ ) to determine air temperature. $^{4}$

2.3.9 Calibrated hygrometer with sufficiently small resolution, stability, and uncertainty (see SOP 2, e.g., accurate to \pm 10 percent) to determine relative humidity. ${ }^{4}$

\subsection{Symbols}

Table 2. Symbols used in this procedure.

\begin{tabular}{|c|l||}
\hline \multicolumn{1}{|c||}{ Symbol } & \multicolumn{1}{|c|}{ Description } \\
\hline \hline$S$ & standard reference weight \\
\hline$S_{c}$ & weight to be calibrated \\
\hline$t$ & $\begin{array}{l}\text { sheck standard } \\
\text { it is associated }\end{array}$ \\
\hline$S w$ & small calibrated weight used to evaluate the sensitivity of the balance \\
\hline$M$ & $\begin{array}{l}\text { the mass (true mass) of a specific weight. Subscripts } s, x, t, s w \text { are used to identify the } \\
\text { weight (equals Nominal plus Correction) }\end{array}$ \\
\hline$N$ & nominal value of a specific weight. Subscripts $s, x$, are used to identify the weight. \\
\hline$C$ & correction for a specific weight. Subscripts $s, x$, are used to identify the weight. \\
\hline$C M$ & $\begin{array}{l}\text { the conventional mass of a specific weight. Subscripts } s, x, t, s w \text { are used to identify the } \\
\text { weight. }\end{array}$ \\
\hline$\rho_{a}$ & density of air at time of calibration \\
\hline$\rho_{n}$ & density of normal air (1.2 kg/m $\left.{ }^{3}\right)$ \\
\hline$\rho$ & density of masses; subscripts $s, x, t_{s}, t_{x}, s w$ are used to identify the weight. \\
\hline \hline
\end{tabular}

\subsection{Procedure}

\subsubsection{Preliminary Procedure}

2.5.1.1 Weights are visually inspected for cleanliness and damage. Follow the laboratory policy, including discussions with customers, to determine if and when standards will be cleaned, or where standards with inadequate cleanliness are returned without calibration and when "as found" and "as left" values will be obtained through duplicate calibrations.

\footnotetext{
${ }^{4}$ The barometer, thermometer, and hygrometer are used to determine the air density at the time of the measurement. The air density is used to make an air buoyancy correction. The limits specified are recommended for high precision calibration.
} 
2.5.1.2 If cleaning weights, it is important to clean weights before any measurements are made, unless "as found' data is to be measured, because the cleaning process will likely change the mass of the weight. Cleaning should not remove any significant amounts of weight material. Weights should be handled and stored in such a way that they stay clean. Before calibration, dust and any foreign particles shall be removed by blowing air across the surface with a clean bulb or by brushing with a clean soft bristled brush. Care must be taken not to change the surface properties of the weight (i.e., by scratching the weight). If a weight contains significant amounts of dirt that cannot be removed by the methods cited above, the weight or some part of it can be washed with clean alcohol, distilled water or other solvents. Weights with internal cavities should normally not be immersed in the solvent to avoid the possibility that the fluid will penetrate the opening. If there is a need to monitor the stability of a weight in use, the mass of the weight should, if possible, be determined before cleaning.

2.5.1.3 If weights are cleaned with solvents, they must be stabilized for the times given in the following table (better class weights need to stabilize for 7 to 10 days):

Table 3. Cleaning stabilization.

\begin{tabular}{|c|c|c|}
\hline \hline Weight class & $\mathbf{F}_{\mathbf{1}}$ & $\mathbf{F}_{\mathbf{2}}$ to $\mathbf{M}_{\mathbf{3}}$ \\
\hline \hline After cleaning with alcohol & 1 to 2 days & 1 hour \\
\hline After cleaning with distilled water & 1 day & 1 hour \\
\hline
\end{tabular}

2.5.1.4 Prior to performing any calibration tests, the weights need to be equilibrated to the ambient conditions of the laboratory. In particular, weights of classes $F_{1}$ (or better) should be close to the temperature in the weighing area. The minimum times (in hours) required for temperature stabilization (depending on weight size, weight class and on the difference between the initial temperature of the weights and the room temperature in the laboratory) are shown in the table below (with appropriate documented evidence). As a practical guideline, a waiting time of 24 hours is recommended. If weights are extremely hot or cold, additional equilibration is required to address problems with varying surface moisture levels. Weights must be completely dry prior to calibration. 
Table 4. Minimum equilibration times. ${ }^{5}$

\begin{tabular}{|c|c|c|c|}
\hline$\Delta \mathbf{T}^{\mathbf{a}}$ & Nominal Mass & $\begin{array}{c}\text { OIML Class } F_{1} \\
\text { (time in } h)\end{array}$ & $\begin{array}{c}\text { OIML Class } F_{2} \text { to } M_{3} \\
\text { (time in } h \text { ) }\end{array}$ \\
\hline \multirow{7}{*}{ $\pm 20^{\circ} \mathrm{C}$} & $1000,2000,5000 \mathrm{~kg}$ & 79 & 5 \\
\hline & $100,200,500 \mathrm{~kg}$ & 33 & 4 \\
\hline & $10,20,50 \mathrm{~kg}$ & 12 & 3 \\
\hline & $1,2,5 \mathrm{~kg}$ & 6 & 2 \\
\hline & $100,200,500 \mathrm{~g}$ & 3 & 1 \\
\hline & $10,20,50 \mathrm{~g}$ & 1 & 1 \\
\hline & $<10 \mathrm{~g}$ & 1 & 0.5 \\
\hline \multirow{6}{*}{ $\pm 5^{\circ} \mathrm{C}$} & $1000,2000,5000 \mathrm{~kg}$ & 24 & 1 \\
\hline & $100,200,500 \mathrm{~kg}$ & 10 & 1 \\
\hline & $10,20,50 \mathrm{~kg}$ & 4 & 1 \\
\hline & $1,2,5 \mathrm{~kg}$ & 3 & 1 \\
\hline & $100,200,500 \mathrm{~g}$ & 2 & 0.5 \\
\hline & $<100 \mathrm{~g}$ & 1 & 0.5 \\
\hline $\pm 2^{\circ} \mathrm{C}$ & $<100$ g to $5000 \mathrm{~kg}$ & 1 & 0.5 \\
\hline $\pm 0.5^{\circ} \mathrm{C}$ & $<100 \mathrm{~g}$ to $5000 \mathrm{~kg}$ & 0.5 & 0.5 \\
\hline
\end{tabular}

${ }^{\mathrm{a}} \Delta \mathrm{T}=$ Initial difference between weight temperature and laboratory temperature.

2.5.1.5 Conduct preliminary measurements to obtain an approximate value for the difference between the standard and the unknown, to identify where in the weighing instrument range the readings occur, to determine if tare weights are required, to determine the sensitivity weight to be used, and to determine the time interval required for the weighing instrument indication to stabilize. See NISTIR 6969, SOP 34 for specific instructions on evaluation of the need for and selection of tare weights and sensitivity weights.

Tare weights are rarely needed for mass standards that are within applicable tolerances. When unequal nominal weights are compared, tare weights are often required. When tare weights are required, carry tare weights, $t_{s}$ and $t_{x}$, with the standard and the unknown, $S$ and $X$, respectively. The tare weights must be calibrated standards with valid uncertainties that are included in the process of determining mass values and calibration uncertainties. The standard and its tare weight, $S+t_{s}$, should be "nearly the same mass" as the unknown with its tare weight, $X+t_{x}$. "Nearly the same mass" depends upon the balance used (See SOP 34, Table 1).

A sensitivity weight must be used on equal-arm balances, single-pan mechanical, and is usually used on electronic balances, to ensure that the measured differences between the standard(s) and unknown test items have valid accuracy and traceability (See SOP 34, Table

\footnotetext{
${ }^{5}$ Consider equivalent ASTM Classes for equilibration times.
} 
2) (e.g., the optical/digital scale is calibrated each time the procedure is performed through the use of a sensitivity weight).

If the sensitivity of the balance has been analyzed and is periodically evaluated and found to introduce negligible errors or uncertainties according to SOP 34 and measurement requirements, the equations in Section 3 must be modified to eliminate the sensitivity factor to avoid "division by zero" errors in the calculations.

Sensitivity weights are selected to meet the criteria in SOP 34.

2.5.1.6 Determine whether optional sequence A or B will be used. Optional sequence $A$ uses the standard on the balance for the first and fourth observations and the unknown on the balance for the second and third observations; this is often called the "SXXS" sequence. Optional sequence B starts with the unknown on the balance first and last with the standard on the balance for the second and third observations; this is often called the "XSSX" sequence. The primary advantage of sequence $B$ is less handling of the mass standards. The advantage of sequence $A$ is in the case where the unknown is a summation of weights that require careful arrangement on the balance pan only once. Option A is used in SOP 5 and SOP 28.

2.5.1.7 Adjust the single pan mechanical balance or the combination balance so the first two readings of the double substitution fall in the first quarter of the optical scale or digital indications. The zero adjustment and tare adjustment may be used. Small weights may be placed on the balance pan to reach the desired reading range. These weights remain on the pan throughout the double substitution and calibration is not required. Once the balance has been adjusted to the desired scale indication, neither the balance dials, the zero and tare adjustments, nor the small weights placed on the balance pan, are to be changed during the measurement.

2.5.1.8 If the balance is equipped with a pan arrestment mechanism, arrest the pan between each observation.

\subsubsection{Measurement Procedure, Optional Sequence A (SXXS)}

Table 5. Optional sequence A.

\begin{tabular}{||c|c|c||}
\hline \hline Measurement No. & Weights on Pan & Observation \\
\hline \hline 1 & $S+t_{s}$ & $O_{1}$ \\
\hline 2 & $X+t_{x}$ & $O_{2}$ \\
\hline 3 & $X+t_{x}+s w$ & $O_{3}$ \\
\hline 4 & $S+t_{s}+s w$ & $O_{4}$ \\
\hline
\end{tabular}


All observations should be recorded on suitable data sheets such as those in the appendix or may be entered into computer software. Measure and record the laboratory ambient temperature, barometric pressure, and relative humidity before and after the mass measurements.

2.5.2.1 Observation 1. Place the standard weight(s), $S$, along with $t_{\mathrm{s}}$ (if applicable) on the balance pan. If equipped with a pan arrestment mechanism, release the balance pan. When the pan is released, time the interval or wait for the stability indicator and record observation $\mathrm{O}_{1}$ once the balance indication has stabilized.

2.5.2.2 Observation 2. Remove weight(s) $S$ and $t_{s}$ (if present) and replace with test weight $X$ and its tare weight, $t_{x}$ (if applicable.) Release the pan, time the interval or wait for the stability indicator, and record observation $\mathrm{O}_{2}$.

2.5.2.3 Observation 3. Add the sensitivity weight, sw, to the weights of observation 2. Pick up the largest weight on the pan to ensure consistent stabilization timing when needed. Release the pan, time the interval or wait for the stability indicator, and record observation $\mathrm{O}_{3}$.

2.5.2.4 Observation 4. Remove weights $X$ and $t_{x}$ (if present) and replace with $S$ and $t_{s}$ (if applicable) on the balance pan. The sensitivity weight, $s w$, remains on the balance pan. Release the pan, time the interval or wait for the stability indicator, and record observation $O_{4}$.

2.5.2.5 Compare the two differences $\left(\mathrm{O}_{2}-\mathrm{O}_{1}\right)$ and $\left(\mathrm{O}_{3}-\mathrm{O}_{4}\right)$ to evaluate within process repeatability; they should not differ from one another by a laboratory determined limit (e.g., 2 standard deviations of the balance or 10 balance divisions are commonly used) for this process and load. If this difference is exceeded, reject the data and redo the measurements. Investigate possible causes of excess variability should within process repeatability exceed the limits.

2.5.2.6 Repeat 2.5.2.1 through 2.5.2.5 with a check standard, $S_{c}$. It is acceptable to begin with the check standard to ensure that the standards and process are in control, followed by the steps with the unknown standard, $X$. 


\subsubsection{Measurement Procedure, Optional Sequence B (XSSX)}

Table 6. Optional Sequence B.

\begin{tabular}{||c|c|c||}
\hline Measurement No. & Weights on Pan & Observation \\
\hline \hline 1 & $X+t_{x}$ & $O_{1}$ \\
\hline 2 & $S+t_{s}$ & $O_{2}$ \\
\hline 3 & $S+t_{s}+s w$ & $O_{3}$ \\
\hline 4 & $X+t_{x}+s w$ & $O_{4}$ \\
\hline
\end{tabular}

Measurements for Option B are made as described in Option A except that $X, S, t_{x}$, and $t_{s}$ are interchanged.

3 Calculations

3.1 If no air buoyancy correction is performed, calculate the conventional mass correction, $C_{S c}$, for the check standard using the appropriate equation from 3.1.1 or 3.1.2, depending on the sequence used, and incorporate an uncorrected systematic uncertainty in the uncertainty calculations when using these equations due to the lack of performing air buoyancy corrections. Use the equations provided in SOP 2 to calculate the magnitude of the air buoyancy correction and treat it as a rectangular distribution. Calculate the value for the test weight correction using the same equations, but substitute $X$ for the $S_{c}$ subscript for the unknown in equations 3.1.1. and 3.1.2. as appropriate.

\subsubsection{Optional Sequence A $(S X X S)$}

$$
C_{S c}=C_{s}+C M_{t_{s}}-C M_{t_{S c}}+\left[\frac{\left(O_{2}-O_{1}\right)+\left(O_{3}-O_{4}\right)}{2}\right]\left[\frac{C M_{s w}}{O_{3}-O_{2}}\right]+N_{s}-N_{S c}
$$

\subsubsection{Optional Sequence B (XSSX)}

$$
C_{S_{C}}=C_{s}+C M_{t_{s}}-C M_{t_{s_{c}}}+\left[\frac{\left(O_{1}-O_{2}\right)+\left(O_{4}-O_{3}\right)}{2}\right]\left[\frac{C M_{s w}}{O_{3}-O_{2}}\right]+N_{s}-N_{S_{c}}
$$

\subsection{Mass Calculation with Air Buoyancy Correction}

3.2.1 Calculate the air density, $\rho_{a}$, as described in the Appendix to SOP No. 2, Option B.

3.2.2 Calculate the mass $M_{S c}$ of the check standard using the mass of the standard weight(s), the tare weights, and the sensitivity weights, according to the optional sequence used. 


\subsubsection{Optional Sequence A (SXXS).}

$$
\frac{M_{S}\left(1-\frac{\rho_{a}}{\rho_{S}}\right)+M_{t_{S}}\left(1-\frac{\rho_{a}}{\rho_{t_{s}}}\right)-M_{t_{s c}}\left(1-\frac{\rho_{a}}{\rho_{t_{s c}}}\right)+\left[\frac{\left(O_{2}-O_{1}\right)+\left(O_{3}-O_{4}\right)}{2}\right]\left[\frac{M_{s w}\left(1-\frac{\rho_{a}}{\rho_{s w}}\right)}{O_{3}-O_{2}}\right]}{\left(1-\frac{\rho_{a}}{\rho_{S c}}\right)}
$$

Eqn. (3)

\subsubsection{Optional Sequence B (XSSX).}

$M_{S c}=\frac{M_{S}\left(1-\frac{\rho_{a}}{\rho_{S}}\right)+M_{t_{s}}\left(1-\frac{\rho_{a}}{\rho_{t_{s}}}\right)-M_{t_{c c}}\left(1-\frac{\rho_{a}}{\rho_{t_{s c}}}\right)+\left[\frac{\left(O_{1}-O_{2}\right)+\left(O_{4}-O_{3}\right)}{2}\right]\left[\frac{M_{s w}\left(1-\frac{\rho_{a}}{\rho_{s w}}\right)}{O_{3}-O_{2}}\right]}{\left(1-\frac{\rho_{a}}{\rho_{S c}}\right)}$

Eqn. (4)

3.2.3 Calculate the Conventional Mass ${ }^{6}$ of $S_{c}, C M_{S c}$.

$$
C M_{S c}=\frac{M_{S_{c}}\left(1-\frac{\rho_{n}}{\rho_{S c}}\right)}{\left(1-\frac{\rho_{n}}{8.0}\right)}
$$

\subsubsection{Calculate the Mass Correction of $\mathrm{S}_{\mathrm{c}}$.}

$$
C_{S c}=M_{S c}-N_{S c}
$$

where $N_{S c}$ is the nominal value for $S c$ and ensure it is within statistical control or take suitable corrective action. The mass or conventional mass (depending on laboratory control charts) determined for the check standard should be plotted on the control chart and must lie within the control limits (see NISTIR 6969, SOP 9). If the value is not within limits, and the source

\footnotetext{
${ }^{6}$ Conventional Mass: "The conventional value of the result of weighing a body in air is equal to the mass of a standard, of conventionally chosen density, at a conventionally chosen temperature, which balances this body at this reference temperature in air of conventionally chosen density." The conventions are: artifact reference density 8.0 $\mathrm{g} / \mathrm{cm}^{3}$; reference temperature $20^{\circ} \mathrm{C}$; normal air density $0.0012 \mathrm{~g} / \mathrm{cm}^{3}$. Conventional mass was formerly called "Apparent Mass versus $8.0 \mathrm{~g} / \mathrm{cm}^{3 ”}$ in the United States. See OIML D28 (2004).
} 
of error cannot be found, measurement must be stopped until suitable corrective action is taken. Corrective action is demonstrated through evaluation of additional measurement results that are within limits.

3.2.5 Calculate the mass of the test weight, $M_{x}$, and its mass correction, $C_{x}$, using the equations in 3.2.2.1 or 3.2.2.2 where $S_{c}$ is replaced by $X$. Calculate the mass correction $C_{x}$, as follows:

$$
C_{x}=M_{x}-N_{x}
$$

where $N_{X}$ is the nominal value for $X$.

3.2.6 Calculate the Conventional Mass of $X, C M_{x}$. The conventional mass should be reported.

$$
C M_{x}=\frac{M_{x}\left(1-\frac{\rho_{n}}{\rho_{x}}\right)}{\left(1-\frac{\rho_{n}}{8.0}\right)}
$$

3.2.7 Calculate the Apparent Mass versus Brass only if requested. This value should only be provided when requested by the customer for use when calibrating mechanical balances that have been adjusted to this reference density. (This is rare.)

$$
A M_{x \text { vs brass }}=\frac{M_{x}\left(1-\frac{\rho_{n}}{\rho_{x}}\right)}{\left(1-\frac{\rho_{n}}{8.3909}\right)}
$$

$4 \quad$ Measurement Assurance

4.1 The process integrates a suitable check standard (See GLP 1, SOP 9, and SOP 30).

4.2 The check standard value is calculated and immediately entered on the control chart to verify that the mass is within established limits. All values must be entered in the control chart, even if failing this statistic, unless a mistake (i.e., typographical error) is identified and corrected, to ensure the variability obtained for the process is not unduly reduced over time.

A t-test may be incorporated to check the observed value of the check standard against the mean value using the following equation and a $95 \%$ confidence level. The t-statistic is calculated for stability analysis. The observed value of the check standard is compared to the accepted mean value of the check standard and divided by the standard deviation for the check standard observations over time. This equation monitors stability over time but should not be used to assess for bias. A 
calculated t-value less than two is within the warning limits of the process. A calculated t-value between two and three represents a value between the warning limits and control/action limits. A calculated t-value exceeding three represents a value outside of the control/action limits and suitable action must be taken. Calculated values of the t-statistic may also be monitored over time to determine the presence of drift.

$$
t=\frac{\left(S_{c}-\overline{S_{c}}\right)}{S_{p}}
$$

4.3 Check standard measurement results obtained over time are used to calculate the standard deviation of the measurement process, $s_{p}$.

4.4 The mean value of the check standard over time is also compared to an appropriate reference value of the check standard with respect to their applicable expanded uncertainties to evaluate bias and drift over time. Excessive drift or bias must be investigated and followed with suitable corrective action. See SOP 9, Section 4.2 for assessment methodology.

4.5 Where SOP 9 is followed, and check standards are used for 2 to 3 nominal values per balance, more frequent calibration intervals may be needed to monitor the working standards and the larger standard deviation of the nominal values bracketing the nominal value should be used. If check standards were already checked on a given day and found to be in control, additional check standard measurements are not required.

\section{Assignment of Uncertainty}

The limits of expanded uncertainty, $U$, include estimates of the standard uncertainty of the mass standards used, $u_{s}$, estimates of the standard deviation of the measurement process, $s_{p}$, and estimates of the effect of other components associated with this procedure, $u_{o}$. These estimates should be combined using the root-sum-squared method (RSS), and the expanded uncertainty, $U$, reported with a coverage factor to be determined based on the degrees of freedom, which if large enough will be 2, $(k=2)$, to give an approximate 95 percent level of confidence. See SOP 29 for the complete standard operating procedure for calculating the uncertainty. 
5.1 The expanded uncertainty for the standard, $U$, is obtained from the calibration certificate. The combined standard uncertainty, $u_{c}$, is used and not the expanded uncertainty, $U$, therefore the reported uncertainty for the standard will usually need to be divided by the coverage factor $k$. When multiple standards are used, see SOP 29 for evaluation of dependent and independent conditions and combining methods for the standard uncertainty of the standard. Tare weights used in determining the mass of unknown weights are treated as additional standards in the measurement process. Where the coverage factor or confidence interval is not given, the laboratory should either contact the calibration provider to obtain the correct divisor or use a value of $k=2$, assuming that the expanded uncertainty was reported with an approximate $95 \%$ confidence interval (95.45\%).

Check standards are not used to assign values to unknown weights; however, the uncertainty of calibration of the check standard may be used to assess the control status.

5.2 The value for $s_{p}$ is obtained from the control chart data for check standards using double substitution measurements. Where the standard deviation is less than the balance resolution, the laboratory may round up to the value of the balance division or use one of the equations in 5.2.1 to determine the smallest standard deviation to be included in the uncertainty calculations. (See SOP No. 9.)

5.2.1 Where the standard deviation of the measurement process from the control chart is less than the resolution of the balance being used, the larger of the standard deviation of the process and one of the following estimates for repeatability is used to represent the standard deviation of the process:

5.2.1.1 If the laboratory prefers a more conservative approach, or when the current and representative degrees of freedom are less than 30, the larger of the control chart $s_{p}$ and the result from Eqn. (11) should be used, where $\mathrm{d}$ is the smallest balance division. For example, if the balance division is $0.1 \mathrm{mg}$, the smallest standard deviation may be $0.06 \mathrm{mg}$. If the laboratory calculated standard deviation is $0.075 \mathrm{mg}$, then $0.075 \mathrm{mg}$ is used. As the most conservative approach, the laboratory may also round up to the value of the balance division as noted earlier.

$$
S_{p}=\frac{d}{\sqrt{3}} \approx 0.6 d
$$


5.2.1.2 When the laboratory has the confidence associated with a well characterized measurement process and has 30 or more degrees of freedom to represent the process, the larger of the control chart $s_{p}$ and the result from Eqn. (12) may be used, where $\mathrm{d}$ is the smallest balance division. For example, if the balance division is $0.1 \mathrm{mg}$, the smallest standard deviation may be $0.03 \mathrm{mg}$. If the laboratory calculated standard deviation is $0.075 \mathrm{mg}$, then $0.075 \mathrm{mg}$ is used. Use of Eqn. (12) is appropriate as the degrees of freedom approaches 30; the check standard calculated standard deviation is less than is calculated using Eqn. (11).

$$
s_{p}=\frac{d}{2 \sqrt{3}} \approx 0.3 d
$$

5.3 Uncertainty due to air buoyancy corrections and air density. Select one of the following options in priority preference for calculating and uncertainty associated with air buoyancy.

5.3.1 Option 1, preferred. Use the formulae provided in OIML R111 (2004), C.6.3-1, C.6.3-2, and C.6.3-3.

5.3.2 Option 2. Calculate the uncertainty by quantify estimated impacts associated with the uncertainties of the air temperature, barometric pressure, relative humidity, and the air density formula based on laboratory uncertainties and calculations given in NISTIR 6969, SOP 2 and the SOP being used. Note: this may be done using a simplified baseline "what if" approach or a Kragten analysis. ${ }^{7}$

5.3.3 Option 3. If buoyancy corrections are not performed, include an uncorrected systematic standard uncertainty due to the buoyancy effect using the equations for the magnitude of the air buoyancy correction per SOP 2 and use a rectangular distribution. This approach is not recommended for precision calibrations; however, if the resulting value from this approach is evaluated and does not significantly affect the expanded uncertainty, it may be adequate.

5.4 Uncertainty associated with the density of the standards and the unknown test weights, $u_{\rho}$. Uncertainties associated with the density of the standards used in the calibration may be incorporated into the estimated calculations in section 5.3 .

5.5 Uncertainty associated with bias, $u_{d}$. Any noted bias that has been determined through analysis of control charts and round robin data must be less than limits

\footnotetext{
${ }^{7}$ A baseline "what if" approach calculates the estimated impact of each variable in the final measurement result by individually changing each variable of interest by the uncertainty quantity. See the EURACHEM/CITAC

Quantitative Guide to Uncertainties in Analytical Methods (QUAM, 2012) for a discussion of Kragten spreadsheets.
} 
provided in SOP 29 and may be included if corrective action is not taken. See SOP 2 and 29 for additional details.

5.6 Example components to be considered for an uncertainty budget table are shown in the following table.

Table 7. Example uncertainty budget table.

\begin{tabular}{|c|c|c|c|}
\hline $\begin{array}{c}\text { Uncertainty Component } \\
\text { Description }\end{array}$ & Symbol & Source & $\begin{array}{c}\text { Typical } \\
\text { Distribution } \\
\end{array}$ \\
\hline $\begin{array}{l}\text { Uncertainty of the standard } \\
\text { mass(es) (5.1) }\end{array}$ & $u_{s}$ & Calibration certificate & $\begin{array}{l}\text { Normal divided by } \\
\text { coverage factor }\end{array}$ \\
\hline $\begin{array}{l}\text { Accepted standard deviation of } \\
\text { the process }(5.2)\end{array}$ & $S_{p}$ & $\begin{array}{c}\text { Control chart, standard } \\
\text { deviation chart } \\
\text { OR estimates when } s_{p} \text { is smaller } \\
\text { than balance division }\end{array}$ & Normal \\
\hline $\begin{array}{l}\text { Uncertainty of the air } \\
\text { buoyancy correction (5.3) }\end{array}$ & $u_{b}$ & OIML R111 & Rectangular \\
\hline $\begin{array}{l}\text { Air temperature (for air } \\
\text { density) }\end{array}$ & $u_{t}$ & SOP 2 or R111 & Rectangular \\
\hline Air pressure (for air density) & $u_{p}$ & SOP 2 or R111 & Rectangular \\
\hline $\begin{array}{l}\text { Air relative humidity (for air } \\
\text { density) }\end{array}$ & $u_{R H}$ & SOP 2 or R111 & Rectangular \\
\hline Air density (formula) & $u_{\rho a}$ & SOP 2 or R111 & Rectangular \\
\hline Mass densities (5.4) & $u_{\rho m}$ & $\begin{array}{c}\text { Measured and reported value } \\
\text { OIML R111 Table B.7 } \\
\text { Typically, } 0.03 \mathrm{~g} / \mathrm{cm}^{3} \text { to } \\
0.05 \mathrm{~g} / \mathrm{cm}^{3} \\
\end{array}$ & Rectangular \\
\hline $\begin{array}{l}\text { Uncertainty associated with } \\
\text { bias (5.5) }\end{array}$ & $u_{d}$ & Control chart, proficiency tests & See SOP 29 \\
\hline
\end{tabular}

5.7 Draft a suitable uncertainty statement for the certificate. For example:

The uncertainty reported is the root sum square of the standard uncertainty of the standard, the standard deviation of the process, and the uncertainty associated with the buoyancy corrections, multiplied by a coverage factor of $2(k=2)$ for an approximate $95 \%$ confidence interval. Factors not considered in the evaluation: magnetism (weights not evaluated for magnetism specifications unless measurement aberrations are noted), balance eccentricity and linearity (these factors are considered as a part of the measurement process when obtaining the standard deviation of the process when using a check standard with adequate degrees of freedom).

NOTE: Where inadequate degrees of freedom are available, $k$, is determined using the appropriate degrees of freedom and the $95.45 \%$ column in the table from Appendix A of NISTIR 6969, SOP 29. 
6.1 Report results as described in SOP No. 1, Preparation of Calibration Certificates. Report the mass (if requested by the customer), conventional mass, environmental conditions during the calibrations, mass density used (reported, measured, or assumed), and calculated expanded uncertainties with coverage factor(s).

\subsection{Conformity assessments.}

Evaluate compliance to applicable tolerances as needed or required by the customer or by legal metrology requirements. Decision criteria for uncertainty and tolerance evaluations include two components: 1 ) the expanded uncertainty, U, must be $<1 / 3$ of the applicable tolerances published in ASTM E617 and OIML R111 documentary standards and 2) the absolute value of the conventional mass correction value plus the expanded uncertainty must be less than the applicable tolerance to confidently state that mass standards are in or out of tolerance. Compliance assessments must note the applicable documentary standard and which portions of the standard were or were not evaluated. 


\section{Appendix A}

\section{Double Substitution Data Sheet \\ (Optional Sequence A, SXXS)}

Laboratory data and conditions:

\begin{tabular}{|r|r|r|r|r||}
\hline \hline Operator & & Before & After \\
\hline Date & & Temperature & & \\
\hline Balance & & Pressure & & \\
\hline Load & Relative Humidity & & \\
\hline $\begin{array}{r}\text { Standard deviation of the process, } \\
\text { from control chart, } s_{p}\end{array}$ & & Degrees of Freedom & & \\
\hline
\end{tabular}

Mass standard(s) data:

\begin{tabular}{|c|c|c|c|c|c|c|}
\hline ID & Nominal & Mass Correction* & $\begin{array}{l}\text { Expanded Unc: } \\
\text { From cal. certificate }\end{array}$ & $\begin{array}{l}\text { Unc: } \\
k \text { factor }\end{array}$ & $\begin{array}{c}\text { Density } \\
\mathrm{g} / \mathrm{cm}^{3}\end{array}$ & $\begin{array}{c}\text { Unc } \\
\text { Density } \\
(k=1)\end{array}$ \\
\hline$S$ & & & & & & \\
\hline$t_{s}$ & & & & & & \\
\hline$X$ & & & & & & \\
\hline$t_{x}$ & & & & & & \\
\hline$S_{c}$ & & & & & & \\
\hline$t s c$ & & & & & & \\
\hline sw & & & & & & \\
\hline
\end{tabular}

*Mass Correction = True Mass if using buoyancy correction. Mass Correction = Conventional Mass if NOT using buoyancy correction. Density is used only with buoyancy corrections.

\section{Observations:}

\begin{tabular}{|c|c|c|}
\hline Observation No. & Weights & Balance Observations, Units \\
\hline \multicolumn{3}{|l|}{ Time: } \\
\hline $1\left(O_{1}\right)$ & $S+t_{s}$ & \\
\hline $2\left(\mathrm{O}_{2}\right)$ & $X+t_{X}$ & \\
\hline $3\left(\mathrm{O}_{3}\right)$ & $X+t_{x}+s w$ & \\
\hline $4\left(\mathrm{O}_{4}\right)$ & $S+t_{s}+s w$ & \\
\hline Time: & & \\
\hline
\end{tabular}

Measurement Assurance (See Section 4.5):

\begin{tabular}{|c|c|c|}
\hline Observation No. & Weights & Balance Observations, Units \\
\hline \multicolumn{3}{|l|}{ Time: } \\
\hline $1\left(O_{1}\right)$ & $S+t_{s}$ & \\
\hline $2\left(\mathrm{O}_{2}\right)$ & $S_{c}+t_{S c}$ & \\
\hline $3\left(\mathrm{O}_{3}\right)$ & $S_{c}+t_{S c}+s w$ & \\
\hline $4\left(\mathrm{O}_{4}\right)$ & $S+t_{s}+s w$ & \\
\hline \multicolumn{3}{|l|}{ Time: } \\
\hline Check Standard in Control? & Yes___ No & \\
\hline
\end{tabular}




\section{Appendix B}

\section{Double Substitution Data Sheet \\ (Optional Sequence B, $X S S X$ )}

Laboratory data and conditions:

\begin{tabular}{|r|r|r|r||}
\hline \hline Operator & & Before & After \\
\hline Date & Temperature & & \\
\hline Balance & Pressure & & \\
\hline Load & Relative Humidity & & \\
\hline $\begin{array}{r}\text { Standard deviation of the process, } \\
\text { from control chart, } s_{p}\end{array}$ & Degrees of Freedom & & \\
\hline
\end{tabular}

\section{Mass standard(s) data:}

\begin{tabular}{|c|c|c|c|c|c|c|}
\hline ID & Nominal & Mass Correction* & $\begin{array}{l}\text { Expanded Unc: } \\
\text { From cal. certificate }\end{array}$ & $\begin{array}{l}\text { Unc: } \\
\text { k factor }\end{array}$ & $\begin{array}{l}\text { Density } \\
\mathrm{g} / \mathrm{cm}^{3}\end{array}$ & $\begin{array}{c}\text { Unc } \\
\text { Density } \\
(k=1)\end{array}$ \\
\hline$S$ & & & & & & \\
\hline$t_{s}$ & & & & & & \\
\hline$X$ & & & & & & \\
\hline$t_{x}$ & & & & & & \\
\hline$S_{c}$ & & & & & & \\
\hline$t_{S c}$ & & & & & & \\
\hline$s w$ & & & & & & \\
\hline
\end{tabular}

*Mass Correction = True Mass if using buoyancy correction. Mass Correction = Conventional Mass if NOT using buoyancy correction. Density is used only with buoyancy corrections.

Observations:

\begin{tabular}{||r|r|r||}
\hline \multicolumn{1}{|c|}{ Observation No. } & Weights & Balance Observations, Units \\
\hline \hline Time: & & $X+t_{x}$ \\
\hline $2\left(\mathrm{O}_{1}\right)$ & $S+t_{s}$ & \\
\hline $3\left(\mathrm{O}_{3}\right)$ & $S+t_{s}+s w$ & \\
\hline $4\left(\mathrm{O}_{4}\right)$ & $X+t_{x}+s w$ & \\
\hline Time: & & \\
\hline
\end{tabular}

Measurement Assurance (See Section 4.5):

\begin{tabular}{|c|c|c|}
\hline Observation No. & Weights & "Balance Observations, Units \\
\hline \multicolumn{3}{|l|}{ Time: } \\
\hline $1\left(O_{1}\right)$ & $S_{c}+t_{S c}$ & \\
\hline $2\left(\mathrm{O}_{2}\right)$ & $S+t_{s}$ & \\
\hline $3\left(\mathrm{O}_{3}\right)$ & $S+t_{s}+s w$ & \\
\hline $4\left(\mathrm{O}_{4}\right)$ & $S_{c}+t_{S c}+s w$ & \\
\hline \multicolumn{3}{|l|}{ Time: } \\
\hline Check Standard in Control? & Yes__ No & \\
\hline
\end{tabular}




\title{
SOP 7
}

\author{
Recommended Standard Operating Procedure \\ for \\ Weighing by Single Substitution \\ Using a Single-Pan Mechanical Balance, a Full Electronic Balance, or a \\ Balance with Digital Indications and Built-In Weights
}

1

Introduction

$1.1 \quad$ Purpose

In the single substitution procedure, a standard and an unknown weight of equal nominal value are compared once to determine the difference in weights. Errors in any built-in weights or in the balance indications are minimized by using the balance only as a comparator and by calibrating the balance indications over the range of use for the measurement with a sensitivity weight. This procedure is suitable for calibration when moderate accuracy (OIML ${ }^{1}$ Classes $\mathrm{F}_{1}$ to $\mathrm{M}_{3}, \mathrm{ASTM}^{2}$ Classes 3 through 7) is required and as a single substitution, does not eliminate errors due to drift. The procedure incorporates measurement assurance through replicate tests using a check standard to monitor the reference value(s) of the standard and the repeatability of the measurement process over time. This procedure may be used for any nominal values provided adequate standards and equipment are available. Detailed measurement ranges, standards, equipment, and uncertainties for this SOP are generally compiled in a separate document in the laboratory.

1.2 Prerequisites

1.2.1 Valid calibration certificates with appropriate values and uncertainties must be available for all reference standards used in the calibration. All standards must have demonstrated metrological traceability to the international system of units (SI), which may be to the SI through a National Metrology Institute such as NIST.

1.2.2 Standards must be evaluated to ensure that standard uncertainties for the intended level of calibration are sufficiently small. Reference standards should not be used to routinely calibrate customer standards using this procedure.

1.2.3 Verify that the balance that is used is in good operating condition with sufficiently small process standard deviation as verified by a valid control chart or preliminary experiments to ascertain its performance quality when a new balance is put into service.

\footnotetext{
${ }^{1}$ OIML is the International Organization for Legal Metrology. Weight classes are published in OIML R 111, which is freely available at http://www.oiml.org.

${ }^{2}$ ASTM International (formerly the American Society for Testing and Materials) publishes the E617 standard for mass specifications and tolerances.
} 
1.2.4 Verify that the operator is experienced in precision weighing techniques and has had specific training in SOP 2, SOP 7, SOP 29, GMP 4, and GMP 10.

1.2.5 Laboratory facilities must comply with the following minimum conditions to meet the expected uncertainty possible with this procedure and to comply with the balance manufacturer's operating conditions specified for the balance. The laboratory environment must be stable within the stated limits for a minimum of 24 hours before a calibration.

Table 1. Environmental conditions.

\begin{tabular}{|c|c|c||}
\hline \hline Echelon $^{3}$ & Temperature Requirements During a Calibration & $\begin{array}{c}\text { Relative Humidity } \\
\text { (\%) }\end{array}$ \\
\hline \hline II & $\begin{array}{c}\text { Lower and upper limits: } 18^{\circ} \mathrm{C} \text { to } 23^{\circ} \mathrm{C} \\
\text { Maximum changes: } \pm 2^{\circ} \mathrm{C} / 12 \mathrm{~h} \text { and } \pm 1.5^{\circ} \mathrm{C} / \mathrm{h}\end{array}$ & 40 to $60 \pm 10 / 4 \mathrm{~h}$ \\
\hline III & $\begin{array}{c}\text { Lower and upper limits: } 18^{\circ} \mathrm{C} \text { to } 27^{\circ} \mathrm{C} \\
\text { Maximum changes: } \pm 5^{\circ} \mathrm{C} / 12 \mathrm{~h} \text { and } \pm 3^{\circ} \mathrm{C} / \mathrm{h}\end{array}$ & 40 to $60 \pm 20 / 4 \mathrm{~h}$ \\
\hline
\end{tabular}

It is important that the difference in temperature between the weights and the air in the laboratory or inside the mass comparator be less than the values noted in the Procedure section. Standards and test artifacts must be allowed to reach equilibration in or near the balance before starting measurements.

$2 \quad$ Methodology

2.1 Scope, Precision, Accuracy

This method is applicable to all weighings utilizing a single-pan mechanical balance, a full electronic balance, or a balance that combines digital indications with the use of built-in weights (combination balance). The precision depends upon the sensitivity of the balance and the care exercised in making the required weighings. The accuracy achievable with this procedure depends on the accuracy of the calibration of the working standards and the precision of the intercomparison.

\subsection{Summary}

The balance is adjusted, if necessary, to obtain balance indications for all measurements that will be within the range of the optical scale or digital indications of the balance without changing the dial settings for the built-in weights, if present. The standard and the test weight are each weighed. A small, calibrated weight, called a sensitivity weight, is added to the test weight and these are weighed

The single substitution procedure is the same for all the balances mentioned above, but the adjustment of the balance to prepare for the intercomparison and the selection of the sensitivity weight differ slightly depending upon the balance used.

\footnotetext{
${ }^{3}$ Echelon II corresponds to weights of Classes OIML $\mathrm{F}_{1}$ and $\mathrm{F}_{2}$, ASTM Classes 2, 3 and 4. Echelon III corresponds to weights of Classes OIML $\mathrm{M}_{1}, \mathrm{M}_{2}$, and $\mathrm{M}_{3}$, ASTM Classes 5, 6 and 7. This procedure does not provide adequate redundancy for OIML Classes $\mathrm{E}_{1}$ or $\mathrm{E}_{2}$, ASTM Classes 000, 00, 0, or 1 and SOP 5 or SOP 28 should be used.
} 
When steps specific to a particular balance are required, they are given in subsections of the procedure identified by a, b, and c along with the balance type.

\subsection{Apparatus/Equipment Required}

2.3.1 Precision analytical balance or mass comparator with sufficient capacity and resolution for the calibrations planned.

2.3.2 Calibrated working standards, of nominally equal mass to the unknown mass standards being calibrated. Calibrated tare weights are used as needed to ensure that the standard(s) and test artifacts are of equal nominal mass (See SOP 34 for suitable limits).

2.3.3 Calibrated sensitivity weights and tare weights selected to comply with the guidelines in SOP 34.

2.3.4 Uncalibrated weights to be used to adjust the balance to the desired reading range if needed.

2.3.5 Forceps to handle the weights, or gloves to be worn if the weights are moved by hand. Forceps and gloves must be selected to avoid damage or contamination of mass standards.

2.3.6 Stop watch or other timing device to observe the time of each measurement (calibration not required; this is used to ensure consistent timing of the measurement). If an electronic balance is used that has a means for indicating a stable reading, the operator may continue to time readings to ensure consistent timing that can minimize errors due to linear drift.

2.3.7 Calibrated barometer with sufficiently small resolution, stability, and uncertainty (See SOP 2, e.g., accurate to $\pm 66.5 \mathrm{~Pa}(0.5 \mathrm{mmHg})$ ) to determine barometric pressure. ${ }^{4}$

2.3.8 Calibrated thermometer with sufficiently small resolution, stability, and uncertainty (see SOP 2, e.g., accurate to $\pm 0.10{ }^{\circ} \mathrm{C}$ ) to determine air temperature. ${ }^{4}$

2.3.9 Calibrated hygrometer with sufficiently small resolution, stability, and uncertainty (see SOP 2, e.g., accurate to \pm 10 percent) to determine relative humidity. ${ }^{4}$

${ }^{4}$ The barometer, thermometer, and hygrometer are used to determine the air density at the time of the measurement. The air density is used to make an air buoyancy correction. The limits specified are recommended for high precision calibration. 


\section{$2.4 \quad$ Symbols}

Table 2. Symbols used in this procedure.

\begin{tabular}{|c|l||}
\hline \hline Symbol & \multicolumn{1}{c|}{ Description } \\
\hline \hline$S$ & standard weight \\
\hline$X$ & weight calibrated \\
\hline$S_{c}$ & check standard \\
\hline$t$ & $\begin{array}{l}\text { small calibrated tare weight, A subscript } s \text { or } x \text { is used to indicate the weight(s) with } \\
\text { which it is associated }\end{array}$ \\
\hline$S w$ & small calibrated weight used to evaluate the sensitivity of the balance \\
\hline$M$ & $\begin{array}{l}\text { the mass (true mass) of a specific weight. Subscripts } s, x, t, s w \text { are used to identify } \\
\text { the weight (equals Nominal plus Correction) }\end{array}$ \\
\hline$N$ & $\begin{array}{l}\text { the nominal value of a specific weight. Subscripts } s, x \text {, are used to identify the } \\
\text { weight. }\end{array}$ \\
\hline$C$ & the correction for a specific weight. Subscripts $s, x$, are used to identify the weight. \\
\hline$C M$ & $\begin{array}{l}\text { the conventional mass of a specific weight. Subscripts } s, x, t, s w \text { are used to identify } \\
\text { the weight. }\end{array}$ \\
\hline$\rho_{a}$ & density of air at time of calibration \\
\hline$\rho_{n}$ & density of normal air (1.2 kg/m ${ }^{3}$ ) \\
\hline$\rho$ & density of masses; subscripts $s, x, t_{s}, t_{x}, s w$ are used to identify the weight \\
\hline \hline
\end{tabular}

\subsection{Procedure}

\subsubsection{Preliminary Procedure}

2.5.1.1 Weights are visually inspected for cleanliness and damage.

2.5.1.2 If cleaning weights, it is important to clean weights before any measurements are made because the cleaning process may change the mass of the weight. Cleaning should not remove any significant amounts of weight material. Weights should be handled and stored in such a way that they stay clean. Before calibration, dust and any foreign particles shall be removed. Care must be taken not to change the surface properties of the weight (i.e., by scratching the weight). If a weight contains significant amounts of dirt that cannot be removed by the methods cited above, the weight or some part of it can be washed with clean alcohol, distilled water or other solvents. Weights with internal cavities should normally not be immersed in the solvent to avoid the possibility that the fluid will penetrate the opening. If there is a need to monitor the stability of a weight in use, the mass of the weight should, if possible, be determined before cleaning.

2.5.1.3 If weights are cleaned with solvents, they must be stabilized for the times given in the following table (better class weights need to stabilize for 7 to 10 days): 
Table 3. Cleaning stabilization.

\begin{tabular}{||c|c|c||}
\hline Weight class & $\mathbf{F}_{\mathbf{1}}$ & $\mathbf{F}_{\mathbf{2}}$ to $\mathbf{M}_{\mathbf{3}}$ \\
\hline \hline After cleaning with alcohol & 1 to 2 days & 1 hour \\
\hline After cleaning with distilled water & 1 day & 1 hour \\
\hline
\end{tabular}

2.5.1.4 Prior to performing any calibration tests, the weights need to be acclimated to the ambient conditions of the laboratory. In particular, weights of classes $F_{1}$ (or better) should be close to the temperature in the weighing area and equilibrate for a minimum of 24 hours. The minimum times (in hours) required for temperature stabilization (depending on weight size, weight class and on the difference between the initial temperature of the weights and the room temperature in the laboratory) are shown in the table below (with appropriate documented evidence). As a practical guideline, a waiting time of 24 hours is recommended. If weights are extremely hot or frozen, additional equilibration may be needed to address problems with condensation and frozen surfaces. Weights must be completely dry prior to calibration.

Table 4. Minimum equilibration times. ${ }^{5}$

\begin{tabular}{|c|c|c|c|}
\hline$\Delta \mathbf{T}^{\mathbf{a}}$ & Nominal Mass & $\begin{array}{c}\text { OIML Class } F_{1} \\
\text { (time in h) }\end{array}$ & $\begin{array}{c}\text { OIML Class } F_{2} \text { to } M_{3} \\
(\text { time in h) }\end{array}$ \\
\hline \multirow{7}{*}{ $\pm 20^{\circ} \mathrm{C}$} & 1 000, 2 000, $5000 \mathrm{~kg}$ & 79 & 5 \\
\hline & $100,200,500 \mathrm{~kg}$ & 33 & 4 \\
\hline & $10,20,50 \mathrm{~kg}$ & 12 & 3 \\
\hline & $1,2,5 \mathrm{~kg}$ & 6 & 2 \\
\hline & $100,200,500 \mathrm{~g}$ & 3 & 1 \\
\hline & $10,20,50 \mathrm{~g}$ & 1 & 1 \\
\hline & $<10 \mathrm{~g}$ & 1 & 0.5 \\
\hline \multirow{6}{*}{ $\pm 5^{\circ} \mathrm{C}$} & $1000,2000,5000 \mathrm{~kg}$ & 24 & 1 \\
\hline & $100,200,500 \mathrm{~kg}$ & 10 & 1 \\
\hline & $10,20,50 \mathrm{~kg}$ & 4 & 1 \\
\hline & $1,2,5 \mathrm{~kg}$ & 3 & 1 \\
\hline & $100,200,500 \mathrm{~g}$ & 2 & 1 \\
\hline & $<100 \mathrm{~g}$ & 1 & 1 \\
\hline $\pm 2^{\circ} \mathrm{C}$ & $<100 \mathrm{~g}$ to $5000 \mathrm{~kg}$ & 1 & 0.5 \\
\hline $\pm 0.5^{\circ} \mathrm{C}$ & $<100 \mathrm{~g}$ to $5000 \mathrm{~kg}$ & 0.5 & 0.5 \\
\hline
\end{tabular}

${ }^{\mathrm{a}} \Delta \mathrm{T}=$ Initial difference between weight temperature and laboratory temperature.

${ }^{5}$ Consider equivalent ASTM Classes for equilibration times. 
2.5.1.5 Conduct preliminary measurements to obtain an approximate value for the difference between the standard and the unknown, to identify where in the weighing instrument range the readings occur, to determine if tare weights are required, to determine the sensitivity weight to be used, and to determine the time interval required for the weighing instrument indication to stabilize. See NISTIR 6969, SOP 34 for specific instructions on evaluation of the need for and selection of tare weights and sensitivity weights.

Tare weights are rarely needed for mass standards that are within applicable tolerances. When unequal nominal weights are compared, tare weights are often required. When tare weights are required, carry tare weights, $t_{s}$ and $t_{x}$, with the standard and the unknown, $S$ and $X$, respectively. The tare weights must be calibrated standards with valid uncertainties that are included in the process of determining mass values and calibration uncertainties. The standard and its tare weight, $S+t_{s}$, should be "nearly the same mass" as the unknown with its tare weight, $X+t_{x}$. "Nearly the same mass" depends upon the balance used (See SOP 34, Table 1).

A sensitivity weight must be used on equal-arm balances, single-pan mechanical, and is usually used on electronic balances, to ensure that the measured differences between the standard(s) and unknown test items have valid accuracy and traceability (See SOP 34, Table 2) (e.g., the optical/digital scale is calibrated each time the procedure is performed through the use of a sensitivity weight).

If the sensitivity of the balance has been analyzed and is periodically evaluated and found to introduce negligible errors or uncertainties according to SOP 34 and measurement requirements, the equations in Section 3 must be modified to eliminate the sensitivity factor to avoid “division by zero" errors in the calculations.

If a sensitivity weight will be used, select one that meets the criteria in SOP 34.

2.5.1.6 Determine whether optional sequence A or B will be used. Optional sequence A uses the standard on the balance for the first observation and the unknown on the balance for the second and third observations; this is often called the " $S X X$ " sequence. Optional sequence B starts with the unknown on the balance first and with the standard on the balance for the second and third observations; this is often called the "XSS" sequence. 
2.5.1.7 Adjust the single pan balance or the combination balance so the first two readings of the single substitution fall in the first quarter of the optical scale or digital indications. The zero adjustment and tare adjustment may be used. Small weights may be placed on the balance pan to reach the desired reading range. These weights remain on the pan throughout the single substitution. Once the balance has been adjusted to the desired position, neither the balance dials, the zero and tare adjustments, nor the small weights placed on the balance pan are to be changed during the measurement.

2.5.1.8 If the balance is equipped with a pan arrestment mechanism, arrest the pan between each observation.

\subsubsection{Measurement Procedure, Optional Sequence A (SXX)}

Table 5. Optional Sequence A.

\begin{tabular}{|c|c|c||}
\hline Measurement No. & Weights on Pan & Observation \\
\hline \hline 1 & $S+t_{s}$ & $O_{1}$ \\
\hline 2 & $X+t_{x}$ & $O_{2}$ \\
\hline 3 & $X+t_{x}+s w$ & $O_{3}$ \\
\hline
\end{tabular}

All observations should be recorded on suitable data sheets, such as those in the appendix. Record the laboratory ambient temperature, barometric pressure, and relative humidity.

2.5.2.1 Observation 1. Place the standard weight(s), $S$, along with $t_{s}$ on the balance pan. If equipped with a pan arrestment mechanism, release the balance pan. When the pan is released, start the stop-watch and record observation $O_{1}$ once the balance indication has stabilized.

2.5.2.2 Observation 2. Remove weight(s) $S$ and $t_{s}$ and replace with test weight $X$ and its tare weight, $t_{x}$. Release the pan, time the interval, and record observation $\mathrm{O}_{2}$.

2.5.2.3 Observation 3. Add the sensitivity weight, sw, to the weights of observation 2. Release the pan, time the interval, and record observation $\mathrm{O}_{3}$.

2.5.2.4 If repeated single substitutions are performed, the values between successive trials should not differ from one another by more than \pm 2 sd of the balance. If this difference is exceeded, reject the data and take a new series of measurements that agree.

\subsubsection{Measurement Procedure, Optional Sequence B (XSS)}

Measurements for Option B are made as described in Option A except that $X, S, t_{x}$, and $t_{s}$ are interchanged. 
Table 6. Optional Sequence B.

\begin{tabular}{||c|c|c||}
\hline Measurement No. & Weights on Pan & Observation \\
\hline \hline 1 & $X+t_{x}$ & $O_{1}$ \\
\hline 2 & $S+t_{s}$ & $O_{2}$ \\
\hline 3 & $S+t_{s}+s w$ & $O_{3}$ \\
\hline
\end{tabular}

3 Calculations

3.1 If no air buoyancy correction is performed, calculate the conventional mass correction, $C_{x}$, for the test weight as follows, according to the optional sequence used. Incorporate an uncorrected systematic uncertainty for the magnitude of the buoyancy correction in the uncertainty calculations according to SOP 2 if using this equation. In each case, the conventional mass corrections for the standard weight(s), $C_{s}$, the conventional mass of the tare weights, $C M_{t s}$ and $C M_{t x}$ and the conventional mass of the sensitivity weight, $C M_{s w}$, are included. The symbols $N_{s}$ and $N_{X}$ refer to the nominal values of $S$ and $X$, respectively. If nominal weights are equal and no tare weights are used, values for nominal values and tare weights may be entered as zero.

\subsubsection{Optional Sequence A (SXX)}

$$
C_{x}=C_{s}+C M_{t_{s}}-C M_{t_{x}}+\left(O_{2}-O_{1}\right)\left[\frac{C M_{s w}}{\left(O_{3}-O_{2}\right)}\right]+N_{s}-N_{x}
$$

\subsubsection{Optional Sequence B (XSS)}

$$
C_{x}=C_{s}+C M_{t_{s}}-C M_{t_{x}}+\left(O_{1}-O_{2}\right)\left[\frac{C M_{s w}}{\left(O_{3}-O_{2}\right)}\right]+N_{s}-N_{x}
$$

\subsection{Mass Calculation with Air Buoyancy Correction}

3.2.1 Calculate the air density, $\rho_{a}$, as described in the Appendix to SOP No. 2, Option B.

3.2.2 Calculate the mass of the test weight, $M_{x}$, and its mass correction $C_{x}$ using the mass of the standard weight(s), the tare weights and the sensitivity weights according to the optional sequence used. 


\subsubsection{Optional Sequence A $(S X X)$}

$$
=\frac{M_{S}\left(1-\frac{\rho_{a}}{\rho_{S}}\right)+M_{t_{s}}\left(1-\frac{\rho_{a}}{\rho_{t_{S}}}\right)-M_{t_{X}}\left(1-\frac{\rho_{a}}{\rho_{t_{X}}}\right)+\left(O_{2}-O_{1}\right)\left[\frac{M_{s w}\left(1-\frac{\rho_{a}}{\rho_{s w}}\right)}{\left(O_{3}-O_{2}\right)}\right]}{\left(1-\frac{\rho_{a}}{\rho_{X}}\right)}
$$

\subsubsection{Optional Sequence B (XSS)}

$$
=\frac{M_{S}\left(1-\frac{\rho_{a}}{\rho_{S}}\right)+M_{t_{S}}\left(1-\frac{\rho_{a}}{\rho_{t_{S}}}\right)-M_{t_{X}}\left(1-\frac{\rho_{a}}{\rho_{t_{X}}}\right)+\left(O_{1}-O_{2}\right)\left[\frac{M_{s w}\left(1-\frac{\rho_{a}}{\rho_{s w}}\right)}{\left(O_{3}-O_{2}\right)}\right]}{\left(1-\frac{\rho_{a}}{\rho_{X}}\right)}
$$

3.2.3 Calculate the mass correction $C_{x}$, as follows:

$$
C_{x}=M_{x}-N_{x}
$$

where $N_{x}$ is the nominal value for $X$.

3.2.4 Calculate the conventional mass ${ }^{6}$ of $X, C M_{x}$. It is recommended that the conventional mass and conventional mass correction be reported. Calculate the conventional mass correction using Eqn. 5 and be sure to designate differences between mass and conventional mass on the certificate.

$$
C M_{x}=\frac{M_{x}\left(1-\frac{\rho_{\mathrm{n}}}{\rho_{\mathrm{x}}}\right)}{\left(1-\frac{\rho_{\mathrm{n}}}{8.0}\right)}
$$

\footnotetext{
${ }^{6}$ Conventional Mass: "The conventional value of the result of weighing a body in air is equal to the mass of a standard, of conventionally chosen density, at a conventionally chosen temperature, which balances this body at this reference temperature in air of conventionally chosen density." The conventions are: reference density $8.0 \mathrm{~g} / \mathrm{cm}^{3}$; reference temperature $20^{\circ} \mathrm{C}$; normal air density $0.0012 \mathrm{~g} / \mathrm{cm}^{3}$. Conventional mass was formerly called "Apparent Mass versus $8.0 \mathrm{~g} / \mathrm{cm}^{3 ”}$ in the United States. See OIML D28 (2004).
} 
3.2.5 If requested, the apparent mass versus the reference density of brass may be calculated. This value should only be provided when requested by the customer for use when calibrating mechanical balances that have been adjusted to this reference density. (This is rare).

Apparent mass versus brass:

$$
A M_{x \text { vs brass }}=\frac{M_{x}\left(1-\frac{\rho_{n}}{\rho_{x}}\right)}{\left(1-\frac{\rho_{n}}{8.3909}\right)}
$$

4 Measurement Assurance

4.1 Duplicate the process with a suitable check standard (See GLP 1, SOP 9, and SOP 30).

4.2 Plot the check standard value on the control chart and verify that it is within established limits.

All values must be entered in the control chart, unless a mistake (i.e., typographical error) is identified and corrected, to ensure the variability obtained for the process is not unduly reduced over time. The observed value of the check standard is compared to the accepted mean value of the check standard and divided by the standard deviation for the check standard observations over time.

A t-test may be incorporated to check the observed value of the check standard against the accepted value using the following equation and a $95 \%$ confidence level. The t-statistic is calculated for stability analysis. This equation monitors stability over time, but should not be used to assess for bias. A calculated t-value less than two is within the warning limits of the process. A calculated t-value between two and three represents a value between the warning limits and control/action limits. A calculated t-value exceeding three represents a value outside of the control/action limits and suitable action must be taken. Calculated values of the t-statistic may also be monitored over time to determine the presence of drift.

$$
t=\frac{\left(S_{c}-\overline{S_{c}}\right)}{S_{p}}
$$

4.3 Check standard measurement results obtained over time are used to calculate the standard deviation of the measurement process, $s_{p}$.

4.4 The mean value of the check standard over time is also compared to an appropriate reference value of the check standard with respect to their applicable expanded uncertainties to evaluate bias and drift over time. The mean value over time may be used to monitor drift in the standard or check standard. Excessive drift or bias must be investigated and followed with suitable corrective action. See SOP 9, Section 4.2 for assessment methodology. 
4.5 Where SOP 9 is followed, and check standards are used for 2 to 3 nominal values per balance, more frequent calibration intervals may be needed to monitor the working standards and the larger standard deviation of the nominal values bracketing the nominal value should be used. If check standards were already checked on a given day and found to be in control, additional evaluations may be conducted, but are not required.

The limits of expanded uncertainty, $U$, include estimates of the standard uncertainty of the mass standards used, $u_{s}$, estimates of the standard deviation of the measurement process, $s_{p}$, and estimates of the effect of other components associated with this procedure, $u_{o}$. These estimates should be combined using the root-sum-squared method (RSS), and the expanded uncertainty, $U$, reported with a coverage factor of two $(k=2)$, to give us an approximate $95 \%$ level of confidence. See SOP 29 for the complete standard operating procedure for calculating the uncertainty.

5.1 The expanded uncertainty for the standard, $U$, is obtained from the calibration certificate. The combined standard uncertainty, $u_{c}$, is used and not the expanded uncertainty, $U$, therefore the reported uncertainty for the standard will usually be divided by the coverage factor $k$. Where the coverage factor or confidence interval is not given, the laboratory should either contact the calibration provider to obtain the correct divisor or use a value of $k=2$, assuming that the expanded uncertainty was reported with an approximate 95 \% confidence interval (95.45 \%).

5.2 The value for $s_{p}$ is obtained from the control chart data for check standards using single substitution measurements. (See SOP No. 9.) Where the standard deviation of the measurement process from the control chart is less than the resolution of the balance being used, the laboratory may use the value of the balance division or may use the larger of the standard deviation of the process or the following estimate for repeatability is used to represent the standard deviation of the process:

$$
s_{p}=\frac{d}{\sqrt{3}} \approx 0.6 d
$$

5.3 Include an uncorrected systematic standard uncertainty if no buoyancy correction was performed. Calculate the magnitude of the air buoyancy correction per SOP 2 and use a rectangular distribution. The uncertainty associated with air density and its associated factors may be calculated using the formula options provided in SOP 4 or 5 .

5.4 Other standard uncertainties that may be included at this calibration level include standard uncertainties associated with the density of the standards used, and may include any noted bias that has been determined through analysis of control charts and round robin data. See SOP 2, 4, and 29 for additional details.

5.5 Example components to be considered for an uncertainty budget table are shown in the following table. 
Table 7. Example uncertainty budget table.

\begin{tabular}{||l|c|c|c||}
\hline \multicolumn{1}{|c|}{ Uncertainty Component Description } & Symbol & Source & Typical Distribution \\
\hline \hline Uncertainty of the standard mass(es) (5.1) & $u_{s}$ & Calibration certificate & $\begin{array}{c}\text { Expanded uncertainty } \\
\text { divided by coverage } \\
\text { factor }\end{array}$ \\
\hline $\begin{array}{l}\text { Accepted standard deviation of the } \\
\text { process (5.2) }\end{array}$ & $s_{p}$ & $\begin{array}{c}\text { Control chart, standard } \\
\text { deviation chart } \\
\text { OR estimates when } s_{p} \text { is } \\
\text { smaller than balance } \\
\text { division }\end{array}$ & Normal \\
\hline $\begin{array}{l}\text { Uncertainty of the air buoyancy } \\
\text { correction (5.3) }\end{array}$ & $u_{b}$ & $\begin{array}{c}\text { SOP 2 or OIML R111 } \\
\text { Or Options as given in } \\
\text { SOP 4 }\end{array}$ & Rectangular \\
\hline Uncertainty associated with bias (5.4) & $u_{d}$ & $\begin{array}{c}\text { Control chart, proficiency } \\
\text { tests }\end{array}$ & See SOP 29 \\
\hline \hline
\end{tabular}

5.6 Draft a suitable uncertainty statement for the certificate. For example:

The uncertainty reported is the root sum square of the standard uncertainty of the standard, the standard deviation of the process, and the uncertainty associated with the buoyancy corrections, multiplied by a coverage factor of $2(k=2)$ for an approximate 95 percent confidence interval. Factors not considered in the evaluation: magnetism (weights are considered to meet magnetism specifications unless measurement aberrations are noted), balance eccentricity and linearity (these factors are considered as a part of the measurement process when obtaining the standard deviation of the process when using a check standard with adequate degrees of freedom.

NOTE: Where inadequate degrees of freedom are available, $k$, is determined using the appropriate degrees of freedom and the $95.45 \%$ column in the table from Appendix A of NISTIR 6969, SOP 29.

6 Certificate

6.1 Report results as described in SOP No. 1, Preparation of Calibration Certificates. Report the mass (if appropriate and requested by the customer), conventional mass, environmental conditions during the calibrations, mass density used (reported, measured, or assumed), and calculated expanded uncertainties with coverage factor(s).

6.1 Conformity assessments.

Evaluate compliance to applicable tolerances as needed or required by the customer or by legal metrology requirements. Decision criteria for uncertainty and tolerance evaluations include two components: 1) the expanded uncertainty, $\mathrm{U}$, must be $<1 / 3$ of the applicable tolerances published in ASTM E617 and OIML R111 documentary standards and 2) the absolute value of the conventional mass 
correction value plus the expanded uncertainty must be less than the applicable tolerance to confidently state that mass standards are in or out of tolerance. Compliance assessments must note the applicable documentary standard and which portions of the standard were or were not evaluated. 


\section{Appendix A}

\section{Single Substitution Data Sheet \\ (Optional Sequence A, SXX)}

Laboratory data and conditions:

\begin{tabular}{|r|r|r|l|l||}
\hline Operator & & Temperature & & After \\
\hline Date & Pressure & & \\
\hline Balance & Road & Delative Humidity & & \\
\hline $\begin{array}{r}\text { Standard deviation of the process, } \\
\text { from control chart, } s_{p}\end{array}$ & & Degrees Freedom & & \\
\hline
\end{tabular}

Mass standard(s) data:

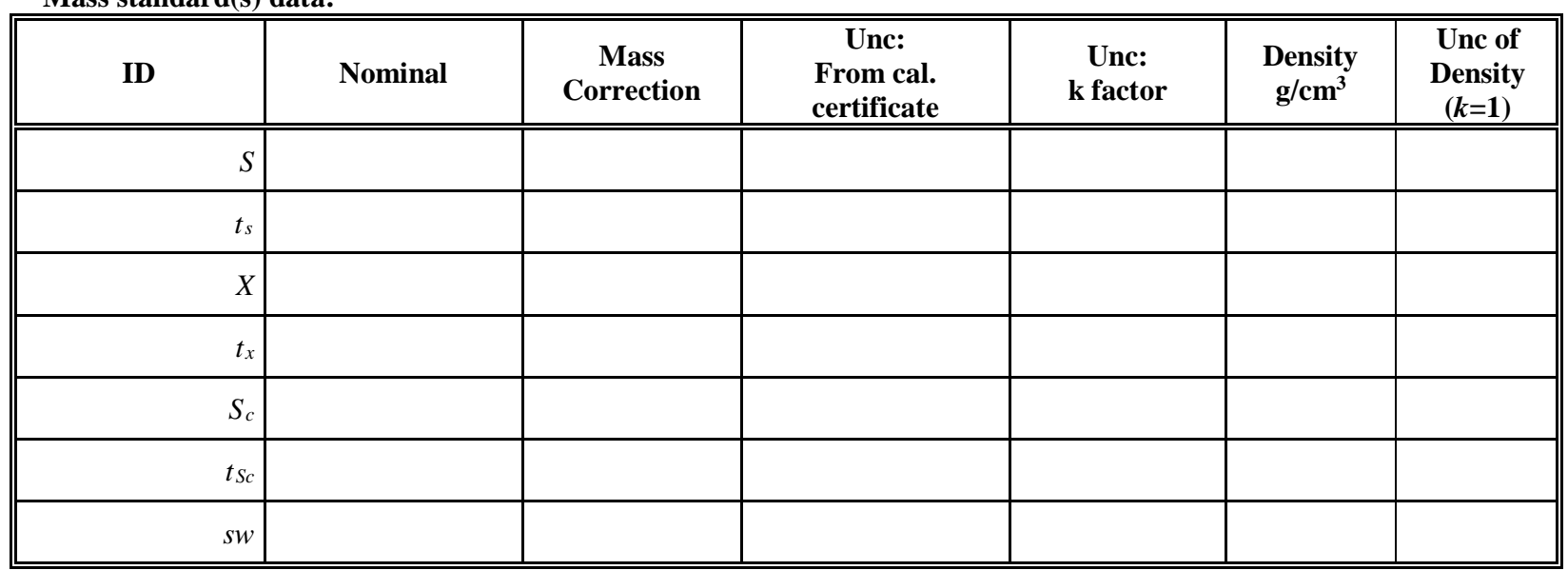

Mass Correction = True Mass if using buoyancy correction. Mass Correction = Conventional Mass if NOT using buoyancy correction. Density is used only with buoyancy corrections.

Observations:

\begin{tabular}{|c|c|c|}
\hline Measurement \# & Weights & Balance Observations, Units \\
\hline \multicolumn{3}{|l|}{ Time: } \\
\hline $1\left(O_{1}\right)$ & $S+t_{s}$ & \\
\hline $2\left(\mathrm{O}_{2}\right)$ & $X+t_{x}$ & \\
\hline $3\left(\mathrm{O}_{3}\right)$ & $X+t_{x}+s w$ & \\
\hline Time: & & \\
\hline
\end{tabular}

Measurement Assurance (See Section 4.5):

\begin{tabular}{|c|c|c|}
\hline Measurement \# & Weights & Balance Observations, Units \\
\hline \multicolumn{3}{|l|}{ Time: } \\
\hline $1\left(O_{1}\right)$ & $S+t_{s}$ & \\
\hline $2\left(\mathrm{O}_{2}\right)$ & $S_{c}+t_{S c}$ & \\
\hline $3\left(\mathrm{O}_{3}\right)$ & $S_{c}+t s_{c}+s w$ & \\
\hline \multicolumn{3}{|l|}{ Time: } \\
\hline Check Standard in Control? & Y Yes___ No & \\
\hline
\end{tabular}




\section{Appendix B}

\section{Single Substitution Data Sheet \\ (Optional Sequence B, XSS)}

Laboratory data and conditions:

\begin{tabular}{|r|r|r|r||}
\hline \hline Operator & & Before & After \\
\hline Date & Temperature & & \\
\hline Balance & Pressure & & \\
\hline Load & Relative Humidity & & \\
\hline $\begin{array}{r}\text { Standard deviation of the process, } \\
\text { from control chart, } s_{p}\end{array}$ & Degrees of Freedom & & \\
\hline
\end{tabular}

Mass standard(s) data:

\begin{tabular}{|c|c|c|c|c|c|c|}
\hline ID & Nominal & $\begin{array}{c}\text { Mass } \\
\text { Correction }\end{array}$ & $\begin{array}{l}\text { Unc: } \\
\text { From cal. } \\
\text { certificate }\end{array}$ & $\begin{array}{c}\text { Unc: } \\
\text { k factor }\end{array}$ & $\begin{array}{c}\text { Density } \\
\mathrm{g} / \mathrm{cm}^{3}\end{array}$ & $\begin{array}{c}\text { Unc of } \\
\text { Density } \\
(k=1)\end{array}$ \\
\hline \multicolumn{7}{|c|}{$S$} \\
\hline \multicolumn{7}{|c|}{$t_{s}$} \\
\hline \multicolumn{7}{|c|}{$X$} \\
\hline \multicolumn{7}{|c|}{$t_{x}$} \\
\hline \multicolumn{7}{|c|}{$S_{c}$} \\
\hline \multicolumn{7}{|c|}{$t_{S C}$} \\
\hline & & & & & & \\
\hline
\end{tabular}

Mass Correction = True Mass if using buoyancy correction. Mass Correction = Conventional Mass if NOT using buoyancy correction. Density is used only with buoyancy corrections.

\section{Observations:}

\begin{tabular}{|c|c|c|}
\hline Measurement \# & Weights & Balance Observations, Units \\
\hline \multicolumn{3}{|l|}{ Time: } \\
\hline $1\left(O_{1}\right)$ & $X+t_{x}$ & \\
\hline $2\left(\mathrm{O}_{2}\right)$ & $S+t_{S}$ & \\
\hline $3\left(\mathrm{O}_{3}\right)$ & $s+t_{S}+s w$ & \\
\hline Time: & & \\
\hline
\end{tabular}

Measurement Assurance (See Section 4.5):

\begin{tabular}{|c|c|c|}
\hline Measurement \# & Weights & Balance Observations, Units \\
\hline \multicolumn{3}{|l|}{ Time: } \\
\hline $1\left(O_{1}\right)$ & $S+t_{s}$ & \\
\hline $2\left(\mathrm{O}_{2}\right)$ & $S_{c}+t S_{c}$ & \\
\hline $3\left(\mathrm{O}_{3}\right)$ & $S_{c}+t_{S c}+s w$ & \\
\hline \multicolumn{3}{|l|}{ Time: } \\
\hline Check Standard in Control? & Yes___ No & \\
\hline
\end{tabular}


This page is intentionally blank. 


\title{
SOP 8
}

\author{
Recommended Standard Operating Procedure \\ for \\ Medium Accuracy Calibration of Mass Standards \\ by \\ Modified Substitution
}

1 Introduction

1.1 This SOP describes procedures to be followed for calibration and conformity assessment of mass standards for particular classes of documentary standards (e.g., NIST Class F, ASTM ${ }^{1}$ Class 5, 6, 7 or OIML ${ }^{2}$ Classes $\mathrm{M}_{1}, \mathrm{M}_{2}$, and $\mathrm{M}_{3}$ ) where the uncertainty is usually much smaller than the tolerance application provided the laboratory maintains standards and balances used for higher precision work. This procedure permits the metrologist to report that the weights being calibrated were compared against a reference standard with the results reported on the laboratory calibration certificate. The comparison is important because the built-in weights of a balance do not represent laboratory standards or provide metrological traceability unless they have been formally calibrated. If a State law or other regulation requires that field weights be compared against the State (or reference) standards, this procedure can be used to fulfill this requirement. It is suitable for calibration when moderate accuracy is required, and limits, but does not eliminate errors due to drift. The procedure incorporates measurement assurance steps to ensure the validity of the standards and the measurement process through the use of check standards. Decision criteria for uncertainty and tolerance evaluations include two components: 1) the expanded uncertainty, U, must be $<1 / 3$ of the applicable tolerances published in ASTM E617, OIML R111, and/or NIST Handbook 105-1 documentary standards and 2) the absolute value of the conventional mass correction value plus the expanded uncertainty must be less than the applicable tolerance to confidently state that mass standards are in or out of tolerance. If uncertainty to tolerance ratios are greater than required, SOP 7 (single substitution) or SOP 4 (double substitution) procedures are preferred. SOP 8 may be used for any nominal values provided adequate standards and equipment are available. Detailed measurement ranges, standards, equipment, and uncertainties for this SOP are generally compiled in a separate document in the laboratory.

Note: When using SOP 8, the laboratory often uses working standards that are equivalent or only slightly better than customer's weights. If this is the case, the working standards must have a higher level of calibration than the weights being calibrated. Therefore, the laboratory will need standards, balances, procedures, and uncertainties better than the customer weights and this procedure to calibrate the laboratory working standards.

${ }^{1}$ ASTM International (formerly the American Society for Testing and Materials) publishes the E617 standard for mass specifications and tolerances.

${ }^{2}$ OIML is the International Organization for Legal Metrology. Weight classes are published in OIML R111, which is freely available at http://www.oiml.org.

SOP 8 - 2019

Page 1 of 15 


\section{$1.2 \quad$ Prerequisites}

1.2.1 Valid calibration certificates with appropriate values and uncertainties must be available for all the standards used in the calibration. All standards must have demonstrated metrological traceability to the international system of units (SI), which may be to the SI, through a National Metrology Institute such as NIST.

1.2.2 Standards must be evaluated to ensure that standard uncertainties for the intended level of calibration are sufficiently small. Reference standards should not be used to routinely calibrate customer standards using this procedure.

1.2.3 Verify that the balance that is used is in good operating condition with sufficiently small process standard deviation as verified by a valid control chart or preliminary experiments to ascertain the performance quality when a new balance is put into service.

1.2.4 Verify that the operator is experienced in precision weighing techniques and has had specific training in SOP 7, SOP 8, SOP 29, and GMP 10.

1.2.5 Laboratory facilities must comply with the following minimum conditions to meet the expected uncertainty possible with this procedure and to comply with the balance manufacturer's operating conditions specified for the balance. The laboratory should have demonstrated environmental controls for a minimum of 24 hours before a calibration.

Table 1. Environmental conditions.

\begin{tabular}{|c|c|c||}
\hline \hline Echelon $^{3}$ & Temperature Requirements During a Calibration & $\begin{array}{c}\text { Relative Humidity } \\
\text { (\%) }\end{array}$ \\
\hline \hline III & $\begin{array}{c}\text { Lower and upper limits: } 18^{\circ} \mathrm{C} \text { to } 27^{\circ} \mathrm{C} \\
\text { Maximum changes: } \pm 5^{\circ} \mathrm{C} / 12 \mathrm{~h} \text { and } \pm 3^{\circ} \mathrm{C} / \mathrm{h}\end{array}$ & 40 to $60 \pm 20 / 4 \mathrm{~h}$ \\
\hline \hline
\end{tabular}

1.2.6 As a practical guideline, a waiting time of 24 hours is recommended for weights calibrated with this procedure to become equilibrated in the laboratory. If weights are extremely hot or cold additional equilibration may be needed to address problems with condensation and frozen surfaces. Weights must be completely dry prior to calibration. Minimum equilibration times are provided in the following table.

\footnotetext{
${ }^{3}$ Echelon III corresponds to weights of Classes OIML $\mathrm{M}_{1}, \mathrm{M}_{2}$, and $\mathrm{M}_{3}$, NIST Class F or ASTM Classes 5, 6 and 7. Uncertainty values must be fully assessed if this procedure is attempted for any higher-class weights. This procedure does not provide adequate redundancy for OIML Classes $E_{1}$ or $E_{2}$, ASTM Classes 000, 00, 0, or 1 and SOP 5 or SOP 28 must be used.

SOP $8-2019$

Page 2 of 15
} 
Table 2. Stabilization time.

\begin{tabular}{|c|c||}
\hline \hline Temperature Range for the Artifact & $\begin{array}{c}\text { Minimum } \\
\text { Equilibration Time }\end{array}$ \\
\hline \hline Inside upper or lower limits $>18^{\circ} \mathrm{C}$ and $<27^{\circ} \mathrm{C}$ & None \\
\hline Outside of upper or lower limits $<18^{\circ} \mathrm{C}$ or $>27^{\circ} \mathrm{C}$ & 24 hours/overnight \\
\hline
\end{tabular}

$2 \quad$ Methodology

2.1 Scope, Precision, Accuracy

This method is applicable to all lower echelon mass calibration provided that the uncertainty requirements can be met. The achievable precision using this procedure is appropriate, provided the expanded uncertainty of the measurement is no more than one-third of the permissible tolerance of the calibrated mass standard. The accuracy achievable with this procedure depends on the accuracy of the calibration of the working standards and the precision of the intercomparison.

\subsection{Summary}

The mass to be calibrated is compared with a calibrated working standard by a modified substitution procedure. The comparison may be made using a single-pan, an equal-arm, or a fully-electronic balance. The reference standard is placed on the balance to obtain a convenient reference point and a sensitivity test is conducted. The error (departure from nominal value) of the weight calibrated is determined by comparing its reading to the reading obtained for the reference standard. A weight is within tolerance when the absolute value of its error plus its uncertainty does not exceed the tolerance established for the class of weight.

\subsection{Apparatus/Equipment}

2.3.1 Single-pan (Option A and $A_{1}$ ), full-electronic balance (Option B), or equalarm balance (Option C) with sufficient capacity for the load calibrated and with resolution equal to or less than one-tenth of the applicable tolerance of the standards to be calibrated.

2.3.2 Calibrated working standards, of nominally equal mass to the unknown mass standards being calibrated. Mass standards must have an expanded uncertainty less than one-tenth of the tolerance calibrated.

2.3.3 Calibrated sensitivity weights, and tare weights if needed, with current calibration certificates selected according to SOP 34.

2.3.4 Uncalibrated counterweights, $T$, of approximately the same mass as the standard weights (for option C).

2.3.5 Calibrated environmental equipment to monitor laboratory conditions and to perform buoyancy corrections if needed. See SOP 2 for appropriate accuracy limits. 


\subsection{Procedure - Option A, Use of Single-Pan Mechanical Balance}

2.4.1 Select a reference standard of the same nominal value as the weight being calibrated. Place the standard on the balance pan. Adjust the optical scale reading (See GMP No. 4) to approximately midscale using uncalibrated tare weights and the balance's coarse and fine Zero controls. This setting must not be altered during a measurement sequence. Record the reading as $O_{1}$.

2.4.2 Add a sensitivity weight equal to approximately one-quarter full scale reading and record reading as $\mathrm{O}_{2}$.

2.4.3 Calculate the value of a scale division using the equation in 3.2. If it is within $\pm 2 \%$ of nominal value (usual case), or another value $<2 \%$ of nominal stated by the laboratory, the nominal value of a division can be used for tolerance testing.

2.4.4 Remove the sensitivity weight and adjust the optical scale to account for the corrected value of the standard used.

Example: Suppose that the nominal range of the optical scale is $100 \mathrm{mg}$ and that the reference standard has a correction of $-2.5 \mathrm{mg}$. The optical scale is adjusted to read $47.5 \mathrm{mg}$ when the standard is on the pan. Under this condition, the reading $50.0 \mathrm{mg}$ represents the nominal mass of the reference standard. The direction and magnitude of the deviation from $50.0 \mathrm{mg}$ indicates the actual deviation of the calibrated weight from nominal.

\subsubsection{Remove the Standard.}

2.4.6 Place the weight to be calibrated on the balance pan, read the optical scale and record the reading as $X_{n}$. The error in the weight is the amount by which the indication deviates from the mid-scale reading. If the weight indication is more than the mid-scale value, the weight is heavy by the indicated difference; if the indication is less than the mid-scale value, the weight is light. E.g., A scale indication of $30.1 \mathrm{mg}$ will indicate that the calibrated weight is $19.9 \mathrm{mg}$ lighter than nominal.

2.4.7 After several weights have been calibrated (no more than 10 unknown weights may be calibrated without rechecking the standard or check standard), put the standard on the balance pan and record the reading. The difference between this indication and the previous one for the standard indicates a balance drift. This drift will normally be very small. If the drift exceeds $5 \%$ to $10 \%$ (limits determined by the laboratory) of the tolerance applicable to the weights being calibrated or affects a measurement result to the extent that a weight may be out of tolerance, the measurement should be repeated and more frequent checks of the standard should be made or a more appropriate procedure should be used. The average drift may be monitored over time to be included as a component of the uncertainty; otherwise $5 \%$ to $10 \%$ of the applicable tolerance, as determined by the 
laboratory, as a rectangular distribution may be included in the uncertainty calculations.

2.4.8 Readjust the optical scale at any time that a significant difference is observed when rechecking a standard.

2.4.9 Calculate the mass correction for the unknown weights using the appropriate equation in Section 3.

\subsection{Procedure - Option $A_{1}$, Use of Single-Pan Mechanical Balance}

2.5.1 Select a reference standard of the same nominal value as the weight being calibrated. Place the standard on the balance pan. Adjust the optical scale reading (See GMP No. 4) to midscale using uncalibrated tare weights and the balance's coarse and fine Zero controls. This setting must not be altered during a measurement sequence. Record the reading as $O_{1}$.

2.5.2 Add a sensitivity weight equal to approximately one-quarter full scale reading and record reading as $\mathrm{O}_{2}$.

2.5.3 Calculate the value of a scale division using the equation in 3.2. If the sensitivity is within $\pm 2 \%$ of nominal value (usual case) of the scale division), or another value $<2 \%$ of nominal stated by the laboratory, the nominal value of a division may be used.

2.5.4 Remove the sensitivity weight and re-adjust the optical scale to obtain a midscale indication, if the indication has changed from that set in 2.5.1.

2.5.5 Remove the Standard.

2.5.6 Place the weight to be calibrated on the balance pan, read the optical scale, and record the indication as $X_{n}$. Using Eqn. (1) calculate the mass correction of the weight. The mass error is the deviation from the nominal value.

\subsubsection{Monitor drift.}

After several weights have been calibrated (no more than 10 unknown weights may be calibrated without rechecking the standard or check standard), put the standard on the balance pan and record the reading. The difference between this indication and the previous one for the standard indicates a balance drift. Evaluate and account for drift per Section 2.8.

2.5.8 Readjust the optical scale at any time that a significant difference is observed when rechecking a standard.

2.5.9 Calculate the correction of the unknown using the equation:

$$
C_{x}=C_{s}+\left(X_{n}-O_{1}\right)
$$




\subsection{Procedure - Option B, Use of Full Electronic Balance}

2.6.1 Select a reference standard of the same nominal value as the weight being calibrated. Place the standard on the pan. Zero the balance and record the stable reading as $O_{1}$. A stopwatch may be used to monitor consistent timing of balance stability but is not required.

2.6.2 Add a calibrated sensitivity weight (sw $\geq 2$ times the tolerance but not exceeding $0.5 \%$ of the balance capacity) and record the reading as $\mathrm{O}_{2}$. Verify whether the nominal scale division is within $\pm 2 \%$ of nominal value of the scale division using the equation in 3.2. If so, the nominal value of the scale division may be used. This value may be monitored less frequently than each operation if stability of the sensitivity factor has been demonstrated and documented.

2.6.3 Remove the sensitivity weight and zero the balance, $O_{3}$, so weight differences, $d$, can be read directly from the balance indications.

2.6.4 Remove all weights from the balance pan.

2.6.5 Place the weight to be calibrated on the balance pan. Record the reading as $X_{n}$.

\subsubsection{Monitor drift.}

After several weights have been calibrated ((no more than 10 unknown weights may be calibrated without rechecking the standard and check standard), put the standard on the balance pan and record the reading. The difference between this indication and the previous one for the standard indicates a balance drift. Evaluate and account for drift per Section 2.8

2.6.7 Readjust the zero at any time that a significant difference is observed when rechecking a standard.

2.6.8 Calculate the mass correction for each weight using the equation:

$$
C_{x}=C_{s}+\left(X_{n}-O_{1}\right)=C_{s}+X_{n} \text {, when } O_{1} \text { is zeroed }
$$




\subsection{Procedure - Option C, Use of Equal Arm Balance}

2.7.1 Select a reference standard of the same nominal value as the weight being calibrated. Place the standard on the left balance pan together with small, calibrated weights equal to the correction required for the standard, provided it is light. If needed, add sufficient counterweights to the right pan to obtain a sum of turning points of approximately twice the midscale value. If necessary, number the graduated scale such that adding weights to the left pan will increase the balance reading. Record the sum of the turning points as $O_{1}$.

2.7.2 Add an appropriate calibrated sensitivity weight to the left pan and record the sum of the turning points as $\mathrm{O}_{2}$. Calculate the sensitivity using this equation:

$$
\text { sensitivity }=\frac{C M_{s w}}{\left(O_{2}-O_{1}\right)}
$$

where $C M_{s w}$ is the conventional mass of the sensitivity weight.

\subsubsection{Remove all weights from the left pan.}

2.7.4 Place the weight to be calibrated on the left pan. If the standard used in 2.7.1 was heavy, add small correction weights to the left pan, equivalent to the correction required for the standard. Add small, calibrated tare weights as required to the left or right pan to obtain an approximate balance and record the sum of the turning points as $X_{n}$.

2.7.5 Calculate the mass correction of the calibrated weight(s) as follows.

2.7.5.1 If added tare weights are placed on the left pan $\left(t_{x}\right)$.

$$
C_{x}=\left(X_{n}-O_{1}\right)\left[\frac{C M_{s w}}{\left(O_{2}-O_{1}\right)}\right]-C M_{t_{x}}
$$

2.7.5.2 If added tare weights are placed on the right pan $\left(t_{s}\right)$.

$$
C_{x}=\left(X_{n}-O_{1}\right)\left[\frac{C M_{s w}}{\left(O_{2}-O_{1}\right)}\right]+C M_{t_{s}}
$$

\subsubsection{Monitor drift.}

After several weights have been calibrated (no more than 10 unknown weights may be calibrated without rechecking the standard or check standard), put the standard on the balance pan and record the reading. The difference between this indication and the previous one for the standard indicates a balance drift. Evaluate and account for drift per Section 2.8. 


\subsection{Drift Evaluation}

Drift effects will normally be very small. If the drift exceeds $5 \%$ to $10 \%$ (limits determined by the laboratory, not to exceed $10 \%$ ) of the tolerance applicable to the weights being calibrated, or affects a measurement result to the extent that a weight may be out of tolerance, the measurement should be repeated and more frequent checks of the standard should be made or a more appropriate procedure should be used. The average drift may be monitored over time to be included as a component of the uncertainty; otherwise $5 \%$ to $10 \%$ of the applicable tolerance, as determined by the laboratory, as a rectangular distribution may be included in the uncertainty calculations.

\subsection{Tolerance Evaluation}

Compare the correction plus the expanded uncertainty of the calibrated weight(s) with the tolerance for the class of weights to which it belongs. If the absolute value of the correction plus the expanded uncertainty is numerically smaller than the tolerance, the weight is within tolerance. If the correction is larger than permissible, the weight is outside the tolerance and appropriate action should be taken. It is recommended that weights whose absolute value of the correction exceeds $75 \%$ of the tolerance limit be adjusted closer to the nominal value where possible. Laboratories may set suitable alternative limits, taking care to ensure that the mass value plus (or minus) the uncertainty is within the tolerance limits. 
Table 3. Example of weighing sequence.

\begin{tabular}{||c|c|c||}
\hline \hline Measurement No. & Weights on Pan & Observation \\
\hline \hline 1 & $\mathrm{~S}$ & $O_{1}$ \\
\hline 2 & $S+s w$ & $O_{2}$ \\
\hline 3 & $S$ & $O_{3}$ \\
\hline 4 & $X_{1}$ & $O_{4}$ \\
\hline 5 & $X_{2}$ & $O_{5}$ \\
\hline 6 & $X_{3}$ & $O_{6}$ \\
\hline 7 & $X_{4}$ & $O_{7}$ \\
\hline 8 & $X_{5}$ & $O_{8}$ \\
\hline 9 & $X_{6}$ & $O_{9}$ \\
\hline 10 & $X_{7}$ & $O_{10}$ \\
\hline 11 & $X_{8}$ & $O_{11}$ \\
\hline 12 & $X_{9}$ & $O_{12}$ \\
\hline 13 & $X_{10}$ & $O_{13}$ \\
\hline 14 & $S_{c}$ & $O_{15}$ \\
\hline 15 & $S$ & $O_{15}$ \\
\hline
\end{tabular}

\section{Calculations}

3.1 Air buoyancy corrections are generally not made with the modified substitution, although with the use of spreadsheets and the need to record environmental conditions, there is no reason why the buoyancy correction may not be routinely included (mass densities must be known or assumed). When performed, use SOP 2, Option B.

3.2 Evaluate the sensitivity of the balance:

$$
\text { sensitivity }=\frac{C M_{s w}}{\left(O_{2}-O_{1}\right)}
$$

If the sensitivity error is less than $2 \%$ of the nominal value of a division on the optical scale or the electronic range of operation, proceed with the modified substitution. If the sensitivity error is greater, SOP 7, Single Substitution may be acceptable. This value may be monitored less frequently on electronic balances if stability of the sensitivity factor has been demonstrated and documented. If corrections for sensitivity are not made, an uncorrected systematic error may be incorporated into the uncertainty but the balance sensitivity requires periodic evaluation; the uncertainty value may be calculated as $2 \%$ of the applicable tolerance as the sensitivity is multiplied by the difference between the standard and the unknown $(d)$.

3.3 Calculate the conventional mass correction, $C_{x}$, for the unknown weight as $C_{x}=C M_{i}-N_{x}$, according to the optional sequence used. In each case, the conventional mass corrections for the standard weight(s) are included. 
Table 4. Symbols used.

\begin{tabular}{||c|l||}
\hline \hline Symbol & \multicolumn{1}{c|}{ Description } \\
\hline \hline$C M_{i}$ & Conventional mass of weight $i$ \\
\hline$N_{S}$ & Nominal value of the standard, $S$ \\
\hline$N_{X}$ & Nominal value of the unknown, $X$ \\
\hline$C_{i}$ & Conventional mass correction of weight $i$ \\
\hline$d$ & Measured difference between X and S \\
\hline
\end{tabular}

3.4 Calculate the conventional mass correction of each unknown weight as follows if the correction for the standard IS NOT used in setting a reference point on the balance:

$$
\begin{aligned}
& C_{x}=C_{s}+d \\
& C_{x}=C_{s}+\left(X_{n}-O_{1}\right)
\end{aligned}
$$

Note: If an electronic balance is used and zeroed with the standard on the balance, $O_{1}$ is " 0 " and $d$ becomes the $X_{n}$ balance reading.

3.5 Calculate the conventional mass correction of each unknown weight as follows if the correction for the standard IS used in setting a nominal reference point on the balance:

$$
C_{x}=\left(X_{\text {balance reading }}-N_{\text {nominal reference point }}\right)
$$

Note: In this case the standard and its correction are used to artificially set a perfect nominal reference point for use in comparing the unknown weights.

3.6 If tare weights and unequal nominal values are used, use the following equation for modifying section 3.3:

$$
C_{x}=C_{s}+C M_{t s}-C M_{t x}+\left(X_{n}-O_{1}\right)+N_{s}-N_{x}
$$

\section{Measurement Assurance}

4.1 Duplicate the process with suitable check standards for each nominal load or a designated number of check standards per balance (See GLP 1, SOP 9, and SOP 30).

4.2 Evaluate the value against the expected limits and plot the check standard value on the control chart to monitor changes over time.

All values must be entered in the control chart, even if failing this statistic, unless a mistake (i.e., typographical error) is identified and corrected, to ensure the variability obtained for the process is not unduly reduced over time. The observed value of the check standard is compared to the accepted mean value of the check standard and divided by the standard deviation for the check standard observations over time. 
A t-test may be incorporated to check the observed value of the check standard against the accepted value using the following equation and a $95 \%$ confidence level. The t-statistic is calculated for stability analysis. This equation monitors stability over time, but should not be used to assess for bias. A calculated t-value less than two is within the warning limits of the process. A calculated t-value between two and three represents a value between the warning limits and control/action limits. A calculated t-value exceeding three represents a value outside of the control/action limits and suitable action must be taken. Calculated values of the t-statistic may also be monitored over time to determine the presence of drift.

$$
t=\frac{\left(S_{c}-\overline{S_{c}}\right)}{S_{p}}
$$

4.3 Check standard measurement results obtained over time are used to calculate the standard deviation of the measurement process, $s_{p}$.

4.4 The mean value of the check standard over time is also compared to an appropriate reference value of the check standard with respect to their applicable expanded uncertainties to evaluate bias and drift over time. Excessive drift or bias must be investigated and followed with suitable corrective action. See SOP 9, Section 3.5.3 and Section 8.16 for assessment methodology.

4.5 Where SOP 9 is followed and check standards are used for 2 to 3 nominal values per balance, more frequent calibration intervals may be needed to monitor the working standards and the larger standard deviation of the nominal values bracketing the nominal value should be used. If check standards were already checked on a given day and found to be in control, additional evaluations may be conducted, but are not required.

The limits of expanded uncertainty, $U$, include estimates of the standard uncertainty of the mass standards used, $u_{s}$, estimates of the standard deviation of the measurement process, $s_{p}$, and estimates of the effect of other components associated with this procedure, $u_{o}$. These estimates should be combined using the root-sum-squared method (RSS), and the expanded uncertainty, $U$, reported with a coverage factor of two $(k=2)$, to give an approximate $95 \%$ level of confidence. See SOP 29 for the complete standard operating procedure for calculating the uncertainty.

5.1 The expanded uncertainty for the standard, $U$, is obtained from the calibration certificate. The combined standard uncertainty, $u_{c}$, is used and not the expanded uncertainty, $U$, therefore the reported uncertainty for the standard will usually be divided by the coverage factor $k$. Where the coverage factor or confidence interval is not given, the laboratory should either contact the calibration provider to obtain the correct divisor or use a value of $k=2$, assuming that the expanded uncertainty was reported with an approximate $95 \%$ confidence interval (95.45\%). 
5.2 Standard deviation of the measurement process from control chart performance (See SOP No. 9.) The value for $s_{p}$ is obtained from the control chart data for check standards using modified substitution measurements. Where the standard deviation of the measurement process from the control chart is less than the resolution of the balance being used, the laboratory may round up to the value of the balance division or use the larger of the standard deviation of the process or the following estimate for repeatability is used to represent the standard deviation of the process:

$$
s_{p}=\frac{d}{\sqrt{3}} \approx 0.6 d
$$

5.3 Uncertainty associated with allowable drift. Include the monitored average drift for each balance and procedure as a rectangular distribution, or include a value that is between $5 \%$ and $10 \%$ of the applicable tolerance (limit set by laboratory policy) for the weight, again as a rectangular distribution. Whenever the drift exceeds the limit of drift stated by the laboratory, conduct a root cause analysis to determine the cause; this situation may require fewer weights to be calibrated in the weighing series, service of the balance, better environmental controls, additional training, and practice by the metrologist, or increasing the allowable drift limits (not to exceed $10 \%)$.

5.4 Uncertainty associated with allowable sensitivity error, $u_{\text {se. }}$. This procedure allows for up to $2 \%$ error (stated by the laboratory) in the optical or electronic range of use. This may result in calibration errors up to $2 \%$ of the applicable tolerance. This is potentially another uncorrected systematic error that may be treated as a rectangular distribution. This value may be monitored less frequently than each operation if stability of the sensitivity factor has been demonstrated. Whenever the sensitivity error exceeds the limit stated by the laboratory, conduct a root cause analysis to determine the cause; this situation may require service of the balance, better environmental controls, additional training, and practice by the metrologist, or increasing the allowable sensitivity error limits (not to exceed $2 \%$ ).

5.5 Uncertainty associated with uncorrected air buoyancy. When buoyancy corrections are not made, the resulting uncorrected systematic error may be treated as a rectangular distribution, with the magnitude of the maximum uncorrected buoyancy correction determined using equations provided in SOP 2. The uncertainty associated with air density and its associated factors may be considered negligible for this procedure or may be calculated using the options provided in SOP 4 or 5.

5.6 Uncertainty associated with bias that is observed in the check standards as determined through analysis of the control charts. When bias is observed in the control charts, it must be assessed according to the equations provided in SOP 29 and may be incorporated as an uncorrected systematic error using the equations in SOP 29.

5.7 Example components to be considered for an uncertainty budget table are shown in the following table. 
Table 5. Example uncertainty budget table.

\begin{tabular}{||l|c|c|c||}
\hline \multicolumn{1}{|c|}{ Uncertainty Component Description } & Symbol & Source & $\begin{array}{c}\text { Typical } \\
\text { Distribution }\end{array}$ \\
\hline Uncertainty of the standard mass(es) (5.1) & $u_{s}$ & Calibration certificate & $\begin{array}{c}\text { Normal divided by } \\
\text { coverage factor }\end{array}$ \\
\hline $\begin{array}{l}\text { Accepted standard deviation of the process } \\
\text { (5.2) }\end{array}$ & $s_{p}$ & $\begin{array}{c}\text { Normal or } \\
\text { estimated } \\
\text { deviation chart }\end{array}$ & $\begin{array}{c}\text { rectangular if actual } \\
s_{p} \text { is less than } \\
\text { balance resolution }\end{array}$ \\
\hline Uncertainty of the allowable drift (5.3) & $u_{d r i f t}$ & $\begin{array}{c}5 \% \text { to } 10 \% \text { of the } \\
\text { tolerance (stated by lab) }\end{array}$ & Rectangular \\
\hline $\begin{array}{l}\text { Uncertainty of the allowable sensitivity } \\
\text { error (5.4) }\end{array}$ & $u_{s e}$ & $\begin{array}{c}\text { SOP 8, 2 \% of the } \\
\text { sensitivity times the } \\
\text { applicable tolerance }\end{array}$ & Rectangular \\
\hline $\begin{array}{l}\text { Uncertainty of the maximum magnitude of } \\
\text { the buoyancy correction (5.5) }\end{array}$ & $u_{b}$ & SOP 2 & Rectangular \\
\hline Uncertainty associated with bias (5.6) & $u_{d}$ & $\begin{array}{c}\text { Control chart, proficiency } \\
\text { tests }\end{array}$ & See SOP 29 \\
\hline
\end{tabular}

5.8 Draft a suitable uncertainty statement for the certificate. For example:

The uncertainty reported is the root sum square of the standard uncertainty of the standard, the standard deviation of the process, and the uncertainty associated with the buoyancy corrections, multiplied by a coverage factor of $2(k=2)$ for an approximate 95 percent confidence interval. Factors not considered in the evaluation: magnetism (weights are considered to meet magnetism specifications unless measurement aberrations are noted), balance eccentricity and linearity (these factors are considered as a part of the measurement process when obtaining the standard deviation of the process when using a check standard with adequate degrees of freedom.

NOTE: Where inadequate degrees of freedom are available, $k$, is determined using the appropriate degrees of freedom and the $95.45 \%$ column in the table from Appendix A of NISTIR 6969, SOP 29.

$6 \quad$ Certificate

6.1 Report results as described in SOP No. 1, Preparation of Calibration Certificates. Report the conventional mass, environmental conditions during the calibrations, and calculated expanded uncertainties with coverage factor(s).

6.2 Conformity assessment.

Evaluate compliance to applicable tolerances as needed or required by the customer or by legal metrology requirements. Decision criteria for uncertainty and tolerance evaluations include two components: 1 ) the expanded uncertainty, $U$, must be $<1 / 3$ of the applicable tolerances published in ASTM E617, OIML R111, and/or NIST Handbook 105-1 documentary standards and 2) the absolute value of the 
conventional mass correction value plus the expanded uncertainty must be less than the applicable tolerance to confidently state that mass standards are in or out of tolerance. Compliance assessments must note the applicable documentary standard and which portions of the standard were or were not evaluated. 


\section{Appendix - Modified Substitution Data Sheet}

Laboratory data and conditions:

\begin{tabular}{|r|r|r|l||}
\hline Operator & & Before & After \\
\hline Date & Temperature & & \\
\hline Balance & Pressure & & \\
\hline Load & Relative Humidity & & \\
\hline $\begin{array}{r}\text { Standard deviation of the } \\
\text { process, from control chart, } s_{p}\end{array}$ & Degrees of Freedom & & \\
\hline
\end{tabular}

Mass standard(s) data:

\begin{tabular}{|r|c|c|c|c|c||}
\hline \multicolumn{1}{|r|}{ ID } & Nominal & $\begin{array}{c}\text { Mass } \\
\text { Correction* }\end{array}$ & $\begin{array}{c}\text { Expanded Unc: } \\
\text { from cal. certificate }\end{array}$ & $\begin{array}{c}\text { Unc: } \\
\boldsymbol{k} \text { factor }\end{array}$ & $\begin{array}{c}\text { Density } \\
\mathbf{g} / \mathbf{c m}^{\mathbf{3}}\end{array}$ \\
\hline \hline$S$ & & & & & \\
\hline$t_{S}$ & & & & & \\
\hline$X$ & & TBD & TBD & TBD & \\
\hline$t_{x}$ & & & & \\
\hline$S_{C}$ & & & & & \\
\hline$t_{S C}$ & & & & & \\
\hline$S W$ & & & & & \\
\hline
\end{tabular}

*Mass Correction = True Mass with buoyancy correction. Mass Correction = Conventional Mass with no buoyancy correction.

Observations:

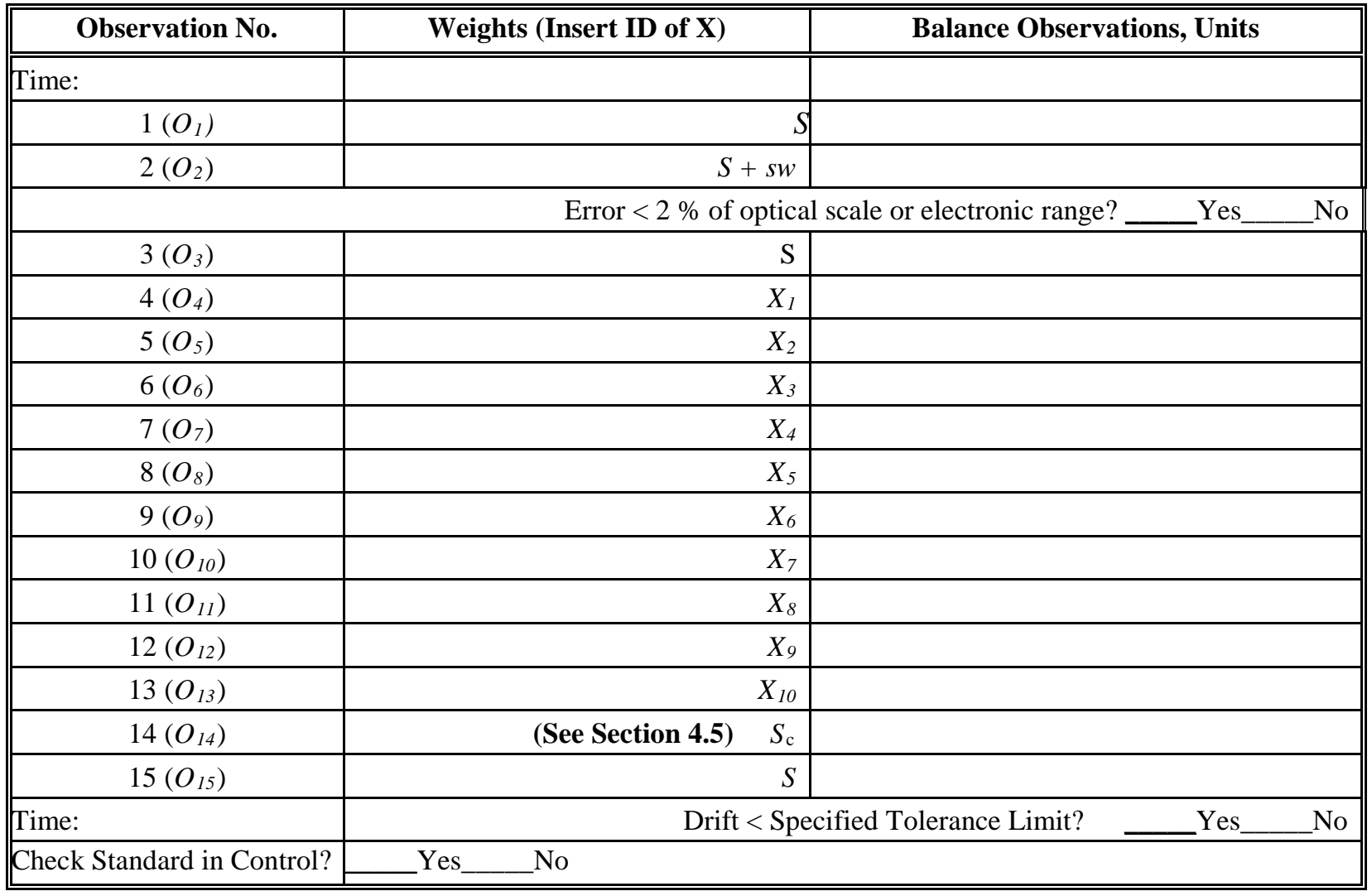

Up to 10 unknown weights may be checked with this procedure if the drift is less than tolerance limits specified by the laboratory. 
This page is intentionally blank. 


\section{SOP 9}

\section{Recommended Standard Operating Procedure \\ for \\ Control Charts for Calibration of Mass Standards}

1 Introduction

1.1 This SOP describes procedures for the development of control charts and their use for demonstrating attainment of statistical control of a mass calibration process. The procedure may be applied to other calibration processes. See also NISTIR 6969, SOP 30 and NISTIR 7383, SOP 17 and 20.

\section{$1.2 \quad$ Prerequisites}

The use of this SOP requires that appropriate apparatus, methodology, and standards are available, and that the laboratory thoroughly understands the basic principles of the measurement process used and has had sufficient experience to perform the necessary operations required for the measurements of concern.

An appropriate check standard (or control standard) is incorporated into the measurement process and weighed at established intervals; the results are plotted on an $\bar{x}(x$-bar) chart. The abscissa $(x)$ represents the sequence of measurements and the ordinate $(y)$ the measured values. A central line is drawn, indicating the mean $(\bar{X})$ of the measured values and control limits are indicated within which the results of measurements are expected to be randomly distributed, based on statistical considerations. The system is in statistical control when the individual values are within the designated statistical limits. The system is out of control if values are present outside established limits for which no reasonable and correctable cause have been determined and corrected, unusual trends are observed, or if the mean exceeds the control limits. The statistical information on which the control limits are based can be used to calculate confidence limits for measurements made while the system is demonstrated to be stable and in a state of statistical control.

3 Procedure

\subsection{Define the Calibration Process}

The monitored system is considered to consist of the balance, the standard operating procedure, the laboratory environment, the check standard or control standard, the operator, and any other sources that contribute to the variance or bias of the measurement data. Any of the above that can show to be constant or negligible variance contributions may be consolidated and monitored by a single control chart. Any that cannot be so considered (for example: different standard, different balance, different SOP) typically require separate control charts. 
The variability of balance precision may be load dependent and must be considered. For many balances, precision is a function of load, and a distinct control chart may be required (according to the SOP) for every load tested. An F-test may be used to assess the standard deviations at varying loads to minimize the number of charts that are required in the laboratory when multiple loads have no significant difference in the standard deviation of the measurement process.

In the case of SOP 5 or 28 (NISTIR 5672) check standards are incorporated into the measurement process and designated charts will be required. Hence, control charts used for measurement assurance and evaluation of measurement uncertainty are generally satisfactory if developed using data from check standards at two or three intervals for each balance appropriately spaced within the range of balance use, or at least with one check standard for each decade. On balances where few nominal values (loads) are tested, a control chart should be established for each load.

In the case of SOP 4, 7, or 8 , where check standards are not required at every nominal value (per this SOP, Table 1), see Section 4 in each of these procedures regarding measurement assurance. When a check standard is not used to monitor each reference or working standard, more frequent monitoring or calibration is essential to assure the accuracy and stability of the mass standards and the laboratory measurement results.

\subsection{Define Type and Number of Check Standards}

3.2.1 A check standard must be stable and is normally comparable to the reference standard or to the typical item submitted for calibration, depending on what is being monitored (standards or process). For lower order calibrations, the check standard should simulate the laboratory's reference or working standards to the extent feasible. It should be calibrated using a better procedure than the one being monitored to ensure that the expanded uncertainty is equal to or better than the uncertainty achievable with the process being monitored. As the uncertainty of the check standard value increases relative to the measurement process, it becomes more difficult to monitor control, drift, and potential bias. All check standards should be cared for in the same way as reference standards to prevent their damage or deterioration. Lower order check standards should be recalibrated at regular intervals according to NISTIR 6969, Good Measurement Practice (GMP) 11 on Setting and Adjusting Calibration Intervals.

3.2.2 Select check standards for mass calibration procedures as shown in in the applicable SOP or as in Table 1 in this SOP. Take care to consider balance load and variability as noted in section 3.1 to ensure that standard deviations of the measurement processes are consistent at different nominal values. Use the next larger standard deviation of the measurement process in uncertainty calculations for intermediate nominal values. When a check standard is not used at each nominal value, additional monitoring of the 
working standards is required and more frequent calibrations may be required.

Table 1. Recommended check standards for typical calibrations.

\begin{tabular}{||l|l|l||}
\hline \multicolumn{1}{|c|}{ Procedure } & \multicolumn{1}{|c|}{ Range of Measurement } & \multicolumn{1}{c|}{ Check Standard(s) } \\
\hline \hline $\begin{array}{l}\text { Echelon III (Class F) } \\
\text { SOP 7, 8 }\end{array}$ & $\begin{array}{l}5000 \mathrm{lb} \text { to } 0.001 \mathrm{lb} \text { or } \\
2268 \mathrm{~kg} \text { to } 1 \mathrm{mg}\end{array}$ & $\begin{array}{l}\text { SOP: Use } 1 \text { chart per nominal value } \\
\text { Optional: 2 to 3 values per balance }\end{array}$ \\
\hline $\begin{array}{l}\text { Echelon II } \\
\text { SOP 3, 4, 6, } 7\end{array}$ & $\begin{array}{l}5000 \mathrm{lb} \text { to } 0.001 \mathrm{lb} \\
\text { and } 1000 \mathrm{~kg} \text { to } 1 \mathrm{mg}\end{array}$ & $\begin{array}{l}\text { SOP: Use } 1 \text { chart per nominal value } \\
\text { Optional: 2 to 3 values per balance }\end{array}$ \\
\hline SOP 5 & Typically, $1 \mathrm{~kg}$ to $1 \mathrm{mg}$ & $\begin{array}{l}\text { Each nominal value incorporates a } \\
\text { check standard }\end{array}$ \\
\hline SOP 28 & Typically, $1 \mathrm{~kg}$ to $1 \mathrm{mg}$ & $\begin{array}{l}\text { Use } 1 \text { check standard per decade } \\
\text { (e.g., } 1 \mathrm{~kg}, 100 \mathrm{~g}, 10 \mathrm{~g}, 1 \mathrm{~g}, 100 \mathrm{mg}, \\
10 \mathrm{mg}, 1 \mathrm{mg})\end{array}$ \\
\hline
\end{tabular}

\subsection{Measure - Perform Initial Measurements to Establish Control Charts}

3.3.1 To establish a new control chart, make at least seven (minimum number) and preferably 12 or more, independent measurements of the check standard using the same standards, equipment, procedure, and under the same conditions that will be used to make routine measurements. No two measurements may be made on the same day. The time of day should be varied as would be typical during routine laboratory operations. This is necessary to estimate the long-term standard deviation to the extent feasible. To make statistically valid decisions or calculate uncertainties based on this data, 25 to 30 points are necessary.

\subsection{Analyze Data - Perform Statistical Analysis}

3.4.1 Create a control chart using the data and the statistics associated with the initial measurement results. The control chart parameters consist of the central line, and control (or "action") and warning limits that represent probabilistic limits for the distribution of results around the central line. These parameters are evaluated based on a reasonable number of initial measurements and updated as additional measurement data are accumulated. A known value is based on a higher-level calibration of the check standard that is preferably independent of the measurement system being monitored. The central line is established by the mean of measurements. If no higher-level calibration is available, the central line may be used as the known value, but this is not recommended since it will allow no evaluation of measurement accuracy or bias. Upper and lower control limits should be fixed, and adjusted after periodic evaluation when/if appropriate. 
3.4.2 Calculate the mean, $\bar{x}$, and the estimate of the standard deviation, $s$ in the conventional manner.

3.4.3 Establish the control chart parameters as follows:

$\begin{array}{ll}\text { Central Line } & =\bar{X} \\ \text { Upper Control/Action Limit } & =\bar{X}+3 s \\ \text { Upper Warning Limit } & =\bar{X}+2 s \\ \text { Lower Warning Limit } & =\bar{X}-2 s \\ \text { Lower Control/Action Limit } & =\bar{X}-3 s\end{array}$

3.4.4 Control chart parameters for Echelon III (Class F or other) may be completed as follows to track practical limits, although this approach may not show potential trends as well as statistical limits show:

$\begin{array}{ll}\text { Central Line } & =\bar{X} \\ \text { Upper Control/Action Limit } & =\bar{X}+1 / 4 \text { tolerance } \\ \text { Upper Warning Limit } & =\bar{X}+1 / 10 \text { tolerance } \\ \text { Lower Warning Limit } & =\bar{X}-1 / 10 \text { tolerance } \\ \text { Lower Control/Action Limit } & =\bar{X}-1 / 4 \text { tolerance }\end{array}$

\subsection{Analyze a Measurement Process on a Control Chart}

Use the following criteria to analyze control charts. Limits on control charts should be fixed at this time to avoid shifting limits as data continues to be collected and entered. Moving limits may indicate in control status of a process and not show potential trends as well. If uncertainty values are determined at fixed intervals, the evaluation and fixing of limits in control charts should be completed at the same time. During the control phase, after analysis (e.g., F-test and t-test) determines data consistency, data may be pooled and all data included in setting new limits.

3.5.1 If plotted points are stable and randomly distributed within the warning limits, the system is in control. If the process is in control (and the process statistic is normal), $99.73 \%$ of the points will fall within the control/action limits. Observations outside the limits, or systematic patterns within, should be investigated and corrected as appropriate or possible.

3.5.2 If a plotted point is outside the warning limits but within the control limits, investigate the presence of calculation errors. If none were made, remeasure the check standard. The re-measured value must be within the warning limits to merit the decision of "in control". If the re-measured results are not within limits, consider the measurement process "out of control" (See 3.5.3.2). Reject all data obtained since the last "in-control" measurement and take corrective action (hence "action” limit). Keep the "out of control" data in the chart and flag it as problematic. Accept no further data until the system is demonstrated to be in-control as indicated by 
at least two successive measurements of the check standard within the warning limits.

If a plotted point is outside the control limits and arithmetically correct, the system is out of control. Data are rejected, corrective actions must be taken and re-attainment of statistical control demonstrated, as above, before data may be accepted.

3.5.3 Additional guidelines for the evaluation of control charts based on probability statistics should be used to evaluate the presence of drift, shifts, and possible bias. Examples for further evaluation include:

3.5.3.1 Any single point or series of points outside of three standard deviations (keeping in mind the probability that a three standard deviation limit could reasonably expect to allow three points out of one thousand to be outside these limits);

3.5.3.2 Two of the last three points are above (or below) two standard deviations;

3.5.3.3 Four of the last five points are above (or below) one standard deviation;

3.5.3.4 Eight consecutive points are on one side of the mean or reference value;

3.5.3.5 Six points in a row are trending up (or down); and

3.5.3.6 Fourteen points are alternating up and down (sawtooth pattern) about the mean or reference value.

3.6 Analyze Reference Values

3.6.1 Absence of a significant difference between the central line and the accepted reference value for the check standard may be considered evidence of insignificant bias at the level of confidence of the statistical test used. This conclusion is valid, if the system remains in control. On occasion, small differences (less than one standard deviation) from unknown sources will become obvious over time and the value observed for the bias may be incorporated into the uncertainty per SOP 29.

Note: this assessment should be conducted during the initial creation of the control chart and periodically thereafter during monitoring and control of the process.

3.6.2 When a Reference Value for the check standard is more than one standard deviation from the mean value, it may necessitate obtaining an updated calibration or evaluating the bias or deviation further to determine the cause 
and correct it. The deviation or offset must be considered with respect to the reported uncertainty for the reference value as well as the measurement process being used to evaluate the value. In some cases, such as with very large tolerances, a measurement process offset might be quite small compared to the tolerance, in which case the offset can be used as an uncorrected systematic error in the uncertainty calculations. Where tolerances are small or uncertainty requirements stringent, updated calibrations may be required.

3.6.3 The Normalized Error, $E_{n}$, may be used to compare the mean mass value of the check standard, $S_{c}$ to the calibrated reference value, $S_{c(\text { cal })}$ taking care to ensure adequate metrological traceability for the reference value. The expanded uncertainty of the reference value is taken from the calibration certificate and the uncertainty of the mean value is determined using the following equation, based on the standard deviation of the process from the control chart, $s_{p}$, where $n$ is the number of relevant data points; other components are the uncertainty for the standards, $u_{s}$, and any other critical components to be considered, $u_{o}$. The coverage factor, $k$, is determined based on the desired level of confidence and the associated effective degrees of freedom.

$$
\begin{aligned}
& u_{c}=\sqrt{\frac{s_{p}^{2}}{n}+u_{s}^{2}+u_{o}^{2}+u_{o}^{2}} \\
& U_{\bar{s}_{c}}=u_{c} * k
\end{aligned}
$$

$E_{n}$ is calculated using the following equation:

$$
E_{n}=\frac{\left|\bar{S}_{c}-S_{c(\text { cal })}\right|}{\sqrt{U_{\bar{S}_{c}}^{2}+U_{S_{c(\text { cal })}}^{2}}}
$$

The $E_{n}$ value must be less than one to pass. If the $E_{n}$ is greater than one, corrective action is required.

Note: the reference value may exceed acceptable limits even when a measurement process appears statistically in control. When tolerances are large compared to process variability, reference value offsets may simply be noted.

\subsection{Improve the Process}

During analysis of the measurement process or the reference and check standards, opportunities for corrective action and improvement action may be identified. Control charts or values that do not have normal distributions or which have significant differences between observed measurement results and reference values are cause for action of some type. During review of the charts, the first step is to 
identify the source/cause of the concern, and the associated actions will generally follow. The following table can provide some ideas.

Table 2. Assignable causes and example action items.

\begin{tabular}{|l|l||}
\hline \multicolumn{1}{|c|}{ Assignable Cause - Source of Problem } & \multicolumn{1}{|c|}{ Example Action Item } \\
\hline $\begin{array}{l}\text { Standard deviation has increased after new staff } \\
\text { member is hired }\end{array}$ & $\begin{array}{l}\text { Staff might need training, instruction, or oversight; } \\
\text { uncertainties may need to be increased }\end{array}$ \\
\hline Standard deviation has increased over the past year & $\begin{array}{l}\text { Balances may need service; uncertainties may need } \\
\text { to be increased }\end{array}$ \\
\hline $\begin{array}{l}\text { Standard deviation has gotten smaller over the past } \\
\text { few months (due to staff training or balance } \\
\text { service) }\end{array}$ & $\begin{array}{l}\text { Uncertainties may benefit from being reduced } \\
\text { (may also not matter if tolerances are large enough) }\end{array}$ \\
\hline $\begin{array}{l}\text { Observed values of the check standards suddenly } \\
\text { changed. Possibilities might be standards were } \\
\text { switched, standards were damaged, values of } \\
\text { standards after calibration were not updated } \\
\text { properly, new software was implemented without } \\
\text { proper validation, standards recently returned from } \\
\text { calibration and the provider cleaned them. }\end{array}$ & $\begin{array}{l}\text { Identify root cause - then take appropriate action. } \\
\text { sor example, replace standards, update values of } \\
\text { provider. Evaluate whether the shift corresponds in } \\
\text { direction and magnitude to changes in the } \\
\text { calibration value of standards used. }\end{array}$ \\
\hline $\begin{array}{l}\text { Standard values are demonstrating a drift over } \\
\text { time. Possibilities may be that standards were not } \\
\text { equilibrated long enough before being placed into } \\
\text { service; standard or check standard type and design } \\
\text { might be inherently unstable. }\end{array}$ & $\begin{array}{l}\text { Allow standards to equilibrate longer; replace } \\
\text { unstable standards or check standards. }\end{array}$ \\
\hline
\end{tabular}

3.8 Control - Updating Control Chart Parameters

Update control chart parameters when a significant amount of additional data is available or when the previously determined parameters are no longer pertinent due to changes in the system.

Note: Ordinarily, updating is merited when the amount of new data is equal to that already used to establish the parameters in use, or when at least seven additional data points have been recorded. Periodic review of control charts on a quarterly basis, and no longer than an annual basis, is common with a workload that supports ongoing staff proficiency. Performing fewer than seven control measurements in any given year in related measurement parameters raises the question of whether there are adequate measurements being made to maintain staff proficiency. Pooling of related processes and quantities may be considered when determining the best frequency for updating control chart parameters.

Calculate $\bar{X}$ and $s$ for the new set of data and examine for significant differences from the former using the t-test and F-test, respectively. If the tests fail and results are significantly different, determine the reason for the difference, if possible, and decide whether corrective action is required. If data do not agree within statistical limits, establish new parameters and limits using the most recent data and note the reasons for not using previous data or correct the causes of variation. If portions of the process or standard variations pass, be sure to note the degrees of freedom to support uncertainty analyses and coverage factors. If no significant differences 
between the data sets are found, pool all data and calculate new control chart parameters based on all existing data.

\subsection{Control the Process - Frequency of Measurement}

The check standard should be measured and plotted with sufficient frequency to minimize the risk of loss of data during the period from last-known-in to firstknown-out of control condition. It is good practice to measure the check standard at least once during each period when a set of test measurements is made. For critical calibrations or those of highest accuracy, it is desirable to alternate measurements of test items and check standards, but for real-time evaluation it is preferable to incorporate the check standard in the calibration design as in SOP 5 or SOP 28.

Whenever there has been a long period of inactivity, it is good practice to make a series of measurements of the check standard and to plot the results on a control chart to demonstrate attainment of statistical control prior to resuming measurements with that specific calibration system.

Check standard measurements should be plotted in control charts as close to real time as feasible to effectively monitor the measurement process and to prevent the possible release of questionable data that may result in the recall of laboratory work.

\section{Transfer of Measurement Statistics}

The estimate of the standard deviation of the process, $s_{p}$, used to establish the control limits may be used to calculate confidence intervals for all pertinent measurements made while the system is in control. However, see each SOP for calculation of measurement uncertainty using the process variability, $s_{p}$. The value of the weight being calibrated is said to be within the limits if the combined mean of the measurements on the test weights and the uncertainty, which is expanded following SOP 29, are within limits. 


\section{Appendix A - Checklist for Creation or Evaluation of Control Charts}

This checklist may be used as design criteria or to assess the quality of control chart construction during an internal audit. It does not evaluate the control status of control charts. Additional evaluations are required for evaluation of stability and trends.

\begin{tabular}{|c|c|}
\hline Control & Charts cover entire scope (are available for each measurement parameter). \\
\hline Control & harts have titles (or otherwise include) \\
\hline & Laboratory name or other identifying information \\
\hline & SOP(s) used to generate measurement result \\
\hline & Balance/Other equipment \\
\hline & Standard Identification, Check standard Identification \\
\hline & Nominal load/value \\
\hline & Dates/chronology/time periods if not used on the $\mathrm{x}$ axis \\
\hline & Legends if multiple series and extra information are plotted; to avoid confusion \\
\hline Control & harts have $\mathrm{x}$ and $\mathrm{y}$ axis with labels and \\
\hline & All measurement values have units of measure associated with them \\
\hline Control & harts have \\
\hline & Mean value (and units) \\
\hline & Standard deviation (and units) \\
\hline & Degrees of freedom or number of points noted (if not obvious or if small number) \\
\hline & Alternative summaries of this information and suitable references (e.g., tables) \\
\hline & Printed summary reports of control data with the charts \\
\hline & Reference values and source and bias if appropriate/available \\
\hline Control & harts have limits that are based on \\
\hline & Statistical controls of: \\
\hline & Warning limits (i.e., two standard deviations) and \\
\hline & Action/control limits (i.e., three standard deviations) \\
\hline & Or, specification limits (e.g., tolerances or smaller ratios of tolerances) \\
\hline $\begin{array}{l}\text { Good Ite } \\
\text { applicab }\end{array}$ & $\begin{array}{l}\text { ms (on chart or in spreadsheet or database table summaries). Control charts have (when } \\
\text { e and meaningful if not otherwise noted, e.g., in a table) }\end{array}$ \\
\hline & Tolerances: when applicable \\
\hline & Uncertainties: for the reference value, check standard, and the process output \\
\hline & Equipment information: device readability, configuration (stability settings/timing) \\
\hline & Standard information: calibration date and interval information \\
\hline & Responsible staff: need on chart or in database \\
\hline & Status of control: in control, out of control with latest date of review \\
\hline & History: previous limits and history of the chart/data with F-test and/or t-test results \\
\hline
\end{tabular}


This page is intentionally blank. 


\section{SOP 29}

\section{Standard Operating Procedure \\ for the \\ Assignment of Uncertainty}

1 Introduction

\section{$1.1 \quad$ Purpose}

Laboratories performing calibrations that meet ISO/IEC 17025 must report uncertainties in conformance with the ISO Guide to the Expression of Uncertainty in Measurement (hereafter called the GUM). This SOP provides instructions for the laboratory to meet this requirement.

\subsection{Prerequisites}

1.2.1 Calibration certificates with valid uncertainties must be available for all standards.

1.2.2 Statistical data regarding the calibration measurement process must be available; preferably from measurement control programs within the laboratory.

1.2.3 Knowledge of the technical basis for the measurement is critical for completeness in uncertainty evaluation. This can be obtained through reference papers, reference procedures, brainstorming, experimentation, interlaboratory comparisons, cause and effect diagrams and the like. Each NIST SOP published in NISTIR 6969, 5672, and 7383 includes detailed uncertainty budget tables that may be used.

$2 \quad$ Methodology

\subsection{Scope, Precision, Accuracy}

Each measurement made in a laboratory has a corresponding uncertainty assigned to the calibration value. The uncertainty is directly related to the measurement parameter (scope), range of the measurement, the equipment or measurement process being used (affecting precision), and the standards available with associated uncertainties.

\subsection{Summary}

This uncertainty analysis process follows the following eight steps:

1) Specify the measurement process;

2) Identify and characterize uncertainty components;

3) Quantify uncertainty components in applicable measurement units; 
4) Convert uncertainty components to standard uncertainties in units of the measurement result;

5) Calculate the combined uncertainty;

6) Expand the combined uncertainty using an appropriate coverage factor;

7) Evaluate the expanded uncertainty against appropriate tolerances, user requirements, and laboratory capabilities; and

8) Report correctly rounded uncertainties with associated measurement results.

Special methods for handling bias/errors and uncertainties associated with the use of multiple standards are addressed as well.

The Process of Measurement Uncertainty Estimation

3.1 Step 1 . Specify the process.

Clearly define the measurand(s) and specify the measurement process in question, including the item being measured and the input quantities upon which it depends. This will usually require a quantitative expression related to the process (i.e., a measurement equation). Where possible, you may reference an SOP or other method description along with the specific standards and measurement assurance process that is used to adequately complete this step.

3.2 Step 2. Identify and characterize uncertainty sources.

Identify all possible sources of uncertainty in a comprehensive list, characterizing them based on the evaluation method that will be used to quantify them (Type A, statistical methods or Type B, scientific judgment) and to categorize them based on their relatedness with something such as an uncertainty budget table.

Table 1. Example uncertainty budget table.

\begin{tabular}{||l|c|c|c|c||}
\hline \multicolumn{1}{|c|}{$\begin{array}{c}\text { Uncertainty Component } \\
\text { Description }\end{array}$} & Symbol & Source & $\begin{array}{c}\text { Type } \\
\text { (A or } \\
\text { B) }\end{array}$ & $\begin{array}{c}\text { Typical } \\
\text { Distribution }\end{array}$ \\
\hline $\begin{array}{l}\text { Standard uncertainty from the } \\
\text { measurement process }\end{array}$ & $s_{\mathrm{p}}$ & Process & $\mathrm{A}$ & Normal \\
\hline $\begin{array}{l}\text { Standard uncertainty for the } \\
\text { standards }\end{array}$ & $u_{\mathrm{s}}$ & $\begin{array}{c}\text { Calibration } \\
\text { Certificate }\end{array}$ & $\mathrm{B}$ & See Certificate \\
\hline $\begin{array}{l}\text { Standard uncertainty due to } \text { other } \\
\text { factors }\end{array}$ & $u_{o}$ & $\begin{array}{c}\text { Analysis or } \\
\text { References }\end{array}$ & $\mathrm{B}$ & Varies \\
\hline \hline
\end{tabular}

Using the measurement equation that was identified in 3.1 provides a good starting point as do the detailed uncertainty budget tables provided in many procedures. All the parameters in measurement equations may have an uncertainty associated with them. When there are discrete steps in the measurement process, additional uncertainties may be associated with each. Identify actual degrees of freedom for each component that is based on statistical data.

What follows are the most common uncertainties associated with metrological measurements. Keep in mind that this list is not exhaustive. Each item listed below 
is identified as a standard uncertainty, $u$, when determined using Type B methods of evaluation (technical judgment, theoretical assessments, reference items) and a standard uncertainty, $s$, when determined with Type A methods of evaluation (statistical methods). Each standard uncertainty is represented by a lower case variable and further defined by a subscript that is arbitrarily assigned and usually related to the source for ease in remembering that source.

3.2.1 Standard uncertainty from the measurement process, $s_{\mathrm{p}}$, (Type A evaluation).

3.2.1.1 Standard deviation from a measurement assurance chart or control chart.

The value for $s_{\mathrm{p}}$ is obtained from the control chart data and the current knowledge that the measurements are in a state of statistical control. This must be ascertained by measuring at least one check standard during the current measurements combined with data accumulated using the same process in previous measurements. The control chart data must reflect the measurement process being performed. Actual degrees of freedom will be identified from the control chart.

3.2.1.2 Standard deviation from a series of replicate measurements.

Measure a stable test object at least seven times, no two measurements of which should be made on the same day. Calculate the standard deviation in the conventional manner to obtain the standard deviation of the process, $s_{\mathrm{p}}$, keeping in mind that it does not fully represent the measurement process under all typically encountered conditions and that additional uncertainty values may need to be addressed more fully. Actual degrees of freedom will be identified from the control chart.

Note: Repetitive measurements made on the same day estimate the short-term standard deviation of the process and may underestimate actual measurement variability.

\subsubsection{Standard deviation when a process standard deviation is "zero".}

When the standard deviation of a measurement process is less than the resolution of the measuring instrument, $d$, the standard deviation must be assessed. Generally, the smallest standard deviation to be used in this instance may be estimated as 0.6 times the instrument resolution from the equation noted below, with $d$ being the instrument resolution. Assess the standard deviation and use the larger of the calculated standard deviation or the value from this equation. (Some procedures will provide for this value to be reduced further through repetitive measurements (e.g., SOP 4 and SOP 5); 
however, adequate degrees of freedom and analysis of laboratory measurement assurance check standard data must be performed and be acceptable, to reduce the standard deviation of the measurement process further.) Actual degrees of freedom may still be identified from the control chart. The laboratory may also round up to the nearest full division of the measuring instrument.

$$
s_{p}=\frac{d}{\sqrt{3}} \approx 0.6 d
$$

\subsubsection{Standard uncertainty for the standards, $u_{\mathrm{s}}$ (Type B evaluation).}

\subsubsection{When using standards calibrated by another laboratory.}

The information for the standards comes from the calibration report, generally reported as an expanded uncertainty with its coverage factor $(k)$. The expanded uncertainty is simply divided by the stated $k$ value to obtain the combined uncertainty for the standard, $u_{c}$, which represents the $u_{s}$ when used in your laboratory. When $k$ is not equal to two, additional factors associated with the degrees of freedom must be included. See Appendix A to determine the degrees of freedom associated with coverage factors. Keep track of the degrees of freedom for later use.

\subsubsection{When using a standard calibrated in your laboratory (Type B} evaluation).

If the standard was calibrated in your own laboratory, calculate the combined standard uncertainty, $u_{c}$, at $k=1$ and use that as the standard uncertainty for the standard, $u_{s}$. Actual degrees of freedom will be identified during the laboratory calibration.

\subsubsection{When using more than one standard (Type B evaluation).}

When more than one standard is used in a calibration, the standard uncertainty for each, $u_{\mathrm{s} 1}, u_{\mathrm{s} 2}, u_{\mathrm{s} 3}$, etc., is included in the RSS equation if the standards have had independent calibrations. Standards with independent calibrations are combined by standard root sum square methods.

When calibrations are performed at the same time with the same reference standards, or when a standard is used multiple times, the standards are likely considered dependent, so the standard uncertainties are added $\left(u_{s 1}+u_{s 2}\right)$ to determine a value to represent $u_{s}$. (This is the case with two $1 \mathrm{~kg}$ standards that were calibrated at the same time using a weighing design and subsequently used together as standards (restraints) in a weighing design. It is also the case when a 25 gal standard is used four times to calibrate a 100 gal 
standard.) There are also circumstances where both approaches are used to combine uncertainties from multiple combinations of standards. Actual degrees of freedom for each standard should be identified during the laboratory calibration.

3.2.3 Standard uncertainty due to other factors, $u_{o}$ (Type B evaluation.)

These are factors related to the measurement equation, but distinct from the standard uncertainties associated with the process and the standards. These items are often much smaller in a well-controlled process than the standard uncertainties associated with the process and the standards. Examples are given in the uncertainty budget tables in each calibration SOP. Each component that is considered is included as an additional standard uncertainty $u_{01}, u_{02}, u_{03}$, etc., and included in the RSS equation when data shows these factors to be significant. Documentation of the assessment of each component must be maintained to complete the documentation required by the specific calibration procedure and ISO/IEC 17025.

Additionally, the laboratory should include any other components that are considered significant. An estimated standard uncertainty that impacts the second significant digit in the combined uncertainty is considered significant. Additional uncertainties are addressed in the uncertainty budget tables provided in the SOPs. Estimates of degrees of freedom for each component in this category is subjective but should be estimated based on the technical knowledge and confidence associated with each component.

3.2.4 Standard uncertainty due to factors unrelated to the measurement process per se, $u_{u}$.

These are factors that may be related to characteristics of the items being calibrated or of the standard and are usually minimized in well-known and controlled measurement processes. Review the uncertainty budget tables in each SOP or applicable international/national procedures or reference papers for more information. Estimates of degrees of freedom for each component in this category is subjective but should be estimated based on the technical knowledge and confidence associated with each component.

3.2.5 Special uncertainties from other sources (Type B evaluations). Includes bias or unidentified errors.

It is a general requirement of the GUM that corrections be applied for all recognized and significant systematic effects and potential errors. Where a correction is applied based on a bias, an estimate of the associated uncertainty must then be included in the uncertainty analysis. Due to the various approaches present in the metrology community, several examples and possible approaches are presented in the section on calculating the combined or expanded uncertainties. At this stage, a determination must be made regarding 1) identifying cause and 2) level of significance. 
Uncertainty components associated with observed bias are not required to be included in the uncertainty; these components should be small relative to other components and may be included in cases where the laboratory needs to increase their uncertainty to ensure enough overlap of reference values or proficiency tests. Estimates of degrees of freedom for this component should be based on associated data from the analysis of bias and confidence regarding its relative contribution to the uncertainty.

\subsubsection{Identifying bias (offsets) and cause.}

Bias or measurement offsets from reference values are often noted on control charts when an independent reference value is available and from results in proficiency testing. Control chart values are obtained over time and usually have more degrees of freedom than results from one or a few proficiency testing results. Therefore, noted offsets on control charts are more reliable estimates of bias when independent reference values are available. Evaluation of data from multiple sources should be considered whenever available (e.g., a recent calibration, a proficiency testing result, and control chart data assessed as a part of an integrated evaluation).

If the cause of bias or error can be identified, it is usually corrected or applied to the measurement equation. In some cases, it is not possible to unarguably define the cause without exhaustive studies that provide little benefit. In those cases, the significance level must be evaluated before incorporating this type of an uncorrected systematic error in the calibration uncertainties.

\subsubsection{Significance level.}

When there is little to be gained from exhaustive studies on the measurement process to identify bias or potential errors, and the laboratory wants to include these components, a test of significance shall be conducted to determine suitability. Alternative approaches for incorporating the bias into the uncertainty calculations are presented.

In deciding whether a known bias can reasonably be included in the uncertainty, the following steps may be followed: 
3.2.5.2.1 Estimate the combined uncertainty without considering the relevant bias.

3.2.5.2.2 Evaluate whether the bias is less than the combined uncertainty (i.e., bias $<\sqrt{u_{\mathrm{s}}^{2}+\mathrm{s}_{\mathrm{p}}^{2}+\mathrm{u}_{\mathrm{o}}^{2}}$ ).

3.2.5.2.3 If the bias is less than the specified limit, it may be included in the uncertainty using one of several approaches that must be clearly communicated in the certificate.

3.2.5.2.4 If the bias is larger than the specified limit, the error must be investigated further and corrected prior to providing calibration data.

If the deviations show that a standard is out of control, it should not be used for calibration until corrective action has been taken and the value for the standard is verified as being within criteria limits.

$$
\text { Criteria Limit }=\left|\bar{x}_{\text {lab }}-x_{\text {ref }}\right|<u_{c}
$$

If bias differences are smaller than the criteria limits, investigation and corrective action may be unrealistic. If the bias is less than the criteria limits shown above, and corrective action is not taken, the deviations, may be included in the uncertainty. Follow one of several options given in the following sections, provided that the resulting uncertainty remains sufficiently small to meet the needs of the customer or application. In all cases, the method used to incorporate bias must be clearly reported.

3.2.5.3 Option 1. Adding the bias to the expanded uncertainty ( $U+$ bias). In this case, the bias is simply added to the expanded uncertainty and is reported as such.

$$
U+\text { bias }=\left(u_{c} \times k\right)+\text { bias }
$$

3.2.5.4 Option 2. When uncertainties for the laboratory data and the reference data are considered equivalent (e.g., laboratory data is compared to data from another laboratory having equivalent precision) the equation below may be used.

A rectangular distribution is considered where the value might possibly be anywhere within the range shown for each laboratory data point. This approach may also be used in the case where a standard is predictably drifting with use over time. However, because it is known that the limits of the potential error are nearer the center of the distribution and not near the extremes, a mid-range 
value is chosen and $u_{d}$ (uncertainty for differences) is calculated as follows, where $d$ is the bias:

$$
u_{d}=\frac{\text { bias }}{2} \frac{1}{\sqrt{3}} \approx 0.3 \text { bias }
$$

3.2.5.5 Option 3. When uncertainties for the laboratory data are considered secondary to a reference value (e.g., the difference between the laboratory data and data from a higher-level calibration with smaller uncertainties) the equation below may be used.

In this case, a reference value is given precedence over the laboratory data and a mid-range value is not chosen. The extreme value is more probable. In this case, the bias is treated as an uncorrected systematic error and the following equation may be used:

$$
u_{d}=\frac{\text { bias }}{\sqrt{3}} \approx 0.6 \text { bias }
$$

3.3 Step 3. Quantify uncertainty estimates.

All uncertainty estimates identified in the previous step must be quantified in, or converted to, units that represent the final measurement results. Type A methods of evaluation usually provide quantified estimates in the units of interest.

Type B methods of evaluation may be conducted with spreadsheets using the basic expression identified in the SOP or identified when the process was specified. Scenario testing can be done to determine the impact and quantify specific variables on the final measured quantity. The knowledge gained in this step often proves useful in identifying potential areas of improvement especially if contributing factors are graphed in a histogram or Pareto chart.

3.4 Step 4. Convert all factors to standard uncertainties.

The impact of the uncertainty estimates quantified in 3.3 on the final measurement result, in the correct units for the measurement result, can be calculated using the measurement equation identified in 3.1. One of several methods can be employed, e.g., partial derivatives, baseline, or Kragten methodology that use the measurement equation to convert the uncertainty estimates into the units of the measurement result.

In cases where the uncertainty factors were determined statistically (Type A methods), the standard deviation is used to represent the standard uncertainty. In other cases, estimates must be made to ensure that the quantified uncertainties represent “one-standard-deviation” values or a $k=1$ coverage level.

The appropriate distribution factor must be used when converting estimated uncertainty values to standard uncertainties. Each SOP provides specific guidance 
if the component is not treated as a rectangular distribution (e.g., a meniscus may be treated as a triangular distribution and some of the mass procedures will use onehalf of the value treated as a rectangular distribution). According to the Guide to the Expression of Uncertainty in Measurement, a rectangular distribution is generally used when detailed information about the distribution is unknown.

$$
u_{n}=\frac{\text { value }}{\sqrt{3}}
$$

3.5 Step 5. Calculate the combined uncertainty.

The combined standard uncertainty, $u_{c}$, includes the standard uncertainty reported for the standards used, $u_{\mathrm{s}}$, the standard uncertainty of the measurement process, $s_{\mathrm{p}}$, the standard uncertainty from other sources, $u_{0}$, which includes all other factors the laboratory considers significant, the standard uncertainty due to factors related to the measured item but unrelated to the measurement process, $u_{u}$, and finally, the standard uncertainty due to bias or differences, $u_{d}$, when $u_{d}$ is included. The standard uncertainties are usually combined using the root-sum-of-the-squares (RSS) method as follows:

$$
u_{c}=\sqrt{s_{p}^{2}+u_{s}^{2}+u_{o}^{2}+u_{u}^{2}+u_{d}^{2}}
$$

Table 2. Symbol descriptions.

\begin{tabular}{|c|l|}
\hline Symbol & \multicolumn{1}{c|}{ Description } \\
\hline$U$ & Expanded uncertainty (this is represented with an upper-case U) \\
\hline$u_{c}$ & combined standard uncertainty \\
\hline$s_{p}$ & standard uncertainty (standard deviation) of the "process" \\
\hline$u_{s}$ & standard uncertainty of the "standard" \\
\hline$u_{o}$ & standard uncertainty of "other factors” \\
\hline$u_{u}$ & standard uncertainty of factors “unrelated" to the measurement process \\
\hline$u_{d}$ & standard uncertainty of "differences” (may be treated in different ways) \\
\hline$k$ & coverage factor \\
\hline
\end{tabular}

3.6 Step 6. Calculate the expanded uncertainty.

The combined standard uncertainty is multiplied by a coverage factor, $k$, based on the degrees of freedom, or the effective degrees of freedom, to provide a level of confidence of approximately $95 \%$ or $99 \%$, respectively (depending on what is required by the customer, but most often $95 \%$ ). The equation used to determine the expanded uncertainty is as follows:

$$
U=u_{c} \times k
$$

where $k=$ a value from the table in Appendix A, taken from the column 95.45, or calculated based on statistical functions to give comparable $k$ values. When there are a small number of degrees of freedom, the coverage factor must be determined by calculating the coverage factor or be taken from a statistical table such as 
provided in the Guide to the Expression of Uncertainty in Measurement (See Appendix A).

A situation where the degrees of freedom associated with the value for a standard in the traceability chain requires special care to ensure that an appropriate coverage factor is used for calculating the uncertainty of subsequent reported values is when there are a small number of degrees of freedom used to determine the standard deviation of the process and/or the $k$ value from the calibration report represents a small number of degrees of freedom. In this case, the effective degrees of freedom must be used to determine an appropriate coverage factor. Use the WelchSatterthwaite equation provided in NISTIR 6969, Section 8 or provided in the Guide to the Expression of Uncertainty in Measurement.

3.7 Step 7. Evaluate the expanded uncertainty.

The expanded uncertainty must be evaluated. The first level of evaluation should be to determine if the calculated results make sense and are reasonable, to ensure that obvious blunders have not been made in the calculations. Evaluation may be against established criteria such as documentary standard or SOP decision limits, tolerance limits, customer requirements, and/or calibration and measurement capabilities listed on the laboratory scope. Laboratories that are accredited generally may not report uncertainties smaller than what has been published on their scope by their accreditation bodies.

For conformity assessments, the uncertainty and risk decisions must be documented if not contained in the documentary standard and need to be communicated to the customer. For example, the specifications for mass standards clearly state that the expanded uncertainty must be less than $1 / 3$ of the maximum permissible errors (tolerances).

3.8 Step 8. Report the uncertainty.

Once the uncertainty has been calculated, round the value according to GLP 9, report the value, and include a statement such as the following:

"The combined standard uncertainty includes the standard uncertainty reported for the standard, for the measurement process, and for any observed deviations from reference values (e.g., from NIST), which are less than surveillance limits. The combined standard uncertainty is multiplied by $k$, a coverage factor of (insert value used) to give the expanded uncertainty which defines an interval with an approximate $95 \%$ level of confidence.”

The value selected for the coverage factor must be appropriate for the degrees of freedom available and the desired level of confidence associated with the uncertainty as noted in Step 7. 


\section{Appendix A}

Value of $t p(v)$ from the $t$-distribution for degrees of freedom $v$ that defines an interval $t p(v)$ to $+t p(v)$ that encompasses the fraction $p$ of the distribution. Note: This table is taken from NIST Technical Note 1297 and matches the comparable table in the Guide to the Expression of Uncertainty in Measurement. The column marked 95.45(a) should be used to give an "approximate 95 \% confidence interval."

\begin{tabular}{|c|c|c|c|c|c|c|}
\hline \multirow{2}{*}{$\begin{array}{c}\text { Degrees of } \\
\text { freedom } \\
v\end{array}$} & \multicolumn{6}{|c|}{ Fraction $p$ in percent } \\
\hline & 68.27(a) & 90 & 95 & 95.45(a) & 99 & 99.73(a) \\
\hline 1 & 1.84 & 6.31 & 12.71 & 13.97 & 63.66 & 235.80 \\
\hline 2 & 1.32 & 2.92 & 4.30 & 4.53 & 9.92 & 19.21 \\
\hline 3 & 1.20 & 2.35 & 3.18 & 3.31 & 5.84 & 9.22 \\
\hline 4 & 1.14 & 2.13 & 2.78 & 2.87 & 4.60 & 6.62 \\
\hline 5 & 1.11 & 2.02 & 2.57 & 2.65 & 4.03 & 5.51 \\
\hline 6 & 1.09 & 1.94 & 2.45 & 2.52 & 3.71 & 4.90 \\
\hline 7 & 1.08 & 1.89 & 2.36 & 2.43 & 3.50 & 4.53 \\
\hline 8 & 1.07 & 1.86 & 2.31 & 2.37 & 3.36 & 4.28 \\
\hline 9 & 1.06 & 1.83 & 2.26 & 2.32 & 3.25 & 4.09 \\
\hline 10 & 1.05 & 1.81 & 2.23 & 2.28 & 3.17 & 3.96 \\
\hline 11 & 1.05 & 1.80 & 2.20 & 2.25 & 3.11 & 3.85 \\
\hline 12 & 1.04 & 1.78 & 2.18 & 2.23 & 3.05 & 3.76 \\
\hline 13 & 1.04 & 1.77 & 2.16 & 2.21 & 3.01 & 3.69 \\
\hline 14 & 1.04 & 1.76 & 2.14 & 2.20 & 2.98 & 3.64 \\
\hline 15 & 1.03 & 1.75 & 2.13 & 2.18 & 2.95 & 3.59 \\
\hline 16 & 1.03 & 1.75 & 2.12 & 2.17 & 2.92 & 3.54 \\
\hline 17 & 1.03 & 1.74 & 2.11 & 2.16 & 2.90 & 3.51 \\
\hline 18 & 1.03 & 1.73 & 2.10 & 2.15 & 2.88 & 3.48 \\
\hline 19 & 1.03 & 1.73 & 2.09 & 2.14 & 2.86 & 3.45 \\
\hline 20 & 1.03 & 1.72 & 2.09 & 2.13 & 2.85 & 3.42 \\
\hline 25 & 1.02 & 1.71 & 2.06 & 2.11 & 2.79 & 3.33 \\
\hline 30 & 1.02 & 1.70 & 2.04 & 2.09 & 2.75 & 3.27 \\
\hline 35 & 1.01 & 1.70 & 2.03 & 2.07 & 2.72 & 3.23 \\
\hline 40 & 1.01 & 1.68 & 2.02 & 2.06 & 2.70 & 3.20 \\
\hline 45 & 1.01 & 1.68 & 2.01 & 2.06 & 2.69 & 3.18 \\
\hline 50 & 1.01 & 1.68 & 2.01 & 2.05 & 2.68 & 3.16 \\
\hline 100 & 1.005 & 1.660 & 1.984 & 2.025 & 2.626 & 3.077 \\
\hline$\infty$ & 1.000 & 1.645 & 1.960 & 2.000 & 2.576 & 3.000 \\
\hline
\end{tabular}


This page is intentionally blank. 


\section{SOP 30}

\section{Recommended Standard Operating Procedure for a \\ Process Measurement Assurance Program}

1 Introduction

\section{$1.1 \quad$ Purpose}

The Process Measurement Assurance Program (PMAP) is used for the control and surveillance of measurement performance using check standards in measurement and calibration procedures. Incorporation of these measurement control steps ensures the validity of the measurement process and the standards used. The variables used in calculation and assignment of uncertainty can be determined and controlled using this Standard Operating Procedure (SOP). See also NISTIR 6969, SOP 9, and NISTIR 7383, SOP 17 and 20.

\subsection{Prerequisites}

1.2.1 A Standard Operating Procedure for the calibration that describes and provides rigor and consistency in the calibration process.

1.2.2 Check standards that represent the standard and/or the items to be calibrated. Check standards must be stable, and their values should be established with accuracy, since they will be used to control the uncertainty in the calibration process. Check standard reference values must be determined by a higher level of calibration than the procedure being monitored, and preferably using an independent standard, process, or laboratory competent to work at that level. As a minimum, the check standard may be calibrated within the laboratory only if qualified to work at the next higher level and using a procedure one level higher than the calibration process to be controlled.

1.2.3 The operator must be experienced in the calibration process and the standard operating procedure for the calibration to which this method is applied. The operator should also have had specific training on SOP 29 (uncertainty identification and calculations).

1.2.4 A calculating system for statistical control that calculates standard deviations, control limits, F-tests, t-tests, root-sum-of-the-squares (RSS), and creates control charts. 
2 Summary

\section{$2.1 \quad$ Scope}

This method can be used on any measurement or calibration process where a check standard can be substituted for, or measured as, the item being calibrated. The method duplicates the standard operating procedure with the check standard serving as a surrogate for the item being calibrated. The results of these check standard measurements are recorded, charted, and analyzed to establish the measurement capability and to set process control and warning limits. The limits are used to establish process uncertainties and to control future measurement performance.

\subsection{Methodology Description}

Process Measurement Assurance Program (PMAP) is used for defining, measuring, analyzing, improving, and controlling the measurement process and uncertainty as the calibration is performed through the use of suitable check (control) standards. The uncertainty includes effects of the measurement instrument, the operator, the procedure, the standards, and the environment over time.

Each process is modeled to meet the following objective for determining and controlling 1) the measurement process; 2) the calibration and check standards; or 3) a balance of both the process and the standards.

The check standard is selected to evaluate the standard deviation of the process, $s_{p}$, other process uncertainties, $u_{\mathrm{o}}$ such as material density or air density accuracy, and possible bias, $u_{\mathrm{d}}$ of the process (see SOP 29). Initial measurements for the check standard should be performed immediately after calibrating the reference or working standards and after the servicing of the measurement instrument.

Control measurements of the check standard are graphed on control charts for visual examination of process performance and are evaluated against statistical control limits.

Statistical tools, F-tests and t-tests, determine if there are process changes in variability and bias (systematic error). These tests are used when process performance is questionable; when current data is evaluated to establish new control limits; and when evaluating uncertainty statements. 
Table 1. Symbols and descriptions.

\begin{tabular}{|c|l|}
\hline \hline Symbol & \multicolumn{1}{|c|}{ Description } \\
\hline \hline$S_{c}$ & Control measurement of check standard \\
\hline$S_{c s}$ & Accepted value of check standard \\
\hline$U$ & Expanded Uncertainty (of the process) \\
\hline$u_{c}$ & Combined standard uncertainty \\
\hline$u_{s}$ & Standard uncertainty of the standard \\
\hline$u_{o}$ & Standard uncertainty of other factors \\
\hline$u_{d}$ & Standard uncertainty of differences \\
\hline$S_{p}$ & Standard deviation of the process \\
\hline$k$ & Coverage factor \\
\hline
\end{tabular}

$3 \quad$ Procedure

3.1 Define the System to be Monitored

\subsubsection{Define and Model the Calibration Process}

Set objectives for the PMAP application. These objectives will establish the value of the check standard, the check standard measurement procedure, and influence the frequency of control measurements of the check standard. Objectives may be: 1) Determine the standard deviation of the process $\left(s_{p}\right)$; 2) Determine the expanded uncertainty, $U$; 3 ) Measure the value of the calibration standard uncertainty $\left(u_{s}\right)$. The model may allow any one objective or a combination of the objectives to be established with a single PMAP application and PMAP control chart.

Diagram the process to clarify the measurement steps and determine the approach that will achieve the established objectives. When determining and controlling the expanded uncertainty, $U$, evaluate the range of use of the process to ensure that the check standard values will determine the variability and the maximum bias that result from the process and the calibration standard. Determining and controlling expanded uncertainty requires duplicating the calibration process and determining where in the process to insert the control measurement using the check standard. When the objective of PMAP is to control the uncertainty of the calibration standard $\left(u_{s}\right)$, the PMAP measurement may vary from the calibration process to allow inserting the check standard measurement close to the measurement of the calibration standard. Diagram the calibration process to establish how many check standards and PMAP applications are required to meet objectives. Also, diagram the process to determine where in the process to insert the control measurements of the check standard. 


\subsubsection{Define and Calibrate Check Standards}

For calibration process uncertainty determination and control, select a check standard that approximates the item to be calibrated. The selected check standard should be selected to evaluate maximum random variation, $s_{p}$, and bias of the process. The check standard selected should also be used to evaluate other objectives, $u_{o}$, of the specific calibration process. For multiple ranges of use, a check standard and PMAP application will be required for various portions of the range. For example, Double Substitution (SOP 4) will require, at a minimum, a check standard for each decade (1000 g, $100 \mathrm{~g}$, $10 \mathrm{~g}, 1 \mathrm{~g}, 100 \mathrm{mg}$, and $10 \mathrm{mg}$ ) on each balance used. The selected check standard, $S_{c}$, should be calibrated to establish its accepted value with an uncertainty level sufficient to control the calibration process uncertainty. The calibration of the check standard must be completed using a standard which is independent of the calibration standard that the PMAP process is designed to control.

For control of the calibration standard, use a check standard that is not part of routine measurement and that will evaluate the changes in the calibration standard's accepted value, not the maximum random variation of the process. The check standard used to control the calibration standard should be used less frequently (less than $1 / 4$ as often) than the calibration standard. For example, SOP 28, using Design A.1.2 (a 4-1 weighing design) at 1000 g, requires the selection of a $1000 \mathrm{~g}$ check standard that is measured less frequently than the item being calibrated to evaluate the two $1000 \mathrm{~g}$ calibration standards. The selected check standard should be calibrated using a calibration standard other than the calibration standard(s) it will be controlling.

\subsection{Measure - Perform Initial Measurements}

3.2.1 Measurements to establish initial reference limits may be made at any time to verify current measurement process performance. But to achieve control of calibration standards accuracy and measurement instrument capability, initial control chart measurements should be made just after calibration of the calibration standards and servicing of the measurement instrument. Any significant change in the calibration status can then be detected by the performance change in the reference limits data.

3.2.2 Make the control measurements by duplicating the calibration process where the check standard is substituted for the calibrated item. Measure the check standard and determine its calculated value by completing calculations as described in the calibration SOP. 
3.2.3 Record the calculated value of the check standard. Evaluate the initial bias (difference) between the mean of the measured check standard values and the accepted value for $S_{c}$ from its calibration report. Use the normalized error process as defined in SOP 9 to evaluate the bias, considering uncertainties of both the observed mean value and the calibrated reference value of the check standard. If a simple check of the bias shows that it is within one standard deviation, more extensive analysis, such as that described in SOP 9, is not required.

Bias (deviation) of check standard $=$ Observed mean of $S_{c}-$ Accepted $S_{c}$

3.2.4 Repeat the initial measurements at various intervals to sample environmental change and other factors than can affect measurement performance. Although a control chart and some statistical control can be established with as few as seven to 12 measurements, at least 30 are recommended for estimates and control of uncertainties.

\subsection{Analyze - Create and Prepare Control Charts}

3.3.1 Construct a graph with the deviation of the check standard measurements on the y-axis and chronological date and time (or observation number) on the $\mathrm{x}$-axis. The accepted value of the check standard is identified near the center of the chart. The y-axis of the control chart should extend plus and minus three standard deviations from the mean $(\overline{\boldsymbol{X}})$ of the control measurements. Control measurements may be charted as deviation from the accepted value of the check standard or as the observed measurement result, or as a calculated correction. However, care must be taken to understand the impact of updating calibration values for the standards on the data maintained in the charts. (For example, it is generally preferred to plot the calculated mass or conventional mass rather than to track the history of the observed differences to another standard or instrument as it is possible not all measurement influences will be included in the difference value depending from what data the difference is calculated.)

3.3.2 Plot initial measurements on the control chart and evaluate it with reference to the accepted value of the check standard. Record the date, time, and information tags with data. 
3.3.3 Establish control chart parameters by calculating the mean and the estimate of the standard deviation, $s_{p}$ of the check standard reference measurements. Control chart parameters to establish limits are as follows:

Reference Line $\quad=$ Calibrated Check Standard value, $S_{c}$

Mean Line $\quad=\bar{x}$ of measured $S_{c}$ data

3s Action Limits $\quad=\overline{\boldsymbol{x}} \pm 3 s_{p}$

$2 s$ Warning Limits $=\bar{X} \pm 2 s_{p}$

Process Bias $\quad=$ Measured $S_{c}-$ Calibrated $S_{c}$ value

\subsubsection{Establish Reference Limits}

Establish reference control limits by calculating control limits and process bias using the control measurements obtained when calibration standards and measurement instruments are calibrated. These limits are to be stored and used as a reference for future control measurements. Future control measurements should be control-charted and tested against these limits for "in" or "out" of control status. This reference data will also be statistically used to periodically evaluate process and calibration standard performance for change from the calibrated reference status.

\subsubsection{Analyze Process Performance at Specific Intervals}

3.3.5.1 Examine each control measurement data point as it is charted. Evaluate each data point for its control status and investigate causes for out of control data. Analyze the measurement process uncertainty, including the process standard deviation, $s_{p}$, process bias, and other uncertainties quarterly or every five to ten data points to ensure that significant changes in uncertainties do not occur.

3.3.5.2 Evaluate current process performance using the control measurement results to establish the current standard deviation of the process, $s_{p}$, process bias and other uncertainties. Perform each evaluation at specific calibration intervals established by the calibration of standards and service of the measurement instrument. This evaluation, referred to as "calibration" of the process, is performed at intervals that will ensure detection of changes in the calibration uncertainty statements.

3.3.5.3 Use statistical tools at specific calibration intervals to evaluate current data performance to reference data that was established at calibration of standards and at the service of the measurement instrument. This evaluation will assist in 
deciding when to recalibrate calibration standards and service the measurement instrument.

Use the F-test to evaluate if a significant change in the standard deviation or process performance has occurred.

$$
\text { F-test }=\frac{\left(s_{p \text { large }}\right)^{2}}{\left(s_{p \text { small }}\right)^{2}}
$$

The current and previously established reference standard deviations are compared and evaluated using F-test table values based on degrees of freedom in the measurements.

Use the t-test to evaluate if a significant change in measurement process bias has occurred between sequential samples of data (e.g., old and new).

$$
\text { t-test }=\left|\frac{\left(\text { bias }_{\text {new }}\right)-\left(\text { bias }_{\text {old }}\right)}{\sqrt{\frac{\left(s_{p \text { new }}\right)^{2}}{n_{\text {new }}}+\frac{\left(s_{p \text { old }}\right)^{2}}{n_{\text {old }}}}}\right|
$$

The current (new) and previous (old) reference bias is compared and evaluated using t-test table values based on the degrees of freedom in the measurements. Keep track of the signs and trends associated with bias over time.

\subsection{Improve the Process}

Take action based on the results of statistical evaluation. If F-tests and ttests reveal no significant change in process performance, use the current data analysis to establish new process reference limits, control chart and uncertainty statements. If the process has a stable history, it is permissible to pool the current data with previous reference limits to establish new reference limits, control chart, and uncertainty statements. Continue control measurements until the next calibration interval.

If F-tests and t-tests reveal significant change in the measurement process, investigate the specific cause. If the cause for the change cannot be identified and corrected, then collect new reference data to establish new reference limits and process uncertainties. If a specific cause is found and corrected, and subsequent control measurements indicate an "in-control" status, continue collecting control measurements and test against established reference limits until the next calibration interval. 


\subsection{Control the Process}

\subsubsection{Measure Check Standards}

Control measurements of the check standard should be made periodically to ensure that the current measurement performance remains in control of the established reference limits. Control measurements should be tested for "in" or "out" of control status and charted on the control chart. The frequency of the control measurements is dependent on the objective of the application.

When the objective is to determine and control the calibration process uncertainties, control measurements should be made during the calibration process to ensure the calibration results are accurate and within reference uncertainty statements. Control measurements should be made prior to returning calibrated items to the customer. A minimum of 25 control measurements are required within the calibration period or interval assigned to the calibration standards and the calibration process.

When the objective is to control calibration standards, working standards, or reference standards, the frequency of control measurements should be less than $1 / 4$ the use of the standard being controlled. The reduction in measurements ensures that the check standard receives less use and wear than the standard being controlled. Control measurements are charted and the process bias (observed mean value - accepted) is evaluated to detect any significant changes in the calibration standard being controlled.

3.5.2 Continue the measurement assurance procedure to determine and control the measurement process capability. Significant changes in the measurement process capability can result from the following:

- measurement procedure change;

- measurement instrument change;

- calibration standards change; and/or

- location change.

These changes can require repeating the procedure. 


\section{SOP 33}

\section{Standard Operating Procedure \\ for \\ Calibration of Weight Carts}

1 Introduction

1.1 This Standard Operation Procedure (SOP) describes the procedure to be followed for the calibration of weight carts used to test livestock and vehicle scales. This procedure may be used for any nominal values provided adequate standards and equipment are available and the item being calibrated meets appropriate specifications. Detailed measurement ranges, standards, equipment, and uncertainties for this SOP are generally compiled in a separate document in the laboratory.

\subsection{Prerequisites}

1.2.1 Facility. Verify that the laboratory facilities meet the following minimum conditions to meet the expected uncertainty possible with this procedure.

Table 1. Environmental conditions.

\begin{tabular}{||c|c|c||}
\hline Echelon & Temperature Requirements During a Calibration & $\begin{array}{c}\text { Relative Humidity } \\
\text { (\%) }\end{array}$ \\
\hline \hline III & $\begin{array}{c}\text { Lower and upper Limit: } 18^{\circ} \mathrm{C} \text { to } 27^{\circ} \mathrm{C} \\
\text { Maximum changes: } \pm 5^{\circ} \mathrm{C} / 12 \mathrm{~h} \text { and } \pm 3^{\circ} \mathrm{C} / \mathrm{h}\end{array}$ & 40 to $60 \pm 20 / 4 \mathrm{~h}$ \\
\hline
\end{tabular}

1.2.2 Balance/scale. Verify that the balance, scale, or load cell is in good operating condition with sufficiently small process standard deviation as verified by a valid control chart or preliminary experiments to ascertain its performance quality. The expanded uncertainty $(k=2)$ must be less than one-third of the applicable tolerance and balance operating characteristics must be evaluated against this requirement prior to calibration.

If a scale or load cell is used for the calibration that is not a permanent piece of equipment in the calibration laboratory, appropriate verification and repeatability statistics must be obtained prior to a calibration to determine suitability and acceptability for calibration. Records must be maintained of this verification. Minimum verification includes an increasing and decreasing load test to at least the capacity of the weight cart, a shift test, a sensitivity test at the test load, and evaluation of the repeatability based on a minimum of 7 repeated weighings (following the same SOP to be used to test the weight cart). 
1.2.3 Standards. Ensure the availability of suitable working standards or recently calibrated (and unused) field standards in quantities up to the capacity of the weight cart(s) that will be calibrated. All standards must have known conventional mass values with valid metrological traceability to the SI, which may be through laboratory working standards to the National Institute of Standards and Technology.

Standards must be evaluated to ensure that standard uncertainties for the intended level of calibration are sufficiently small. Reference standards should not be used to routinely calibrate customer standards using this procedure. The expanded uncertainty $(k=2)$ must be less than one-third of the applicable tolerance and evaluated prior to calibration. The contribution of the mass standards must be assessed prior to calibration and Class F mass standards without corrections or with uncertainties greater than $1 / 3$ of the tolerance will not be acceptable.

1.2.4 Staff. Verify that the operator is experienced in precision weighing techniques and has had specific training in SOP 8, SOP 4, SOP 29, and GMP 10. Safety precaution: weight carts should be calibrated with at least two people present.

2 Methodology

2.1 Scope, Precision, Accuracy

This method is applicable to lower echelon mass calibration (tolerance testing) of weight carts, provided that the uncertainty requirements can be met. The achievable precision using this procedure is appropriate, provided the expanded uncertainty of the measurement is no more than one-third of the permissible tolerance of the weight cart. The accuracy achievable with this procedure depends on the accuracy of the calibration of the working standards and the precision of the comparison equipment/devices chosen and the procedure selected (e.g., SOP 8 or SOP 4).

\subsection{Summary}

A weight cart is calibrated by substitution with standards having known values, using weighing equipment that has been evaluated as having sufficient resolution and repeatability, to maintain uncertainty to tolerance ratios needed in legal metrology. Modified or double substitution methods are used (SOP 8, SOP 4) and are modified to obtain the replicate observations needed for measurement assurance and determination of the calibration uncertainty. 


\subsection{Equipment /Apparatus/Assistance}

2.3.1 A balance, scale, or load cell with suitable resolution and repeatability, in good repair.

2.3.1.1 General guidelines regarding selection of weighing equipment must include consideration of the device repeatability to determine the achievable standard deviation of the measurement process. To ensure that appropriate uncertainty to tolerance ratios are maintained, the following guidance is provided:

When using Modified SOP 8:

- For a $1000 \mathrm{lb}$ to $2000 \mathrm{lb}$ cart, the maximum division size should be $0.01 \mathrm{lb}$ or less.

- For a $5000 \mathrm{lb}$ cart, the maximum division size should be $0.05 \mathrm{lb}$ or less.

When using Modified SOP 4:

- For a $1000 \mathrm{lb}$ to $2000 \mathrm{lb}$ cart, the maximum division size should be $0.05 \mathrm{lb}$ or less.

- For a $5000 \mathrm{lb}$ cart, the maximum division size should be $0.1 \mathrm{lb}$ or less.

Some balances will require suitable supports to be mounted on the scale deck (platform) to receive the weight cart dimensions without damage to the scale or weight cart. Supports must be appropriately stable and sturdy.

2.3.2 Standards and correction weights, meeting NIST Class F tolerances with current Calibration Reports and known values and uncertainties (as listed with prerequisites).

2.3.3 Hand tools such as the following are needed: wrenches; screw driver; wire cutters; lead and wire seals, and seal press.

2.3.4 Means to move the weight cart safely. Weight carts are large, bulky items and are awkward to move safely. Appropriate safety precautions must be followed in the laboratory. Movement of liquid powered fuel carts is usually not done using the power system of the carts because exhaust from gasoline or diesel powered carts is considered unsafe in the laboratory; if no other options exist, suitable air handling must be available. Use of forklifts to move the carts should only be considered when other options are unavailable and extreme care must be taken. Use of a hoist may provide adequate means to move the cart, however, adequate care must be taken to prevent tipping the cart or bumping into other items in the laboratory as the cart is lifted and moved. 
2.3.5 A basic knowledge of weight carts, including the braking system and operating controls is required. Only qualified personnel should operate and inspect the weight cart. Verification that the brakes are operative prior to movement of the cart is essential.

2.3.6 Suitable adjustment material must be available for placement in the adjusting compartments; lead or steel shot is recommended.

2.3.7 Inspection checklist (See Appendix A). Weight carts are not considered Class F standards due to the extent of motorized and mechanical parts and fluids; therefore, special care must be taken in their calibration and use. An inspection checklist must be completed for each new cart prior to placing it into service. The checklist becomes a permanent part of the records for each weight cart and must be available for review prior to each use or calibration.

2.3.8 For safety reasons, two people should be present to conduct a calibration of a weight cart.

3 Fundamental Considerations

3.1 Weight carts must be properly cleaned and painted, with all repairs and maintenance completed (as needed) prior to calibration. Obtaining actual "as found" values for reverse traceability is not possible with this procedure. Obtaining "as found" values may be achieved by performing a calibration before and after repairs and maintenance are completed. Alternatively, see the "Recommended Method for Intermediate Verification of Mass Values for Weight Cart Users" included as Appendix B.

3.2 Weight carts must be completely dry, with no ice or moisture on the surface or under carriage of the cart.

Experience has shown that a light coating of frost can cause errors more than the tolerance for the cart. In heated facilities, the cart must be allowed enough time to warm to prevent condensation.

Table 2. Stabilization Time.

\begin{tabular}{|c|c|c|}
\hline $\begin{array}{c}\text { Temperature Range } \\
22^{\circ} \mathrm{C} \text { (lab temp) }\end{array}$ & $\begin{array}{c}\text { Temperature Range } \\
72^{\circ} \mathrm{F} \text { (lab temp) }\end{array}$ & $\begin{array}{c}\text { Minimum } \\
\text { Equilibration Time }^{\mathrm{a}}\end{array}$ \\
\hline $\pm 5^{\circ} \mathrm{C}, 17^{\circ} \mathrm{C}$ to $28^{\circ} \mathrm{C}$ & $\pm 10^{\circ} \mathrm{F}, 62^{\circ} \mathrm{F}$ to $82^{\circ} \mathrm{F}$ & 4 hours \\
\hline$<17^{\circ} \mathrm{C}$ and $>28^{\circ} \mathrm{C}$ & $<62^{\circ} \mathrm{F}$ and $>82^{\circ} \mathrm{F}$ & 24 hours/overnight \\
\hline
\end{tabular}


3.3 Weight carts that repeatedly demonstrate excessive "as found" out-oftolerance conditions from the previous calibration date, may be required to be submitted on a more frequent basis; with every consideration being given to determine the cause of the variance.

Complete the Weight Cart Inspection Checklist that is included in Appendix A. The Inspection Checklist is an integral part of the Calibration Report of a weight cart and must be transported with each weight cart and verified prior to each use or calibration. Note and ensure completion of any needed repairs or maintenance prior to calibration.

5 Procedure

5.1 Follow SOP 8 or SOP 4 to determine the conventional mass value of the weight cart, except for items modified and clarified in this SOP. Follow good laboratory practices such as properly exercising the balance prior to calibration.

\subsection{SOP 8 Modifications.}

5.2.1 Repeat the intermediate weighing of the weight cart as if multiple weights were being verified. Obtain at least 3 observations that are taken with a release/removal of the weight from the sensing device. Determine the calculated differences per SOP 8 and calculate the range between the largest and smallest numerical mass value differences. Record the range values in a suitable control chart for weight cart calibrations.

5.2.2 Mass adjustments to the cart may be made at the end of exercising the balance or after the first observation. The cart must be adjusted as close as possible to zero error. The first reading then becomes a "zero" difference when compared to the standards (the correction values of the standard must be considered). Adjustments must be made quickly to avoid errors due to balance drift or shifting. If balance drift or shifts are noticed, the 3 replicate observations should be made after the adjustment is completed.

5.2.3 Care must be taken to ensure that the center of the mass of the weight cart is centered on the balance pan as much as is possible. By rotating the cart by 180 degrees and remeasuring it, off-center loading factors may be considered as a part of standard deviation.

\subsection{SOP 4 Modifications.}

5.3.1 Repeat the double substitution procedure 3 times. Determine the calculated differences per SOP 4 and calculate the range between 
the largest and smallest differences. Record the range information in a suitable control chart for weight cart calibration range values.

5.3.2 Mass adjustments to the cart may be made at the end of exercising the balance or after the first double substitution. The cart must be adjusted as close as possible to zero error. The first reading then becomes a "zero" difference when compared to the standards (the correction values of the standard must be considered). Adjustments must be made quickly to avoid errors due to balance drift or shifting. If balance drift or shifts are noticed, the 3 replicate double substitutions should be made after the adjustment is completed.

5.3.3 Care must be taken to ensure that the center of the mass of the weight cart is centered on the balance pan as much as is possible. By rotating the cart by 180 degrees and remeasuring it, off-center loading factors may be considered as a part of standard deviation.

6.1 Follow calculations as described in SOP 4 or SOP 8 as appropriate.

6.2 Calculate and report the mean of the 3 replicate measurements as the calibrated mass of the weight cart. When adjustments are made, use the mean of the adjusted value as the "as left" reported value.

$7 \quad$ Tolerance

7.1 Tolerances are established in NIST Handbook $105-8^{1}$. Weight carts must be adjusted as close as possible to zero error during calibration. The expanded $(k=2)$ combined uncertainty of the calibration must be less than one-third of the tolerance specified in Handbook 105-8.

7.2 The values of weight carts and their tolerance status are issued and evaluated based on Conventional Mass (previously called Apparent Mass versus a reference density of $8.0 \mathrm{~g} / \mathrm{cm}^{3}$ at $20^{\circ} \mathrm{C}$ ). If a reference density other than $8.0 \mathrm{~g} / \mathrm{cm}^{3}$ is used, the reference density must be reported. No correction for the effect of air buoyancy is general made unless stated on the test report.

${ }^{1}$ NIST Handbook 105-8, Specifications and Tolerances for Weight Carts, 2019. 
7.3 Tolerances for weight carts (See also NIST Handbook 105-8). Tolerances are calculated as $0.035 \%$ of the nominal mass, rounded to the nearest 10 grams.

Table 3: Weight Cart Tolerances

\begin{tabular}{|c|c|c|c|c|c|}
\hline $\begin{array}{c}\text { Nominal } \\
\text { (lb) }\end{array}$ & $\begin{array}{l}\text { Tolerance } \\
\quad( \pm g)\end{array}$ & $\begin{array}{c}\text { Nominal } \\
\text { (kg) }\end{array}$ & $\begin{array}{c}\text { Tolerance } \\
\qquad( \pm \mathbf{g})\end{array}$ & $\begin{array}{c}\text { Nominal } \\
\text { (kg) }\end{array}$ & $\begin{array}{l}\text { Tolerance } \\
\qquad( \pm \text { g) }\end{array}$ \\
\hline 1000 & 160 & 400 & 140 & 2600 & 910 \\
\hline 1500 & 240 & 500 & 170 & 2700 & 940 \\
\hline 2000 & 320 & 600 & 210 & 2800 & 980 \\
\hline 2500 & 400 & 700 & 240 & 2900 & 1010 \\
\hline 3000 & 480 & 800 & 280 & 3000 & 1050 \\
\hline 3500 & 560 & 900 & 310 & 3100 & 1080 \\
\hline 4000 & 640 & 1000 & 350 & 3200 & 1120 \\
\hline 4500 & 710 & 1100 & 380 & 3300 & 1150 \\
\hline 5000 & 790 & 1200 & 420 & 3400 & 1190 \\
\hline 5500 & 870 & 1300 & 450 & 3500 & 1220 \\
\hline 6000 & 950 & 1400 & 490 & 3600 & 1260 \\
\hline 6500 & 1030 & 1500 & 520 & 3700 & 1290 \\
\hline 7000 & 1110 & 1600 & 560 & 3800 & 1330 \\
\hline 7500 & 1190 & 1700 & 590 & 3900 & 1360 \\
\hline 8000 & 1270 & 1800 & 630 & 4000 & 1400 \\
\hline 8500 & 1350 & 1900 & 660 & 4100 & 1430 \\
\hline 9000 & 1430 & 2000 & 700 & 4200 & 1470 \\
\hline 9500 & 1510 & 2100 & 730 & 4300 & 1500 \\
\hline \multirow[t]{4}{*}{10000} & 1590 & 2200 & 770 & 4400 & 1540 \\
\hline & & 2300 & 800 & 4500 & 1570 \\
\hline & & 2400 & 840 & 4600 & 1610 \\
\hline & & 2500 & 870 & & \\
\hline
\end{tabular}

8 Measurement Assurance

8.1 Adequate measurement assurance is a required component of every quality system and uncertainty analysis but maintaining a surrogate weight cart for use in the laboratory as a check standard is impractical.

8.2 Three repeated observations are made and the standard deviation of the values or the range of values (largest mass difference minus the smallest mass difference) is entered in a control chart. The pooled standard deviation of the process is used, or the pooled mean range value is used to estimate a standard deviation of the process. When plotting each new variability value, verify that it is within previously accepted limits.

8.3 Alternatively, though not preferred, 7 to 12 repeated observations are made (following the same SOP to be used to test the weight cart) and a short-term 
standard deviation of the process is calculated each time a weight cart is calibrated. A minimum of 7 replicate weighings may be used if a balance is not permanent equipment of the laboratory (with additional balance evaluations).

The limits of expanded uncertainty, $U$, include estimates of the standard uncertainty of the mass standards used, $u_{s}$, and estimates of the standard deviation of the measurement process, $s_{p}$. These estimates should be combined using the root-sumsquared method (RSS), and the expanded uncertainty, $U$, reported with a coverage factor of two $(k=2)$, to give an approximate 95 percent level of confidence. See SOP 4 or SOP 8 for a detailed uncertainty budget table as appropriate. See SOP 29 for the complete standard operating procedure for calculating and reporting the measurement uncertainty.

9.1 The expanded uncertainty for the standards, $U$, are obtained from the calibration report. The combined standard uncertainty, uc, is used and not the expanded uncertainty, $U$, therefore the reported uncertainty for the standards will usually need to be divided by the coverage factor $k$.

9.1.1 A combination or summation of standards is typically needed for the calibration of weight carts. The dependence or independence of the calibration of such standards must be determined prior to combining the uncertainties associated with the standards. In the case of dependent standards (calibrated against the same working standard), the us values are summed by addition prior to including them in a root sum square calculation: $\left(u_{s 1}+u_{s 2}+\ldots u_{s n}\right)$. In the case of independent standards, the us values are summed by root sum square: $\left(u_{s 1}^{2}+u_{s 2}^{2}+\ldots u_{s n}^{2}\right)^{0.5}$. All $u_{s}$ values must represent one standard deviation prior to combining.

9.2 Standard deviation of the measurement process, sp, is obtained by using the pooled standard deviation of similar size carts over time or by calculating the estimated standard deviation of the process based on the mean range value calculated from applicable range charts

9.3 Buoyancy corrections are not generally needed at the uncertainty level this procedure is designed for. An uncorrected systematic error should be included for the uncorrected magnitude of the air buoyancy correction, following NISTIR 6969, SOP 2; this value is treated as a rectangular distribution.

9.4 Additional components due to balance drift or sensitivity errors need to be evaluated and may need to be included per SOP 8. 
10.1 Prepare a Calibration Certificate according to SOP 1. Report the mean of the calculated conventional mass measurement result and the calculated uncertainty. A sample calibration certificate is included in Appendix A; review the final certificate against the checklist provided in SOP 1.

\subsection{Conformity Assessment.}

The Inspection Checklist is an integral part of the calibration certificate. The expanded uncertainty, $U$, must be $\leq 1 / 3$ of the applicable tolerance from NIST Handbook 105-8. Compliance assessments must note the applicable documentary standard and which portions of the standard were or were not evaluated. 
Appendix A

\section{Sample Calibration Certificate \\ for \\ Weight Cart}

Test Number: $\quad$ Date Issued: Date of Calibration:

Submitted by:

Manufacturer:

Date of Manufacture:

Model Number:

Identification/Serial Number:

Calibration Values:

\begin{tabular}{|c|c|c|}
\hline $\begin{array}{c}\text { As Found } \\
\text { Conventional Mass }^{\mathrm{a}} \text { (lb) }\end{array}$ & $\begin{array}{c}\text { As Left } \\
\text { Conventional Mass (lb) }\end{array}$ & Uncertainty (lb) \\
\hline & & \\
\hline
\end{tabular}

${ }^{a}$ The Conventional Mass is the mass determined/calculated by weighing in air of reference density $1.2 \mathrm{mg} / \mathrm{cm}^{3}$, reference weights of density $8.0 \mathrm{~g} / \mathrm{cm}^{3}$ and at a reference temperature of $20^{\circ} \mathrm{C}$. Buoyancy corrections are considered negligible and were not made unless otherwise stated.

\section{Conditions of Test \& Traceability:}

The above weight cart was compared with standards of the State of XXXX, which are traceable to the International System of Units (SI) and/or the National Institute of Standards and Technology (NIST) and have current calibration values. The assigned test number shown above provides documented evidence for metrological traceability.

Test method: \{Enter SOP 4 or 8 as applicable\} NISTIR 6969, Selected Procedures for Mass Calibrations. $\{$ Enter publication date $\}$

Balance:

Temperature:

Pressure:

Relative Humidity:

\section{Components of Uncertainty:}

The uncertainty is reported as an expanded uncertainty at an approximate $95 \%$ confidence interval $(k=2)$ and calculated according to SOP 29 which is compliant with the ISO/IEC Guide to the Expression of Uncertainty in Measurement. Components included in the calibration uncertainty are the uncertainty associated with the standards and the standard deviation of the measurement process as determined through repeated observations or other suitable range chart for this measurement process. Factors included on the inspection checklist have not been included in the calibration uncertainty. However, factors on the 
checklist may contribute measurement errors that are significant if not properly maintained during use.

\section{Conformity Assessment:}

The weight cart identified on this calibration certificate complies with NIST Handbook 105-8, 2019 specifications and tolerances. Additional details regarding the assessment are included in the associated checklist that is an integral part of this calibration certificate. The weight cart was found (or adjusted) to within the specified tolerances. 


\section{Inspection Checklist}

The weight cart was cleaned and painted and allowed to come to thermal and environmental equilibrium in the laboratory prior to calibration. The weight cart was adjusted (as needed and noted above) as close as possible to zero error. All fluid levels were adjusted as close as possible to the full/reference marks and sealed. Liquid levels must be maintained as close to reference levels as possible during use. The fluid levels include:

Engine Oil;

Hydraulic Fluid (sealed);

Battery Water Level (sealed battery); and

Liquid Fuel \{Enter gasoline or diesel here\} (note reference mark).

The attached Inspection Checklist is an integral component of this Calibration Report and a copy must be maintained with the cart and reviewed prior to use.

Any maintenance, repairs, replacement of parts, or damage to weight cart or its components will likely result in an out-of-tolerance condition; therefore, maintenance or replacement of components such as batteries, tires, filters, or other items listed on the checklist, require calibration of the weight cart prior to subsequent use.

\section{Tolerance:}

Reference: NIST Handbook 105-8, Specifications and Tolerances for Weight Carts, 2019. The applicable tolerances are as follows:

Inspection Checklist Table 1: Weight Cart Tolerances

\begin{tabular}{|c|c|c|c|}
\hline $\begin{array}{c}\text { Nominal } \\
\text { (lb) } \\
\end{array}$ & $\begin{array}{c}\text { Tolerance } \\
( \pm \text { g) }\end{array}$ & $\begin{array}{c}\text { Nominal } \\
\text { (kg) } \\
\end{array}$ & $\begin{array}{c}\text { Tolerance } \\
( \pm \text { g) }\end{array}$ \\
\hline 1000 & 160 & 500 & 170 \\
\hline 2000 & 320 & 1000 & 350 \\
\hline 3000 & 480 & 1500 & 520 \\
\hline 4000 & 640 & 2000 & 700 \\
\hline 5000 & 790 & 2500 & 870 \\
\hline 6000 & 950 & 3000 & 1050 \\
\hline 7000 & 1110 & 3500 & 1220 \\
\hline 8000 & 1270 & 4000 & 1400 \\
\hline 9000 & 1430 & 4500 & 1570 \\
\hline 10000 & 1590 & & \\
\hline
\end{tabular}

For carts intermediate between these values, tolerances are calculated as $0.035 \%$ of the nominal mass, rounded to the nearest ten grams.

Authorized Signature 


\section{Inspection Checklist for Weight Cart}

Test Number:

Manufacturer:

Model Number:

Nominal Mass of Weight Cart:

Powered by: Electric/Generator
Date of Inspection:

Date of Manufacture:

ID/SN Number:

Suitably marked: Yes/No Diesel Gasoline

Fluid Levels: $\quad$ Engine Oil

Hydraulic Fluid

Sealed: Yes/No

Battery

Sealed: Yes/No

Liquid Fuel

Reference line present: Yes/No

Fluid drain tubes extend beyond the body of the cart: Yes/No

Number of axles:

Number/Size of Tires:

Sealed wheel bearings: Yes/No

Drain holes present in locations where water may accumulate: Yes/No

Weight restraint railing permanently fixed and solid: Yes/No

Adjusting cavity accessible: Yes/No

Adjusting cavity approximate capacity:

Adjusting cavity sealed: Yes/No

Service brakes functioning properly: Yes/No

Parking brakes functioning properly: Yes/No

Remote control functioning properly: Yes/No

General condition at time of calibration (note any accumulated dirt/debris, damage, loose parts, or evidence of tampering or unauthorized entry of seals).

List and report any repair and maintenance performed, parts replaced, etc., Leaks repaired, new battery, carburetor, exhaust system, wheels changed, welding performed, etc. Include any comments or changes since the last calibration. 


\section{Appendix B}

\section{Recommended Method \\ for \\ Intermediate Verification of Mass Values for Weight Cart Users}

1. Introduction

1.1. This Recommended Method is intended to provide an intermediate verification of weight cart mass values to obtain a rough estimate of an "as found" value to provide adequate evidence for or against the need for corrective action on scales that have been tested.

1.2. This method may be performed as often as needed during a calibration cycle as a preventive action due to the inherent instability of weight cart mass values. It should also be performed prior to repairs or maintenance to obtain and record adequate evidence of mass values and calibration status prior to the change of mass values resulting from repair and maintenance.

1.3. Records of all such intermediate tests should be retained with the Inspection Checklist and should be submitted with the completed Inspection Checklist when the weight cart is submitted for calibration.

1.4. This method may NOT be used as a substitute for a proper laboratory calibration according to SOP 33 and does NOT provide a traceable mass value with an appropriate calibration uncertainty. Recall that the error on the standard must be less than one third of the applicable tolerance applied to a scale under test. This level of verification is difficult and may be impossible to determine under field conditions. Only errors more than Handbook 44 requirements may be determined using this method.

2. $\quad$ Prerequisites

2.1. Facility. Intermediate verification tests are normally conducted under field or under maintenance shop/garage conditions rather than in a controlled laboratory environment. As such, the avoidance of extreme conditions of temperature, wind, and precipitation are critical. A rough estimate of conditions at the time of verification must be recorded when data is obtained.

2.2. Equipment. A suitable scale must be selected. This typically needs to be of better resolution than the scales being tested with the weight cart or as a minimum, a scale with the smallest resolution on which the cart may be used. A repeatability test, with a minimum of 3 repetitions is needed to ensure that the mass values will repeat to within one-half of a scale division at the load of the weight cart. 
2.3. Standards. Class F field standards are used if they are within the prescribed calibration cycle. A small Class F weight kit is used as correction weights to determine small errors and partial division values.

2.4. Staff. Staff must be trained in substitution calibration methods and be able to perform calculations associated with determining mass values.

2.5. The weight cart fuel levels, where liquid fuels are used, must be set at the reference mark on the fuel sight gauge.

3. Fundamental Considerations

Weight carts must be completely clean and dry, with no mud, ice or moisture on the surface or under carriage of the cart. Tires must be cleaned as well. (Values obtained under actual operating conditions may provide some insight to the user regarding the impact of maintenance and cleanliness of the weight cart).

4. $\quad$ Pretest Weight Cart Inspection

Complete the Weight Cart Inspection Checklist that is included in Appendix A.

5. $\quad$ Procedure

5.1. Establish scale repeatability with a minimum of three repetitions such that the scale repeats to within one-half of a division at the weight cart capacity.

5.2. Load Class F field standards onto the scale in the same location(s) where the weight cart will be placed to the same load as the stated conventional mass of the weight cart. Assign a mass value to this summation of standards based on the nominal values of the weights. The added mass values of these weights is the value for your standards. With the weights loaded on the scale deck, use small error weights to determine the break point of the nearest larger scale division.

5.3. Remove the large Class F field standards and leave the small error weights on the scale.

5.4. Load the weight cart onto the scale in the same location(s) where the weights were loaded. Add or remove the small error weights until the scale responds in the same way as the previously loaded mass standards to determine the break point of the same scale division.

6. Calculations

Calculate the difference between the error weights used with the Class F field standards and the error weights used with the weight cart. Because this is not an accepted calibration method, the observed difference in these values only represents an estimated mass value. (Error weights used with Class F standards - Error weights used with the weight cart $=$ Observed Estimated Error) . 
7. Tolerance and Evaluation

The observed estimated error must be less than one third of the smallest tolerance applied to a scale on which the weight cart might be used. Corrective action is required if the observed mass of the weight cart exceeds the calibrated mass by more than one-third of the applicable tolerance.

8. Measurement Assurance

Measurement assurance is obtained through three replicate measurements.

9. Assignment of Uncertainty

An uncertainty is not calculated, estimated, or assigned with this intermediate verification method. It is not considered a valid calibration with evidence of traceability.

10. Calibration Certificate

A calibration certificate is not prepared for an intermediate verification. Recorded and observed data must be maintained. 


\section{Example of Intermediate Verification Procedure and Calculations}

A. A $2000 \mathrm{lb}$ weight cart is to be tested on a scale with $10 \mathrm{lb}$ divisions.

B. When 2) $1000 \mathrm{lb}$ Class F field standards are placed on the scale, the scale reading repeats to within one-half of a division when 3 replicate weighings are performed (weights must be moved on and off the scale or the scale arrested and released to determine this repeatability). The scale reads $2000 \mathrm{lb}$ for each test.

C. Error weights are slowly placed on the scale deck in increments of $0.1 \mathrm{lb}$ and the addition of $5.5 \mathrm{lb}$ causes the scale to read the next larger division of $2010 \mathrm{lb}$.

D. The 2) $1000 \mathrm{lb}$ Class F field standards are removed and the $2000 \mathrm{lb}$ weight cart is placed on the scale deck, leaving the previous $5.5 \mathrm{lb}$ error weights. Error weights of $6.5 \mathrm{lb}$ are needed for the scale to break to $2010 \mathrm{lb}$ with the weight cart on the scale deck (an additional $1.0 \mathrm{lb}$ was added).

E. $\quad$ Error weights used with Class F standards $=5.5 \mathrm{lb}$

F. $\quad$ Error weights used with the weight cart $=6.5 \mathrm{lb}$.

G. Error weights used with Class F standards - Error weights used with the weight cart $=$ Observed Estimated Error; $5.5 \mathrm{lb}-6.5 \mathrm{lb}={ }^{-} 1 \mathrm{lb}$

H. Evaluation: the smallest tolerance on the scale will be one-half of a division, or $5 \mathrm{lb}$. One third of $5 \mathrm{lb}$ is $1.7 \mathrm{lb}$. The error on standards used on the scale must be less than this level. The observed error on the cart of $-1.0 \mathrm{lb}$ is less than $1.7 \mathrm{lb}$ and corrective action for previous scale tests is not needed at this time. The ${ }^{-} 1 \mathrm{lb}$ value is recorded on the Inspection Checklist as an Intermediate Verification.

I. If the cart has been damaged or if repairs to the cart are needed, calibration is required at this time. 
This page is intentionally blank. 


\title{
SOP 34
}

\section{Standard Operating Procedure ${ }^{1}$ for the \\ Selection and Use of Sensitivity Weights and Tare Weights in Weighing Procedures}

1 Introduction

\begin{abstract}
Mass calibration procedures are based on comparing the unknown mass, $X$, to a standard mass, $S$, utilizing the balance as a comparator. This comparison relies on the accuracy of balance indications. When balance indications are not accurate enough for precision mass calibrations, and they drift with time, appropriate procedural adjustments are required. Drift can often be assumed to be linear over a short period. Concerns over balance inaccuracy and drift result in two possible causes of errors in mass determination procedures. Inaccuracy of the balance indications can be corrected by incorporating a sensitivity weight in the procedure that calibrates the range of use of the optical scale (mechanical balances) or of the digital indications (electronic balances). Errors due to drift can be minimized by using the correct comparison method, selecting a suitable sensitivity weight, and by consistent timing within the procedure. The proper selection of procedures (GMP 12), the adherence to those procedures, and equal time intervals between weighing operations will allow the measured difference between $X$ and $S$ to be corrected for inaccuracy of the balance indications and for balance drift.
\end{abstract}

Mass comparison procedures rely on the unknown and standard masses to be nominally equal. When the mass standards are not near to each other, tare weights need to be used to bring them closer together. Tare weights in this case function as additional mass standards and are essentially be treated as additional mass standards in summation.

\section{$1.1 \quad$ Purpose}

The following practice will guide you through the process of selecting and using a correct sensitivity weight and/or tare weight(s) for mass determination procedures.

\subsection{Prerequisites}

1.2.1 Valid calibration certificates with appropriate values and sufficiently small uncertainties must be available for all the sensitivity weights and tare weights used in a calibration. All mass standards must have demonstrated metrological traceability to the international system of units (SI), which may be through a National Metrology Institute such as NIST.

1.2.2 Verify that weight-handling equipment is available and in good operational condition.

\footnotetext{
${ }^{1}$ This SOP was formerly Good Measurement Practice 14 (2003, 2012) and provides the procedure and general guidelines for the use of tare weights and sensitivity weights.
} 
1.2.3 Verify that the operator is familiar with the design and the operation of the balances and familiar with weighing procedures.

\subsection{Safety}

1.3.1 Handling of large or small weights can represent a hazard to either the weights or personnel if the weights are dropped.

\subsection{Summary}

A sensitivity weight is selected to calibrate the balance over the range to be used in the measurement procedure. Minimizing the difference in mass values between $X$ and $S$ is critical when choosing an appropriate sensitivity weight. Therefore, tare weights may be necessary whenever the difference in mass values is significant. Minimizing the difference between $X$ and $S$ works to our benefit since the range of the measurements is minimized and reduces potential errors that can be introduced by nonlinearity or span inaccuracies of the balance as well as bringing the mass standards within range on mass comparators with limited weighing ranges.

\subsection{Apparatus}

Clean forceps to handle the weights, or gloves to be worn if the weights are to be moved by hand.

\subsection{Procedure for selection}

2.3.1 Conduct preliminary measurements to determine the approximate mass value for the difference between the standard and the unknown $(X-S)$.

2.3.2 Define the range of use for the balance to be used:

2.3.2.1 Equal arm - number of scale divisions

2.3.2.2 Mechanical - optical scale

2.3.2.3 Combination (Electro-mechanical) and Comparators - digital indications

\subsubsection{Fully electronic - capacity}

2.3.3 Determine the need for tare weights if the difference between $X$ and $S$ exceeds the values shown in Table 1, considering the impact of potential errors based on comparison with calibration uncertainties. 
Table 1. Recommended maximum difference between $X$ and $S$.

\begin{tabular}{|l|l||}
\hline \multicolumn{1}{|c||}{ Balance } & \multicolumn{1}{c|}{$(\boldsymbol{X}-\boldsymbol{S})$} \\
\hline \hline Equal arm & $\begin{array}{l}\text { balance each other within one division on the } \\
\text { scale }\end{array}$ \\
\hline Mechanical & $\begin{array}{l}1 / 10 \text { of the optical scale or the applicable } \\
\text { tolerance depending on weight class and } \\
\text { suitability }\end{array}$ \\
\hline $\begin{array}{l}\text { Combination Electro-mechanical } \\
\text { and Comparator }\end{array}$ & \\
\hline Fully electronic & \\
\hline
\end{tabular}

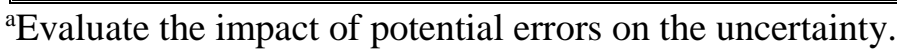

2.3.4 Select tare weights, if necessary, making sure that the difference between $X$ and $S$, with the appropriate tare weights, is generally less than the values shown in Table 1 . If weights are of equal nominal value and all are within applicable tolerances, the need for tare weights is rare. Tare weights or multiple standards in summation are often required for unequal nominal values.

2.3.5 Select a sensitivity weight within the ranges give according to Table 2 . Round the estimated mass of the sensitivity weight to the nearest convenient standard nominal mass (1-2-3-5).

Table 2. Selection of Sensitivity Weight.

\begin{tabular}{|c|c|c|}
\hline Balance & Procedures & $\begin{array}{c}\text { Sensitivity Weight } \\
\text { (Criteria should be met by the selected sensitivity weight.) }\end{array}$ \\
\hline Equal Arm & SOP 3, 5, 6, 7, 8, 28 & change turning points by about $20 \%$ \\
\hline Mechanical & $\begin{array}{l}\text { SOP 4, 5, 7, } 28 \\
\text { SOP } 8\end{array}$ & $\begin{array}{l}\geq 4 \text { times }(X-S)^{\text {a }} ; \\
\leq 1 / 2 \text { optical scale, usually } \approx 1 / 4 \text { optical scale }\end{array}$ \\
\hline $\begin{array}{l}\text { Combination } \\
\text { Electro-mechanical } \\
\text { and } \\
\text { Comparator }\end{array}$ & SOP 4, 5, 7, 8, 28 & $\begin{array}{l}\geq 4 \text { times }(X-S) \\
\leq 1 / 2 \text { digital range }\end{array}$ \\
\hline Fully Electronic & $\begin{array}{l}\text { SOP } 4,5,7,28 \\
\text { SOP } 8\end{array}$ & $\begin{array}{l}\geq 4 \text { times }(X-S) \\
\geq 2 \text { times the applicable tolerance; } \\
\leq 0.5 \% \text { capacity }\end{array}$ \\
\hline
\end{tabular}

${ }^{a} 4$ times the difference between $X$ and $S$ is required to avoid flagged errors in the output report when using the NIST Mass Code. 
2.3.6 A sensitivity weight is not required if using an electronic mass comparator or fully electronic balance that has been evaluated (with supporting data and documented analysis available), and which has ongoing periodic validation (e.g., prior to each use) to determine that the balance has sufficient accuracy, resolution, repeatability, and stability so that no advantage is gained by using a sensitivity weight. For example, any possible errors must be less than the last digit retained in the expanded uncertainty. Monitoring is required to verify metrological traceability. See calculations and uncertainties noted in Section 3.

\section{$2.4 \quad$ Using sensitivity weights}

2.4.1 The sensitivity weight is incorporated into the mass procedures to ensure that the mass differences determined with the optical scale, or electronic range, have valid accuracy and traceability. The sensitivity weight calibrates the range of use of the balance used for making the mass determinations. Using a sensitivity weight provides us with a sensitivity value in terms of mass units per division. If the sensitivity is not constant with time, temperature and load, its variation must be included in the mass correction and in the uncertainty. What follows is a generic equation for the sensitivity correction factor. Equations are modified in each SOP when buoyancy corrections are performed.

$$
\text { sensitivity }=\frac{\text { mass units }}{\text { divisions }}=\frac{M_{s w}}{\text { deflection }}
$$

where $M_{s w}$ represents the mass of the sensitivity weight.

3 Calculations

3.1 See each mass SOP for calculation of sensitivity as it is included in the procedure. Examples of sensitivity accuracy evaluation include the following:

3.1.1 SOP 8 - The error in sensitivity must be less than 2 percent of the balance reading. That is, the sensitivity factor portion of the mass calculation must be between 0.98 and 1.02 mass units per division when the sensitivity is equal to 1 (or 980 to 1020 if sensitivity is equal to 1000).

3.1.2 Comparison SOPs - The potential systematic error due to sensitivity inaccuracies may be calculated by determining the average observed deflection of a sensitivity weight divided by the mass of the sensitivity weight and multiplied by the average or maximum difference between $X$ and $S$, from the following equation:

Potential sensitivity error $=\overline{\frac{\text { Observed deflection }-M_{s w}}{M_{s w}} \mid} \times$ Average max $d \quad$ Eqn. (2) 
The applicable tolerance may be substituted for the average maximum difference between $X$ and $S, d$.

$4 \quad$ Uncertainty

4.1 Sensitivity errors that may be incorporated in SOP 8 where sensitivity is assessed but not included in the calculations need to be evaluated and included as an uncorrected systematic error in the uncertainty (treated as a rectangular distribution), according to this approach and to instructions in SOP 8.

4.2 The uncertainty of the sensitivity weight may be treated in the same way as the difference between the observed deflection and mass of the sensitivity weight in the equation given in 3.1.2 to determine significance.

$$
\text { Potential sensitivity uncertainty }=\overline{\left|\frac{u_{s w}}{M_{s w}}\right|} \times \text { Average max } d
$$

Again, the applicable tolerance may be substituted for the average maximum difference, $d$. The uncertainty of the sensitivity weight is generally relatively small and insignificant. However, it does no harm to incorporate it in uncertainty calculations when spreadsheets are set up to handle all of the data which will account for possible larger uncertainties on sensitivity weights.

The resulting systematic errors that are calculated in Section 3.1.2 that are evaluated and not corrected as a part of the procedure may be treated as a rectangular distribution in combination with all other sources of uncertainty. Note: An alternative equation such as C.6.4.2, from OIML R111 may be used as well.

4.3 Uncertainties associated with all tare weights are treated as if multiple standards are used in summation and evaluated accordingly (See SOP 29 for references to dependencies). 
This page is intentionally blank. 


\section{Section 8}

\section{Statistical Techniques}

Statistics are used in metrology to summarize experimental data, to provide the basis for assessing its quality, and to provide a basis for making probabilistic decisions in its use. The essential basic statistical information for describing a simple data set is:

$\begin{array}{ll}\text { The mean of the sample, } & \bar{x} \\ \text { The standard deviation of the sample, } & \mathrm{s} \\ \text { The number of individuals in the sample, } & n\end{array}$

If the set is a random sample of the population from which it was derived, if the measurement process is in statistical control, and if all of the observations are independent of one another, then $\mathrm{s}$ is an estimate of the population standard deviation, $\sigma$, and $\bar{X}$ is an unbiased estimate of the mean, $\mu$.

The population consists of all possible measurements that could have been made under the test conditions for a stable test sample. In this regard, the metrologist must be aware that any changes in the measurement system (known or unknown) could possibly result in significant changes in its operational characteristics, and, hence the values of the mean and standard deviation. Whenever there is doubt, statistical tests should be made to determine the significance of any apparent differences and whether statistics should be combined (pooled).

The following discussion reviews some useful statistical techniques for interpreting measurement data. In presenting this information, it is assumed that the reader is already familiar with basic statistical concepts. For a detailed discussion of the following techniques and others not presented here, it is recommended that the reader consult NIST/SEMATECH e-Handbook of Statistical Methods, http://www.itl.nist.gov/div898/handbook/, January 2018 (or NBS Handbook 91 - Experimental Statistics, by Mary G. Natrella, (1963), reprinted 1966. Handbook 91 contains comprehensive statistical tables from which many of the tables contained in Section 9 of this publication were taken.

\subsection{Estimation of Standard Deviation from a Series of Measurements on a Given Object}

Given $n$ measurements $x_{1}, x_{2}, x_{3}, \ldots \ldots, x_{n}$

Mean: $\quad \bar{x}=\frac{\left(x_{1}+x_{2}+x_{3}+\ldots+x_{n}\right)}{n}$

Standard deviation estimate: $\quad s=\sqrt{\frac{\sum\left(x_{i}-\bar{x}\right)^{2}}{n-1}}$

The estimate, s, is based on n-1 degrees of freedom.

8.2 Estimation of Standard Deviation from the Differences of $k$ Sets of Duplicate Measurements

Given $k$ differences of duplicate measurements, $d_{1}, d_{2}, d_{3}, \ldots, d_{k}$, a useful formula for estimating the standard deviation is: 


$$
s_{d}=\frac{\sum d_{i}^{2}}{2 k} \text { where } s_{d} \text { is based on } k \text { degrees of freedom. }
$$

Note that $d_{i}=\bar{x}_{i}^{\prime}-\bar{x}_{i}^{\prime \prime}$, for example.

The values $d_{1}$, $d_{2}$ etc., may be differences of duplicate measurements of the same sample (or object) at various times, or they may be the differences of duplicate measurements of several similar samples (or objects). Note: It is recommended to calculate the standard deviation for each set of duplicates and then to calculate a pooled standard deviation whenever possible.

\subsection{Estimation of Standard Deviation from the Average Range of Several Sets of Measurements}

The range, $R$, is defined as the difference between the largest and smallest values in a set of measurements.

Given $R_{1}, R_{2}, R_{3}, \ldots, R_{k}$

Mean: $\quad \bar{R}=\frac{\left(R_{1}+R_{2}+R_{3}+\ldots+R_{k}\right)}{k}$

Standard deviation can be estimated by the formula: $\quad S_{R}=\frac{\bar{R}}{d_{2}^{*}}$

The value of $d_{2}^{*}$ will depend on the number of sets of measurements used to calculate $s_{R}$, and on the number of measurements in each set, i.e., 2 for duplicates, 3 for triplicates, etc. Consult a table such as Table 9.1 for the appropriate value of $d_{2}^{*}$ to use. The effective number of degrees of freedom for $s_{R}$ is in the table. Note: It is recommended to calculate the standard deviation for each set of replicates and then to calculate a pooled standard deviation whenever possible.

\subsection{Pooling Estimates of Standard Deviations}

Estimates of the standard deviation obtained at several times may be combined (pooled) to obtain a better estimate based upon more degrees of freedom if F-tests demonstrate that variation is statistically similar. The following equation may be used for this purpose of pooling:

$$
s_{p}=\sqrt{\frac{\left(n_{1}-1\right) s_{1}^{2}+\left(n_{2}-1\right) s_{2}^{2}+\left(n_{3}-1\right) s_{3}^{2}+\ldots+\left(n_{k}-1\right) s_{k}^{2}}{\left(n_{1}-1\right)+\left(n_{2}-1\right)+\left(n_{3}-1\right)+\ldots+\left(n_{k}-1\right)}} \text { where }
$$

$s_{p}$ will be based on $\left(n_{1}-1\right)+\left(n_{2}-1\right)+\left(n_{3}-1\right)+\ldots+\left(n_{k}-1\right)$ degrees of freedom.

\section{5 "Within" and "Between" Standard Deviation}

See the NIST/SEMATECH e-Handbook of Statistical Methods, Section 2.3.3.3.4. Calculation of standard deviations for 1,1,1,1 design, for detailed descriptions of within and between standard deviations. http://www.itl.nist.gov/div898/handbook/mpc/section3/mpc3334.htm. See NISTIR 5672 for mass calibration applications. 


\subsection{Confidence Interval for the Mean}

The estimation of the confidence interval for the mean of $n$ measurements is one of the most frequently used statistical calculations. The formula used will depend on whether the population standard deviation, $\sigma$, is known or whether it is estimated on the basis of measurements of a sample(s) of the population. (See also section 8.16 to determine the uncertainty of the mean value for a calibration process.)

\subsubsection{Using Population Standard Deviation, $\sigma$}

Strictly speaking, $\sigma$, is never known for a measurement process. However, the formula for use in such a case is:

$$
\bar{x} \pm \frac{z \sigma}{\sqrt{n}}
$$

Table 1. Variables for equation in 8.6.1.

\begin{tabular}{||c|l||}
\hline \hline Variable & \multicolumn{1}{|c||}{ Description } \\
\hline \hline $\bar{x}$ & sample mean \\
\hline $\mathrm{s}$ & known standard deviation \\
\hline$n$ & number of measurements of sample \\
\hline$z$ & standard normal variate, depending on the confidence level desired \\
\hline
\end{tabular}

For $95 \%$ confidence $z=1.960$; for $99.7 \%$ confidence $z=3.0$.

For other confidence levels, see Table 9.2

\subsubsection{Using Estimate of Standard Deviation, s}

In the usual situation, $\mathrm{s}$ is known, based on $v$ degrees of freedom and the formula for use is:

$$
\bar{x} \pm \frac{t s}{\sqrt{n}}
$$

Table 2. Variables for equation in 8.6.2.

\begin{tabular}{|c|l||}
\hline \hline Variable & \multicolumn{1}{c||}{ Description } \\
\hline \hline $\bar{X}$ & sample mean \\
\hline$s$ & estimate of standard deviation \\
\hline$n$ & number of measurements on which the mean is based \\
\hline$t$ & $\begin{array}{l}\text { Student's } t \text { value, based on the confidence level desired and the } \\
v \text { degrees of freedom associated with } s \text { (see Table 9.3). }\end{array}$ \\
\hline
\end{tabular}

Note that $t \rightarrow Z$ as $n \rightarrow \infty$. For many practical purposes, the standard deviation may be considered as known when estimated by at least 30 degrees of freedom. 


\subsection{Confidence Interval for $\sigma$}

The standard deviation, $\sigma$, is ordinarily not known but is, instead, an estimated value based on a limited number of measurements, using procedures such as have been described above. Such estimates may be pooled, as appropriate, to obtain better estimates. In any case, the uncertainty of the estimated value of the standard deviation may be of interest and can be expressed in the form of a confidence interval, computed as indicated below.

The interval is asymmetrical because the standard deviation is ordinarily underestimated when small numbers of measurements are involved due to the fact that large deviations occur infrequently in a limited measurement process. Indeed, it is the general experience of metrologists that a few measurements appear to be more precise than they really are.

The basic information required to compute the interval is an estimate of the standard deviation, s, and the number of degrees of freedom on which the estimate is based. The relationships to use are:

$$
\begin{array}{ll}
\text { Lower limit } & B_{L S} \\
\text { Upper limit } & B_{U S} \\
\text { Interval } & B_{L S} \text { to } B_{U S}
\end{array}
$$

The values for $B_{L}$ and $B_{U}$ depend upon the confidence level and degrees of freedom associated with $s$. Values for use in calculating the confidence level are given in Table 9.7. A more extensive table (Table A-20) is available in NBS Handbook 91.

\subsection{Statistical Tolerance Intervals}

Statistical tolerance intervals define the bounds within which a percentage of the population is expected to lie with a given level of confidence. For example, one may wish to define the limits within which $95 \%$ of measurements would be expected to lie with a $95 \%$ confidence of being correct. The interval is symmetrical and is computed using the expression

$$
\bar{x} \pm k s
$$

where $k$ depends on three things

Table 3. Variables used to select $k$.

\begin{tabular}{||c|l||}
\hline \hline Variable & \multicolumn{1}{c|}{ Description } \\
\hline \hline$p$ & the proportion or percentage of the individual measurements to be included \\
\hline$\gamma$ & the confidence coefficient to be associated with the interval \\
\hline$n$ & the number of measurements on which the estimate, $s$, is based \\
\hline \hline
\end{tabular}

Table 9.6 may be used to obtain values for $k$ for frequently desired values of $\gamma$ and p. A more extensive table is Table A-6 found in NBS Handbook 91.

\subsection{Comparing Estimates of a Standard Deviation (F-Test)}

The F-test may be used to decide whether there is sufficient reason to believe that two estimates of a standard deviation differ significantly. The ratio of the variances (square of the standard 
deviation) is calculated and compared with tabulated values. Unless the computed ratio is larger than the tabulated value, there is no reason to believe that the observed standard deviations are significantly different.

The F-ratio is calculated using the generic equation:

$$
F=\frac{s^{2}}{s^{2}}
$$

The critical value of $\mathrm{F}$ depends on the significance level chosen for the decision (test) and the number of degrees of freedom associated with each standard deviation.

Three cases using the F-test are considered here.

8.9.1 Evaluation of two samples to determine whether variability is statistically the same.

$$
F=\frac{s_{L}^{2}}{s_{S}^{2}}
$$

In this case, the larger of the two standard deviations is placed in the numerator (sL) and the smaller of the two in the denominator (ss).

Table 9.4 contains critical values for $\mathrm{F}$ at the $95 \%$ level of confidence. The tabulated values of $\mathrm{F}$ are not expected to be exceeded with $95 \%$ confidence on the basis of chance alone. As an example, if both the numerator and the denominator values for s were each based on 9 degrees of freedom, an F value no larger than 4.03 is expected with $95 \%$ confidence, due to the uncertainties of the s values, themselves. Table A-5 of NBS Handbook 91 [19] contains values for $\mathrm{F}$ for other confidence levels.

This F-test is useful for comparing the precision of methods, equipment, laboratories, or metrologists, for example. An inspection of Table 9.4 shows that when either of the values of $\mathrm{s}$ is based on a small number of degrees of freedom, the F value is large. Consequently, the significance of decisions based on small changes in precision can be supported statistically only by a relatively large number of measurements. If such changes are suspected, but the data requirement is difficult to meet, the decision may need to be made on the basis of information about the measurement process itself.

This F-test is also useful for deciding whether estimates of the standard deviation made at various times differ significantly. Such questions need to be answered when deciding on whether to revise control limits of a control chart, for example.

8.9.2 Evaluation of observed within-process standard deviation compared to the accepted/pooled within process standard deviation to determine whether the process has degraded.

$$
F=\frac{s_{w \text { Observed }}^{2}}{s_{w \text { Accepted }}^{2}}
$$


In this case, the observed standard deviation of a measurement process is compared to the accepted standard deviation of the process that has been gathered and pooled over time. Table 9.12 provides the statistical limits at $95 \%$ confidence for this statistic. If the F-test demonstrates that the observed standard deviation agrees with the accepted value to the extent that the values are statistically similar, the process is considered to remain stable.

This F-test is useful for integrating a measurement assurance check on the process into the measurement procedure before proceeding to report calibration results. This F-test is integrated into SOP 5 (Section 3.4), SOP 28, and weighing designs as presented in NBS Technical Note 952, NISTIR 5672, and the catalog of designs shown in the NIST/SEMATECH e-Handbook of Statistical Methods.

\subsubsection{Evaluation of standard deviations from replicate measurement results.}

When the laboratory performs replicate measurements as a part of each procedure, it may be valuable to evaluate the standard deviation of the data pool for a measurement process. The within-process standard deviation is calculated for each set of replicate measurements in a data pool.

Once all of within process standard deviations, $s_{w}$, are calculated, they are analyzed using the F-max test. The F-max test uses the equation:

$$
F=\frac{s_{M a x}^{2}}{S_{M i n}^{2}}
$$

where s signifies the standard deviation of each data set being compared, the subscript "Max" refers to the larger (maximum) standard deviation in the data pool and the subscript "Min" refers to the smallest standard deviation in the data pool. Equation scenario 1 in Section 8.9.1 is identical to the one provided here, but as presented in that case, it is used when comparing two samples rather than sets of replicate data. Table 9.13 is used to evaluate the level of significance for the F-max test, taking into consideration the number of replicate samples. When the ratio of the variances is close to 1 , further analysis is not required.

This version of the F-test is useful when comparing many results from calibrations that use replicate measurements to determine a mean value, or several processes with similar equipment and standard deviations, especially in situations where check standards are not practical or feasible. For example, large prover volume calibrations of differing volumes that have similar within-process standard deviations, large mass weight carts where replicate measurements are made per SOP 33, or even multiple balances within a laboratory that are used for the same procedures. See Section 8.13 for more information on evaluation and use of the F-max test.

\subsection{Comparing a Set of Measurements with a Given Value}

The question may arise as to whether a measured value agrees or significantly disagrees with a stated value for the measured object. The evaluation can be based on whether or not the confidence interval for the measured value encompasses the stated value. The confidence interval is calculated using the expression: 


$$
\bar{x} \pm \frac{t s}{\sqrt{n}}
$$

as previously described in Section 8.6. In using this expression, $n$ represents the number of measurements used to calculate the mean, $\bar{x}$, and $t$ depends on the degrees of freedom, $v$, associated with $s$ and the confidence level needed when making the decision. Note that one may use historical data for estimating $s$, such as a control chart for example, in which case $v$ will represent the degrees of freedom associated with establishment of the control limits and may be considerably larger than $n-1$.

8.11 Comparing Two Sets of Measurements with Regard to Their Means (Two-sample t-test with 1. Equal variation and 2. Unequal variation)

This discussion is concerned with deciding whether the means of two measured values, A and $\mathrm{B}$, are in agreement. The data sets used for this purpose may consist of the following:

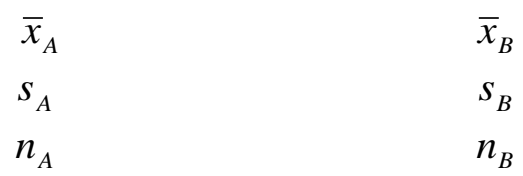

The first question to be resolved is whether $s_{A}$ and $s_{B}$ can be considered to be different estimates of the same standard deviation or whether they do, indeed, differ. An F-test may be used for this purpose. However, it will be recalled that this is not sensitive to small real differences, so the decision may need to be based on physical considerations, such as the known stability of the measurement process, for example.

\subsubsection{Case I - Equal variation}

Confirming (or assuming) that $s_{A}$ and $s_{B}$ are not significantly different, they are pooled, as already described (but repeated here for convenience) and used to calculate a confidence interval for the difference of the means. If this is larger than the observed difference, there is no reason to believe that the means differ. The steps to follow when making the calculation described above are:

Step 1. Choose $\alpha$, the level of significance for the test.

Step 2. Calculate the pooled estimate of the standard deviation, $s_{p}$ :

$$
s_{p}=\sqrt{\frac{\left(n_{A}-1\right) s_{A}^{2}+\left(n_{B}-1\right) s_{B}^{2}}{\left(n_{A}-1\right)+\left(n_{B}-1\right)}}
$$

$s_{p}$ will be estimated with $n_{\mathrm{A}}+n_{\mathrm{B}}-2$ degrees of freedom.

Step 3. Calculate the respective variances of the means:

$$
v_{A}=\frac{s_{A}^{2}}{n_{A}} \text { and } v_{B}=\frac{s_{B}^{2}}{n_{B}}
$$


Step 4. Calculate the uncertainty of $\left|\mathrm{X}_{\mathrm{A}}-\mathrm{X}_{\mathrm{B}}\right|=\Delta$ :

$$
U_{\Delta}=t \sqrt{\left(V_{A}+V_{B}\right)}
$$

using a value for $t$ based on $\frac{\alpha}{2}$ and $v=n_{A}+n_{B}-2$.

Step $5 . \quad$ Compare $U_{\Delta}$ with $\Delta$.

If $U_{\Delta} \geq \Delta$, there is no reason to believe that $\Delta$ is significant at the level of confidence chosen.

\subsubsection{Case II - Unequal variation}

Confirming (or assuming) that $s_{A}$ and $s_{B}$ are significantly different, their individual values are used to calculate $U_{\Delta}$ as outlined below.

Step 1. Choose $\alpha$, the level of significance for the test.

$$
v_{A}=\frac{s_{A}^{2}}{n_{A}} \text { and } v_{B}=\frac{s_{B}^{2}}{n_{B}}
$$

Step 2. Calculate the respective variances of the means:

Step 3. Calculate the uncertainty of $\left|\mathrm{X}_{\mathrm{A}}-\mathrm{X}_{\mathrm{B}}\right|=\Delta$ :

$$
U_{\Delta}=t \sqrt{\left(v_{A}+v_{B}\right)}
$$

using a value for $t$ based on $\frac{\alpha}{2}$ and $f$, the effective number of degrees of freedom calculated as described in Step 4.

Step 4. Calculate $f$, the effective number of degrees of freedom using the equation below or the Welch-Satterthwaite formula given in NIST Technical Note 1297 or the Guide to the Expression of Uncertainty in Measurement:

$$
f=\left(\frac{\left(V_{A}^{2}+V_{B}^{2}\right)}{\frac{V_{A}^{2}}{f_{A}}+\frac{V_{B}^{2}}{f_{B}}}\right)
$$

Step 5. $\quad$ Compare $U_{\Delta}$ with $\Delta$.

If $U_{\Delta} \geq \Delta$, there is no reason to believe that $\Delta$ is significant at the level of confidence chosen. 
One goal of these assessments is to determine if the difference between two mean values is less than the combined variation of the processes, keeping in mind that it does not evaluate the full uncertainty from a calibration process.

$$
\text { Is }\left|\bar{X}_{A}-\bar{x}_{B}\right|<t \sqrt{\frac{s_{A}^{2}}{n_{A}}+\frac{s_{B}^{2}}{n_{B}}} \text { ? }
$$

Note: Another common way to view this test and equation is as follows (as presented, this equation may be used for both Case I and Case II.

$$
\frac{\left|\bar{x}_{A}-\bar{x}_{B}\right|}{\sqrt{\frac{s_{A}^{2}}{n_{A}}+\frac{s_{B}^{2}}{n_{B}}}} \leq t_{\text {table }}
$$

\subsection{Use of Random Numbers}

Conducting operations in random sequences can avert problems of bias that might stem from a particular order of operations. For example, in the measurement of a series of items, it might be difficult to determine whether systematic trends in the measured values were due to differences in the items or to measurement system drift unless the items were measured in random order.

Use of tables of random numbers is a convenient means for randomizing measurement operations. The operations, test objects, and other matters requiring randomization may be assigned serial numbers. The order of selection is then determined by use of a random number table, as described below. When the number of operations or test items is less than 100, a table such as Table 9.11, reproduced from NIST Handbook 91 [19], may be used conveniently. One may start from any arbitrarily selected position in the table and proceed from it in any pre-determined arbitrary manner. If the first number encountered is not that of one of any item, ignore it and proceed until a valid match is encountered. This becomes the first item in the sequence. Continuing in the same manner, items are selected in the sequence in which their serial numbers are encountered ignoring the repetition of previously identified items. The procedure is continued until all items have been randomly selected.

As an example, select 10 specimens (numbered 01 to 10) in random order. Start from a randomly selected place, say column 2, row 5 of Table 9.11. Proceed from this point along the table as one would read a book. The starting number is 14, which is not usable. The first useful number encountered is 08 , the next 03 , and so on. Using the procedure described above, the following random order was found:

\begin{tabular}{||c|c|c|c|c|c|c|c|c|c||}
\hline \hline \multicolumn{10}{||c||}{ Specimen No. } \\
\hline \hline 08 & 03 & 09 & 05 & 06 & 02 & 07 & 10 & 04 & 01 \\
\hline \multicolumn{8}{|c|}{ Order } \\
\hline \hline 1 & 2 & 3 & 4 & 5 & 6 & 7 & 8 & 9 & 10 \\
\hline
\end{tabular}




\subsection{Estimating a Pooled Standard Deviation for Multiple Sets of Replicate Measurements}

When uncertainty estimates require the use of process variability and degrees of freedom from replicate measurements where check standards are not feasible, and where reported measurement results are mean values from replicate measurements, the following approaches may be applied.

Step 1. First calculate the within process standard deviation for each set of replicate measurements in a data pool.

Step 2. Once all of the within process standard deviations, $s_{w}$, are calculated, analyze them using the F-max test (Section 8.9, Case 3) to evaluate whether the levels of variability from replicate measurements are sufficiently similar. Table 9.13 is used to evaluate the level of significance for the F-max test, taking into consideration the number of replicate samples. When the ratio of the variances is close to 1 , further analysis is not required.

Step 3. If the standard deviations pass the F-max test, signifying that the samples in the data pool represent the same population of measurements, then following 8.4 above, calculate the pooled standard deviation of all measurements in the pool of values.

When a new $\mathrm{s}_{\mathrm{w}}$ value is obtained from additional replicate measurements, assess it with another F-test. If it is in statistical agreement with the other $s_{w}$ values, add it to the data pool and combine with the pooled $\mathrm{s}_{\mathrm{w}}$ values.

Using this method, within process standard deviations of measurement results that have unequal nominal values (and different measurement results) can be combined based on common parameters of the measurement system. These common parameters are typically a combination of factors like the resolution of the device where the measurement data originates, i.e., scale plate resolution or balance resolution, and similarity of the process, i.e., multiple deliveries from a volumetric standard or replicate weighings of a weight cart.

The pooled standard deviation is then treated as the process standard deviation, $s_{p}$, and combined in quadrature with other uncertainty components deemed significant to the measurement result per the measurement SOP and SOP 29.

$$
U_{(k=?)}=k \sqrt{\left(u_{s}^{2}+s_{p}^{2}+u_{1}^{2}+\ldots+u_{x}^{2}\right)}
$$

The degrees of freedom associated with the estimated process standard deviation are combined

based on $\left(n_{1}-1\right)+\left(n_{2}-1\right)+\left(n_{3}-1\right)+\ldots+\left(n_{k}-1\right)$ for each set of replicates in the data pool as shown in Section 8.4. Pooled degrees of freedom associated with this estimate of process variability are then used with other estimates of degrees of freedom to calculate effective degrees of freedom for the uncertainty using the usual methods.

The benefit of this process is to provide a better estimate for the standard deviation of a measurement process over time, and increase the degrees of freedom to reduce the coverage factor, $\mathrm{k}$, required for the uncertainty calculations. Monitoring the standard 
deviations of replicate processes on a standard deviation chart also allows visual assessment of the process, which helps to determine the stability of the variation over time.

\subsection{Calculating Effective Degrees of Freedom for Uncertainty Calculations}

The degrees of freedom used to calculate the uncertainty expansion factor, $k$, can be the degrees of freedom associated with the pooled standard deviation, or more correctly the effective degrees of freedom, $v_{\text {eff }}$, calculated using the Welch-Satterthwaite equation from the Guide to the Expression of Uncertainty in Measurement (JCGM 100:2008, G.4.1):

$$
v_{\text {eff }}=\frac{u_{c}^{4}}{\sum_{i=1}^{N} \frac{u_{i}^{4}(y)}{v_{i}}}
$$

For this application, we can rewrite this equation:

$$
v_{\text {eff }}=\frac{u_{c}^{4}}{\frac{u_{s}^{4}}{d f_{u_{s}}}+\frac{s_{p}^{4}}{d f_{s_{p}}}+\frac{u_{1}^{4}}{d f_{u 1}}+\ldots+\frac{u_{x}^{4}}{d f_{u_{x}}}}
$$

Table 4. Variables for equations in 8.14.

\begin{tabular}{|c|l|}
\hline Variable & \multicolumn{1}{c|}{ Description } \\
\hline \hline$u_{c}$ & combined standard uncertainty \\
\hline$u_{s}$ & standard uncertainty attributed to the standards used \\
\hline$u_{1}$ & first additional uncertainty component \\
\hline$u_{x}$ & $\mathrm{x}^{\text {th }}$ additional uncertainty component \\
\hline$s_{p}$ & $\begin{array}{l}\text { standard uncertainty attributed to the process obtained by using the } \\
\text { standard deviation of a check standard or the pooled standard deviation } \\
\text { of replicate measurements }\end{array}$ \\
\hline$d f$ & degrees of freedom associated with the indicated standard uncertainty \\
\hline
\end{tabular}

The Welch-Satterthwaite equation weights the impact of each uncertainty component based on the significance of the component to the overall uncertainty and considers the associated degrees of freedom of each component in the calculation. The components having a more significant uncertainty contribution also contribute more to the effective degrees of freedom calculation.

8.15 Comparing an Observed Value of a Check Standard to the Mean Value from a Control Chart Using the t-Statistic

A t-test may be incorporated to check the observed value of the check standard against the mean value using the following equation and a $95 \%$ confidence level. All values must be entered in the control chart, even if failing this statistic, to ensure the variability obtained for the process is not unduly reduced over time. The observed value of the check standard is compared to the accepted mean value of the check standard and divided by the standard deviation for the check standard observations over time. 


$$
t=\frac{\left(S_{c}-\overline{S_{c}}\right)}{S_{p}}
$$

This equation monitors the output of a measurement process compared to the stable value over time. A calculated t-value less than two is within the warning limits of the process. A calculated t-value between two and three represents a value between the warning limits and control/action limits. A calculated t-value exceeding three represents a value outside of the control/action limits and suitable action must be taken. Calculated values of the t-statistic may also be monitored over time to determine the presence of drift in the measurement standards.

This t-test is routinely incorporated into mass measurements, weighing designs, and the NIST Mass Code as standard practice.

\subsection{Comparing the Mean Value of a Check Standard to a Reference Value}

The Normalized Error, $E_{n}$, may be used to compare the mean value of a check standard, $S_{c}$ to the calibrated reference value, $S_{c(c a l)}$ taking care to ensure adequate metrological traceability for the reference value. The uncertainty of the reference value is taken from the calibration certificate and the uncertainty of the mean value is determined using the following equation, using the standard deviation of the process from the control chart, $s_{p}$, and where $n$ is the number of relevant data points; other components are the uncertainty for the standards, $u_{s}$, and any other critical components to be considered, $u_{o}$ based on the SOP in use. The coverage factor, $k$, is determined based on the desired level of confidence and the associated effective degrees of freedom.

$$
\begin{aligned}
& u_{c}=\sqrt{\frac{s_{p}^{2}}{n}+u_{s}^{2}}+u_{o}^{2} \\
& U_{\bar{S}_{c}}=u_{c} \times k
\end{aligned}
$$

$E_{n}$ is calculated using the following equation:

$$
E_{n}=\frac{\left|\bar{S}_{c}-S_{c(c a l)}\right|}{\sqrt{U_{\bar{S}_{c}}^{2}+U_{S_{c(c a l)}}^{2}}}
$$

The $E_{n}$ value must be less than one to pass. If the $E_{n}$ is greater than one, corrective action is required. In the usual method for propagating expanded uncertainties, standard uncertainties will be combined at the $k=1$ level, using the root sum square method, and then multiplied by the effective coverage factor. This version of the equation for normalized error is commonly used for proficiency testing.

Note: the reference value may exceed acceptable limits even when a measurement process appears statistically in control. When tolerances are large compared to process variability, reference value offsets may simply be noted. A control chart should be reviewed prior to performing this evaluation to ensure that the measurement process appears stable, otherwise, corrective action is needed prior to attempting this assessment. 


\section{Reference Tables}

Table 9.1 Use of Range to Estimate Standard Deviation

Table 9.2 Z Factors for Two-sided Confidence Intervals

Table 9.3 Student t-Variate (for Two-Sample t-Test for Equal Means)

Table 9.4 Critical Values for the F-test, $\mathrm{F}_{0.975}$

Table 9.5 Critical Values for the F-test, $\mathrm{F}_{0.99}$

Table 9.6 Two-sided Tolerance Interval Factors

Table 9.7 Factors for Computing Two-sided Confidence Intervals for $\alpha$

Table 9.8 Density of Air-free Water

Table 9.9 Density of Air

Table 9.10 Coefficient of Linear and Cubical Expansion for Materials Commonly Used in Laboratory Apparatus and Standards

Table 9.11 A Short Table of Random Numbers

Table 9.12 Critical Values for the F-test, $\mathrm{F}_{0.95}$

Table 9.13 Critical Values for the F-test, $F_{\max }$ 
Table 9.1 Use of Range to Estimate Standard Deviation

\begin{tabular}{|c|c|c|c|c|c|c|}
\hline \multirow{2}{*}{$\begin{array}{l}\text { Number of } \\
\text { Sets of } \\
\text { Replicates } \\
k \\
\end{array}$} & \multirow{2}{*}{$\begin{array}{l}\text { Factor } \\
\text { Degrees of } \\
\text { Freedom }\end{array}$} & \multicolumn{5}{|c|}{ Number of Replicates in a Set } \\
\hline & & 2 & 3 & 4 & 5 & 6 \\
\hline 1 & $\begin{array}{r}d_{2}^{*} \\
v\end{array}$ & $\begin{array}{l}1.41 \\
1.00\end{array}$ & $\begin{array}{l}1.91 \\
1.98\end{array}$ & $\begin{array}{l}2.24 \\
2.93\end{array}$ & $\begin{array}{l}2.48 \\
3.83\end{array}$ & $\begin{array}{l}2.67 \\
4.68\end{array}$ \\
\hline 3 & $\begin{array}{r}d_{2}^{*} \\
v\end{array}$ & $\begin{array}{l}1.23 \\
2.83\end{array}$ & $\begin{array}{l}1.77 \\
5.86\end{array}$ & $\begin{array}{l}2.12 \\
8.44\end{array}$ & $\begin{array}{l}2.38 \\
11.1\end{array}$ & $\begin{array}{l}2.58 \\
13.6\end{array}$ \\
\hline 5 & $\begin{array}{r}d_{2}^{*} \\
v\end{array}$ & $\begin{array}{l}1.19 \\
4.59\end{array}$ & $\begin{array}{l}1.74 \\
9.31\end{array}$ & $\begin{array}{l}2.10 \\
13.9\end{array}$ & $\begin{array}{l}2.36 \\
18.4\end{array}$ & $\begin{array}{l}2.56 \\
22.6\end{array}$ \\
\hline 10 & $\begin{array}{r}d_{2}^{*} \\
v\end{array}$ & $\begin{array}{l}1.16 \\
8.99\end{array}$ & $\begin{array}{l}1.72 \\
18.4\end{array}$ & $\begin{array}{l}2.08 \\
27.6\end{array}$ & $\begin{array}{l}2.34 \\
36.5\end{array}$ & $\begin{array}{l}2.55 \\
44.9\end{array}$ \\
\hline 15 & $\begin{array}{r}d_{2}^{*} \\
v\end{array}$ & $\begin{array}{l}1.15 \\
13.4\end{array}$ & $\begin{array}{l}1.71 \\
27.5\end{array}$ & $\begin{array}{l}2.07 \\
41.3\end{array}$ & $\begin{array}{l}2.34 \\
54.6\end{array}$ & $\begin{array}{l}2.54 \\
67.2\end{array}$ \\
\hline 20 & $\begin{array}{c}d_{2}^{*} \\
v\end{array}$ & $\begin{array}{l}1.14 \\
17.8\end{array}$ & $\begin{array}{l}1.70 \\
36.5\end{array}$ & $\begin{array}{l}2.07 \\
55.0\end{array}$ & $\begin{array}{l}2.33 \\
72.7\end{array}$ & $\begin{array}{l}2.54 \\
89.6\end{array}$ \\
\hline$\infty$ & $d_{2}^{*}$ & 1.13 & 1.69 & 2.06 & 2.33 & 2.53 \\
\hline & & & $=$ & & & \\
\hline
\end{tabular}

Intermediate values for $\mathrm{d}_{2}{ }^{*}$ and $v$ may be obtained by interpolation, or from the reference from which this table was adapted. Example: When using a Range chart for volume calibrations, based on two runs for each unknown test item, the $\mathrm{d}_{2}{ }^{*}$ value is 1.41 . If testing 10 points on a tape measure, using 3 runs, the average range value is calculated for all points and $\mathrm{d}_{2}{ }^{*}$ is 1.72 .

Adapted from Lloyd S. Nelson, J. Qual. Tech. 7 No. 1, January 1975. @American Society for Quality Control, Reprinted by permission. 
Table 9.2 Z-Factors for Two-sided Confidence Intervals for the Normal Distribution

\begin{tabular}{||c|l||}
\hline $\begin{array}{c}\text { Confidence Level } \\
\text { (\%) }\end{array}$ & Z Factor \\
\hline \hline 50 & 0.68 \\
\hline 67 & 1.00 \\
\hline 75 & 1.15 \\
\hline 90 & 1.645 \\
\hline 95 & 1.960 \\
\hline 95.28 & 2.000 \\
\hline 99.00 & 2.575 \\
\hline 99.74 & 3 \\
\hline 99.9934 & 4 \\
\hline 99.99995 & 5 \\
\hline $100,10^{-9}$ & 6 \\
\hline $100,10^{-12}$ & 7 \\
\hline $100,10^{-15}$ & 8 \\
\hline $100,10^{-18.9}$ & 9 \\
\hline $100,10^{-23}$ & 10 \\
\hline & \\
\hline & \\
\hline
\end{tabular}


Table 9.3 Student t-Variate

\begin{tabular}{||c|c|c|c|c|c|c||}
\hline$*$ & $80 \%$ & $90 \%$ & $95 \%$ & $98 \%$ & $99 \%$ & $99.73 \%$ \\
\hline d.f. & $\mathrm{t}_{0.90}$ & $\mathrm{t}_{0.95}$ & $\mathrm{t}_{0.975}$ & $\mathrm{t}_{0.99}$ & $\mathrm{t}_{0.995}$ & $\mathrm{t}_{0.9985}$ \\
\hline \hline 1 & 3.078 & 6.314 & 12.706 & 31.821 & 63.657 & 235.80 \\
\hline 2 & 1.886 & 2.920 & 4.303 & 6.965 & 9.925 & 19.207 \\
\hline 3 & 1.638 & 2.353 & 3.182 & 4.541 & 5.841 & 9.219 \\
\hline 4 & 1.533 & 2.132 & 2.776 & 3.747 & 4.604 & 6.620 \\
\hline 5 & 1.476 & 2.015 & 2.571 & 3.365 & 4.032 & 5.507 \\
\hline \hline 6 & 1.440 & 1.943 & 2.447 & 3.143 & 3.707 & 4.904 \\
\hline 7 & 1.415 & 1.895 & 2.365 & 2.998 & 3.499 & 4.530 \\
\hline 8 & 1.397 & 1.860 & 2.306 & 2.896 & 3.355 & 4.277 \\
\hline 9 & 1.383 & 1.833 & 2.262 & 2.821 & 3.250 & 4.094 \\
\hline 10 & 1.372 & 1.812 & 2.228 & 2.764 & 3.169 & 3.957 \\
\hline \hline 11 & 1.363 & 1.796 & 2.201 & 2.718 & 3.106 & 3.850 \\
\hline 12 & 1.356 & 1.782 & 2.179 & 2.681 & 3.055 & 3.764 \\
\hline 13 & 1.350 & 1.771 & 2.160 & 2.650 & 3.012 & 3.694 \\
\hline 14 & 1.345 & 1.761 & 2.145 & 2.624 & 2.977 & 3.636 \\
\hline 15 & 1.341 & 1.753 & 2.131 & 2.602 & 2.947 & 3.586 \\
\hline \hline 16 & 1.337 & 1.746 & 2.120 & 2.583 & 2.921 & 3.544 \\
\hline 17 & 1.333 & 1.740 & 2.110 & 2.567 & 2.898 & 3.507 \\
\hline 18 & 1.330 & 1.734 & 2.101 & 2.552 & 2.878 & 3.475 \\
\hline 19 & 1.328 & 1.729 & 2.093 & 2.539 & 2.861 & 3.447 \\
\hline 20 & 1.325 & 1.725 & 2.086 & 2.528 & 2.845 & 3.422 \\
\hline \hline 25 & 1.316 & 1.708 & 2.060 & 2.485 & 2.787 & 3.330 \\
\hline 30 & 1.310 & 1.697 & 2.042 & 2.457 & 2.750 & 3.270 \\
\hline 40 & 1.303 & 1.684 & 2.021 & 2.423 & 2.704 & 3.199 \\
\hline 60 & 1.296 & 1.671 & 2.000 & 2.390 & 2.660 & 3.130 \\
\hline$\infty$ & 1.282 & 1.645 & 1.960 & 2.326 & 2.576 & 3.00 \\
\hline \hline
\end{tabular}

* Columns to be used in calculating corresponding two-sided confidence interval. From: NIST Handbook 91 p. T-5; Last column from B.J. Joiner, J. Research NIST. (for Two-Sample t-Test for Equal Means) 
Table 9.4 Critical values for the F-Test, $F_{0.975}$

$\mathrm{n}_{1}=$ degrees of freedom for numerator $\quad \mathrm{n}_{2}=$ degrees of freedom for denominator

\begin{tabular}{|c|c|c|c|c|c|c|c|c|c|c|c|c|c|c|c|c|}
\hline $\mathrm{n}_{2}$ & 1 & 2 & 3 & 4 & 5 & 6 & 7 & 8 & 9 & 10 & 12 & 15 & 20 & 24 & 30 & 40 \\
\hline 1 & 647.8 & 799.5 & 864.2 & 899.6 & 921.8 & 937.1 & 948.2 & 956.7 & 963.3 & 968.6 & 976.7 & 984.9 & 993.1 & 997.2 & 1001 & 1006 \\
\hline 2 & 38.51 & 39.00 & 39.17 & 39.25 & 39.30 & 39.33 & 39.36 & 39.37 & 39.39 & 39.40 & 39.41 & 39.43 & 39.45 & 39.46 & 39.46 & 39.47 \\
\hline 3 & 17.44 & 16.04 & 15.44 & 15.10 & 14.88 & 14.73 & 14.62 & 14.54 & 14.47 & 14.42 & 14.34 & 14.25 & 14.17 & 14.12 & 14.08 & 14.04 \\
\hline 4 & 12.22 & 10.65 & 9.98 & 9.60 & 9.36 & 9.20 & 9.07 & 8.98 & 8.90 & 8.84 & 8.75 & 8.66 & 8.56 & 8.51 & 8.46 & 8.41 \\
\hline 5 & 10.01 & 8.43 & 7.76 & 7.39 & 7.15 & 6.98 & 6.85 & 6.76 & 6.68 & 6.62 & 6.52 & 6.43 & 6.33 & 6.28 & 6.23 & 6.18 \\
\hline 6 & 8.81 & 7.26 & 6.60 & 6.23 & 5.99 & 5.83 & 5.70 & 5.60 & 5.52 & 5.46 & 5.37 & 5.27 & 5.17 & 5.12 & 5.07 & 5.01 \\
\hline 7 & 8.07 & 6.54 & 5.89 & 5.52 & 5.29 & 5.12 & 4.99 & 4.90 & 4.82 & 4.76 & 4.67 & 4.57 & 4.47 & 4.42 & 4.36 & 4.31 \\
\hline 8 & 7.57 & 6.06 & 5.42 & 5.05 & 4.82 & 4.65 & 4.53 & 4.43 & 4.36 & 4.30 & 4.20 & 4.10 & 4.00 & 3.95 & 3.89 & 3.84 \\
\hline 9 & 7.21 & 5.71 & 5.08 & 4.72 & 4.48 & 4.32 & 4.20 & 4.10 & 4.03 & 3.96 & 3.87 & 3.77 & 3.67 & 3.61 & 3.56 & 3.51 \\
\hline 10 & 6.94 & 5.46 & 4.83 & 4.47 & 4.24 & 4.07 & 3.95 & 3.85 & 3.78 & 3.72 & 3.62 & 3.52 & 3.42 & 3.37 & 3.31 & 3.26 \\
\hline 11 & 6.72 & 5.26 & 4.63 & 4.28 & 4.04 & 3.88 & 3.76 & 3.66 & 3.59 & 3.53 & 3.43 & 3.33 & 3.23 & 3.17 & 3.12 & 3.06 \\
\hline 12 & 6.55 & 5.10 & 4.47 & 4.12 & 3.89 & 3.73 & 3.61 & 3.51 & 3.44 & 3.37 & 3.28 & 3.18 & 3.07 & 3.02 & 2.96 & 2.91 \\
\hline 13 & 6.41 & 4.97 & 4.35 & 4.00 & 3.77 & 3.60 & 3.48 & 3.39 & 3.31 & 3.25 & 3.15 & 3.05 & 2.95 & 2.89 & 2.84 & 2.78 \\
\hline 14 & 6.30 & 4.86 & 4.24 & 3.89 & 3.66 & 3.50 & 3.38 & 3.29 & 3.21 & 3.15 & 3.05 & 2.95 & 2.84 & 2.79 & 2.73 & 2.67 \\
\hline 15 & 6.20 & 4.77 & 4.15 & 3.80 & 3.58 & 3.41 & 3.29 & 3.20 & 3.12 & 3.06 & 2.96 & 2.86 & 2.76 & 2.70 & 2.64 & 2.59 \\
\hline 16 & 6.12 & 4.69 & 4.08 & 3.73 & 3.50 & 3.34 & 3.22 & 3.12 & 3.05 & 2.99 & 2.89 & 2.79 & 2.68 & 2.63 & 2.57 & 2.51 \\
\hline 17 & 6.04 & 4.62 & 4.01 & 3.66 & 3.44 & 3.28 & 3.16 & 3.06 & 2.98 & 2.92 & 2.82 & 2.72 & 2.62 & 2.56 & 2.50 & 2.44 \\
\hline 18 & 5.98 & 4.56 & 3.95 & 3.61 & 3.38 & 3.22 & 3.10 & 3.01 & 2.93 & 2.87 & 2.77 & 2.67 & 2.56 & 2.50 & 2.44 & 2.38 \\
\hline 19 & 5.92 & 4.51 & 3.90 & 3.56 & 3.33 & 3.17 & 3.05 & 2.96 & 2.88 & 2.82 & 2.72 & 2.62 & 2.51 & 2.45 & 2.39 & 2.33 \\
\hline 20 & 5.87 & 4.46 & 3.86 & 3.51 & 3.29 & 3.13 & 3.01 & 2.91 & 2.84 & 2.77 & 2.68 & 2.57 & 2.46 & 2.41 & 2.35 & 2.29 \\
\hline 21 & 5.83 & 4.42 & 3.82 & 3.48 & 3.25 & 3.09 & 2.97 & 2.87 & 2.80 & 2.73 & 2.64 & 2.53 & 2.42 & 2.37 & 2.31 & 2.25 \\
\hline 22 & 5.79 & 4.38 & 3.78 & 3.44 & 3.22 & 3.05 & 2.93 & 2.84 & 2.76 & 2.70 & 2.60 & 2.50 & 2.39 & 2.33 & 2.27 & 2.21 \\
\hline 23 & 5.75 & 4.35 & 3.75 & 3.41 & 3.18 & 3.02 & 2.90 & 2.81 & 2.73 & 2.67 & 2.57 & 2.47 & 2.36 & 2.30 & 2.24 & 2.18 \\
\hline 24 & 5.72 & 4.32 & 3.72 & 3.38 & 3.15 & 2.99 & 2.87 & 2.78 & 2.70 & 2.64 & 2.54 & 2.44 & 2.33 & 2.27 & 2.21 & 2.15 \\
\hline 25 & 5.69 & 4.29 & 3.69 & 3.35 & 3.13 & 2.97 & 2.85 & 2.75 & 2.68 & 2.61 & 2.51 & 2.41 & 2.30 & 2.24 & 2.18 & 2.12 \\
\hline 26 & 5.66 & 4.27 & 3.67 & 3.33 & 3.10 & 2.94 & 2.82 & 2.73 & 2.65 & 2.59 & 2.49 & 2.39 & 2.28 & 2.22 & 2.16 & 2.09 \\
\hline 27 & 5.63 & 4.24 & 3.65 & 3.31 & 3.08 & 2.92 & 2.80 & 2.71 & 2.63 & 2.57 & 2.47 & 2.36 & 2.25 & 2.19 & 2.13 & 2.07 \\
\hline 28 & 5.61 & 4.22 & 3.63 & 3.29 & 3.06 & 2.90 & 2.78 & 2.69 & 2.61 & 2.55 & 2.45 & 2.34 & 2.23 & 2.17 & 2.11 & 2.05 \\
\hline 29 & 5.59 & 4.20 & 3.61 & 3.27 & 3.04 & 2.88 & 2.76 & 2.67 & 2.59 & 2.53 & 2.43 & 2.32 & 2.21 & 2.15 & 2.09 & 2.03 \\
\hline 30 & 5.57 & 4.18 & 3.59 & 3.25 & 3.03 & 2.87 & 2.75 & 2.65 & 2.57 & 2.51 & 2.41 & 2.31 & 2.20 & 2.14 & 2.07 & 2.01 \\
\hline 40 & 5.42 & 4.05 & 3.46 & 3.13 & 2.90 & 2.74 & 2.62 & 2.53 & 2.45 & 2.39 & 2.29 & 2.18 & 2.07 & 2.01 & 1.94 & 1.88 \\
\hline 60 & 5.29 & 3.93 & 3.34 & 3.01 & 2.79 & 2.63 & 2.51 & 2.41 & 2.33 & 2.27 & 2.17 & 2.06 & 1.94 & 1.88 & 1.82 & 1.74 \\
\hline 120 & 5.15 & 3.80 & 3.23 & 2.89 & 2.67 & 2.52 & 2.39 & 2.30 & 2.22 & 2.16 & 2.05 & 1.94 & 1.82 & 1.76 & 1.69 & 1.61 \\
\hline$\infty$ & 5.02 & 3.69 & 3.12 & 2.79 & 2.57 & 2.41 & 2.29 & 2.19 & 2.11 & 2.05 & 1.94 & 1.83 & 1.71 & 1.64 & 1.57 & 1.48 \\
\hline
\end{tabular}

For use for a one-tailed test of equality of standard deviation estimate at $2.5 \%$ level of confidence, or for a two-tailed test at $5 \%$ level of confidence. 
Table 9.5 Critical values for the F-Test, $F_{0.99}$

$v_{1}=$ degrees of freedom for numerator $\quad v_{2}=$ degrees of freedom for denominator

\begin{tabular}{|c|c|c|c|c|c|c|c|c|c|c|}
\hline & 1 & 2 & 3 & 4 & 5 & 6 & 7 & 8 & 9 & 10 \\
\hline 10 & 10.04 & 7.56 & 6.55 & 5.99 & 5.64 & 5.39 & 5.20 & 5.06 & 4.94 & 4.85 \\
\hline 11 & 9.65 & 7.21 & 6.22 & 5.67 & 5.32 & 5.07 & 4.89 & 4.74 & 4.63 & 4.54 \\
\hline 12 & 9.33 & 6.93 & 5.95 & 5.41 & 5.06 & 4.82 & 4.64 & 4.50 & 4.39 & 4.30 \\
\hline 13 & 9.07 & 6.70 & 5.74 & 5.21 & 4.86 & 4.62 & 4.44 & 4.30 & 4.19 & 4.10 \\
\hline 14 & 8.86 & 6.51 & 5.56 & 5.04 & 4.69 & 4.46 & 4.28 & 4.14 & 4.03 & 3.94 \\
\hline 15 & 8.68 & 6.36 & 5.42 & 4.89 & 4.56 & 4.32 & 4.14 & 4.00 & 3.89 & 3.80 \\
\hline 16 & 8.53 & 6.23 & 5.29 & 4.77 & 4.44 & 4.20 & 4.03 & 3.89 & 3.78 & 3.69 \\
\hline 17 & 8.40 & 6.11 & 5.18 & 4.67 & 4.34 & 4.10 & 3.93 & 3.79 & 3.68 & 3.59 \\
\hline 18 & 8.29 & 6.01 & 5.09 & 4.58 & 4.25 & 4.01 & 3.84 & 3.71 & 3.60 & 3.51 \\
\hline 19 & 8.18 & 5.93 & 5.01 & 4.50 & 4.17 & 3.94 & 3.77 & 3.63 & 3.52 & 3.43 \\
\hline 20 & 8.10 & $\bar{c} 5.85$ & 4.94 & 4.43 & 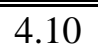 & 3.87 & $\begin{array}{l}3.70 \\
\end{array}$ & 3.56 & 3.46 & ב3.37 \\
\hline 22 & 7.95 & 5.72 & 4.82 & 4.31 & 3.99 & 3.76 & 3.59 & 3.45 & 3.35 & 3.26 \\
\hline 24 & 7.82 & 5.61 & 4.72 & 4.22 & 3.90 & 3.67 & 3.50 & 3.36 & 3.26 & 3.17 \\
\hline 26 & 7.72 & 5.53 & 4.64 & 4.14 & 3.82 & 3.59 & 3.42 & 3.29 & 3.18 & 3.09 \\
\hline 28 & 7.64 & 5.45 & 4.57 & 4.07 & 3.75 & 3.53 & 3.36 & 3.23 & 3.12 & 3.03 \\
\hline 30 & 7.56 & 5.39 & 4.51 & 4.02 & 3.70 & 3.47 & 3.30 & 3.17 & 3.07 & 2.98 \\
\hline 35 & 7.42 & 5.27 & 4.40 & 3.91 & 3.59 & 3.37 & 3.20 & 3.07 & 2.96 & 2.88 \\
\hline 40 & 7.31 & 5.18 & 4.31 & 3.83 & 3.51 & 3.29 & 3.12 & 2.99 & 2.89 & 2.80 \\
\hline 45 & 7.23 & 5.11 & 4.25 & 3.77 & 3.45 & 3.23 & 3.07 & 2.94 & 2.83 & 2.74 \\
\hline 50 & 7.17 & 5.06 & 4.20 & 3.72 & 3.41 & 3.19 & 3.02 & 2.89 & 2.78 & 2.70 \\
\hline 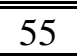 & 7.12 & 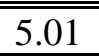 & 4.16 & 3.68 & 3.37 & 3.15 & 2.98 & 2.85 & 2.75 & 2.66 \\
\hline 60 & 7.08 & 4.98 & 4.13 & 3.65 & 3.34 & 3.12 & 2.95 & 2.82 & 2.72 & 2.63 \\
\hline 65 & 7.04 & 4.95 & 4.10 & 3.62 & 3.31 & 3.09 & 2.93 & 2.80 & 2.69 & 2.61 \\
\hline 70 & 7.01 & 4.92 & 4.07 & 3.60 & 3.29 & 3.07 & 2.91 & 2.78 & 2.67 & 2.59 \\
\hline 75 & 6.99 & 4.90 & 4.05 & 3.58 & 3.27 & 3.05 & 2.89 & 2.76 & 2.65 & 2.57 \\
\hline 80 & 6.96 & 4.88 & 4.04 & 3.56 & 3.25 & 3.04 & 2.87 & 2.74 & 2.64 & 2.55 \\
\hline 85 & 6.94 & 4.86 & 4.02 & 3.55 & 3.24 & 3.02 & 2.86 & 2.73 & 2.62 & 2.54 \\
\hline 90 & 6.93 & 4.85 & 4.01 & 3.53 & 3.23 & 3.01 & 2.84 & 2.72 & 2.61 & 2.52 \\
\hline 95 & 6.91 & 4.84 & 3.99 & 3.52 & 3.22 & 3.00 & 2.83 & 2.70 & 2.60 & 2.51 \\
\hline 100 & 6.90 & 4.82 & 3.98 & 3.51 & 3.21 & 2.99 & 2.82 & 2.69 & 2.59 & 2.50 \\
\hline 105 & 6.88 & 4.81 & 3.97 & 3.50 & 3.20 & 2.98 & 2.81 & 2.69 & 2.58 & 2.49 \\
\hline 110 & 6.87 & 4.80 & 3.96 & 3.49 & 3.19 & 2.97 & 2.81 & 2.68 & 2.57 & 2.49 \\
\hline 115 & 6.86 & 4.79 & 3.96 & 3.49 & 3.18 & 2.96 & 2.80 & 2.67 & 2.57 & 2.48 \\
\hline 120 & 6.85 & 4.79 & 3.95 & 3.48 & 3.17 & 2.96 & 2.79 & 2.66 & 2.56 & 2.47 \\
\hline$\infty$ & 6.63 & 4.61 & 3.78 & 3.32 & 3.02 & 2.80 & 2.64 & 2.51 & 2.41 & 2.32 \\
\hline
\end{tabular}

For use for a one-tailed test of equality of standard deviation estimate at $1 \%$ level of confidence, or for a two-tailed test at $2 \%$ level of confidence. 
Table 9.6 Factors for Two-sided Tolerance Intervals

for the Normal Distribution

\begin{tabular}{|c|c|c|c|c|c|c|c|c|c|c|}
\hline & \multicolumn{5}{|c|}{$=0.95$} & \multicolumn{5}{|c|}{$=0.99$} \\
\hline & 0.75 & 0.90 & 0.95 & 0.99 & 0.999 & 0.75 & 0.90 & 0.95 & 0.99 & 0.999 \\
\hline 2 & 22.858 & 32.019 & 37.674 & 48.430 & 60.573 & 114.363 & 160.193 & 188.491 & 242.300 & 303.054 \\
\hline 3 & 5.922 & 8.380 & 9.916 & 12.861 & 16.208 & 13.378 & 18.930 & 22.401 & 29.055 & 36.616 \\
\hline 4 & 3.779 & 5.369 & 6.370 & 8.299 & 10.502 & 6.614 & 9.398 & 11.150 & 14.527 & 18.383 \\
\hline 5 & 3.002 & 4.275 & 5.079 & 6.634 & 8.415 & 4.643 & 6.612 & 7.855 & 10.260 & 13.015 \\
\hline 6 & 2.604 & 3.712 & 4.414 & 5.775 & 7.337 & 3.743 & 5.337 & 6.345 & 8.301 & 10.548 \\
\hline 7 & 2.361 & 3.369 & 4.007 & 5.248 & 6.676 & 3.233 & 4.613 & 5.488 & 7.187 & 9.142 \\
\hline 8 & 2.197 & 3.136 & 3.732 & 4.891 & 6.226 & 2.905 & 4.147 & 4.936 & 6.468 & 8.234 \\
\hline 9 & 2.078 & 2.967 & 3.532 & 4.631 & 5.899 & 2.677 & 3.822 & 4.550 & 5.966 & 7.600 \\
\hline 10 & 1.987 & 2.839 & 3.379 & 4.433 & 5.649 & 2.508 & 3.582 & 4.265 & 5.594 & 7.129 \\
\hline 11 & 1.916 & 2.737 & 3.259 & 4.277 & 5.452 & 2.378 & 3.397 & 4.045 & 5.308 & 6.766 \\
\hline 12 & 1.858 & 2.655 & 3.162 & 4.150 & 5.291 & 2.274 & 3.250 & 3.870 & 5.079 & 6.477 \\
\hline 13 & 1.810 & 2.587 & 3.081 & 4.044 & 5.158 & 2.190 & 3.130 & 3.727 & 4.893 & 6.240 \\
\hline 14 & 1.770 & 2.529 & 3.012 & 3.955 & 5.045 & 2.120 & 3.029 & 3.608 & 4.737 & 6.043 \\
\hline 15 & 1.735 & 2.480 & 2.954 & 3.878 & 4.949 & 2.060 & 2.945 & 3.507 & 4.605 & 5.876 \\
\hline 16 & 1.705 & 2.437 & 2.903 & 3.812 & 4.865 & 2.009 & 2.872 & 3.421 & 4.492 & 5.732 \\
\hline 17 & 1.679 & 2.400 & 2.858 & 3.754 & 4.791 & 1.965 & 2.808 & 3.345 & 4.393 & 5.607 \\
\hline 18 & 1.655 & 2.366 & 2.819 & 3.702 & 4.725 & 1.926 & 2.753 & 3.279 & 4.307 & 5.497 \\
\hline 19 & 1.635 & 2.337 & 2.784 & 3.656 & 4.667 & 1.891 & 2.703 & 3.221 & 4.230 & 5.399 \\
\hline 20 & 1.616 & 2.310 & 2.752 & 3.612 & 4.614 & 1.860 & 2.659 & 3.168 & 4.161 & 5.312 \\
\hline 21 & 1.599 & 2.286 & 2.723 & 3.577 & 4.567 & 1.833 & 2.620 & 3.121 & 4.100 & 5.234 \\
\hline 22 & 1.584 & 2.264 & 2.697 & 3.543 & 4.523 & 1.808 & 2.584 & 3.078 & 4.044 & 5.163 \\
\hline 23 & 1.570 & 2.244 & 2.673 & 3.512 & 4.484 & 1.785 & 2.551 & 3.040 & 3.993 & 5.098 \\
\hline 24 & 1.557 & 2.225 & 2.651 & 3.483 & 4.447 & 1.764 & 2.522 & 3.004 & 3.947 & 5.039 \\
\hline 25 & 1.545 & 2.208 & 2.631 & 3.457 & 4.413 & 1.745 & 2.494 & 2.972 & 3.904 & 4.985 \\
\hline 26 & 1.534 & 2.193 & 2.612 & 3.432 & 4.382 & 1.727 & 2.469 & 2.941 & 3.865 & 4.935 \\
\hline 27 & 1.523 & 2.178 & 2.595 & 3.409 & 4.353 & 1.711 & 2.446 & 2.914 & 3.828 & 4.888 \\
\hline
\end{tabular}

From: NBS Handbook 91, p T-11 
Table 9.7 Factors for Computing Two-sided Confidence Limits for $\alpha$ (Part 1)

\begin{tabular}{|c|c|c|c|c|c|c|}
\hline \multirow{2}{*}{ 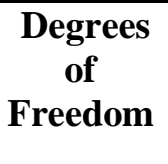 } & \multicolumn{2}{|c|}{$\alpha=\mathbf{0 . 0 5}$} & \multicolumn{2}{|c|}{$\alpha=\mathbf{0 . 0 1}$} & \multicolumn{2}{|c|}{$\alpha=\mathbf{0 . 0 0 1}$} \\
\hline & $\mathbf{S}_{\mathbf{U}}$ & $S_{L}$ & $\mathbf{S}_{\mathbf{U}}$ & $S_{L}$ & $\mathbf{S}_{\mathbf{U}}$ & $S_{L}$ \\
\hline 1 & 17.79 & 0.3576 & 86.31 & 0.2969 & 844.4 & 0.2480 \\
\hline 2 & 4.859 & 0.4581 & 10.70 & 0.3879 & 33.29 & 0.3291 \\
\hline 3 & 3.183 & 0.5178 & 5.449 & 0.4453 & 11.65 & 0.3824 \\
\hline 4 & 2.567 & 0.5590 & 3.892 & 0.4865 & 6.938 & 0.4218 \\
\hline 5 & 2.248 & 0.5899 & 3.175 & 0.5182 & 5.085 & 0.4529 \\
\hline 6 & 2.052 & 0.6143 & 2.764 & 0.5437 & 4.128 & 0.4784 \\
\hline 7 & 1.918 & 0.6344 & 2.498 & 0.5650 & 3.551 & 0.5000 \\
\hline 8 & 1.820 & 0.6513 & 2.311 & 0.5830 & 3.167 & 0.5186 \\
\hline 9 & 1.746 & 0.6657 & 2.173 & 0.5987 & 2.894 & 0.5348 \\
\hline 10 & 1.686 & 0.6784 & 2.065 & 0.6125 & 2.689 & 0.5492 \\
\hline 11 & 1.638 & 0.6896 & 1.980 & 0.6248 & 2.530 & 0.5621 \\
\hline 12 & 1.598 & 0.6995 & 1.909 & 0.6358 & 2.402 & 0.5738 \\
\hline 13 & 1.564 & 0.7084 & 1.851 & 0.6458 & 2.298 & 0.5845 \\
\hline 14 & 1.534 & 0.7166 & 1.801 & 0.6549 & 2.210 & 0.5942 \\
\hline 15 & 1.509 & 0.7240 & 1.758 & 0.6632 & 2.136 & 0.6032 \\
\hline 16 & 1.486 & 0.7808 & 1.721 & 0.6710 & 2.073 & 0.6116 \\
\hline 17 & 1.466 & 0.7372 & 1.688 & 0.6781 & 2.017 & 0.6193 \\
\hline 18 & 1.448 & 0.7430 & 1.658 & 0.6848 & 1.968 & 0.6266 \\
\hline 19 & 1.432 & 0.7484 & 1.632 & 0.6909 & 1.925 & 0.6333 \\
\hline 20 & 1.417 & 0.7535 & 1.609 & 0.6968 & 1.886 & 0.6397 \\
\hline 21 & 1.404 & 0.7582 & 1.587 & 0.7022 & 1.851 & 0.6457 \\
\hline 22 & 1.391 & 0.7627 & 1.568 & 0.7074 & 1.820 & 0.6514 \\
\hline 23 & 1.380 & 0.7669 & 1.550 & 0.7122 & 1.791 & 0.6568 \\
\hline 24 & 1.370 & 0.7709 & 1.533 & 0.7169 & 1.765 & 0.6619 \\
\hline 25 & 1.360 & 0.7747 & 1.518 & 0.7212 & 1.741 & 0.6668 \\
\hline
\end{tabular}

From: NBS Handbook 91, p T-34 
Table 9.7 Factors for Computing Two-sided Confidence Limits for $\alpha$ (Part 2)

\begin{tabular}{|c|c|c|c|c|c|c|}
\hline \multirow{2}{*}{$\begin{array}{l}\text { Degrees of } \\
\text { Freedom }\end{array}$} & \multicolumn{2}{|c|}{$\alpha=\mathbf{0 . 0 5}$} & \multicolumn{2}{|c|}{$\alpha=\mathbf{0 . 0 1}$} & \multicolumn{2}{|c|}{$\alpha=\mathbf{0 . 0 0 1}$} \\
\hline & $\mathbf{S}_{\mathbf{U}}$ & $\mathbf{S}_{\mathbf{L}}$ & $\mathrm{S}_{\mathrm{U}}$ & $S_{L}$ & $\mathbf{S}_{\mathbf{U}}$ & $\mathbf{S}_{\mathbf{L}}$ \\
\hline 26 & 1.351 & 0.7783 & 1.504 & 0.7253 & 1.719 & 0.7130 \\
\hline 27 & 1.343 & 0.7817 & 1.491 & 0.7293 & 1.698 & 0.6758 \\
\hline 28 & 1.335 & 0.7849 & 1.479 & 0.7331 & 1.679 & 0.6800 \\
\hline 29 & 1.327 & 0.7880 & 1.467 & 0.7367 & 1.661 & 0.6841 \\
\hline 30 & 1.321 & 0.7909 & 1.457 & 0.7401 & 1.645 & 0.6880 \\
\hline 31 & 1.314 & 0.7937 & 1.447 & 0.7434 & 1.629 & 0.6917 \\
\hline 32 & 1.308 & 0.7964 & 1.437 & 0.7467 & 1.615 & 0.6953 \\
\hline 33 & 1.302 & 0.7990 & 1.428 & 0.7497 & 1.601 & 0.6987 \\
\hline 34 & 1.296 & 0.8015 & 1.420 & 0.7526 & 1.588 & 0.7020 \\
\hline 35 & 1.291 & 0.8089 & 1.412 & 0.7554 & 1.576 & 0.7052 \\
\hline 36 & 1.286 & 0.8062 & 1.404 & 0.7582 & 1.564 & 0.7083 \\
\hline 37 & 1.281 & 0.8085 & 1.397 & 0.7608 & 1.553 & 0.7113 \\
\hline 38 & 1.277 & 0.8106 & 1.390 & 0.7633 & 1.543 & 0.7141 \\
\hline 39 & 1.272 & 0.8126 & 1.383 & 0.7658 & 1.533 & 0.7169 \\
\hline 40 & 1.268 & 0.8146 & 1.377 & 0.7681 & 1.523 & 0.7197 \\
\hline 41 & 1.264 & 0.8166 & 1.371 & 0.7705 & 1.515 & 0.7223 \\
\hline 42 & 1.260 & 0.8184 & 1.365 & 0.7727 & 1.506 & 0.7248 \\
\hline 43 & 1.257 & 0.8202 & 1.360 & 0.7748 & 1.498 & 0.7273 \\
\hline 44 & 1.253 & 0.8220 & 1.355 & 0.7769 & 1.490 & 0.7297 \\
\hline 45 & 1.249 & 0.8237 & 1.349 & 0.7789 & 1.482 & 0.7320 \\
\hline 46 & 1.246 & 0.8253 & 1.345 & 0.7809 & 1.475 & 0.7342 \\
\hline 47 & 1.243 & 0.8269 & 1.340 & 0.7828 & 1.468 & 0.7364 \\
\hline 48 & 1.240 & 0.8285 & 1.335 & 0.7847 & 1.462 & 0.7386 \\
\hline 49 & 1.237 & 0.8300 & 1.331 & 0.7864 & 1.455 & 0.7407 \\
\hline 50 & 1.234 & 0.8314 & 1.327 & 0.7882 & 1.449 & 0.7427 \\
\hline
\end{tabular}

From: NBS Handbook 91, p. T-34 
Table 9.8 Density of Air-free Water in $\mathrm{g} / \mathrm{cm}^{3}$ as a Function of Celsius Temperature

\begin{tabular}{|c|c|c|c|c|c|c|c|c|c|c|}
\hline $\mathbf{T}$ & $0.0^{\circ} \mathrm{C}$ & $0.1^{\circ} \mathrm{C}$ & $0.2^{\circ} \mathrm{C}$ & $0.3^{\circ} \mathrm{C}$ & $0.4^{\circ} \mathrm{C}$ & $0.5^{\circ} \mathrm{C}$ & $0.6^{\circ} \mathrm{C}$ & $0.7^{\circ} \mathrm{C}$ & $0.8^{\circ} \mathrm{C}$ & $0.9^{\circ} \mathrm{C}$ \\
\hline 0.0 & 0.999840 & 0.999846 & 0.999853 & 0.999859 & 0.999865 & 0.999871 & 0.999877 & 0.999883 & 0.999888 & 0.999893 \\
\hline 1.0 & 0.999899 & 0.999903 & 0.999908 & 0.999913 & 0.999917 & 0.999921 & 0.999925 & 0.999929 & 0.999933 & $\begin{array}{l:l}0.999 & 937\end{array}$ \\
\hline 2.0 & 0.999940 & 0.999943 & 0.999946 & 0.999949 & 0.999952 & 0.999954 & 0.999956 & 0.999959 & 0.999961 & 0.999963 \\
\hline 3.0 & 0.999964 & 0.999966 & 0.999967 & 0.999968 & 0.999969 & 0.999970 & 0.999971 & 0.999971 & 0.999972 & $\begin{array}{l}0.999972 \\
\end{array}$ \\
\hline 4.0 & 0.999972 & 0.999972 & 0.999972 & 0.999971 & 0.999971 & 0.999970 & 0.999969 & 0.999968 & 0.999967 & 0.999965 \\
\hline 5.0 & 0.999964 & 0.999962 & 0.999960 & 0.999958 & 0.999956 & 0.999954 & 0.999951 & 0.999949 & 0.999946 & 0.999943 \\
\hline 6.0 & 0.999940 & 0.999937 & 0.999933 & 0.999930 & 0.999926 & 0.999922 & 0.999918 & 0.999914 & 0.999910 & 0.999906 \\
\hline 7.0 & 0.999901 & 0.999896 & 0.999892 & 0.999887 & 0.999881 & 0.999876 & 0.999871 & 0.999865 & 0.999860 & 0.999854 \\
\hline 8.0 & 0.999848 & 0.999842 & 0.999835 & 0.999829 & 0.999822 & 0.999816 & 0.999809 & 0.999802 & 0.999795 & 0.999787 \\
\hline 9.0 & 0.999780 & 0.999773 & 0.999765 & 0.999757 & : 0.999749 & 0.999741 & 0.999733 & 0.999725 & 0.999716 & 0.999707 \\
\hline 10.0 & 0.999699 & 0.999690 & 0.999681 & 0.999672 & 0.999662 & 0.999653 & 0.999643 & 0.999634 & 0.999624 & 0.999614 \\
\hline 11.0 & 0.999604 & 0.999594 & 0.999583 & 0.999573 & 0.999562 & 0.999552 & 0.999541 & 0.999530 & 0.999519 & 0.999507 \\
\hline 12.0 & 0.999496 & 0.999485 & 0.999473 & 0.999461 & 0.999449 & 0.999437 & 0.999425 & 0.999413 & 0.999401 & 0.999388 \\
\hline 13.0 & 0.999376 & 0.999363 & 0.999350 & 0.999337 & 0.999324 & 0.999311 & 0.999297 & 0.999284 & 0.999270 & 0.999256 \\
\hline 14.0 & 0.999243 & 0.999229 & 0.999215 & 0.999200 & 0.999186 & 0.999172 & 0.999157 & 0.999142 & 0.999128 & 0.999113 \\
\hline 15.0 & 0.999098 & 0.999083 & 0.999067 & 0.999052 & $\begin{array}{lll}0.999036\end{array}$ & 0.999021 & 0.999005 & 0.998989 & 0.998973 & 0.998957 \\
\hline 16.0 & 0.998941 & 0.998925 & 0.998908 & 0.998892 & 0.998875 & 0.998858 & 0.998841 & 0.998824 & 0.998807 & 0.997890 \\
\hline 17.0 & 0.998773 & 0.998755 & 0.998738 & 0.998720 & 0.998702 & 0.998684 & 0.998666 & 0.998648 & 0.998630 & 0.998612 \\
\hline 18.0 & 0.998593 & 0.998575 & 0.998556 & 0.998537 & 0.998519 & 0.998500 & 0.998480 & 0.998461 & 0.998442 & 0.998422 \\
\hline 19.0 & 0.998403 & 0.998383 & 0.998364 & 0.998344 & $\begin{array}{l:l} & 0.998324\end{array}$ & 0.998304 & 0.998284 & 0.998263 & 0.998243 & $\begin{array}{l:l}0.998222\end{array}$ \\
\hline 20.0 & 0.998202 & 0.998181 & 0.998160 & 0.998139 & 0.998118 & 0.998097 & 0.998076 & 0.998055 & 0.998033 & 0.998012 \\
\hline 21.0 & 0.997990 & 0.997968 & 0.997947 & 0.997925 & 0.997903 & 0.997881 & 0.997858 & 0.997836 & 0.997814 & 0.997791 \\
\hline 22.0 & 0.997768 & 0.997746 & 0.997723 & 0.997700 & 0.997677 & 0.997654 & 0.997630 & 0.997607 & 0.997584 & 0.997560 \\
\hline 23.0 & 0.997536 & 0.997513 & 0.997489 & 0.997465 & 0.997441 & 0.997417 & 0.997392 & 0.997368 & 0.997344 & 0.997319 \\
\hline 24.0 & 0.997294 & 0.997270 & 0.997245 & 0.997220 & $\begin{array}{l:l}0.997195\end{array}$ & 0.997170 & 0.997145 & 0.997119 & 0.997094 & 0.997068 \\
\hline 25.0 & 0.997043 & 0.997017 & 0.996991 & 0.996966 & 0.996940 & 0.996913 & 0.996887 & 0.996861 & 0.996835 & 0.996808 \\
\hline 26.0 & 0.996782 & 0.996755 & 0.996728 & 0.996702 & 0.996675 & 0.996648 & 0.996621 & 0.996593 & 0.996566 & 0.996539 \\
\hline 27.0 & 0.996511 & 0.996484 & 0.996456 & 0.996428 & 0.996401 & 0.996373 & 0.996345 & 0.996316 & 0.996288 & 0.996260 \\
\hline 28.0 & 0.996232 & 0.996203 & 0.996175 & 0.996146 & 0.996117 & 0.996088 & 0.996060 & 0.996031 & 0.996001 & 0.995972 \\
\hline 29.0 & 0.995943 & 0.995914 & 0.995884 & 0.995855 & 0.995825 & 0.995795 & 0.995765 & 0.995736 & 0.995706 & 0.995676 \\
\hline 30.0 & 0.995645 & 0.995615 & 0.995585 & 0.995554 & 0.995524 & 0.995493 & 0.995463 & 0.995432 & 0.995401 & 0.995370 \\
\hline 31.0 & 0.995339 & 0.995308 & 0.995277 & 0.995246 & 0.995214 & 0.995183 & 0.995151 & 0.995120 & 0.995088 & 0.995056 \\
\hline 32.0 & 0.995024 & 0.994992 & 0.994960 & 0.994928 & 0.994896 & 0.994864 & 0.994831 & 0.994799 & 0.994766 & 0.994734 \\
\hline 33.0 & 0.994701 & 0.994668 & 0.994635 & 0.994602 & 0.994569 & 0.994536 & 0.994503 & 0.994470 & 0.994436 & 0.994403 \\
\hline 34.0 & 0.994369 & 0.994336 & 0.994302 & 0.994268 & 0.994234 & 0.994201 & 0.994167 & 0.994132 & 0.994098 & 0.994064 \\
\hline 35.0 & 0.994030 & 0.993995 & 0.993961 & 0.993926 & $\begin{array}{lll}0.993891\end{array}$ & 0.993857 & 0.993822 & 0.993787 & 0.993752 & 0.993717 \\
\hline 36.0 & 0.993682 & 0.993647 & 0.993611 & 0.993576 & 0.993541 & 0.993505 & 0.993469 & 0.993434 & 0.993398 & 0.993362 \\
\hline 37.0 & 0.993326 & 0.993290 & 0.993254 & 0.993218 & 0.993182 & 0.993146 & 0.993109 & 0.993073 & 0.993036 & 0.993000 \\
\hline 38.0 & 0.992963 & 0.992926 & 0.992889 & 0.992852 & 0.992815 & 0.992778 & 0.992741 & 0.992704 & 0.992667 & 0.992629 \\
\hline 39.0 & 0.992592 & 0.992554 & 0.992517 & 0.992479 & 0.992442 & 0.992404 & 0.992366 & 0.992328 & 0.992290 & 0.992252 \\
\hline
\end{tabular}

Based on the work of H. Wagenbreth and W. Blanke, PTB - Mitteilingen 6-71. Reference equations for CIPM adopted, airsaturated distilled water should be used and are provided in GLP 10 as published in NISTIR 7383, see latest edition. 
Table 9.9 Density of Air, $\mathbf{g} / \mathrm{cm}^{3}$, as Function of Temperature and Air Pressure*

\begin{tabular}{||c|c|c|c|c|c|c|c|c||}
\hline \multicolumn{6}{||c|}{ Barometric Pressure } & \multicolumn{7}{|c||}{ Temperature ( $\left.{ }^{\circ} \mathbf{C}\right)$} \\
\hline kPa & mbar & $\mathbf{m m H g}$ & $\mathbf{1 8}$ & $\mathbf{2 0}$ & $\mathbf{2 2}$ & $\mathbf{2 4}$ & $\mathbf{2 6}$ & $\mathbf{2 8}$ \\
\hline \hline 77.33 & 773 & 580 & 0.00092 & 0.00092 & 0.00091 & 0.00091 & 0.00090 & 0.00090 \\
\hline 79.99 & 800 & 600 & 0.00095 & 0.00095 & 0.00094 & 0.00093 & 0.00093 & 0.00092 \\
\hline 82.66 & 827 & 620 & 0.00099 & 0.00098 & 0.00097 & 0.00096 & 0.00096 & 0.00095 \\
\hline 85.33 & 853 & 640 & 0.00102 & 0.00101 & 0.00100 & 0.00100 & 0.00099 & 0.00098 \\
\hline 87.99 & 880 & 660 & 0.00105 & 0.00104 & 0.00103 & 0.00103 & 0.00102 & 0.00101 \\
\hline 90.66 & 907 & 680 & 0.00108 & 0.00107 & 0.00107 & 0.00106 & 0.00105 & 0.00104 \\
\hline 93.33 & 933 & 700 & 0.00111 & 0.00110 & 0.00110 & 0.00109 & 0.00108 & 0.00107 \\
\hline 95.99 & 960 & 720 & 0.00114 & 0.00114 & 0.00113 & 0.00112 & 0.00112 & 0.00110 \\
\hline 98.66 & 987 & 740 & 0.00118 & 0.00117 & 0.00116 & 0.00115 & 0.00114 & 0.00113 \\
\hline 101.32 & 1013 & 760 & 0.00121 & 0.00120 & 0.00119 & 0.00118 & 0.00117 & 0.00117 \\
\hline 103.99 & 1040 & 780 & 0.00124 & 0.00123 & 0.00122 & 0.00121 & 0.00121 & 0.00120 \\
\hline 106.66 & 1067 & 800 & 0.00127 & 0.00126 & 0.00125 & 0.00124 & 0.00124 & 0.00123 \\
\hline \hline
\end{tabular}

Computed for air at $50 \%$ relative humidity using Option A in SOP 2. Conversions of barometric pressure are not exact. See NIST Special Publication 811 for exact conversions.

*Equations to compute the density of air at any pressure, temperature, and relative humidity are given in Section 8 of the Appendix to SOP No. 2 and Option B is preferred for all precision mass and volume calibrations. 
Table 9.10 Density and Coefficient of Expansion

\begin{tabular}{|c|c|c|c|c|}
\hline \multirow{2}{*}{ Material } & \multirow{2}{*}{$\begin{array}{l}\text { Density } \\
\left(\mathrm{g} / \mathrm{cm}^{3}\right)\end{array}$} & \multicolumn{3}{|c|}{ Coefficient of Expansion } \\
\hline & & Linear $\left(/{ }^{\circ} \mathbf{C}\right)$ & Cubical $\left(/{ }^{\circ} \mathrm{C}\right)$ & Cubical $\left(/{ }^{\circ} \mathbf{F}\right)$ \\
\hline $\begin{array}{l}\text { Aluminum (not suitable for } \\
\text { provers) }\end{array}$ & 2.7 & 0.000024 & 0.000069 & 0.000038 \\
\hline Brass & $\begin{array}{c}8.4 \text { at } 0{ }^{\circ} \mathrm{C} \\
8.3909 \text { at } 20^{\circ} \mathrm{C}\end{array}$ & 0.000019 & 0.000054 & \\
\hline Cast iron & $\begin{array}{l}7.0 \\
7.2\end{array}$ & 0.000010 & 0.000030 & \\
\hline Copper & & 0.000017 & 0.000050 & \\
\hline Diamond & & 0.00000118 & 0.0000035 & \\
\hline Fused silica (quartz) & & 0.0000005 & 0.0000016 & \\
\hline Glass, borosilicate (T1CA) & & & 0.000010 & \\
\hline Glass, borosilicate (T1CB) & & & 0.000015 & \\
\hline Glass, soda-lime & & & 0.000025 & \\
\hline Gold & 18.0 & & 0.000043 & \\
\hline Invar & & 0.0000004 & 0.0000012 & \\
\hline Lead & 11.34 & 0.000029 & 0.000087 & \\
\hline Length bench & & 0.0000106 & & \\
\hline Mercury & & & 0.000018 & \\
\hline Nichrome & 8.39 & & 0.000039 & \\
\hline Nichrome V & 8.5 & & 0.000039 & \\
\hline Platinum & & 0.000011 & 0.000027 & \\
\hline Polycarbonate plastic & & & 0.00045 & \\
\hline Polypropylene plastic & & & 0.00024 & \\
\hline Polystyrene plastic & & & 0.00021 & \\
\hline Steel, stainless (mass) & $7.84,7.95,8.0,8.03$ & & 0.000045 & \\
\hline Steel, stainless (provers) & & & 0.0000477 & 0.0000265 \\
\hline Steel, 304 stainless (provers) & & & 0.0000518 & 0.0000288 \\
\hline Steel, tape, mild & & 0.0000116 & 0.0000335 & \\
\hline Steel, pressure vessel, low carbon & & & 0.0000288 & 0.000016 \\
\hline Steel, prover, low carbon & & 0.000012 & 0.0000335 & 0.0000186 \\
\hline Steel, terne plate & & 0.000012 & 0.000035 & 0.0000195 \\
\hline Tantalum & 16.6 & & 0.000020 & \\
\hline Water $\left(20^{\circ} \mathrm{C}\right)$ & & & 0.00021 & \\
\hline
\end{tabular}

Reference values for cubical coefficient of expansion given in per ${ }^{\circ} \mathrm{F}$ are provided as reference for prover calibrations used for petroleum products where the reference temperature is $60{ }^{\circ} \mathrm{F}$. 


\section{Table 9.11 A Short Table of Random Numbers}

$\begin{array}{lllllllllllllllllllllllll}46 & 96 & 85 & 77 & 27 & 92 & 86 & 26 & 45 & 21 & 89 & 91 & 71 & 42 & 64 & 64 & 58 & 22 & 75 & 81 & 74 & 91 & 48 & 46 & 18\end{array}$

$\begin{array}{lllllllllllllllllllllllll}44 & 19 & 15 & 32 & 63 & 55 & 87 & 77 & 33 & 29 & 45 & 00 & 31 & 34 & 84 & 05 & 72 & 90 & 44 & 27 & 78 & 22 & 07 & 62 & 17\end{array}$

$\begin{array}{lllllllllllllllllllllllll}34 & 39 & 80 & 62 & 24 & 33 & 81 & 67 & 28 & 11 & 34 & 79 & 26 & 35 & 34 & 23 & 09 & 94 & 00 & 80 & 55 & 31 & 63 & 27 & 91\end{array}$

$\begin{array}{llllllllllllllllllllllllllll}74 & 97 & 80 & 30 & 65 & 07 & 71 & 30 & 01 & 84 & 47 & 45 & 89 & 70 & 74 & 13 & 04 & 90 & 51 & 27 & 61 & 34 & 63 & 87 & 44\end{array}$

$\begin{array}{lllllllllllllllllllllllll}22 & 14 & 61 & 60 & 86 & 38 & 33 & 71 & 13 & 33 & 72 & 08 & 16 & 13 & 50 & 56 & 48 & 51 & 29 & 48 & 30 & 93 & 45 & 66 & 29\end{array}$

$\begin{array}{lllllllllllllllllllllllll}40 & 03 & 96 & 40 & 03 & 47 & 24 & 60 & 09 & 21 & 21 & 18 & 00 & 05 & 86 & 52 & 85 & 40 & 73 & 73 & 57 & 68 & 36 & 33 & 91\end{array}$

$\begin{array}{lllllllllllllllllllllllll}52 & 33 & 76 & 44 & 56 & 15 & 47 & 75 & 78 & 73 & 78 & 19 & 87 & 06 & 98 & 47 & 48 & 02 & 62 & 03 & 42 & 05 & 32 & 55 & 02\end{array}$

$\begin{array}{llllllllllllllllllllllllllll}37 & 59 & 20 & 40 & 93 & 17 & 82 & 24 & 19 & 90 & 80 & 87 & 32 & 74 & 59 & 84 & 24 & 49 & 79 & 17 & 23 & 75 & 83 & 42 & 00\end{array}$

$\begin{array}{lllllllllllllllllllllllll}11 & 02 & 55 & 47 & 48 & 84 & 74 & 36 & 22 & 67 & 19 & 20 & 15 & 92 & 53 & 37 & 13 & 75 & 54 & 89 & 56 & 73 & 23 & 39 & 07\end{array}$

$\begin{array}{llllllllllllllllllllllllll}10 & 33 & 79 & 26 & 34 & 54 & 71 & 33 & 89 & 74 & 68 & 48 & 23 & 17 & 49 & 18 & 81 & 05 & 52 & 85 & 70 & 05 & 73 & 11 & 17\end{array}$

$\begin{array}{llllllllllllllllllllllllll}67 & 59 & 28 & 25 & 47 & 89 & 11 & 65 & 65 & 20 & 42 & 23 & 96 & 41 & 64 & 20 & 30 & 89 & 87 & 64 & 37 & 93 & 36 & 96 & 35\end{array}$

$\begin{array}{lllllllllllllllllllllllll}93 & 50 & 75 & 20 & 09 & 18 & 54 & 34 & 68 & 02 & 54 & 87 & 23 & 05 & 43 & 36 & 98 & 29 & 97 & 93 & 87 & 08 & 30 & 92 & 98\end{array}$

$\begin{array}{lllllllllllllllllllllllll}24 & 43 & 23 & 72 & 80 & 64 & 34 & 27 & 23 & 46 & 15 & 36 & 10 & 63 & 21 & 59 & 69 & 76 & 02 & 62 & 31 & 62 & 47 & 60 & 34\end{array}$

$\begin{array}{llllllllllllllllllllllllllll}39 & 91 & 63 & 18 & 38 & 27 & 10 & 78 & 88 & 84 & 42 & 32 & 00 & 97 & 92 & 00 & 04 & 94 & 50 & 05 & 75 & 82 & 70 & 80 & 35\end{array}$

$\begin{array}{lllllllllllllllllllllllll}74 & 62 & 19 & 67 & 54 & 18 & 28 & 92 & 33 & 69 & 98 & 96 & 74 & 35 & 72 & 11 & 68 & 25 & 08 & 95 & 31 & 79 & 11 & 79 & 54\end{array}$

$\begin{array}{lllllllllllllllllllllllll}91 & 03 & 35 & 60 & 81 & 16 & 61 & 97 & 25 & 14 & 78 & 21 & 22 & 05 & 25 & 47 & 26 & 37 & 80 & 39 & 19 & 06 & 41 & 02 & 00\end{array}$

$\begin{array}{lllllllllllllllllllllllll}42 & 57 & 66 & 76 & 72 & 91 & 03 & 63 & 48 & 46 & 44 & 01 & 33 & 53 & 62 & 28 & 80 & 59 & 55 & 05 & 02 & 16 & 13 & 17 & 54\end{array}$

$\begin{array}{llllllllllllllllllllllllll}06 & 36 & 63 & 06 & 15 & 03 & 72 & 38 & 01 & 58 & 25 & 37 & 66 & 48 & 56 & 19 & 56 & 41 & 29 & 28 & 76 & 49 & 74 & 39 & 50\end{array}$

$\begin{array}{llllllllllllllllllllllllll}92 & 70 & 96 & 70 & 89 & 80 & 87 & 14 & 25 & 49 & 25 & 94 & 62 & 78 & 26 & 15 & 41 & 39 & 48 & 75 & 64 & 69 & 61 & 06 & 38\end{array}$

$\begin{array}{llllllllllllllllllllllllll}91 & 08 & 88 & 53 & 52 & 13 & 04 & 82 & 23 & 00 & 26 & 36 & 47 & 44 & 04 & 08 & 84 & 80 & 07 & 44 & 76 & 51 & 52 & 41 & 59\end{array}$

$\begin{array}{lllllllllllllllllllllllllllll}68 & 85 & 97 & 74 & 47 & 53 & 90 & 05 & 90 & 84 & 87 & 48 & 25 & 01 & 11 & 05 & 45 & 11 & 43 & 15 & 60 & 40 & 31 & 84 & 59\end{array}$

$\begin{array}{lllllllllllllllllllllllll}59 & 54 & 13 & 09 & 13 & 80 & 42 & 29 & 63 & 03 & 24 & 64 & 12 & 43 & 28 & 10 & 01 & 65 & 62 & 07 & 79 & 83 & 05 & 59 & 61\end{array}$

$\begin{array}{lllllllllllllllllllllllllll}39 & 18 & 32 & 69 & 33 & 46 & 58 & 19 & 34 & 03 & 59 & 28 & 97 & 31 & 02 & 65 & 47 & 47 & 70 & 39 & 74 & 17 & 30 & 22 & 65\end{array}$

$\begin{array}{lllllllllllllllllllllllll}67 & 43 & 31 & 09 & 12 & 60 & 19 & 57 & 63 & 78 & 11 & 80 & 10 & 97 & 15 & 70 & 04 & 89 & 81 & 78 & 54 & 84 & 87 & 83 & 42\end{array}$

$\begin{array}{lllllllllllllllllllllllllll}61 & 75 & 37 & 19 & 56 & 90 & 75 & 39 & 03 & 56 & 49 & 92 & 72 & 95 & 27 & 52 & 87 & 47 & 12 & 52 & 54 & 62 & 43 & 23 & 13\end{array}$

$\begin{array}{lllllllllllllllllllllllll}78 & 10 & 91 & 11 & 00 & 63 & 19 & 63 & 74 & 58 & 69 & 03 & 51 & 38 & 60 & 36 & 53 & 56 & 77 & 06 & 69 & 03 & 89 & 91 & 24\end{array}$

$\begin{array}{lllllllllllllllllllllllllll}93 & 23 & 71 & 58 & 09 & 78 & 08 & 03 & 07 & 71 & 79 & 32 & 25 & 19 & 61 & 04 & 40 & 33 & 12 & 06 & 78 & 91 & 97 & 88 & 95\end{array}$

$\begin{array}{lllllllllllllllllllllllll}37 & 55 & 48 & 82 & 63 & 89 & 92 & 59 & 14 & 72 & 19 & 17 & 22 & 51 & 90 & 20 & 03 & 64 & 96 & 60 & 48 & 01 & 95 & 44 & 84\end{array}$

$\begin{array}{llllllllllllllllllllllllll}62 & 13 & 11 & 71 & 17 & 23 & 29 & 25 & 13 & 85 & 33 & 35 & 07 & 69 & 25 & 68 & 57 & 92 & 57 & 11 & 84 & 44 & 01 & 33 & 66\end{array}$

$\begin{array}{llllllllllllllllllllllllll}29 & 89 & 97 & 47 & 03 & 13 & 20 & 86 & 22 & 45 & 59 & 98 & 64 & 53 & 89 & 64 & 94 & 81 & 55 & 87 & 73 & 81 & 58 & 46 & 42\end{array}$

$\begin{array}{lllllllllllllllllllllllll}16 & 94 & 85 & 82 & 89 & 07 & 17 & 30 & 29 & 89 & 89 & 80 & 98 & 36 & 25 & 36 & 53 & 02 & 49 & 14 & 34 & 03 & 52 & 09 & 20\end{array}$

$\begin{array}{llllllllllllllllllllllllll}04 & 93 & 10 & 59 & 75 & 12 & 98 & 84 & 60 & 93 & 68 & 16 & 87 & 60 & 11 & 50 & 46 & 56 & 58 & 45 & 88 & 72 & 50 & 46 & 11\end{array}$

$\begin{array}{llllllllllllllllllllllllll}95 & 71 & 43 & 68 & 97 & 18 & 85 & 17 & 13 & 08 & 00 & 50 & 77 & 50 & 46 & 92 & 45 & 26 & 97 & 21 & 48 & 22 & 23 & 08 & 32\end{array}$

$\begin{array}{lllllllllllllllllllllllll}86 & 05 & 39 & 14 & 35 & 48 & 68 & 18 & 36 & 57 & 09 & 62 & 40 & 28 & 87 & 08 & 74 & 79 & 91 & 08 & 27 & 12 & 43 & 32 & 03\end{array}$

$\begin{array}{llllllllllllllllllllllllll}59 & 30 & 60 & 10 & 41 & 31 & 00 & 69 & 63 & 77 & 01 & 89 & 94 & 60 & 19 & 02 & 70 & 88 & 72 & 33 & 38 & 88 & 20 & 60 & 86\end{array}$

$\begin{array}{llllllllllllllllllllllllll}05 & 45 & 35 & 40 & 54 & 03 & 98 & 96 & 76 & 27 & 77 & 84 & 80 & 08 & 64 & 60 & 44 & 34 & 54 & 24 & 85 & 20 & 85 & 77 & 32\end{array}$

$\begin{array}{lllllllllllllllllllllllll}71 & 85 & 17 & 74 & 66 & 27 & 85 & 19 & 55 & 56 & 51 & 36 & 48 & 92 & 32 & 44 & 40 & 47 & 10 & 38 & 22 & 52 & 42 & 29 & 96\end{array}$

$\begin{array}{lllllllllllllllllllllllll}80 & 20 & 32 & 80 & 98 & 00 & 40 & 92 & 57 & 51 & 52 & 83 & 14 & 55 & 31 & 99 & 73 & 23 & 40 & 07 & 64 & 54 & 44 & 99 & 21\end{array}$

$\begin{array}{llllllllllllllllllllllllll}13 & 50 & 78 & 02 & 73 & 39 & 66 & 82 & 01 & 28 & 67 & 51 & 75 & 66 & 33 & 97 & 47 & 58 & 42 & 44 & 88 & 09 & 28 & 58 & 06\end{array}$

$\begin{array}{llllllllllllllllllllllllll}67 & 92 & 65 & 41 & 45 & 36 & 77 & 96 & 46 & 21 & 14 & 39 & 56 & 36 & 70 & 15 & 74 & 43 & 62 & 69 & 82 & 30 & 77 & 28 & 77\end{array}$

$\begin{array}{lllllllllllllllllllllllll}72 & 56 & 73 & 44 & 26 & 04 & 62 & 81 & 15 & 35 & 79 & 26 & 99 & 57 & 28 & 22 & 25 & 94 & 80 & 62 & 95 & 48 & 98 & 23 & 86\end{array}$

$\begin{array}{lllllllllllllllllllllllll}28 & 86 & 85 & 64 & 94 & 11 & 58 & 78 & 45 & 36 & 34 & 45 & 91 & 38 & 51 & 10 & 68 & 36 & 87 & 81 & 16 & 77 & 30 & 19 & 36\end{array}$

$\begin{array}{lllllllllllllllllllllllll}69 & 57 & 40 & 80 & 44 & 94 & 60 & 82 & 94 & 93 & 98 & 01 & 48 & 50 & 57 & 69 & 60 & 77 & 69 & 60 & 74 & 22 & 05 & 77 & 17\end{array}$

$\begin{array}{lllllllllllllllllllllllll}71 & 20 & 03 & 30 & 79 & 25 & 74 & 17 & 78 & 34 & 54 & 45 & 04 & 77 & 42 & 59 & 75 & 78 & 64 & 99 & 37 & 03 & 18 & 03 & 36\end{array}$

$\begin{array}{lllllllllllllllllllllllll}89 & 98 & 55 & 98 & 22 & 45 & 12 & 49 & 82 & 71 & 57 & 33 & 28 & 69 & 50 & 59 & 15 & 09 & 25 & 79 & 39 & 42 & 84 & 18 & 70\end{array}$

$\begin{array}{llllllllllllllllllllllllllllll}58 & 74 & 82 & 81 & 14 & 02 & 01 & 05 & 77 & 94 & 65 & 57 & 70 & 39 & 42 & 48 & 56 & 84 & 31 & 59 & 18 & 70 & 41 & 74 & 60\end{array}$

$\begin{array}{lllllllllllllllllllllllll}50 & 54 & 73 & 81 & 91 & 07 & 81 & 26 & 25 & 45 & 49 & 61 & 22 & 88 & 41 & 20 & 00 & 15 & 59 & 93 & 51 & 60 & 65 & 65 & 63\end{array}$

$\begin{array}{llllllllllllllllllllllllll}49 & 33 & 72 & 90 & 10 & 20 & 65 & 28 & 44 & 63 & 95 & 86 & 75 & 78 & 69 & 24 & 41 & 65 & 86 & 10 & 34 & 10 & 32 & 00 & 93\end{array}$

$\begin{array}{lllllllllllllllllllllllll}11 & 85 & 01 & 43 & 65 & 02 & 85 & 69 & 56 & 88 & 34 & 29 & 64 & 35 & 48 & 15 & 70 & 11 & 77 & 83 & 01 & 34 & 82 & 91 & 04\end{array}$

$\begin{array}{llllllllllllllllllllllllll}34 & 22 & 46 & 41 & 84 & 74 & 27 & 02 & 57 & 77 & 47 & 93 & 72 & 02 & 95 & 63 & 75 & 74 & 69 & 69 & 61 & 34 & 31 & 92 & 13\end{array}$

From: NBS Handbook 91, p T-82 
Table 9.12 Percentiles of the $F$ Distribution $F_{0.95}\left(n_{1}, n_{2}\right)$

$n_{1}=$ degrees of freedom for numerator $\quad n_{2}=$ degrees of freedom for denominator

\begin{tabular}{|c|c|c|c|c|c|c|c|c|c|c|c|c|c|c|c|}
\hline & $n_{1}$ & & & & & & & & & & & & & & \\
\hline$n_{2}$ & 1 & 2 & 3 & 4 & 5 & 6 & 7 & 8 & 9 & 10 & 20 & 40 & 60 & 120 & $\infty$ \\
\hline 1 & 161.4 & 199.5 & 215.7 & 224.6 & 230.2 & 234.0 & 236.8 & 238.9 & 240.5 & 241.9 & 248.0 & 251.1 & 252.2 & 253.3 & 254.3 \\
\hline 2 & 18.51 & 19.00 & 19.16 & 19.25 & 19.30 & 19.33 & 19.35 & 19.37 & 19.38 & 19.40 & 19.45 & 19.47 & 19.48 & 19.49 & 19.50 \\
\hline 3 & 10.13 & 9.55 & 9.28 & 9.12 & 9.01 & 8.94 & 8.89 & 8.85 & 8.81 & 8.79 & 8.66 & 8.59 & 8.57 & 8.55 & 8.53 \\
\hline 4 & 7.71 & 6.94 & 6.59 & 6.39 & 6.26 & 6.16 & 6.09 & 6.04 & 6.00 & 5.96 & 5.80 & 5.72 & 5.69 & 5.66 & 5.63 \\
\hline 5 & 6.61 & 5.79 & 5.41 & 5.19 & 5.05 & 4.95 & 4.88 & 4.82 & 4.77 & 4.74 & 4.56 & 4.46 & 4.43 & 4.40 & 4.36 \\
\hline 6 & 5.99 & 5.14 & 4.76 & 4.53 & 4.39 & 4.28 & 4.21 & 4.15 & 4.10 & 4.06 & 3.87 & 3.77 & 3.74 & 3.70 & 3.67 \\
\hline 7 & 5.59 & 4.74 & 4.35 & 4.12 & 3.97 & 3.87 & 3.79 & 3.73 & 3.68 & 3.64 & 3.44 & 3.34 & 3.30 & 3.27 & 3.23 \\
\hline 8 & 5.32 & 4.46 & 4.07 & 3.84 & 3.69 & 3.58 & 3.50 & 3.44 & 3.39 & 3.35 & 3.15 & 3.04 & 3.01 & 2.97 & 2.93 \\
\hline 9 & 5.12 & 4.26 & 3.86 & 3.63 & 3.48 & 3.37 & 3.29 & 3.23 & 3.18 & 3.14 & 2.94 & 2.83 & 2.79 & 2.75 & 2.71 \\
\hline 10 & 4.96 & 4.10 & 3.71 & 3.48 & 3.33 & 3.22 & 3.14 & 3.07 & 3.02 & 2.98 & 2.77 & 2.66 & 2.62 & 2.58 & 2.54 \\
\hline 11 & 4.84 & 3.98 & 3.59 & 3.36 & 3.20 & 3.09 & 3.01 & 2.95 & 2.90 & 2.85 & 2.65 & 2.53 & 2.49 & 2.45 & 2.40 \\
\hline 12 & 4.75 & 3.89 & 3.49 & 3.26 & 3.11 & 3.00 & 2.91 & 2.85 & 2.80 & 2.75 & 2.54 & 2.43 & 2.38 & 2.34 & 2.30 \\
\hline 13 & 4.67 & 3.81 & 3.41 & 3.18 & 3.03 & 2.92 & 2.83 & 2.77 & 2.71 & 2.67 & 2.46 & 2.34 & 2.30 & 2.25 & 2.21 \\
\hline 14 & 4.60 & 3.74 & 3.34 & 3.11 & 2.96 & 2.85 & 2.76 & 2.70 & 2.65 & 2.60 & 2.39 & 2.27 & 2.22 & 2.18 & 2.13 \\
\hline 15 & 4.54 & 3.68 & 3.29 & 3.06 & 2.90 & 2.79 & 2.71 & 2.64 & 2.59 & 2.54 & 2.33 & 2.20 & 2.16 & 2.11 & 2.07 \\
\hline 16 & 4.49 & 3.63 & 3.24 & 3.01 & 2.85 & 2.74 & 2.66 & 2.59 & 2.54 & 2.49 & 2.28 & 2.15 & 2.11 & 2.06 & 2.01 \\
\hline 17 & 4.45 & 3.59 & 3.20 & 2.96 & 2.81 & 2.70 & 2.61 & 2.55 & 2.49 & 2.45 & 2.23 & 2.10 & 2.06 & 2.01 & 1.96 \\
\hline 18 & 4.41 & 3.55 & 3.16 & 2.93 & 2.77 & 2.66 & 2.58 & 2.51 & 2.46 & 2.41 & 2.19 & 2.06 & 2.02 & 1.97 & 1.92 \\
\hline 19 & 4.38 & 3.52 & 3.13 & 2.90 & 2.74 & 2.63 & 2.54 & 2.48 & 2.42 & 2.38 & 2.16 & 2.03 & 1.98 & 1.93 & 1.88 \\
\hline 20 & 4.35 & 3.49 & 3.10 & 2.87 & 2.71 & 2.60 & 2.51 & 2.45 & 2.39 & 2.35 & 2.12 & 1.99 & 1.95 & 1.90 & 1.84 \\
\hline 21 & 4.32 & 3.47 & 3.07 & 2.84 & 2.68 & 2.57 & 2.49 & 2.42 & 2.37 & 2.32 & 2.10 & 1.96 & 1.92 & 1.87 & 1.81 \\
\hline 22 & 4.30 & 3.44 & 3.05 & 2.82 & 2.66 & 2.55 & 2.46 & 2.40 & 2.34 & 2.30 & 2.07 & 1.94 & 1.89 & 1.84 & 1.78 \\
\hline 23 & 4.28 & 3.42 & 3.03 & 2.80 & 2.64 & 2.53 & 2.44 & 2.37 & 2.32 & 2.27 & 2.05 & 1.91 & 1.86 & 1.81 & 1.76 \\
\hline 24 & 4.26 & 3.40 & 3.01 & 2.78 & 2.62 & 2.51 & 2.42 & 2.36 & 2.30 & 2.25 & 2.03 & 1.89 & 1.84 & 1.79 & 1.73 \\
\hline 25 & 4.24 & 3.39 & 2.99 & 2.76 & 2.60 & 2.49 & 2.40 & 2.34 & 2.28 & 2.24 & 2.01 & 1.87 & 1.82 & 1.77 & 1.71 \\
\hline 26 & 4.23 & 3.37 & 2.98 & 2.74 & 2.59 & 2.47 & 2.39 & 2.32 & 2.27 & 2.22 & 1.99 & 1.85 & 1.80 & 1.75 & 1.69 \\
\hline 27 & 4.21 & 3.35 & 2.96 & 2.73 & 2.57 & 2.46 & 2.37 & 2.31 & 2.25 & 2.20 & 1.97 & 1.84 & 1.79 & 1.73 & 1.67 \\
\hline 28 & 4.20 & 3.34 & 2.95 & 2.71 & 2.56 & 2.45 & 2.36 & 2.29 & 2.24 & 2.19 & 1.96 & 1.82 & 1.77 & 1.71 & 1.65 \\
\hline 29 & 4.18 & 3.33 & 2.93 & 2.70 & 2.55 & 2.43 & 2.35 & 2.28 & 2.22 & 2.18 & 1.94 & 1.81 & 1.75 & 1.70 & 1.64 \\
\hline 30 & 4.17 & 3.32 & 2.92 & 2.69 & 2.53 & 2.42 & 2.33 & 2.27 & 2.21 & 2.16 & 1.93 & 1.79 & 1.74 & 1.68 & 1.62 \\
\hline 40 & 4.08 & 3.23 & 2.84 & 2.61 & 2.45 & 2.34 & 2.25 & 2.18 & 2.12 & 2.08 & 1.84 & 1.69 & 1.64 & 1.58 & 1.51 \\
\hline 60 & 4.00 & 3.15 & 2.76 & 2.53 & 2.37 & 2.25 & 2.17 & 2.10 & 2.04 & 1.99 & 1.75 & 1.59 & 1.53 & 1.47 & 1.39 \\
\hline 120 & 3.92 & 3.07 & 2.68 & 2.45 & 2.29 & 2.18 & 2.09 & 2.02 & 1.96 & 1.91 & 1.66 & 1.50 & 1.43 & 1.35 & 1.25 \\
\hline$\infty$ & 3.84 & 3.00 & 2.60 & 2.37 & 2.21 & 2.10 & 2.01 & 1.94 & 1.88 & 1.83 & 1.57 & 1.39 & 1.32 & 1.22 & 1.00 \\
\hline
\end{tabular}

Created with Excel function: =ROUND(F.INV(0.95, Numerator,Denominator),2); validated with NBS Handbook 91. 
Table 9.13 Critical Values for the F-test, $F_{\max } 0.05$

\begin{tabular}{|c|c|c|c|c|c|c|c|c|c|c|c|}
\hline & \multicolumn{11}{|c|}{ Number of treatments, levels, groups } \\
\hline$n-1$ & 2 & 3 & 4 & 5 & 6 & 7 & 8 & 9 & 10 & 11 & 12 \\
\hline 2 & 39.00 & 87.50 & 142.00 & 202.00 & 266.00 & 333.00 & 403.00 & 475.00 & 550.00 & 626.00 & 704.00 \\
\hline 3 & 15.40 & 27.80 & 39.20 & 50.70 & 62.00 & 72.90 & 83.50 & 93.90 & 104.00 & 114.00 & 124.00 \\
\hline 4 & 9.60 & 15.50 & 20.60 & 25.20 & 29.50 & 33.60 & 37.50 & 41.10 & 44.60 & 48.00 & 51.40 \\
\hline 5 & 7.20 & 10.80 & 13.70 & 16.30 & 18.70 & 20.80 & 22.90 & 24.70 & 26.50 & 28.20 & 29.90 \\
\hline 6 & 5.82 & 8.38 & 10.40 & 12.10 & 13.70 & 15.00 & 16.30 & 17.50 & 18.60 & 19.70 & 20.70 \\
\hline 7 & 4.99 & 6.94 & 8.44 & 9.70 & 10.80 & 11.80 & 12.70 & 13.50 & 14.30 & 15.10 & 15.80 \\
\hline 8 & 4.43 & 6.00 & 7.18 & 8.12 & 9.03 & 9.78 & 10.50 & 11.10 & 11.70 & 12.20 & 12.70 \\
\hline 9 & 4.03 & 5.34 & 6.31 & 7.11 & 7.80 & 8.41 & 8.95 & 9.45 & 9.91 & 10.30 & 10.70 \\
\hline 10 & 3.72 & 4.85 & 5.67 & 6.34 & 6.92 & 7.42 & 7.87 & 8.28 & 8.66 & 9.01 & 9.34 \\
\hline 12 & 3.28 & 4.16 & 4.75 & 5.30 & 5.72 & 6.09 & 6.42 & 6.72 & 7.00 & 7.25 & 7.43 \\
\hline 15 & 2.86 & 3.54 & 4.01 & 4.37 & 4.68 & 4.95 & 5.19 & 5.40 & 5.59 & 5.77 & 5.95 \\
\hline 20 & 2.46 & 2.95 & 3.29 & 3.54 & 3.76 & 3.94 & 4.10 & 4.24 & 4.37 & 4.49 & 4.59 \\
\hline 30 & 2.07 & 2.40 & 2.61 & 2.78 & 2.91 & 3.02 & 3.12 & 3.21 & 3.29 & 3.36 & 3.39 \\
\hline 60 & 1.67 & 1.85 & 1.96 & 2.04 & 2.11 & 2.17 & 2.22 & 2.26 & 2.30 & 2.33 & 2.36 \\
\hline$\infty$ & 1.00 & 1.00 & 1.00 & 1.00 & 1.00 & 1.00 & 1.00 & 1.00 & 1.00 & 1.00 & 1.00 \\
\hline
\end{tabular}

If the F-ratio is close to 1 in the calculations, the variation among the samples/replicates is not statistically different. Look up the number of levels and the degrees of freedom (number of items in each level minus 1 ) in the $F_{\max }$ table. For example, if there were 11 replicate observations ( $\mathrm{n}$ $=11$ ), then the degrees of freedom is $11-1$ or 10 and with two treatments (replicates) for a $\mathrm{k}$ of 2 ( $\mathrm{k}$ is the number of levels/groups and not the coverage factor used for uncertainties), the table shows an $F_{\max }$ value of 3.72. 
This page is intentionally blank. 